\title{
Spatial redistribution of organic phosphorus in hay and grass pastures of eastern West Virginia following longterm animal manure applications
}

Michael B. Harman

Follow this and additional works at: https://researchrepository.wvu.edu/etd

\section{Recommended Citation}

Harman, Michael B., "Spatial redistribution of organic phosphorus in hay and grass pastures of eastern West Virginia following longterm animal manure applications" (2016). Graduate Theses, Dissertations, and Problem Reports. 5766.

https://researchrepository.wvu.edu/etd/5766

This Dissertation is protected by copyright and/or related rights. It has been brought to you by the The Research Repository @ WVU with permission from the rights-holder(s). You are free to use this Dissertation in any way that is permitted by the copyright and related rights legislation that applies to your use. For other uses you must obtain permission from the rights-holder(s) directly, unless additional rights are indicated by a Creative Commons license in the record and/ or on the work itself. This Dissertation has been accepted for inclusion in WVU Graduate Theses, Dissertations, and Problem Reports collection by an authorized administrator of The Research Repository @ WVU.

For more information, please contact researchrepository@mail.wvu.edu. 
SPATIAL REDISTRIBUTION OF ORGANIC PHOSPHORUS IN HAY AND GRASS PASTURES OF

EASTERN WEST VIRGINIA FOLLOWING LONGTERM ANIMAL MANURE APPLICATIONS

\author{
Michael B. Harman \\ Dissertation submitted to the \\ Davis College of Agriculture, Natural Resources and Design \\ at West Virginia University \\ in partial fulfillment of the requirements for the degree of \\ Doctor of Philosophy \\ In \\ Agricultural Science
}

\author{
James A. Thompson, Ph.D., Chair \\ Louis M. McDonald, Jr., Ph.D. \\ Trevor M. Harris, Ph.D. \\ Edward B. Rayburn, Ph.D. \\ Jeffrey G. Skousen, Ph.D.
}
Division of Plant and Soil Science
Morgantown, West Virginia
2016

Keywords: Phosphorus, Hedley Fractionation, Topographic Wetness Index, GIS, Sequential

Extracted Phosphorus Fractions, Soil-Test Phosphorus, Soil Landscape Modeling, Mantel

Test, West Virginia, Geovisualization, 3D Modeling, Exploratory Spatial Data Analysis

Copyright 2013 Michael Brian Harman 
ABSTRACT
Spatial Redistribution of Organic Phosphorus in Hay and Grass Pastures of Eastern West Virginia

Following Long-term Animal Manure Applications

Michael B. Harman

This study was conceived to investigate the fate of organic $P\left(P_{o}\right)$ in typical hay and grass pasture of eastern West Virginia. It is not uncommon in this region of West Virginia for hay and grass pastures to receive annual applications of animal manure, often on a nitrogen basis. As P management has evolved, many farms in the region have begun to use management tools such as a P index to continue use of animal manure as $\mathrm{N}$ fertilizer. However, many hay and grass pastures in the region already have a high degree of $\mathrm{P}$ saturation. There are reasonable expectations that in time the $\mathrm{P}$ saturation at these sites may reach thresholds whereby actions to lower $P$ saturation become necessary. At such time it may become necessary to develop interception strategies to prevent movement of $P$ into surface and ground water from there extremely saturated locations. While most $P$ research focuses on $P$ loss via surface erosion, or on tile drained land, and rarely is $\mathrm{P}_{\mathrm{o}}$ considered. To fully evaluate the risks of $\mathrm{P}$ loss and develop remediation and interception strategies, data specific to $P_{\circ}$ movement at field scales across complex landscapes is needed to increase assurances that existing research is compatible with or applicable to West Virginia pastures. To develop this data, sequentially extracted $P$ fractions were measured in samples from both spatially-explicit locations across typical hay and grass pastures and from bench top experiments to evaluate the applicability of existing research. I examined patterns in $\mathrm{P}_{\mathrm{o}}$ distributions to determine if $P_{0}$ levels significantly exceeded what could be explained by changes in soil properties. Results support the presence of spatial structure in the variability of the $\mathrm{NaHCO}_{3}$ and $\mathrm{HCl}$ extractable $\mathrm{P}_{\mathrm{o}}$ fractions in some locations, but no purely spatial component is present in the variability of the $\mathrm{NaOH}$ and $\mathrm{H}_{2} \mathrm{O}$ extractable fractions. Various topographic parameters were evaluated to determine their efficacy in explaining $P_{0}$ variability and soil-landscape modeling techniques were successfully used to develop relatively simple models based on soil test $\mathrm{P}$ results and topographic data to predict the distributions of the sequential extracted $P_{0}$ fractions across these landscapes. The bench top experiment indicated no significant effects from actively growing plants or $P$ sources on the disposition of $\mathrm{P}_{\mathrm{o}}$. As such, the bench top results support the acceptance of existing data in decision making processes, and the field scale data supports development of soil landscape models to afford future environment professional a higher degree of understanding relative to the spatial distribution of sequentially extracted $P_{0}$ fractions at a landscape scale. 


\section{DEDICATION}

I dedicate my dissertation to my paternal grandmother, Eva Elizabeth Harman. She was born in 1903 and passed away in 1983. She was like a second mother to me. She was a strong and savvy woman, atypical of her era, and a remarkable person. She was kind, generous, and well-liked in the community. She was the matriarch of the Harman family as I know it. She was the best of us, and I wish she was here to witness what I have accomplished. Words cannot express the void her passing created and this void remains in our hearts to this day. I love her, I miss her, and I dedicate this dissertation in her honor. 


\section{ACKNOWLEDGEMENTS}

It goes without saying; I would like to thank Dr. Jim Thompson for allowing me the opportunity to fulfill a lifelong dream of maximizing my education. Additionally, I would like to recognize the members of my committee for providing insight, support, and direction. Your willingness to work with me was a welcomed component to my dissertation experience. Furthermore, I would like to thank my fellow graduate students for allowing me to learn with you and from you. We all learn best when we learn together. I owe a special thanks to the staff at the West Virginia GIS Technical Center, USDA-Natural Resources Conservation Service staff across West Virginia, the farm managers at the WVU Agronomy Farm and WVU Animal Science Farm in Morgantown and the Reymann Memorial Farm in Wardensville, and the administrative staff of the Division of Plant and Soil Science at the Davis College of Agriculture, Natural Resources, and Design. I would also like to take this opportunity to thank Tom Basden, Denzil Blosser, Tara Helmick, Katie Yoast, and E. Joan Wright. Over the years, I have learned a great deal form each of you and you have my gratitude for making this process a memorable experience. Thank you all for your support, assistance, and contributions. 


\section{Table of Contents}

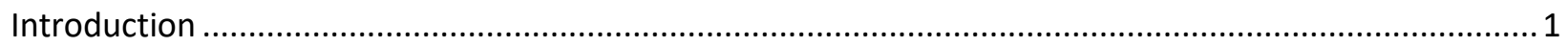

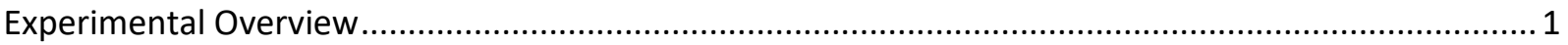

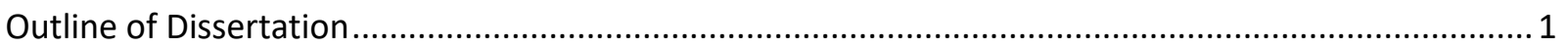

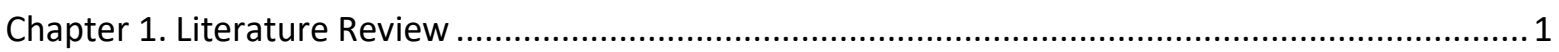

Chapter 2. Lab-Scale Experiments ….................................................................................... 1

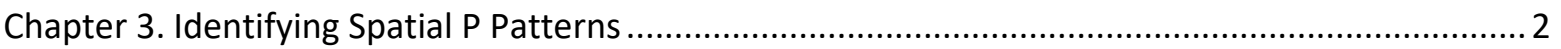

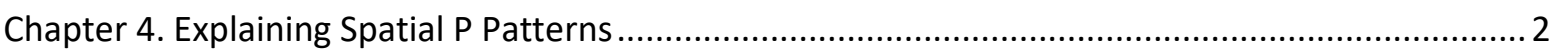

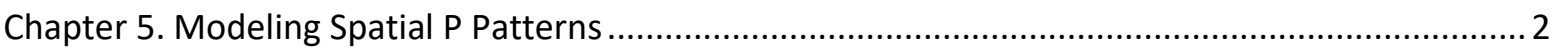

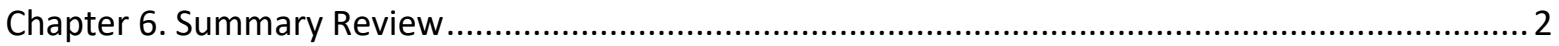

Chapter 1. Topographic Influence on the Movement and Transformation of Organic Phosphorus in Hay

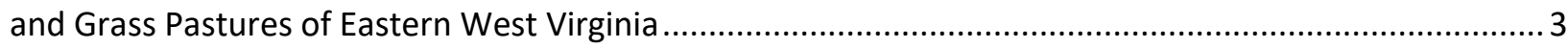

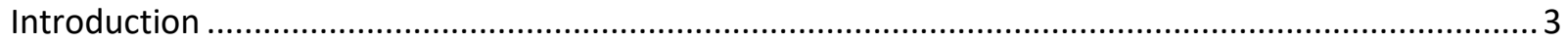

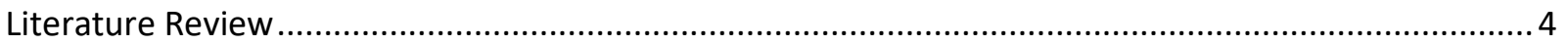

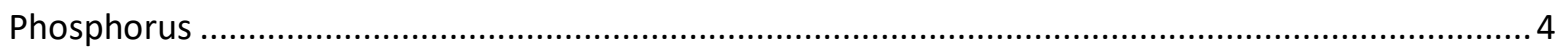

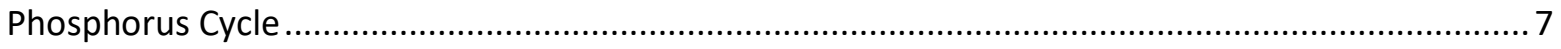

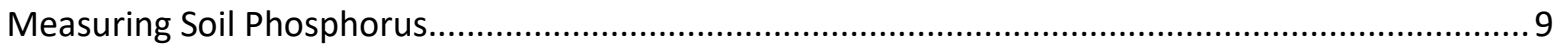

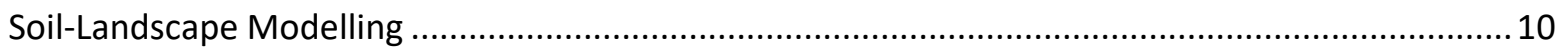

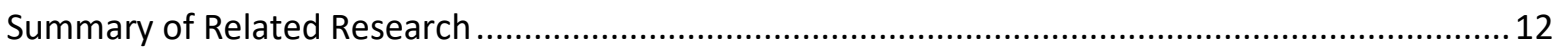

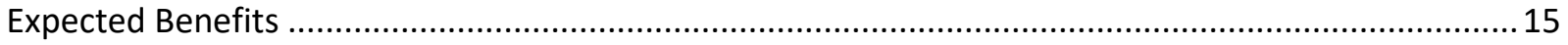

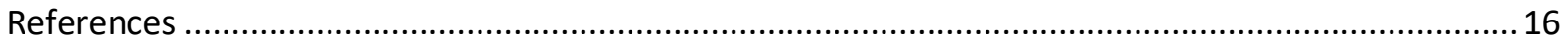

Chapter 2. Effect of Vegetation and Phosphorus Source on Sequential-Extracted Phosphorus Fractions in

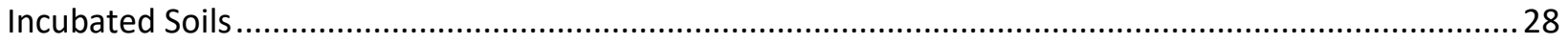

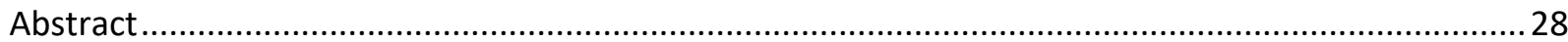

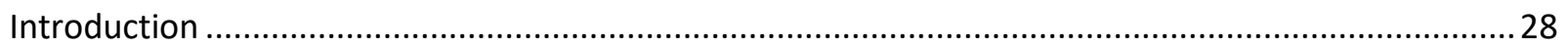

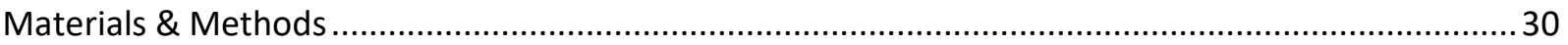

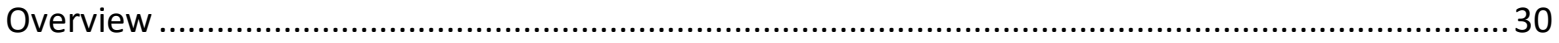

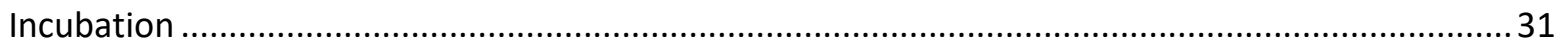

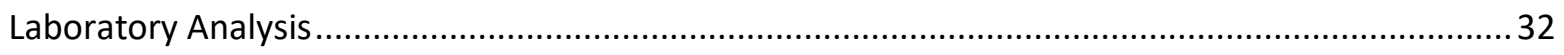

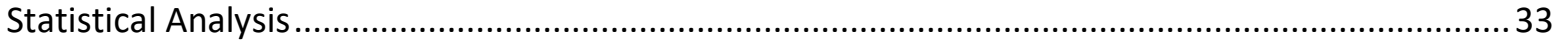

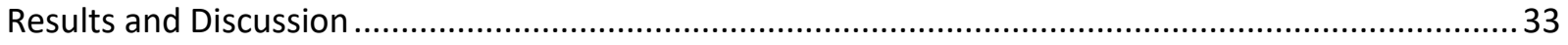

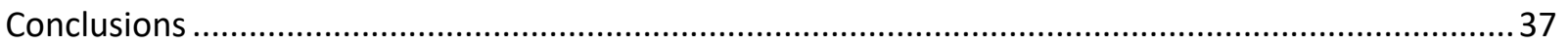




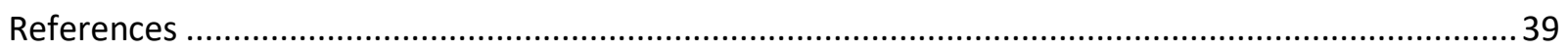

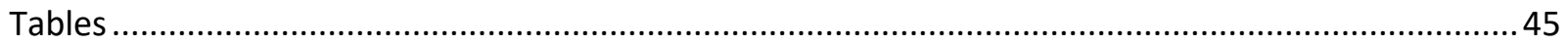

Table 2.1 Soil map unit information from locations where soil was collected for benchtop

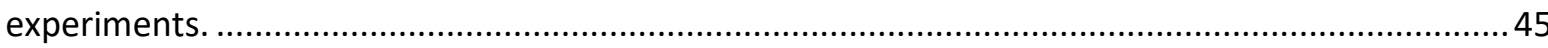

Table 2.2 MANOVA Test Criteria and F approximations for history treatment vegetation ...............45

Table 2.3 MANOVA Test Criteria and F approximations for interactions .........................................46

Table 2.4 Analysis of Variance for $\mathrm{H}_{2} \mathrm{O}$-Organic, using Adjusted SS for Tests.................................. 46

Table 2.5 Analysis of Variance for $\mathrm{NaHCO}_{3}$-Organic, using Adjusted SS for Tests ...........................46

Table 2.6 Analysis of Variance for $\mathrm{NaOH}-O r g a n i c$, using Adjusted SS for Tests .............................. 47

Table 2.7 Analysis of Variance for HCl-Organic, using Adjusted SS for Tests .................................. 47

Table 2.8 Grouping Information Using Tukey Method and 90.0\% Confidence for $\mathrm{H}_{2} \mathrm{O}$ Extractable

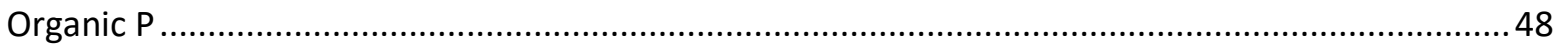

Table 2.9 Grouping Information Using Tukey Method and 90.0\% Confidence for $\mathrm{NaHCO}_{3}$ Extractable

Organic $P$

Table 2.10 Grouping Information Using Tukey Method and 90.0\% Confidence for $\mathrm{NaOH}$ Extractable

Organic $P$

Table 2.11 Grouping Information Using Tukey Method and 90.0\% Confidence for $\mathrm{HCl}$ Extractable

Organic $P$

Chapter 3. Identifying the Effects of Space on the Distribution of Sequential Extracted Organic Phosphorus Fractions in Hay and Grass Pastures of Eastern West Virginia Following Long-Term Nitrogen-

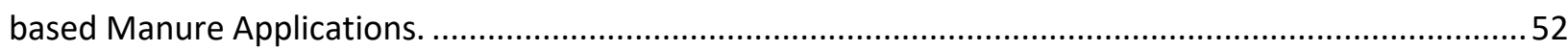

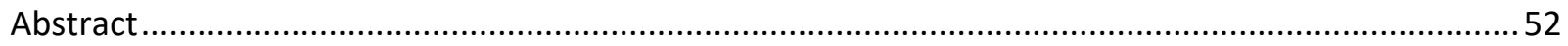

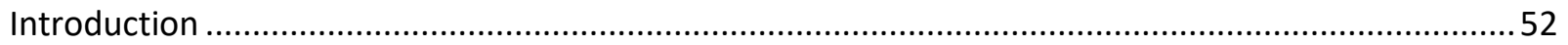

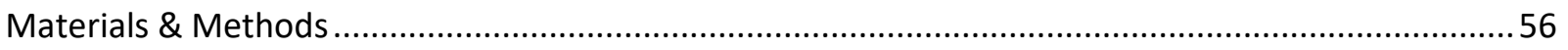

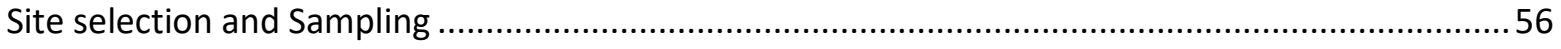

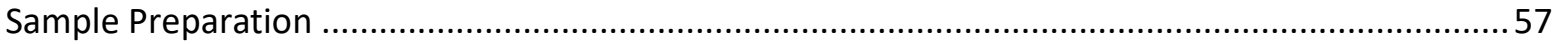

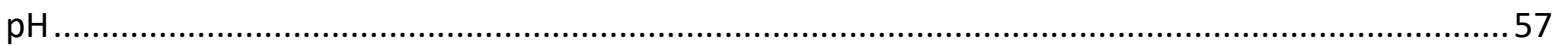

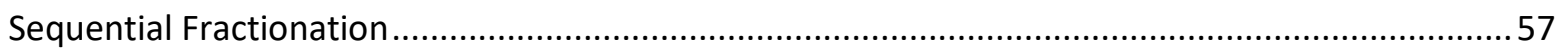

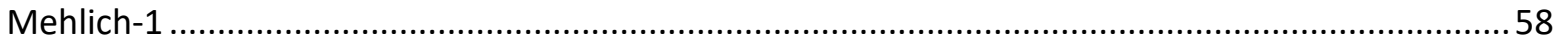

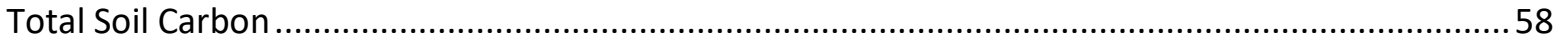

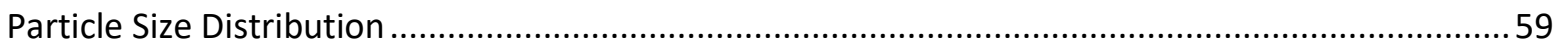

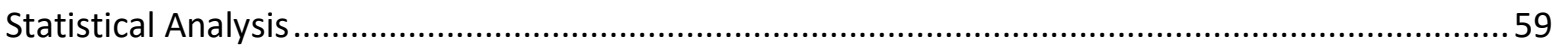

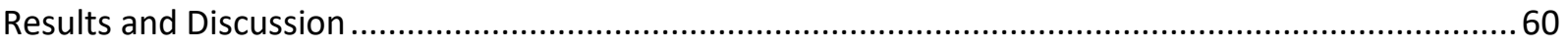




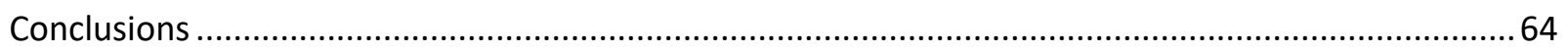

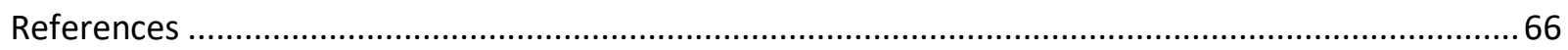

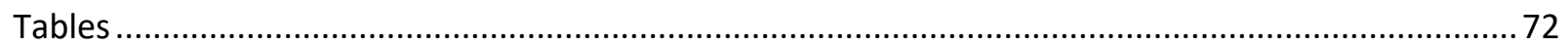

Table 3.1 MANOVA for fertility levels surface samples ................................................................ 72

Table 3.2 MANOVA for fertility levels subsurface samples ........................................................... 72

Table 3.3 Summary of Bonferroni corrected one-way ANOVA of soil test values............................72

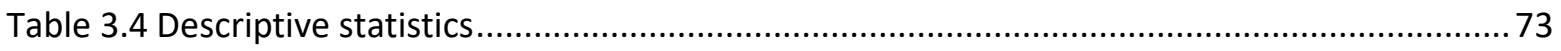

Table 3.5 Summary groupings from one-way ANOVA of soil test values ....................................... 74

Table 3.6 Stepwise regression of soil properties for surface samples with STP as the response, and Mehlich 1 extractable Fe, Al, and Ca; \% soil carbon; \% sand, silt, and clay; surface horizon thickness;

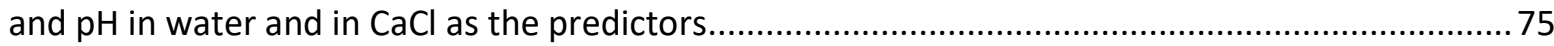

Table 3.7 Stepwise regression of soil properties for subsurface samples with STP as the response, and Mehlich 1 extractable Fe, Al, and Ca; the soil carbon; sand, silt, and clay percentages; surface horizon thickness; $\mathrm{pH}$ in water and in $\mathrm{CaCl}$; and STP levels of the surface horizon as predictors .....76

Table 3.8 Mantel and Partial Mantel tests for spatial structure in surface samples ......................... 77

Chapter 4. Topographic Influence on the Movement and Transformation of Organic Phosphorus in Hay

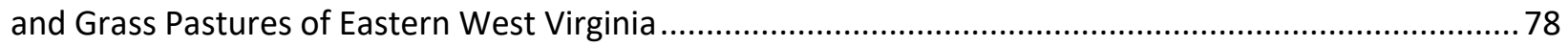

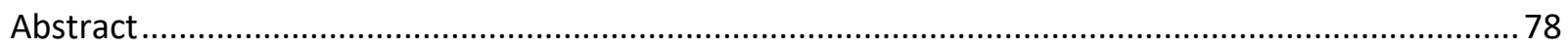

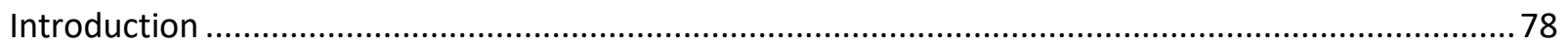

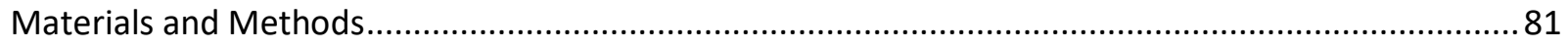

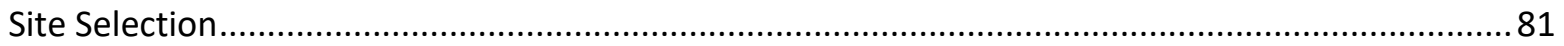

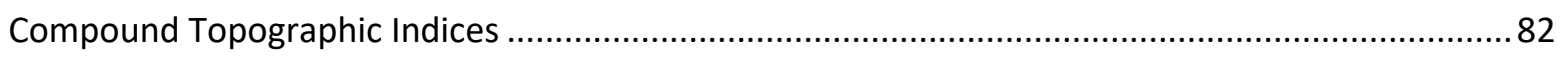

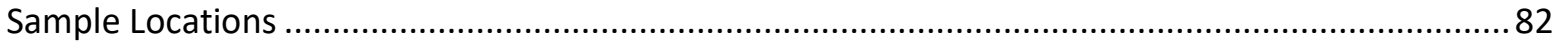

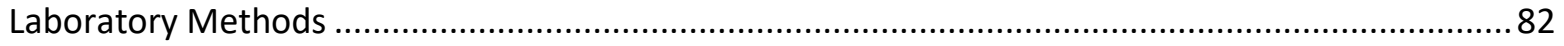

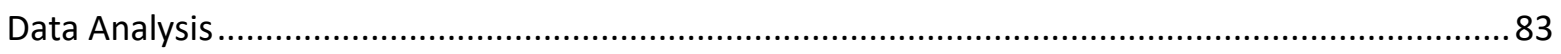

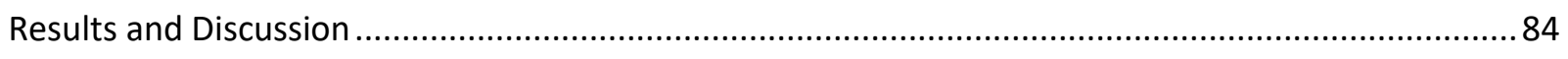

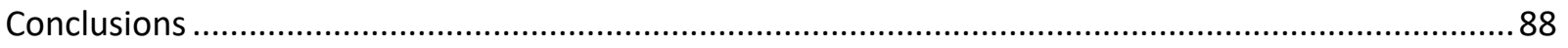

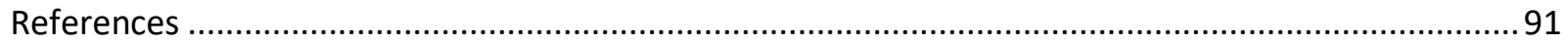

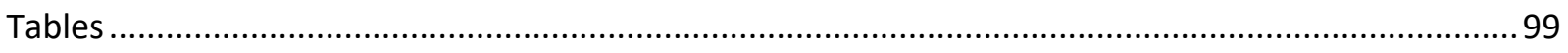

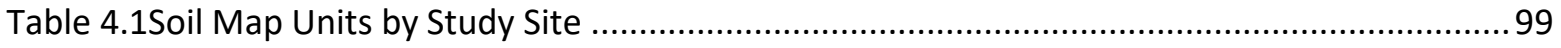

Table 4.2 Location - horizon - fraction combinations with a significant spatial component to the

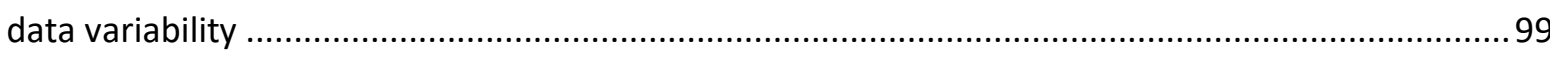


Table 4.3 Pearson's product-moment correlation matrix for sequential extracted $\mathrm{P}_{\mathrm{o}}$ fractions from location Fertilized 1. 101

Table 4.4 Stepwise regression of surface horizon from location Fertilized 1 with $1.0 \mathrm{M} \mathrm{HCl}$ extracted $\mathrm{P}_{\mathrm{o}}$ as the response and Mehlich 1 extractable $\mathrm{Fe}, \mathrm{Al}$, and $\mathrm{Ca}$; the soil carbon; sand, silt, and clay percentages; surface horizon thickness; $\mathrm{pH}$ in water and in $\mathrm{CaCl}$; and $\mathrm{TWI}_{\mathrm{s}}$ as the predictors .......102

Table 4.5 Mantel and partial Mantel correlations all unique combinations with a spatial component in the data variability 103

Table 4.6 Pearson's product-moment correlation matrix for sequential extracted $\mathrm{P}_{\mathrm{o}}$ fractions from location Fertilized 2 104

Table 4.7 Stepwise regression of soil properties for surface horizons of location fertilized 2 with $0.5 \mathrm{M} \mathrm{NaHCO}_{3}$ as the response and Mehlich 1 extractable $\mathrm{Fe}, \mathrm{Al}$, and $\mathrm{Ca}$; the soil carbon; sand, silt, and clay percentages; surface horizon thickness; $\mathrm{pH}$ in water and in $\mathrm{CaCl}$; and $\mathrm{TWI}_{\mathrm{s}}$ as the predictors

Table 4.8 Pearson's product-moment correlation matrix for sequential extracted $\mathrm{P}_{\mathrm{o}}$ fractions from location Unfertilized 1 .

Table 4.9 Stepwise regression of soil properties for surface horizon of location Unfertilized 1 with $0.5 \mathrm{M} \mathrm{NaHCO}_{3}$ as the response and Mehlich 1 extractable $\mathrm{Fe}, \mathrm{Al}$, and $\mathrm{Ca}$; the soil carbon; sand, silt, and clay percentages; surface horizon thickness; $\mathrm{pH}$ in water and in $\mathrm{CaCl}$; and $\mathrm{TWI}_{\mathrm{s}}$ as the predictors

Table 4.10 Stepwise regression of soil properties for subsurface horizon of location low one with Mehlich 1 extractable $\mathrm{Fe}, \mathrm{Al}$, and $\mathrm{Ca}$; the soil carbon; sand, silt, and clay percentages; surface horizon thickness; $\mathrm{pH}$ in water and in $\mathrm{CaCl}$; and STP levels of the surface horizon as predictors ...107

Table 4.11 Stepwise regression of soil properties for subsurface horizon of location Unfertilized 1 with Mehlich 1 extractable $\mathrm{Fe}, \mathrm{Al}$, and $\mathrm{Ca}$; the soil carbon; sand, silt, and clay percentages; surface horizon thickness; $\mathrm{pH}$ in water and in $\mathrm{CaCl}$; $\mathrm{TWI}_{\mathrm{s}}$; and STP levels of the surface horizon as predictors

Table 4.12 Stepwise regression of soil properties for subsurface horizon of location low one 109

Figures.

Figure 4.1 Hot spot analysis of Mehlich 1 soil test phosphorus data at location fertilized 1where locations with high value, surrounded by other features with high values are identified and hot spots and locations with low value, surrounded by other features with low values are identified and cold spots.

Figure 4.2 Hot spot analysis of Mehlich 1 soil test phosphorus data at location fertilized 2 where locations with high value, surrounded by other features with high values are identified and hot spots and locations with low value, surrounded by other features with low values are identified and cold spots .111 
Figure 4.3 Hot spot analysis of Mehlich 1 soil test phosphorus data at location unfertilized 1 where locations with high value, surrounded by other features with high values are identified and hot spots and locations with low value, surrounded by other features with low values are identified and cold spots.....

Figure 4.4 Hot spot analysis of Mehlich 1 soil test phosphorus data at location unfertilized 2 where locations with high value, surrounded by other features with high values are identified and hot spots and locations with low value, surrounded by other features with low values are identified and cold spots.....

Figure 4.5 Hot spots near former gated entrance and winter feeding area at entrance of the pasture area at location unfertilized 2 where locations with high value, surrounded by other features with high values are identified and hot spots and locations with low value, surrounded by other features with low values are identified and cold spots. 114

Figure 4.6 Isolines of location fertilized 1 with sample points divided into three distinct subsets with the sample points located in the summit position (blue), the sample points contributing to a midfield concave feature draining out of the field (yellow), and the remaining points (red).

Figure 4.7 Isolines of location fertilized 2 with sample points divided into two subsets: a limited subset of sample points located on the higher landscape positons in the foot slope that appear to be hydrologically isolated from the remaining data points (blue) and the remaining data points (yellow).

Figure 4.8 Isolines of location unfertilized 1 is composed of four basic elements, a summit, two back slopes and a foot slope position. The sample points in the summit drained into one of two back slopes, who converged at the foot slope of the landscape. The data points are divided into three parts: the two back slopes (red and blue) and data points at the foot slope position (yellow).......117

Chapter 5. Modeling Sequentially Extracted Organic Phosphorus Fractions from Soil Test Phosphorus and Topographic Data

Abstract. .118

Introduction .118

Materials and Methods.. .121

Study Sites and Sample Locations 121

Sample Preparation 121

Sequential Fractionation .121

Mehlich-1 122

Mehlich-3. 122

Modeling Parameters

Statistical Analysis and Modeling. .123

Results and Discussion .... .124 


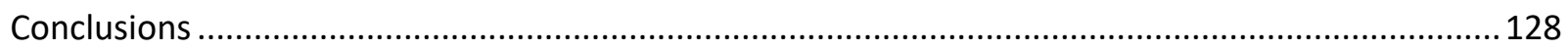

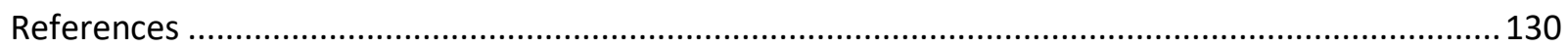

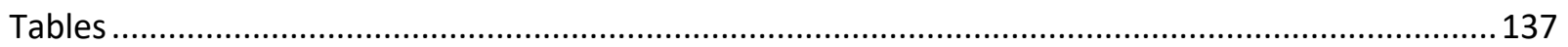

Table 5.1 Initial regression models using stepwise procedure with adjusted $\mathrm{R}^{2}$ - a modified version of R-squared that has been adjusted for the number of predictors in the model, Mallow's CP - when close to the number of predictors in a model indicates unbiased in estimating the true regression coefficients and predicting future responses and $\mathrm{S}$ the standard error of the regression. 137

Table 5.2 All topographic variables considered \& selected by the initial stepwise regression procedure.

Table 5.3 Pearson product moment correlation of topographic model terms selected by initial stepwise regression procedure.

Table 5.4 Summary model data for surface stepwise regression models with potentially collinear model terms.

Table 5.5 Summary model data for subsurface stepwise regression models with potentially collinear model terms

Table 5.6 Frequency of terms across all initial stepwise regression models

Table 5.7 Final regression models for sequentially extracted $P$ fractions with adjusted $R^{2}$ - a modified version of R-squared that has been adjusted for the number of predictors in the model, $\mathrm{R}^{2}$ fit 1 - fit against the validation set using point STP data, $R^{2}$ fit 2 - fit against the validation set using field average STP data and $\mathrm{S}$ the standard error of the regression..... 143

Table 5.8 Mean fit of Mehlich 1 \& 3 models using point and field average soil test $P$ values for surface, subsurface, and all data .144

Chapter 6. Summary .... 145

Summary of Findings..... 145

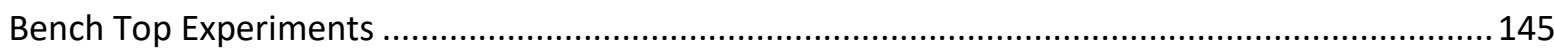

Identifying Actual Patterns in Sequentially Extracted P Fractions ................................................ 146

Explaining Spatially Significant Patterns in Sequentially Extracted P Fractions............................. 147

Modeling Sequentially Extracted P Fractions Across Complex Landforms...................................148

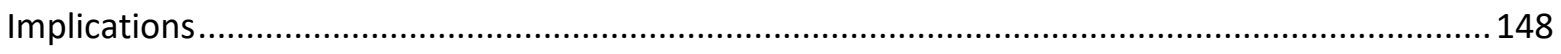

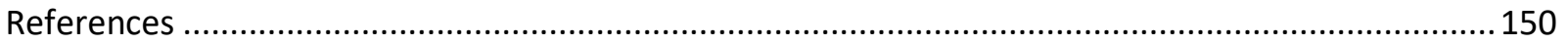

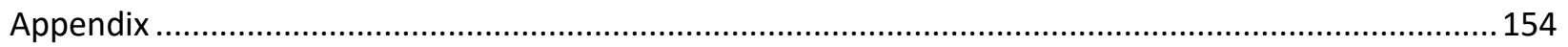

Sequentially extracted phosphorus fractions (benchtop) ............................................................ 154

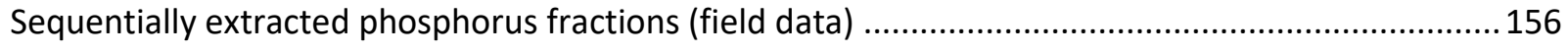

Soil test, $\mathrm{pH}, \mathrm{carbon}$, and particle size data (field data) ................................................................ 163 


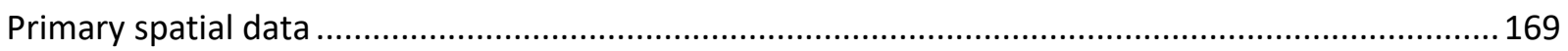

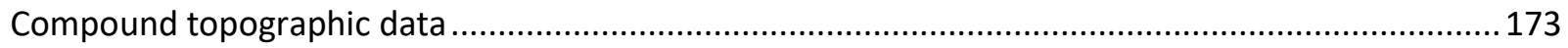




\section{Introduction}

\section{Experimental Overview}

This research consists of both field- and lab-scale experiments designed to examine the transformation and movement of $\mathrm{P}_{\mathrm{o}}$ in typical hay or pasture setting on marginal soil in the poultry-producing region of West Virginia.

The selected study sites were typical of hay or grass pasture fields in eastern West Virginia. The study sites consisted of one set of two (fertilized) locations with a lengthy history (approximately 10+ yr) of annual N-based manure applications, and one set of two (unfertilized) locations with very infrequent manure applications (maximum of one application every $10 \mathrm{yr}$ ). All locations were as similar to each other as practically possible.

\section{Outline of Dissertation}

This dissertation is divided into six chapters, beginning with an extensive review of the literature (Chapter 1) and ending with a brief summary of the important findings of this body of work (Chapter 6). In between are four chapters that describe aspects of both lab-based experiments (Chapter 2) and fieldbased analysis and modeling (Chapters 3 through 5). While all of the field-based research utilized the same study sites and the same data, the results and discussion were divided into three separate chapters to more clearly organize and communicate both the methods and the results of the somewhat complex field-based research.

\section{Chapter 1. Literature Review}

The overall literature review covers the fundamental research in this field of study. This review is written to place in the proper context the issues related to this problem, the extent of research efforts to explain this phenomena, and areas in need to additional research.

\section{Chapter 2. Lab-Scale Experiments}

To understand the interactions between soils and nutrients one approach is to combine various soils and nutrients and, after an appropriate period of time, examine the changes that have occurred. The purpose of this experiment was to evaluate these changes under more realistic conditions than typically employed during such experiments. To this end, lengthy soil incubations with multiple P sources under conditions more similar to the pasture and hay land environments of the poultry producing region of West Virginia were implemented. Accordingly, operationally defined sequential extracted organic $P$ fractions were examined in the presence of vegetation, variability in P sources, and management history 
of soil to determine if these variables have a significant effect on the ultimate disposition of organic $P$ in the afore mentioned operationally defined sequential extracted $\mathrm{P}$ fractionations.

\section{Chapter 3. Identifying Spatial P Patterns}

In general, advanced understanding of the complex redistribution of $\mathrm{P}_{\mathrm{o}}$ is critical for making the best decisions in terms of how to intercept $\mathrm{P}$ movement, how to model $\mathrm{P}$ behavior, and how to infer the relative value of this complex and costly data from relatively inexpensive and readily available surrogate data. To this end, the purpose of this chapter was to determine if there is an unidentified spatial component to the field-scale distribution of sequentially-extracted $\mathrm{P}_{\mathrm{o}}$ beyond what can be explained by changes in soil properties across the landscape. Various experimental design and statistical analysis techniques were used to evaluate possible spatial relationships obvious changes in soil properties.

\section{Chapter 4. Explaining Spatial P Patterns}

This chapter describes efforts to incorporate exploratory spatial data analysis (ESDA) and geovisualization techniques while evaluating field-scale distribution of sequentially-extracted $\mathrm{P}_{\mathrm{o}}$ in greater. Using similar techniques to chapter 3, a more detail examination was conducted to determine if the variability identified in Chapter 3 could be explained by including landscape-scale physical processes. The purpose of this inquiry was to evaluate the theoretical potential for successful soil landscape modeling applications related to the spatial distribution of sequentially extracted organic $P$ fractions.

\section{Chapter 5. Modeling Spatial P Patterns}

This chapter was developed to construct and evaluate soil test P-based predictive models. Specifically, these models combine STP data and Landscape data to predict operationally defined sequentiallyextracted $P_{0}$ fractions. Successful development of such models could facilitate the accurate estimation of otherwise difficult and costly to collect data from readily available and significantly less costly inputs. This could facilitate new and exciting ways to approach P management regionally in locations like tie poultry producing region in West Virginia.

\section{Chapter 6. Summary Review}

The summary review brings together the concepts and ideas from the preceeding chapters to attempt to answer the broader questions related to $\mathrm{P}$ management in the poultry producing region of West Virginia. 


\section{Chapter 1. Topographic Influence on the Movement and Transformation of Organic Phosphorus in Hay and Grass Pastures of Eastern West}

\section{Virginia}

\section{Introduction}

Understanding the interactions between soils, fertilizers, and management practices is critical for sustainable agriculture and the protection of sensitive watersheds. Some regions of the U.S., because of the presence of high density animal agriculture production, are inherently more likely to experience environmental impacts derived from excess manure availability. The poultry-producing region of West Virginia is one such location. Grant, Hardy, and Pendleton Counties in eastern West Virginia account for about $83 \%$ of the broiler and other meat type chicken sales annually (USDA NASS, 2014). This regionally dense production generates substantial volumes of poultry manure. Given current production of approximately 78,000,000 broilers per year (USDA NASS, 2014) and an estimated 2.3 pound of poultry manure per broiler (Beegle, 2007), this region has the potential to generate in excess of 80,000 tons of poultry litter per year. Historically in this region of West Virginia as much as $90 \%$ of the poultry manure has been used as fertilizer and over $80 \%$ of that has been applied to grasslands (Basden et al., 1994). When concentrated animal agriculture and long-term $\mathrm{N}$-based manure management occur together, phosphorus $(\mathrm{P})$ saturation and elevated risks to water quality following are potential outcomes (Beck et al., 2004).

As concerns over pending regulation mount, a strategic long-term approach to research should become a higher priority within the poultry producing and regulatory communities. Over time more land uses will become regulated and it is reasonable to assume some of this land, currently receiving animal manure applications on a $\mathrm{N}$ basis or in excess of crop removal rates, will attain a degree of $\mathrm{P}$ saturation that will prohibit further manure application. As some lands are removed from the manure application pool, other locations within the surrounding area will be needed, or the manure resources will need to be moved greater distances. In the coming years, the effort of reduce the P saturation of the existing sites and prevent $\mathrm{P}$ loss from all sites will become a greater priority. Thus, some portion of current research efforts should focus on answering questions about the fate of $P$ in these agricultural lands with extensive histories of animal manure applications.

Understanding the composition and distribution of the P pool on marginal lands could assist land managers in remediating $\mathrm{P}$ saturated locations, maximizing environmentally safe manure usage, 
reducing costly sampling, and focus the application of limited resources to maximize their affect. The utilization of a soil-landscape modelling approach could allow researchers to meet some of these goals. The soil-landscape modelling approach provides a quantitative means of estimating soil properties across an area by combining physiographic properties, and georeferenced soil sample data (McSweeney et al., 1994). In place of resource dependent sampling regimens, relatively inexpensive high-resolution surrogate data are collected and correlated with georeferenced soil sample data to develop a regression based estimate at the resolution of the surrogate data (Thompson et al., 2006).

To date, the majority of $\mathrm{P}$-soil-environment research has focused on inorganic $\mathrm{P}\left(\mathrm{P}_{\mathrm{i}}\right)$ (Laboski and Lamb, 2003; Anderson and Magdoff, 2005). However, organic $P\left(P_{o}\right)$ may be a significant part of the total soil $P$ pool. To understand the implications of management decisions, relative to manure applications, a greater understanding of potential $\mathrm{P}_{\mathrm{o}}$ movement and soil interactions is needed (Condron et al., 2005). Developing that understanding and generating the means of extending that knowledge is paramount. The goal of this research is evaluate the applicability of incubation studies, evaluate $P_{0}$ patterns across farm fields, assess soil and topographic parameters to understand potential $\mathrm{P}_{\mathrm{o}}$ movement, and ultimately model $\mathrm{P}_{\mathrm{o}}$ distribution in fields. Specific hypotheses related to these individual overarching goals will follow in the individual chapters to follow.

\section{Literature Review}

The following literature review is subdivided into general topics and a summary of related research. The section on phosphorus will briefly address $\mathrm{P}$ in the environment, in soils, and in animal manure. The section on the phosphorus cycle will briefly discuss the P cycle, P movement, and how P was measured and defined in its various forms. The section on soil-landscape modelling will explain what soillandscape modelling is, how it can and has been used to model soil properties. The summary of related research will examine previous $\mathrm{P}_{\mathrm{o}}$ research in West Virginia, $\mathrm{P}_{\mathrm{o}}$ fractionation, manure-soil incubations, and landscape modelling in the context of this research, examining what has been done and outlining what is needed.

\section{Phosphorus}

Long-term applications of plant nutrients in the form of chemical fertilizers or animal manures at rates in excess of crop or plant removal can lead to the accumulation of nutrients (Sims et al., 2002; Beck et al., 2004; Johnson et al., 2005; Miller et al., 2010). If excess nutrients are lost or transported from agricultural land to either ground or surface waters, the excess nutrients generate a degree of risk to water quality in the surrounding environment (Sharpley et al., 1992). Of particular concern are $\mathrm{N}$ and $\mathrm{P}$ 
because excess amounts of $\mathrm{N}$ and $\mathrm{P}$ in aquatic ecosystems can stimulate excessive algal growth, limit light penetration, and causes hypoxia as the algae decomposes (USEPA, 1996; Gachter et al., 1998; Tarkalson and Mikkelsen, 2004). The USEPA (1995) considers P among the leading causes of pollution in lakes, estuaries, and rivers. In freshwater systems, $\mathrm{P}$ is often the limiting nutrient for algal growth (Newton et al., 1999; Conley, 2000). Consequently, agricultural sources have been identified in some instances as contributing to algal blooms and perhaps even fish kills (Shedlock et al., 1999; Sharpley, 2000; Boesch et al., 2001).

Historically, most research on P sorption and availability has focused on inorganic sources, with significantly less attention given to organic species of $\mathrm{P}$ (Laboski and Lamb, 2003; Anderson and Magdoff, 2005). Some researchers hypothesize this may be due to a perception that $P_{i}$ is the dominant form of $\mathrm{P}$ and it is the plant available form, and the analysis of organic forms was simply too problematic (Jansson et al., 1988; Turner and Haygarth, 2000; Anderson and Magdoff, 2005). However, the loss of any bioavailable $\mathrm{P}$ is potentially damaging to the environment (Sharpley et al., 1992).

Sorption is the generic term used to describe a series of physical (precipitation) and chemical (adsorption and absorption) processes (Bache, 1964; Sanyal and De Datta, 1991; Abekoe 1996). McGechan and Lewis (2002) stated, "Sorption is the process by which reactive chemicals become attached to surfaces, sometimes of otherwise relatively harmless solids." Pierzynski et al (2005) likened $\mathrm{P}$ sorption to the generic transfer of $\mathrm{P}$ from the solution to the solid phase. This capacity to sorb $\mathrm{P}$ is typically described or defined in terms of a sorption isotherm or related function. These sorption isotherms are equations or models used to represent the sorption process (McGechan and Lewis 2002). A sorption isotherm can be used to model maximum P sorption, short-term sorption, slower long-term sorption processes, and desorption (McGechan and Lewis 2002).

The strength of the P-soil bonds affect soil solution concentrations (Brady and Weil, 2002; Blake et al., 2003; Pierzynski et al., 2005). Fundamentally, P sorption capacity is related to the soil surface chemistry, reactivity, Fe and Al content, clay content, and pH (Barrow, 1984; Fox, 1985; McGechan and Lewis, 2002). $P$ in soils is often bound to metal oxides, carbonates, and sometimes displaces water and hydroxyl groups on surfaces (Smeck, 1985; Pierzynski et. al 2005). In solution, P tends to act like a hard Lewis base, forming inner and outer sphere complexes with hard Lewis acids such as $\mathrm{Al}^{3+}, \mathrm{Ca}^{2+}$, and $\mathrm{Fe}^{3+}$ (Pierzynski et. al 2005). In mineral soils, some anions of organic acids compete with the $\mathrm{P}$ anions for the Fe and Al cations (Struthers and Sieling, 1950). In organic soils, Gerke and Hermann (1992) found the Fe and Al compounds were crucial in creating bridges between $\mathrm{P}$ and the humic substances. When $\mathrm{P}$ forms 
bidentate inner sphere complexes with metal cations, he $\mathrm{P}$ compounds are stronger complexes and not as readily reversible as outer sphere, or monodentate, inner sphere complexes (Sims and Pierzynski 2005). The strength of these relationships with sorption capacity has allowed researchers to effectively predict the P sorption capacity of similar soils (Scheinost and Schwertmann, 1995).

In terms of $\mathrm{P}$ composition in soil, the $\mathrm{P}_{\mathrm{o}}$ pool in soil is typically composed of inositol phosphates, phospholipids, nucleic acids, phosphoproteins and other unidentified P compounds (Schroeder and Kovar, 2006). $P_{i}$ in soils typically comes from the weathering of apatite (Pierzynski et al., 2005). The exact speciation of these phospho-metal-oxides and hydroxides is dependent upon the available components and soil conditions (Pierzynski et al., 2005).

P within animal manure can be identified or described in a similar manner to soil. The dominant forms of $P$ in poultry litter are orthophosphate (inorganic) and phytate (organic) and the concentrations of orthophosphate and phytate correlate well with some sequential fractionations techniques (Warren et al., 2008). The majority of the $\mathrm{P}$ in poultry litter is extractable with $\mathrm{H}_{2} \mathrm{O}$ and $\mathrm{NaHCO}_{3}$ (Codling, 2006; Dou et al., 2000; Dail et al., 2007). Phytate is the principal form of $P$ in the grain-based (Maize) diets of nonruminants (poultry) and most of it is passed along into the feces undigested (Harland and Morris, 1995; Sharpley, 2000). The $\mathrm{P}_{\mathrm{i}}$ percentage is typically highest in the $\mathrm{H}_{2} \mathrm{O}$ extractable fraction (Codling, 2006). However, some reports indicate that $72-83 \%$ of $\mathrm{H}_{2} \mathrm{O}$-extractable $\mathrm{P}$ in poultry manure is in an organic form (Sistani et al., 2001). A four-step fractionation $\left(\mathrm{H}_{2} \mathrm{O}, \mathrm{NaHCO}_{3}, \mathrm{NaOH}\right.$, and $\mathrm{HCl}$ ) has been shown to extract between 85 to $97 \%$ of the total P in poultry manure (Warren et al., 2008; McGrath et al. 2005) and is similar to the numerous other sequential extraction procedures used to fractionate $\mathrm{P}$ in soils.

Continuous applications of manures can lead to the modification of soil properties, $\mathrm{P}$ sorption characteristics, and perhaps increase P translocation through the soil profile (Hao et al., 2008; Harman et al., 2013). For example, by elevating the Ca content of the soil, $P_{\circ}$ additions could alter $P$ sorption characteristics (Robinson and Sharpley, 1996). The more labile nature of some of these Ca-P complexes following long-term manure applications could contribute to potential $\mathrm{P}$ translocation within the soil profile (Holford et al., 1997; Siddique and Robinson, 2003). This is supported by the research of Lehmann et al. (2005). In research on locations with long-term application of animal manure, Lehman et al. (2005) documented P leaching consistent with accumulation and translocation.

Continual additions of poultry manure shift $\mathrm{P}$ from binding with Fe and Al products to binding with $\mathrm{Ca}$ (Sharpley et al., 2004). In addition to elevating $\mathrm{P}, \mathrm{N}, \mathrm{pH}$, and $\mathrm{Ca}$, poultry manure elevates the levels of 
bicarbonates and of organic acids with carboxyl and phenolic hydroxyl groups (Sharpley et al., 2004). The introduction of these compounds and their associated functional groups provide new reactive surfaces within soil and change the composition of the soil solution, affecting everything from $\mathrm{pH}$ to ionic strength. When poultry manure is added continuously to soil, more and more $\mathrm{P}$ becomes contained within the most easily extractable, labile fractions (Blake et al., 2003). Ultimately, the number and type of sorbtive surfaces in the soil determine the fate of $\mathrm{P}$ fractions (Blake et al., 2003).

\section{Phosphorus Cycle}

The soil solution P concentration is typically very low, thus requiring a constant turnover from other pools to replace P removed from the soil solution (Pierzynski et al., 2005). This replacement or replenishment of solution $\mathrm{P}$ comes from the $\mathrm{P}$ referred to as labile $\mathrm{P}$. Labile $\mathrm{P}$ is "soil or sediment $\mathrm{P}$ that rapidly equilibrates with an aqueous solution" (Pierzynski et. al 2005). Nonlabile P is the form of $P$ in soil that is more stable and less useful in maintaining $\mathrm{P}$ levels in solution. This overly simplified re-allocation of $P$ between $P$ pools and $P$ forms is the basis of the $P$ cycle.

The phosphorus cycle is an extremely complex interaction of $\mathrm{P}_{\mathrm{i}}, \mathrm{P}_{0}$, biogeochemical processes, and environmental factors, by which a semi-steady state of solution $\mathrm{P}$ is maintained via the transformation of $\mathrm{P}$ forms. It is the conceptual model of how $\mathrm{P}_{\mathrm{i}}$ and $\mathrm{P}_{\mathrm{o}}$ move between labile and non-labile pools through biological, chemical, and physical pathways within the environment. There are four major coupled processes within the P cycle: sorption-desorption, precipitation-dissolution, mineralizationimmobilization, and input-loss.

The sorption -desorption process is a mechanism by which P can be removed from or added to the soil solution (Bunemann 2015). Sorption-desorption is a complex process of $\mathrm{P}$ temporarily bonding with a particle surface in the soil system. Excess $P$ in solution becomes sorbed to the surface of primarily AL and Fe oxides (Fossard et al., 1995). When P levels in the soil solution change, P may be sorbed or desorbed from the soil particles until equilibrium between the relative attraction to the particles and the concentration in solution is achieved. Accordingly, as soils become more saturated with $P$, the soils have a lower ability to retain additional P (Giles et al., 2015).

Dissolution - precipitation is a very important abiotic process regulating $\mathrm{P}$ levels in the soil solution as labile $\mathrm{P}$ is only a small part of the total P pool in soil (Fossard et al., 2000). Precipitation-dissolution is the process of $\mathrm{P}$ forming or dissolving of primary and secondary $\mathrm{P}$ minerals from the soil solution. Primary P mineral generally refer to apatite, while secondary P minerals include sorbed $\mathrm{P}$, as well as Al 
phosphate, Fe phosphates, and Ca phosphates like brushite, monetite, and octacalcium phosphate (Smeck, 1985). As soils weather and acidify, the formation of Fe and Al phosphates and $P_{0}$ is favored (Smeck, 1985; Pierzynski et. al 2005). Ultimately, if the soluble pool of P becomes depleted, the encapsulation of these secondary $\mathrm{P}$ minerals by metal oxides and formation of occluded $\mathrm{P}$ becomes likely (Smeck, 1985).

The third of the major coupled process in the P cycle is mineralization - immobilization. Mineralizationimmobilization is the process where P moves between organic and inorganic forms. This is the biotic phase of the P cycle. In short, organisms access P from the soil solution decreasing solution concentrations while increasing their mass or number. Over time, these organisms die and decay releasing $\mathrm{P}$ back into the soil solution. Thus as conditions dictate, available $\mathrm{P}$ can be immobilized (made unavailable) within biological entities in various states of growth or decay or mineralized (released) as various inorganic and organic $\mathrm{P}$ compounds.

The final phase of the P cycle includes inputs and losses. P input is typically either weathering of primary P minerals or anthropogenic additions. P loss typically takes the form of sediment mediated transport and leaching losses (Pierzynski et. al 2005). Simultaneously, sorption-desorption, precipitationdissolution, and mineralization-immobilization reactions are actively transforming $P$ to satisfy the plant and microbiological communities. P can change forms, shift between inorganic and organic forms, and be leached away or move with sediments and organic matter.

While, in a general sense, $\mathrm{P}$ is limited in its mobility, $\mathrm{P}$ does move in soil. In native conditions, long-term water movement can lead to slow migration of P across the landscape. Smeck (1973) and Smeck and Runge (1971) have proposed that $P$ can move laterally within a landscape, and that $P$ will accumulate in lower landscape positions. Measuring changes in $\mathrm{P}$ across a landscape can infer a reasonable approximation of how water movement occurred across and through that landscape historically (Smeck, 1973). In addition to physically moving $P$, water can chemically alter the soil, and this can alter the longterm fate and transport of P. For example, dryer soils found in well-drained, upland positions, rich in iron and aluminum oxides tend to have higher P sorption capacities then less oxidized soils more common in wetter landscape positions (Walker and Syers, 1976; Abekoe, 1996).

In terms of $\mathrm{P}$ movement, $\mathrm{P}$ loss from agricultural lands generally occurs via one of two mechanisms, surface and subsurface movement (King et al., 2015). When transported via subsurface flow mechanisms, P from fertilizer or manure moves through the soil into the ground or surface water. 
Erosion losses occur when overland flow moves $\mathrm{P}$ from fertilizer, manure, or P enriched soil materials across the soil surface and or into surface waters. Historically best management practices focused on reducing or eliminating erosional losses, as erosional losses were considered the more important pathway of $\mathrm{P}$ loss (King et al., 2015). P leaching was generally not considered as important due to the low dissolved $\mathrm{P}$ concentrations in the soil solution and the sorbtive properties of the soil matrix (Baker et al., 1975). However, soils receiving large quantities of $P$ fertilizer, soils with lower concentrations of reactive surfaces, coarser textures, pronounced structure, high concentrations of rock fragments, and extensive macropores networks pose a greater risk for P loss (Anderson and Magdoff, 2005; Harman et al., 2013). Yet, $P_{i}$ is only part of the $P$ picture. Literature indicates organic $P\left(P_{o}\right)$ could be as low as $29 \%$ or as high as $65 \%$ of the total P (Harrison, 1987) and some research indicates it could be as high as $90 \%$ of $\mathrm{P}$ in the soil solution phase (Helal and Dressler, 1989; Shand et al., 1994; Turner and Haygarth, 2000; Anderson and Magdoff, 2005). Only considering $P_{i}$ in risk assessment is overlooking the rather large remaining portion of the total $\mathrm{P}$ pool, or assuming it behaves proportional to the $\mathrm{P}_{\mathrm{i}}$ component.

\section{Measuring Soil Phosphorus}

Similar to how a P extraction method is selected; how $\mathrm{P}$ is physically measured is equally important. Colorimetric methods of P measurement are common. However, inductively coupled plasma (ICP) spectroscopy has been the most significant development in agricultural sample analysis since the development of the atomic absorption spectroscopy (AAS) (Isaac and Johnson, 1983). The ICP has facilitated rapid and consistent measurement of many soil nutrients. However, with $P$ there are complications when comparing colorimetric to ICP based methods. ICP P measurements can be as much as $36 \%$ higher than colorimetric methods (Ziadi et al., 2009). The obvious explanation for this increase is the ability of ICP based methods to measure $\mathrm{P}_{0}$, polyphosphates, and orthophosphate (measured by the colorimetric methods). Identification of individual P components would require lengthy examination, and many additional analytical steps.

The most rapid, complete approach to $\mathrm{P}$ characterization would be ${ }^{31} \mathrm{P}$ nuclear magnetic resonance. However, it is believed the preparative steps in ${ }^{31} \mathrm{P}$ nuclear magnetic resonance can lead to partial hydrolysis of some $P_{0}$ forms, thus introducing a degree of inaccuracy (He et al., 2008). The identification of $P_{o}$ fractions by enzymatic hydrolysis is the more accurate method of $P_{0}$ identification if identification of specific labile $P_{0}$ species as opposed to the entire labile pool (He et al., 2008). Understanding the operationally defined nature of the measurement is as critical as understanding the limitations of the extraction methodology. 
In general, $\mathrm{P}$ extracted with any hydroxide solution is assumed to be $\mathrm{P}_{\mathrm{o}}$ and $\mathrm{P}_{\mathrm{i}}$ typically bound to $\mathrm{Al}$ and Fe (Sharpley et al., 2004). P extracted with acid, is assumed to be $P_{o}$ and $P_{i}$ typically bound to Ca (Sharpley et al., 2004). P extracted with bicarbonate, ion exchange resin, and water-based extractions is assumed to remove only the most weakly bound most labile P components (Sharpley et al., 2004). Bicarbonate, ion exchange resin, and water-based extractions are said to remove the easily exchangeable and plant available forms of P (Sharpley et al., 2004). These examples describe parts of the pool based on the perceived role that the parts play in the P cycle (plant nutrients), how researchers extract them (ion exchange resin $\mathrm{P}$ ), and the expected mechanism of retention in the soil ( $\mathrm{Al}$ and Fe bound P).

Sequential $\mathrm{P}$ fractionation integrates a collection of chemical extractions such that the $\mathrm{P}$ is characterized by the type and strength of their physicochemical interactions with soil components (Bowman and Cole 1978; Hedley et al., 1982; Cross and Schlesinger, 1995). An individual fraction in a sequential fractionation is conceptually different but not necessarily pure or unique. The most common extractions used in these sequential fractionations are water $\left(\mathrm{H}_{2} \mathrm{O}\right)$, anion exchange resin, sodium bicarbonate $\left(\mathrm{NaHCO}_{3}\right)$, hydrochloric acid $(\mathrm{HCl})$, and sodium hydroxide ( $\mathrm{NaOH}$ ) (Guppy et al., 2000; Schroeder and Kovar, 2006). It is common to label these groups by the chemicals or chemical processes that removed them from the soil, by the believed mechanism of sorption, or the extraction's name. Typically, total P and $\mathrm{P}_{\mathrm{i}}$ are determined in each sequential fraction and in the residual soil following the final extraction.

\section{Soil-Landscape Modelling}

Soil-landscape modelling is an integration of Milne's (1935) catena concept, and Jenny's (1941) contention of topography controlling landscape scale variability in soil (Thompson et al., 2006). Terrain variables can be used to model significant variance in soil properties (Gessler et al., 2000). Soillandscape modelling techniques were developed as a means to quantitatively predict patterns of soil properties (Gessler et al., 1995; McBratney et al., 2000; Thompson et al., 2006). In fact, in locations with uniform geology and geomorphic history, variability in topographic properties can provide appropriate means of spatial prediction of soil properties (Gessler et al., 1995). Moore et al. (1991) indicated that topography can be used as an indirect measure of the spatial processes that occur at catchment scale, thus making topography an ideal means of estimating soil properties at field scale. Terrain variables can be used to model many soil properties, such as soil organic matter, moisture content, soil depth, and erodibility (Moore et al., 1991; Bell et al., 2000; Gessler et al., 2000; Mueller and Pierce, 2003; Pei et al., 2010). Jenny (1941) cited the work of Ellis (1938) as an example of soil moisture differentiation across a 
landscape based on slope and landscape position. The topography factor has proven to be important in terms of the spatial distribution of soil moisture (Sorensen et.al, 2005; Thompson et a., 2012) and soil properties influenced by soil moisture content and water movement (Hall, 1983). In humid environments, water continuously moves across and through a landscape interacting with the soil influencing the physical, chemical, and biological properties of the soil and the water. This subsequent re-distribution of water within a landscape can cause changes in soil properties in multiple dimensions (Hall, 1983).

It is common for terrain attributes to correlate with soil properties (Moore et al., 1993; Bell et al., 1994; Tomer et al., 1995; Boer et al., 1996; Park et al., 2001). As water is redistributed across the landscape, any soluble or suspended material contained within the water will be redistributed as well. As sediments and any dissolved materials move, the water effectively generates a degree of soil differentiation (Girgin and Frazier, 1996; Young and Hammer, 2000; Pachepsky et al., 2001; Ziadat, 2005). Thus, the physical, chemical, biological, and development status of soil is related to the factors controlling this redistribution of materials. Cognizant of this relationship between landscape and soil properties, researchers have used numerous forms of regression and correlation procedures to study these relationships between landscape position and soil properties (Lane, 2002; Webster, 2001; Guisan et al., 2002; Park and Vlek, 2002; Ziadat, 2005).

The basis for most of these regression and correlation procedures is the digital elevation model (DEM). A DEM is a representation of the variability of the elevation across a landscape (Bishop and Minasny 2006). The elevation data from the DEM is used to create spatial explicit derivatives known as primary or secondary (sometimes called compound) terrain attributes (Bishop and Minasny 2006). These primary terrain attributes are calculated directly from DEM while the secondary or compound terrain attributes are mathematical combinations of primary terrain attributes (Moore et al., 1991). The most common primary terrain attributes are slope gradient, slope aspect, and slope curvature. The most common secondary attribute is the topographic wetness index (TWI) sometimes referred to as the compound topographic index (CTI) or wetness index (WI) (Bishop and Minasny 2006). Secondary attributes are often more useful than primary attributes for predicting soil properties as secondary attributes tend to explain more complex physical properties and may be useful for modeling nonlinear relationships (Bell et al. 1994; McBratney et al., 2000; Bishop and Minasny 2006).

Topographic wetness index has been used in one form or another in many contexts to estimate properties associated with wetness (e.g., Moore et al., 1991; Hornberger \& Boyer, 1995; Iverson et al., 
1997; Boerner et al., 2000; Gessler et al., 2000; Case et al., 2005). The concept of TWI was developed by Beven and Kirkby (1979) as a component in a basin hydrology model. TWI is a compound terrain attribute, as it is made up of multiple primary terrain attributes (Bishop and Minasny 2006; Murphy et al., 2009). Specifically, TWI is defined as $\ln (A / \tan B)$ where $A$ is the local upslope contributing area for that point and B is the local slope gradient (Beven and Kirkby, 1979; Bishop and Minasny 2006; Murphy et al., 2009). TWI infers relative wetness within a landform.

TWI values are dependent on flow accumulation calculations (Murphy et al., 2009). Flow accumulation is contingent on first determining flow direction (Bishop and Minasny 2006). Flow direction is simply a directional assignment of likely flow for each cell. Flow accumulation is the collection of cells flowing together as defined by the flow direction layer (Murphy et al., 2009). Flow accumulation can be unidirectional, multidirectional, or dispersive; and each of these three methods of representing flow accumulation has its own specific limitations (Murphy et al., 2009). Murphy et al. (2009) contends that some TWI calculations do not adequately consider downslope topography, hydrologic conditions, and dispersive flow when modelling moisture. Others contend that the $(\tan B)$ does reflect the local drainage potential (Beven and Kirkby, 1979; Quinn et al., 1995).

\section{Summary of Related Research}

The West Virginia University Agricultural Experiment Station cataloged the amounts and types of $\mathrm{P}_{\mathrm{o}}$ found in 17 soil series at 34 locations across WV in the 1960's (Jencks et al., 1964). This research measured total $\mathrm{P}$, total $\mathrm{P}_{\mathrm{o}}$, phytin, available $\mathrm{P}$, organic matter, and $\mathrm{pH}$ in these unfertilized and unlimed soils. $P_{\mathrm{o}}$ accounted for between 7 and $66 \%$ of the total $\mathrm{P}$ in the surface horizons, and from 13 to $55 \%$ in the subsurface horizons (Jencks et al., 1964). Phytin or phytic acid (an inositol phosphate) accounted for between 13 and $63 \%$ of the total $P$ in the surface horizons, and from 10 to $48 \%$ in the subsurface horizons (Jencks et al., 1964). The Jencks et al. (1964) findings are corroborated by the assertions of others (Harrison, 1987; Helal and Dressler, 1989; Shand et al., 1994; Turner and Haygarth, 2000; Anderson and Magdoff, 2005) that significant portions of the total soil P pool may in fact be $P_{0}$.

There are numerous examples of research that utilized a sequential extraction process to separate the total P pool into operational defined fractions (Bowman and Cole 1978; Hedley et al., 1982; Tiessen et al., 1984; Schoenau et al., 1989; Cross and Schlesinger, 1995; lyamuremye et al., 1996; Sui et al., 1999; Guppy et al., 2000; Qian and Schoenau, 2000; Yang et al., 2002; He et al., 2004; Schroeder and Kovar, 2006). Similarly, there are numerous examples of soil research that utilizes incubations with soil and fertilizers (Iyamuremye et al., 1996; Qian and Schoenau, 2000; Whalen et al., 2001; Maguire et al., 2001; 
Yang et al., 2002; Crouse et al., 2002; Laboski and Lamb, 2003; He et al., 2004). However, in instances where researchers examine the fractions in a location under some set of conditions, it is rare that the study is accompanied by incubation experiments to further the understanding of potential sources of specific operationally defined sequentially extracted $\mathrm{P}$ fractions.

Historically, there have been multistep fractionation procedures developed for soil P (Chang and Jackson, 1957; Bowman and Cole 1978; Hedley et al. 1982), marine sediment P (Martin et al. 1987 and Ruttenberg, 1992), and countless modifications to these methods. The most commonly cited and modified method used in soil P research is the Hedley et al. (1982) fractionation (Guppy et al., 2000). The Hedley et al. (1982) fractionation partitions the P pool into soluble, aluminum/iron-bound, calciumbound, and residual forms. The more recent efforts to characterize the $P_{\mathrm{o}}$ pool in soil has utilized enzymes to separate specific $P_{0}$ compounds (He et al., 2004), 31P nuclear magnetic resonance analysis (Toor et al. 2003; Hill and Cade-Menun, 2009), and a sequential fractionation. Often these approaches are combined in some fashion to further differentiate $\mathrm{P}$ forms.

To learn how $\mathrm{P}$ additions change in soil over time, mixtures of fertilizer and soil are often incubated to examine changes relative to some factor or $\mathrm{P}$ type. This approach has been used to define changes in the soil P pool (He et al., 2004; Qian and Schoenau, 2000; Yang et al., 2002). However, long-term, field scale studies have shown $\mathrm{P}$ fractions do not change uniformly, and P concentrations decrease in the soil profile with depth (Hountin et al., 2000). In fact, long term applications of poultry manure (a source of $P_{0}$ ) can even cause the proportion of $P_{i}$ in the total pool to increase (Sharply et al., 2004).

Robinson and Sharpley (1996) examined sorption and fractionation on multiple soil samples from untreated locations after adding poultry manure leachate and concluded manure fertilizers and chemical fertilizers act differently in soils. When applying deliberate $P_{0}$ fractions to packed soil columns, Anderson and Magdoff (2005) found different classes of $\mathrm{P}_{\mathrm{o}}$ fraction moved through the soil at different rates. Specifically, orthophosphate diesters are more likely to leach in soils than monoesters or $\mathrm{P}_{\mathrm{i}}$ (Anderson and Magdoff, 2005). Other researchers have incubated poultry manure in soil and fractionated the soil, manure, and soil-manure mixture after the incubation (Warren et al., 2008). However, the incubations were not in the presence of actively growing plants. Some researchers have looked at $\mathrm{P}$ loss and characterized the $\mathrm{P}$ in manure, in farm fields, and in drainage way sediment downstream (creating a theoretical transects form source to stream) using the latest ${ }^{31} \mathrm{P}$ nuclear magnetic resonance analysis (Hill and Cade-Menun, 2009) but did not look for differentiation within a field, or examined if $\mathrm{P}_{\mathrm{o}}$ had changed at any other scale in their theoretical transect. 
A better approach to understanding the changes and movement of $P_{o}$ in soils would combine aspects of these and similar studies with landscape modelling techniques. Topographic data has been shown to be a useful parameter when modelling spatial patterns in soil P. Using TWI, Moore et al. (1993) explained $48 \%$ of the variability in data from a STP extraction at landscape scale. Given, that (i) $P_{0}$ fractions moved through the soil at different rates (Anderson and Magdoff, 2005), (ii) the properties that can control soil P sorption vary across the landscape (Daniels et al., 2001), and (iii) the re-distribution of water within a landscape can cause changes in soil properties (Hall, 1983), TWI is a logical choice for a high-resolution, low-cost surrogate variable to model $\mathrm{P}_{\mathrm{o}}$ fractions at a landscape scale.

Spatially explicit sampling strategies for measuring $\mathrm{P}_{\mathrm{o}}$ at landscape scales may be necessary due to spatial autocorrelation, and the potential effect of space on the distribution or redistribution of applied P. As Tobler (1970) put it, "Everything is related to everything else, but near things are more related than distant things." Failing to consider the potential of sample autocorrelation can jeopardize the reliability of some analysis (Fagroud and Van Meirvenne, 2002). Many statistical methodologies rely on independence within the sampling design, while in reality much of this data could be spatially autocorrelated (not independent). Sampling strategies can be devised to measure or evaluate spatial variability and autocorrelation. However, these strategies are typically resource dependent and too often are not used (Bridgham et al., 2001). In their place, researchers rely on replication, blocking, sample independence, and randomization; but these measures do not necessarily generate independent data (Fagroud and Van Meirvenne, 2002).

Acknowledging that $\mathrm{P}$ added from animal manures is a unique mixture of $\mathrm{P}_{\mathrm{i}}$ and $\mathrm{P}_{\mathrm{o}}$ with various solubility (Harland and Morris, 1995; Schroeder and Kovar, 2006; Warren et al., 2008), it seems reasonable to expect overland flow and infiltration to move these fractions at different rates, over different distances, and by potentially by different processes. Given that $P$ forms vary in their ability to participate in the sorption-desorption process, the precipitation-dissolution process, and the mineralizationimmobilization process, (Pierzynski et. al 2005) it would seem logical that these forms could accumulate or be transformed relative to their specific differences. Knowing that different organic $P$ fractions are sorbed preferentially (Anderson and Magdoff, 2005) and P sorption capacity is dictated by soil properties (Blake et al., 2003), it would seem likely that individual $P_{0}$ fractions could be partitioned in accordance with soil properties. Given the plethora of examples where landscape data has been correlated with soil properties (Moore et al., 1993; Bell et al., 1994; Tomer et al., 1995; Boer et al., 1996; Young and Hammer, 2000; Pachepsky et al., 2001; Park et al., 2001; Ziadat, 2005; and others), it would 
seem logical to assume this sort of data could be used for modelling P fractions at field or landscape scale.

\section{Expected Benefits}

This research should answer fundamental questions about how $\mathrm{P}$ from primarily poultry manure applications change within the landscape and determine if incubation with soil only is adequate for modelling $\mathrm{P}$ change. Additionally, the multi-dimensional distribution of $\mathrm{P}_{\mathrm{o}}$ fractions may generate new hypothesis about $\mathrm{P}$ transformations, translocations, and movement, as well as potential remediation techniques that may become necessary in the years to come. Lastly, this research will develop a modeling approach that could be used to estimate a much more detailed description of the P pool in locations where site specific $\mathrm{P}$ distribution knowledge could be useful in designing and implementing $\mathrm{P}$ loss management, and remediation plans.

As concerns over regulation are becoming more common, it is reasonable to assume land currently receiving $\mathrm{N}$-based animal manure applications could face $\mathrm{P}$ saturation. At that time, the continued application of manure will likely cease. However, that does not mean the problem will go away. Surrounding areas will become attractive destinations for excess manure. Many of these locations may be land previously unfertilized perhaps due to costs. As producers are forced to move manure off-farm, it could lead to a declining cost associated with manure. It would seem reasonable that these conditions could lead to marginally productive local farm lands seeing an increase in manure applications.

In the future there are two general problems that may need to be addressed. First, what management decisions need to be made on farmland that has become saturated with $\mathrm{P}$, and second, how can resource managers maximize applications on new fields without repeating the current situation. Understanding how $\mathrm{P}_{\mathrm{o}}$ moves at field scale could help answer these questions and more. For example, land managers could implement $\mathrm{P}$ remediation strategies at subfield scales to reduce cost by targeting the topographic conditions in fields where labile and possible moderately labile $\mathrm{P}$ accumulates. Additionally, when allocating sparse government resources to improve water quality, regional assessment of topographic data could identify farms where remediation could potential yield the most environmental impact. Lastly, the lab-scale experiment answers important questions about how different constituents of the manure respond differently; how incubation studies could be biasing the results; and how STP results correctly or incorrectly estimate risk, and determine the effect of vegetation on these transformations. 
These same questions could be answered with massive field scale trials and site specific sampling in every field, but this is a poor use of resources when looking at the "big picture". This research will provide a quantitative means of estimating $\mathrm{P}_{\mathrm{o}}$ distribution within fields based on typical soil test results and relatively inexpensive high-resolution geospatial data. When specific questions about a field arise, additional examination would always remain an option. Voluntary precision sampling of individual fields would yield definitive answers, but would likely be too costly for many producers. This research provides valued data at a low cost and a wide scale to help solve problems of local, regional, and national importance, thus allowing limited resources to be used in such a manner as to do the most public good.

\section{References}

Abekoe, M.K. 1996. Phosphorus fractions and rock phosphate transformations in soils from different landscape positions in northern Ghana. Dissertation Department of Soil Science University of Saskatchewan, Saskatoon.

Anderson, B.H. and F.R. Magdoff. 2005. Relative movement and soil fixation of soluble organic and inorganic phosphorus. J. Environ. Qual. 34:2228-2233.

Bache, B.W. 1964. Aluminum and iron-phosphate studies relating to soils. II. Reactions between phosphate and hydrous oxides. J. Soil Sci. 15: 110-116.

Baker, J.L., K.L. Campbell, H.P. Johnson, and J.J. Hanway. 1975. Nitrate, phosphorus, and sulfate in subsurface drainage water. J. Environ. Qual. 4:406-412.

Barrow, N.J. 1984. Modelling the effects of pH on phosphate sorption by soils. J. Soil Sci. 35: 283-297.

Basden T., A. Walker, and C. Ritz. 1994. West Virginia Poultry Production Survey: A Report on Implementation of Water Quality Improvement Practices in the Five Eastern Panhandle Poultry Producing Countries. West Virginia University Extension Service, Morgantown, WV.

Beck, M.A., L.W. Zelazny, W.L. Daniels, and G.L. Mullins. 2004. Using the mehlich-1 extract to estimate soil phosphorus saturation for environmental risk assessment. Soil Science Society of America Journal 68:1762-1771. 
Beegle, D.B. 2007. Pennsylvania's Nutrient Management Act (Act 38): Who is Affected? Agronomy Facts 54. Penn State College of Agricultural Sciences. The Pennsylvania State University, University Park, PA.

Bell, J.C., C.A. Butler, J.A. Thompson. 1994. Soil-terrain modelling for site specific agricultural management. In Site specific management for agricultural systems, P.C. Robert, R.H. Rust, W.E. Larson, Eds. ASA-CSSA-SSSA, Madison WI, pp 209-228.

Bell, J.C., Grigal, D.F., Bates, P.C., 2000. A soil-terrain model for estimation spatial patterns of soil organic carbon. In: Wilson, J.P., Gallant, J.C. (Eds.), Terrain Analysis: Principles and Applications. John Wiley \& Sons, Inc., NY, USA, pp. 295-309.

Beven, K. J. and M.J. Kirkby. 1979. A physically based, variable contributing area model of basin hydrology. Hydrol. Sci. Bull., 24, 43-69.

Bishop, T.F.A., and B. Minasny. 2006. Digital soil-terrain modeling: the predictive potential and uncertainty. In: Grunwald, S. (Ed.), Environmental Soil-Landscape Modeling - Geographic Information Technologies and Pedometrics. CRC Press, New York, pp. 185-214.

Blake, L., A.E. Johnston, P.R. Poulton and K.W.T. Goulding. 2003. Changes in soil phosphorus fractions following positive and negative phosphorus balances for long periods. Plant and Soil 254: 245261.

Boerner, R.E.J., Morris, S.J., Sutherland, E.K. \& Hutchinson, T.F. 2000. Spatial variability in soil nitrogen dynamics after prescribed burning in Ohio mixed-oak forests. Landscape Ecology, 15, 425- 439.

Boesch, D.F., R.B. Brinsfield, and R.E. Magnien. 2001. Chesapeake Bay eutrophication: Scientific understanding, ecosystem restoration, and challenges for agriculture. J. Environ. Qual. 30:303320.

Bowman, R.A., and C.V. Cole. 1978. An exploratory method for fractionation of organic phosphorus from grassland soils. Soil Sci. 125, 95-101.

Brady, N. C., and R.R. Weill. 2002. The Nature and Properties of Soils; Prentice Hall: Englewood Cliffs, NJ.

Bridgham, S.D., C.A. Johnston and J.P. Schubaurer-Berigan. 2001. P sorption dynamics in soils and coupling with surface and pore water in riverine wetlands. Soil Sci. Soc. Am. J. 65:577-588. 
Bunemann, E.K. 2015. Assessment of gross and net mineralization rates of soil organic phosphorus - A review. Soil Biology \& Biochemistry 89 pp. 82-98.

Case, B.S., Meng, F.-R. \& Arp, P.A. 2005. Digital elevation modelling of soil type and drainage within small forested catchments. Canadian Journal of Soil Science, 85, 127-137.

Chang, S.C., and M.L. Jackson. 1957. Fraction of soil phosphorus. Soil Sci. 84:133-144.

Codling, E.E. 2006. Laboratory characterization of extractable phosphorus in poultry litter and poultry litter ash. Soil Sci. Vol. 171 No. 11. 854 - 864.

Condron, L.M., B.L. Turner, and B.J. Cade-Menun. 2005. The chemistry and dynamics of soil organic phosphorus. p. 87-121. In J.T. Sims and A.N. Sharpley (ed.) Phosphorus: Agriculture and the environment. Agron. Monogr. 46. ASA, CSSA, and SSSA, Madison, WI.

Cross, A.F., and W.H. Schlesinger. 1995. A literature review and evaluation of the Hedley fractionation: applications to the biogeochemical cycle of soil phosphorus in natural ecosystems. Geoderma 64, 197-214.

Crouse, D.A., H. Sierzputowska-Gracz, R.L. Mikkelson, and A.G. Wollum. 2002. Monitoring phosphorus mineralization from poultry manure using phosphatase assays and phosphorus-31 nuclear magnetic resonance spectroscopy. Commun. Soil Sci. Plant Anal. 33:1205-1217.

Conley, D.J. 2000. Biogeochemical nutrient cycles and nutrient management strategies. Hydrobiologia 410:87-96.

Dail, H.W., Z. He, M.S. Erich, and C. Wayne. 2007. Effect of drying on phosphorus distribution in poultry manure. Communications in Soil Science and Plant Analysis, 38: 1879-1895.

Daniels, M.B., P. Delaune, P.A. Moore, Jr., A. Mauromoustakos, S.L. Chapman, and J.M. Langston. 2001. Soil phosphorus variability in pastures: implications for sampling and environmental management strategies. J. Environ. Qual. 30:2157-2165.

Dou, Z., J.D. Toth, D.T. Galligan, C.F. Ramberg Jr., and J.D. Ferguson. 2000. Laboratory procedures for characterizing manure phosphorus. J. Environ. Qual. 2000, 29, 508-514.

Ellis, J.H., 1938. The soils of Manitoba, Manitoba Economic Survey Board, Winnipeg, Manitoba, 1938. 
Fagroud, M. and M. Van Meirvenne. 2002. Accounting for soil spatial autocorrelation in the design of experimental trials. Soil Sci. Soc. Am. J. 66:1134-1142.

Frossard, E., M. Brossard, M.J. Hedley, A. Metherell. 1995. Reactions controlling the cycling of P in soils. In: Tiessen, H. (Ed.), Phosphorus in the Global Environment. Transfers, Cycles and Management. Wiley, Chichester, pp. $107-137$.

Frossard, E., L.M. Condron, A. Oberson, S. Sinaj, J.C. Fardeau. 2000. Processes governing phosphorus availability in temperate soils. Journal of Environmental Quality 29, 15 -23.

Fox, R.L. 1985. External phosphorus requirements of crops. In: Stelly, M., D.M. Kral, and M.K. Cousin (Eds). Chemistry of the Soil Environment. 223-259. ASA Special Publ. No. 40. Madison, W.I., U.S.A.

Gachter, R., J.M. Ngatiah, and C. Stamm. 1998. Transport of phosphate from soil to surface waters by preferential flow. Environmental Science \& Technology. 32:1865-1869.

Gerke, J and R. Hermann. 1992. Adsorption of orthophosphate to humic-Fe-complexes and to amorphous Fe-oxide. Zeitschrift der Pflanzenern.ahrung und Bodenkunde, 155, 233-236.

Gessler, P.E., I.D. Moore, N.J. McKenzie, P.J. Ryan. 1995. Soil-landscape modelling and spatial prediction of soil attributes. International Journal of Geographical Information Systems, 9:4, 421-432.

Gessler, P.E., O.A., Chadwick, F. Chamran, L. Althouse, and K. Holmes. 2000. Modelling soil-landscape and ecosystem properties using terrain attributes. Soil Science Society of America Journal, 64, 2046- 2056.

Giles, C.D., B.J. Cade-Menum, C.W. Liu, J.E. Hill. 2015. The short-term transport and transformation of phosphorus species in a saturated soil following poultry manure amendment and leaching. Geoderma 257-258 pp. 134-141.

Girgin, B.N., and B.E. Frazier. 1996. Landscape position and surface curvature effects on soils developed in the Palouse area, WA. Washington State University, Department of Crop and Soil Sciences, Pullman, WA.

Guisan, A., Edwards Jr., T.C., Hastie, T., 2002. Generalized linear and generalized additive models: in studies of species distributions: setting the scene. Ecol. Model. 157, 89-100. 
Guppy, C.N., N.W. Menzies, P.W. Moody, B.L. Compton, F.P.C. Blamey. 2000. A simplified, sequential, phosphorus fractionation method. Communications in soil science and plant analysis vol: 31 $1981-1991$.

Hall, G.F. 1983. Pedology and geomorphology. In: L.P. Wilding, N.S. Smeck and Hall, G.F. (Eds). Pedogenesis and soil taxonomy: concepts and interactions. 117-140 Elsevier Scientific Publishing, New York, Amsterdam.

Hao, X., F. Godlinski, C. Chang. 2008. Distribution of phosphorus forms in soil following long-term continuous and discontinuous cattle manure applications. Soil Sci. Soc. Am. J. 72:90-97.

Harland, B.F., and E.R. Morris. 1995. Phytate- a good or a bad food component. Nutr. Res. 15:733-754.

Harman, M.B., J.A. Thompson, L.M. McDonald, E.M. Pena-Yewtukhiw, J. Beard. 2013. Phosphorus translocation in pastures on benchmark soils in West Virginia. Soil Horizons Vol.54 - No.3.

Harrison, A.F. 1987. Soil organic phosphorus. A review of world literature. CAB International, Oxon.

He, Z., C.W. Honeycutt, B.J. Cade-Menun, Z.N. Senwo, and I.A. Tazisong. 2008. Phosphorus in poultry litter and soil: enzymatic and nuclear magnetic resonance characterization. Soil Sci. Soc. Am. J. 72:1425-1433.

He, Z., T.S. Griffin, and C.W. Honeycutt. 2004. Evaluation of soil phosphorus transformations by sequential fractionation and phosphatase hydrolysis. Soil Sci. 169:515-527.

Hedley, M.J., J.W.B. Stewart, and B.S. Chauhan. 1982. Changes in inorganic and organic soil phosphorus fractions induced by cultivation practices and by laboratory incubations. Soil. Sci. Soc. Am. J. 46, 970-976.

Helal, H.M., and A. Dressler. 1989. Mobilization and turnover of phosphorus in the rhizosphere. Z. Pflanzenernahr. Bodenkunde. 152:175-180.

Hill, J.E., and B.J. Cade-Menun. 2009. Phosphorus-31 Nuclear Magnetic Resonance Spectroscopy Transect Study of Poultry Operations on the Delmarva Peninsula. J. Environ. Qual. 38:130-138.

Holford, I.C.R., C. Hird, and R. Lawrie. 1997. Effects of animal effluents on the phosphorus sorption characteristics of soils. Aust. J. Soil Res. 35:365-374. 
Hornberger, G.M. \& Boyer, E.W. 1995. Recent advances in watershed modelling. Review of Geophysics, 33, 949-957.

Hountin, J.A., A. Karam, D. Couillard, and M.P. Cescas. 2000. Use of a fractionation procedure to assess the potential for $\mathrm{P}$ movement in a soil profile after 14 years of liquid pig manure fertilization. Agric. Ecosyst. Environ. 78:77-84.

Isaac, R.A. and W.C. Johnson. 1983. High speed analysis of agricultural samples using inductively coupled plasma atomic emission spectroscopy. Spectrochemica Acta. 38B (1-2) 277-282.

Iverson, L.R., Dale, M.E., Scott, C.T. \& Prasad, A. 1997. A GIS-derived integrated moisture index to predict forest composition and productivity of Ohio forests (U.S.A). Landscape Hydrology, 12, 331-348.

Iyamuremye, F., R.P. Dick, and J. Baham. 1996. Organic amendments and soil phosphorus dynamics: I. Phosphorus chemistry and sorption. Soil Sci. 161:426-435.

Jansson, M., H. Olsson, and K. Pettersson. 1988. Phosphatase: Origin, characteristics and function in lakes. Hydrobiologia 170:157-175.

Jencks, E.M., J.T. Raese, and C.D. Reese. 1964. Organic phosphorus content of some West Virginia soils. Bulletin of the. West Virginia University Agricultural Experimental Station 489.

Jenny, H., 1941. Factors of Soil Formation, A System of Quantitative Pedology. Dover publications, New York.

Johnson, A.M., D.L. Osmond, and S.C. Hodges. 2005. Predicted impact and evaluation of North Carolina's phosphorus indexing tool. J. Environ. Qual. 34:1801-1810.

King, K.W., M.R. Williams, M.L. Macrae, N.R. Fausey, J. Frankenberger, D.R. Smith, P.J.A. Kleinman, L.C. Brown. 2015. Phosphorus transport in agricultural subsurface drainage: a review. J. Environ. Qual. doi: 10.2134

Lane, P.W., 2002. Generalized linear models in soil science. Eur. J. Soil Sci. 53, 241-251.

Laboski, C.A.M., and J.A. Lamb. 2003. Changes in soil test phosphorus concentration after application of manure or fertilizer. Published in Soil Sci. Soc. Am. J. 67:544-554. 
Lehmann, J., Z. Lan, C. Hyland, S. Sato, D. Solomom, and Q.M. Ketterings. 2005. Long-term dynamics of phosphorus forms and retention in manure-amended soils. Environ. Sci. Technol. 39: 6672-6680.

Maguire, R.O., J.T. Sims, S.K. Dentel, F.J. Coale, and J.T. Mah. 2001. Relationships between biosolids treatment process and soil phosphorus availability. J. Environ. Qual. 30:1023-1033.

Martin, J.M., P. Nirel, A.J. Thomas. 1987. Sequential extraction techniques: promises and problems. Marine Chem. 22: 313-341.

McBratney, A.B., I.O.A. Odeh, T.F.A. Bishop, M.S. Dunbar, T.M. Shatar. 2000. An overview of pedometric techniques for use in soil survey. Geoderma 97: 293-327.

McGechan, M.B., and D.R. Lewis. 2002. Sorption of phosphorus by soil, part 1: principles, equations and models. Biosystems Engineering 82 (1), 1-24.

McGrath, J.M., J.T. Sims, R.O. Maguire, W.W. Saylor, S.R. Angel, and B.L. Turner. 2005. Broiler diet modification and litter storage: Impacts on phosphorus in litters, soils, and runoff. J. Environ. Qual. 34:1896-1909.

McBratney, A.B., I.O.A. Odeh, T.F.A. Bishop, M.S. Dunbar, T.M. Shatar. 2000. An overview of pedometric techniques for use in soil survey. Geoderma 97: 293-327.

McSweeney, K., P.E. Gessler, B. Slater, R.D. Hammer, J.C. Bell, G.W. Petersen. 1994. Towards a new framework for modelling the soil-landscape continuum. In: Amundson, R.G., et al. (Ed.), Factors of Soil formation: A fiftieth Anniversary Retrospective. SSSA Spec. Publ., vol. 33. SSSA, Madison, WI, pp. 127-145.

Miller, J.C., T. Astatkie, A. Madani. 2010. Soil test phosphorus from livestock manures compared with inorganic fertilizers in soil incubations. Applied and Environmental Soil Science. 2010:1-6.

Milne, G., 1935. Some suggested units of classification and mapping particularly for East African soils. Soil Res. 4, 183-198.

Moore, I.D., R. B. Grayson and A. R. Ladson. 1991 "Digital terrain modelling: A review of hydrological, geomorphological, and biological applications. Hydrological Processes, 5, 1: pp. 3-30.

Moore, I.D., P.E. Gessler, G.A. Nielsen, G.A. Peterson. 1993. Soil attribute prediction using terrain analysis. Soil Sci. Soc. Am. J. 57:443-452. 
Mueller, T.G. and F.J. Pierce. 2003. Soil carbon maps: enhancing spatial estimates with simple terrain attributes at multiple scales. Soil Science Society of America Journal 67, 258-267.

Murphy, P.N.C., J. Ogilvie and P. Arp. 2009. Topographic modelling of soil moisture conditions: a comparison and verification of two models. European Journal of Soil Science. 60, 94-109.

Newton B., J. Wesley, and M. Jarrell, 1999. Response of aquatic systems to changes in P and N inputs. USDA NRCS National water and climate center. Portland, Oregon

Pachepsky, Y.A., D.J. Timlin, and W.J. Rawls. 2001. Soil water retention as related to topographic variables. Soil Sci. Soc. Am. J. 65: 1787-1795.

Park, S.J., and L.G. Vlek. 2002. Environmental correlation of three-dimensional soil spatial variability: a comparison of three environmental correlation techniques. Geoderma 109, 117-140.

Pei, T., C. Qin, A. Zhu, L. Yang, M. Luo, B. Li, C. Zhou. 2010. Mapping soil organic matter using the topographic wetness index: A comparative study based on different flow-direction algorithms and kriging methods. Ecological Indicators 10 p.p. 610-619.

Pierzynski, G.M., RW McDowell, J.T. Sims. 2005. Chemistry, cycling, and potential movement of inorganic phosphorus in soils. in J.T. Sims and A.N. Sharpley. 2005. Phosphorus: Agriculture and the Environment. Soil Science Society of America. Madison Wisconsin, USA. pp. 53-87.

Qian, P., and J.J. Schoenau. 2000. Fractionation of P in soil as influenced by a single addition of liquid swine manure. Can. J. Soil Sci. 80:561-566.

Quinn, P., Beven, K.J., Lamb, R., 1995. The In (a/tan ß) index: how to calculate it and how to use it within the TOPMODEL framework. Hydrological Process 9, 161- 182.

Robinson, J.S., and A.N. Sharpley. 1996. Reaction in soil of phosphorus released from poultry litter. Soil Sci. Soc. Am. J. 6:1583-1588.

Ruttenberg, K.C. 1992. Development of a sequential extraction method for different forms of phosphorus in marine sediments. Limnology and Oceanography 37: 1460-1482.

Sanyal, S.K. and S.K. De Datta. 1991. Chemistry of phosphorus transformations in soil. A review. Adv. Soil Sci. 6: 1-120. Springer-Verlag New York Inc. U.S.A. 
Scheinost, A.C. and U. Schwertmann. 1995. Predicting phosphate adsorption-desorption in a soilscape. Soil Sci. Soc. Am. J. 59: 1575-1580.

Schoenau, J.J., J.W.B. Stewart, and J.R. Bettany. 1989. Forms and cycling of phosphorus in prairie and boreal forest soils. Biogeochemistry 8:223-237.

Schroeder, P.D., and J.L. Kovar. 2006. Comparison of organic and inorganic phosphorus fractions in an established buffer and adjacent production field. Communications in Soil Science and Plant Analysis, 37: 1219-1232.

Shand, C.A., A.E.S. Macklon, A.C. Edwards, and S. Smith. 1994. Inorganic and organic $P$ in soil solutions from three upland soils: I. Effect of soil solution extraction conditions, soil type and season. Plant Soil 159:255-264.

Sharpley, A.N. 2000. Agriculture and phosphorus management: The Chesapeake Bay. Lewis Publishers, Boca Raton, FL. p. 3-5.

Sharpley, A.N., S.J. Smith, O.R. Jones, W.A. Berg, G.A. Coleman. 1992. The transport of bioavailable phosphorus in agricultural runoff. J. Environ. Qual. 21:30-35.

Sharpley, A.N., R.W. McDowell, P.J.A. Kleinman. 2004. Amounts, forms, and solubility of phosphorus in soils receiving manure. Soil Sci. Soc. Am. J. 68:2048-2057.

Shedlock, R.J., J.M. Denver, M.A. Hayes, P.A. Hamilton, M.T. Koterba, L.J. Bachman, P.J. Phillips, and W.S.L. Banks. 1999. Water quality assessment of Delmarva Peninsula, Delaware, Maryland, and Virginia: Results of investigation 1987-1991. U.S. Geological Survey Water Supply Paper. USGS, Washington, DC. p. 1-41

Siddique, M.T., and J.S. Robinson. 2003. Phosphorus sorption and availability in soils amended with animal manures and sewage sludge. J. Environ. Qual. 32:1114-1121.

Sims, J.T., R.O. Maguire, A.B. Leytem, K.L. Gartley, and M.C. Pautler. 2002. Evaluation of Mehlich-3 as an agri-environmental soil phosphorus test for the mid-Atlantic United States of America. Soil Sci. Soc. Am. J. 66:2016-2032. 
Sims, J. T., G.M. Pierzynski, 2005. Chemistry of phosphorus in soils. In (eds.) M.A. Tabatabai, and D.L. Sparks. 2005. Chemical processes in soils. Soil Science Society of America. Madison Wisconsin, USA. pp151- 186.

Sistani, K.R., D.M. Miles, D.E. Rowe, G.E. Brink, and S.L. McGowen. 2001. Impact of drying method, dietary phosphorus levels, and methodology on phosphorus chemistry of broiler manure. Communications in Soil Science and Plant Analysis, 32: 2783-2793.

Smeck, N.E. 1973. Phosphorus: an indicator of pedogenetic weathering processes. Soil Sci. 115: 199-206.

Smeck, N.E., 1985. Phosphorus dynamics in soils and landscapes. Geoderma, 36:185-199.

Smeck, N.E. and E.C.A. Runge. 1971. Phosphorus availability and redistribution in relation to soil profile development in an Illinois landscape segment. Soil Sci. Soc. Am. Proc. 35: 952-959.

Sorensen, R., U. Zinko, and J. Seibert. 2005. On the calculation of the topographic wetness index: evaluation of different methods based on field observations. Hydrol. Earth Sys. Sci. Discuss., 2, 1807-1834.

Struthers, P.H., and D.H. Sieling. 1950. Effect of organic anions on phosphate precipitation by iron and aluminum as influenced by pH. Soil Sci. 69:205-213.

Sui, Y., M.L. Thompson, and C. Shang. 1999. Fractionation of phosphorus in a Mollisol with biosolids. Soil Sci. Soc. Am. J. 63: 1174-1180.

Tarkalson, D.D., and R.L. Mikkelsen. 2004. Runoff phosphorus losses as related to phosphorus source, application method, and application rate on a Piedmont soil. J. Environ. Qual. 33:1424-1430.

Thompson, J.A. E.M. Pena-Yewtukhiw, J.H. Grove. 2006. Soil-landscape modelling across a physiographic region: Topographic patterns and model transportability. Geoderma 133: pp. 57-70

Thompson, J.A., Roecker, S.M., Grunwald, S., and P.R. Owens. 2012. Digital soil mapping: Interactions with and applications for hydropedology. In "Hydropedology - Synergistic Integration of Pedology and Hydrology" (Lin, H.S., Ed.), pp665-709. Academic Press, Elsevier B.V.

Tiessen, H, J.W.B. Stewart, C.V. Cole. 1984. Pathways of phosphate transformations in soils of differing pedogenesis. Soil Sci. Soc. Amer. J. 48: 853-858. 
Tobler, W.R. 1970. Movie simulating urban growth in the Detroit region. Economic Geography, Vol. 46, Supplement: Proceedings. International Geographical Union. Commission on Quantitative Methods.

Tomer, M.D., J.L. Anderson, J.A. Lamb. 1995. Landscape analysis of soil and crop data using regression. In: Robert, P.C., Rust, R.H., Larson, W.E. _Eds.., Site-Specific Management for Agricultural Systems. ASA-CSSA-SSSA, Madison, WI, pp. 273-284.

Toor, G.S., L.M. Condron, H.J. Di, K.C. Cameron, B.J. Cade-Menun. 2003. Characterization of organic phosphorus in leachate from a grassland soil. Soil Biology \& Biochemistry 35: pp. 1317-1323.

Turner, B.L., and P.M. Haygarth. 2000. Phosphorus forms and concentrations in leachate from four grassland soil types. Soil Sci. Soc. Am. J. 64:1090-1097.

USDA NASS. 2014. 2012 Census of Agriculture West Virginia State and County Data. Vol. 1 Prt. 48. [Online] at http://www.agcensus.usda.gov/Publications/2012/Full Report/Volume 1, Chapter 2 County Level/West Virginia/wvv1.pdf (verified 17 April 2016).

USEPA. 1995. National water quality inventory: 1994 Report to congress. USEPA Rep. 841-R-95-005. Office of Water, USEPA, Washington, DC

USEPA. 1996. Environmental indicators of water quality in the United States. Rep. 841-R-96-002. USEPA, Office of Water (4503F). U.S. Gov. Print. Office, Washington, DC.

Walker, T.W. and J.K. Syers. 1976. The fate of phosphorus during pedogenesis. Geoderma 15: 1-19.

Warren, J.G., C.J. Penn, J.M. McGrath, K. Sistani. 2008. The impact of alum addition on organic $p$ transformations in poultry litter and litter-amended soil. J. Environ. Qual. 37:469-476.

Webster, R., 2001. Statistics to support soil research and their presentation. Eur. J. Soil Sci. 52, 331-340.

Whalen, J.K., and C. Chang. 2001. Phosphorus accumulation in cultivated soils from long-term annual application of cattle feedlot manure. J. Environ. Qual. 30:229-237.

Yang, J.E., C.A. Jones, H.J. Kim, and J.S. Jacobsen. 2002. Soil inorganic phosphorus fractions and Olsen-P in phosphorus-responsive calcareous soils: Effects of fertilizer amount and incubation time. Commun. Soil Sci. Plant Anal. 33:855-871. 
Young, F.J., and R.D. Hammer. 2000. Soil-landform relationships on a loess-mantled, upland landscape in Missouri. Soil Sci. Soc. Am. J. 64:1443-1454.

Ziadat, F.M., 2005. Analyzing digital terrain attributes to predict soil attributes for a relatively large area. Soil Sci. Soc. Am. J. 69:1590-1599.

Ziadi, N., G. Belanger, B. Gagnon, and D. Mongrain. 2009. Mehlich 3 soil phosphorus as determined by colorimetry and inductively coupled plasma. Communications in Soil Science and Plant Analysis. 40: $132-140$. 


\section{Chapter 2. Effect of Vegetation and Phosphorus Source on Sequential- Extracted Phosphorus Fractions in Incubated Soils}

\section{Abstract}

Incubation-based $\mathrm{P}$ transformation studies provide valuable insight into the fate of nutrients. However, the practical utility of such experiments is contingent on the characterization of the transformed P forms being consistent with characterization approaches that are used at field scales. Furthermore, this utility is limited by the ability of the incubations to mimic field conditions. This research is focused on applying experimental conditions that more closely resemble field conditions to a traditional incubation experiment, and characterize the $P$ in a fashion that could prove useful at examining $P$ movement and transformation at a field or landscape scale. Soil samples from locations with very high soil test P levels and locations with very low soil test $\mathrm{P}$ levels with and without actively growing vegetation were incubated for 16 weeks, following $P$ additions from manure, manure leachate, leached manure, phytic acid, or $\mathrm{CaPO}_{4}$. During the incubation, the samples were repeatedly wetted and allowed to dry such that the gravimetric soil moisture ranged between 80 and 105\% container capacity. Consequently, the sequentially-extracted, operationally defined $\mathrm{P}$ fractions in the samples following the incubation were measured and examined for significant multivariate effects. The analysis identified significant differences between several fractions relative to $P$ source and fertilization history, but no difference relative the presence of vegetation. It appears that most $\mathrm{P}$ additions generally end up in the $\mathrm{NaOH}$ extracted fractions and the presence of actively growing vegetation does not alter the fate of these $P$ additions. Accordingly, data from other incubation studies where $\mathrm{P}$ is assumed to be sorbed to Fe and $\mathrm{Al}$ should be applicable when trying to understand $P$ transformations. As such, the transformation seen in most of these incubations should be reflective of what would occur in field-scale situations.

\section{Introduction}

Knowledge of the interactions between soils, fertilizers, and management practices is critical for sustainable agriculture and environmental protection (Maguire and Sims, 2002; He et al., 2004; Harman et al., 2013). These concerns are most relevant in regions with extensive confined animal feeding operations or $\mathrm{N}$-based manure management. When these conditions occur together, $\mathrm{P}$ saturation and an elevated risk to water quality become potential outcomes (Beck et al., 2004; Miller et al., 2010). In addition, the availability of $P$ in soil can be influenced by microbial and chemical properties of the soil, manure composition, and rhizosphere processes (Waldrip et al., 2011). To better manage the 
relationship between soils, fertilizers, and management practices researchers must first understand how differences in $\mathrm{P}$ sources, $\mathrm{P}$ saturation, and vegetation alter the forms of $\mathrm{P}$ that are retained, sorbed, or transformed within the soil.

One approach to facilitate examination of the interactions between soils and nutrients is to combine them and after an appropriate period of time examine any changes that have occurred. There are numerous examples of research that utilize this approach to examine changes relative to various soil amendments (Iyamuremye et al., 1996; Qian and Schoenau, 2000; Whalen et al., 2001; Maguire et al., 2001; Yang et al., 2002; Crouse et al., 2002; Laboski and Lamb, 2003; He et al., 2004; Miller et al., 2010; Gagnon et al., 2012). These lab-scale experiments are low cost alternatives to inelegant field-scale experiments (Sharpley and Sisak, 1997). Another approach is to describe in greater detail the distribution of a nutrient, such as $\mathrm{P}$, within soil. Combined, lab scale and sequential extracted spatially explicit experiments allows researchers to document the changes that occur in fertilized soil over time in greater detail.

A sequential P fractionation (one approach to describe $\mathrm{P}$ in soils in greater detail) is a collection of successive chemical extractions that characterize $\mathrm{P}$ by the type and or strength of the assumed physicochemical interactions with the soil (Bowman and Cole 1978; Hedley et al., 1982; Cross and Schlesinger, 1995; Negassa and Leinweber 2009; Gagnon et al., 2012). Some research (Qian and Schoenau, 2000; Yang et al., 2002; He et al., 2004; Warren et al., 2008; Negassa and Leinweber 2009; Gagnon et al., 2012) has used this approach to define changes in the soil P pool. Recent efforts to describe organic $P\left(P_{0}\right)$ pools have included additional analytical measures such as enzymatic hydrolysis (He et al., 2008) and nuclear magnetic resonance analysis (Toor et al. 2003; Hill and Cade-Menun, 2009) in conjunction with sequential $P$ fractionation. More advanced analytical techniques such as enzymatic hydrolysis and nuclear magnetic resonance analysis can generate a great deal of information about specific $\mathrm{P}$ compounds and retention mechanisms, but may not be practical for use by producers.

To improve management decisions there is a need for research that can assist in translating the existing body of knowledge into more useable formats. For example, it is known that manure application can increase soil concentrations of both total, soluble, and stable organic forms of P (Erich et al. 2002; Ylivainio et al. 2008; Waldrip-Dail et al. 2009). Research on the complex interactions between plant roots, manure, soil, and P is ongoing, but a full understanding has not yet been achieved (Waldrip et al., 2011). $P_{0}$ must be mineralized into inorganic forms to fully participate in the $P$ cycle and that ability is impacted by the biological activity within the soil matrix (Magid et al., 1996, Waldrip et al., 2011). 
Specifically, insight into how manure applications change sequentially-extracted P pools in a more natural environment, with plant interactions, in a more biologically active setting is critical to updating management paradigms to reflect the latest research. Understanding the composition of the P pool relative to unique combinations of conditions could streamline research by culling ill designed and ineffective remediation strategies before research resources are consumed. Surface applications and protective berms of low cost materials with specific affinities for labile P compounds could be developed to limit P loss.

The objective of this research was to determine if the presence of vegetation, variability in $\mathrm{P}$ sources, and management history of soil has a significant effect on the disposition of organic $\mathrm{P}$ in sequential fractionations. To examine the potential $\mathrm{P}$ transformations, a series of laboratory incubations were performed to examined how organic $P$ pools changed in soils given the presence of vegetation and the effect of hydrological differentiation (separation of soluble and non-soluble portions of a manure $P$ sources) along with traditional $\mathrm{P}$ sources. The first research hypothesis $\left(\mathrm{H} 1_{\mathrm{a}}\right)$ states that an addition of $\mathrm{P}$ causes a significant difference in operationally defined sequentially extracted $\mathrm{P}_{\mathrm{o}}$ fractions relative to the source of the $\mathrm{P}$ addition and the fertilization history of the sample. The null hypothesis $\left(\mathrm{HO}_{\mathrm{a}}\right)$ states that additions of $\mathrm{P}$ does not cause a significant difference in operationally defined sequentially extracted $\mathrm{P}_{\mathrm{o}}$ fractions relative to the source of the $\mathrm{P}$ addition and the fertilization history of the sample. The second hypothesis $\left(\mathrm{H}_{\mathrm{b}}\right)$ states that the presence of active growing vegetation can affect sequentially extracted $\mathrm{P}_{\mathrm{o}}$ fractions in incubated soil samples. The null hypothesis $\left(\mathrm{HO}_{\mathrm{b}}\right)$ states, that the presence of active growing vegetation does not affect sequentially extracted $\mathrm{P}_{\mathrm{o}}$ fractions in incubated soil samples.

\section{Materials \& Methods}

\section{Overview}

To achieve a more realistic model of typical growing conditions and evaluate change over time, manure, manure leachate, leached manure, phytic acid, and $\mathrm{Ca}\left(\mathrm{H}_{2} \mathrm{PO}_{4}\right)_{2}$ were incubated with soil under controlled conditions more similar to the pasture and hay land environments of the poultry producing region of West Virginia. This bench top experiment includes vegetation, repeated wetting and drying, and soil from locations with very low and very high P concentrations. Under these conditions, changes in the operationally defined sequential extracted organic $P$ pools were measured to determine what parameters, if any, altered the $P$ pools. These considerations should place the utility of existing research in a proper context and designate a clearer direction for future research relative to both remediation and preventive strategies. 
The experiment was arranged as a randomized complete block within a factorial design (Dowdy et al., 2004), with factors of management history, $P$ sources, and vegetation. The two levels of management history are annually fertilized (Fertilized) and rarely fertilized (Unfertilized). There are six levels of the fertilizer factor (control, manure, manure leachate, leached manure, phytic acid, and $\left.\mathrm{Ca}\left(\mathrm{H}_{2} \mathrm{PO}_{4}\right)_{2}\right)$. The two levels of the vegetation factor (with and without vegetation) were constructed by seeding the appropriate samples with $0.1 \mathrm{~g}$ of tall fescue [Lolium arundinaceum (Schreb.) Darbysh. $=$ (Schedonorus arundinaceus (Schreb.) Dumort.] seed at the onset of incubation. The experimental block was replicated three times.

The soils used in this incubation experiment came from two locations: One location with a lengthy history of poultry manure applications and one location with no know history of poultry manure fertilization. These locations have been managed as pastures in excess of 25 years. These locations are mapped as Berks-Weikert channery silt loams. The map unit composition is typically $55 \%$ Berks and similar soils, $35 \%$ Weikert and similar soils, and $10 \%$ minor components. For additional details on theses soils see Table 2.1. Berks is among the most common soil series identified under hay and grass pastures in the poultry producing region of West Virginia (Harman et al. 2011). The soil used during this experiment came from Ap horizon of these locations and were air dried ground, sieved, and mixed repeatedly to create a homogenous bulk samples from each location.

\section{Incubation}

Forty grams of air dried soil were incubated 16 weeks with one of six levels of the fertilizer treatments. In the manure treatment, $1.2 \mathrm{mg}$ of $\mathrm{P}$ (95 mg of manure) was added. In the phytic acid, and monocalcium phosphate treatments, $1.2 \mathrm{mg}$ of $\mathrm{P}$ were added. In the other treatments $95 \mathrm{mg}$ of manure was leached with distilled deionized water and the leached manure added to the leached manure treatment and the leachate added to the manure leach treatment. The application $1.2 \mathrm{mg}$ of P per sample is roughly equal to a field scale application of 60 pound per acre. The literature indicates watersoluble P levels stabilize as quickly as 3 weeks after fertilization (Bond, et.al, 2006) or could continue to increasing in availability for up to 13 weeks before leveling off and stabilizing for up to 6 months (Gagnon and Simard, 1999). There is a great deal of variation in incubation times, from days (Warren et.al, 2008; Leytem et.al, 2004) to months (Ebeling et.al 2003; Laboski and Lamb, 2003). The 16-week incubation period exceeds the minimum time ( 3 weeks) for stabilization of water soluble P (Bond, et al., 2006) and the initial increase in available P reported by Gagnon and Simard (1999), while being more directly comparable to the first 16 week cycle of Ebeling et al. (2003). 
Gravimetric soil moisture was adjusted based on percent container capacity (CC) (Leytem et al., 2004). $\mathrm{CC}$ is similar to field capacity. Gravimetric soil moisture is determined by saturating $50 \mathrm{~g}$ of soil with distilled deionized water (DDI) and allowing it to drain freely for $48 \mathrm{hr}$. under normal atmospheric pressure and room temperature, followed by reweighing the sample, and calculating water content per unit soil (Cassel and Nielsen, 1986). The moisture level was measured and adjusted approximately every 3-5 d. DDI was added when the sample weights fell below $80 \%$ of CC until the weight of the sample reached approximately $105 \%$ CC.

\section{Laboratory Analysis}

The chemical properties of the soils used in the experiment were characterized by a sequential extraction procedure developed to divide the P pool into operationally-defined segments. Sequential fractionation evolved from the works of Chang and Jackson (1957) and Bowman and Cole (1978), through Hedley et al. (1982). The most common extractions used in sequential fractionations are water $\left(\mathrm{H}_{2} \mathrm{O}\right)$, anion exchange resin, sodium bicarbonate $\left(\mathrm{NaHCO}_{3}\right)$, hydrochloric acid $(\mathrm{HCl})$, and sodium hydroxide ( $\mathrm{NaOH}$ ) (Guppy et al., 2000; Schroeder and Kovar, 2006). The P in this study was characterized with a modified Hedley fractionation as suggested by (Sui et al., 1999) and described by He et al. (2003). For each sample, approximately $1.0 \mathrm{~g}$ of soil and $25 \mathrm{~mL}$ of extractant was placed in a centrifuge tube in a reciprocal shaker at 180 oscillations per minute for $16 \mathrm{~h}$ at room temperature. The samples were centrifuged for $15 \mathrm{~min}$ at $3500 \mathrm{~g}$ and the supernatant filtered through a medium porosity filter paper. This process was repeated sequentially from DDI through $0.5 \mathrm{M} \mathrm{NaHCO}_{3}, 0.1 \mathrm{M} \mathrm{NaOH}$, and $1 \mathrm{M} \mathrm{HCl}$. The extracted $P$ from these samples were further differentiated into operationally- defined categories of organic $\mathrm{P}$ and inorganic $\mathrm{P}$. Inorganic $\mathrm{P}$ includes orthophosphate plus any molybdate reactive organic and inorganic species of $P$. Organic $P$ is defined as the difference between total $P$ as measured by an ICP-OES and the molybdate reactive organic and inorganic species of $P$, as identified by the ammonium molybdate-ascorbic acid colorimetric method (Knudsen and Beegle, 1988).

The ammonium molybdate-ascorbic acid colorimetric method of Knudsen and Beegle (1988) is a two reagent procedure. The first reagent is the concentrated ammonium paramolybdate solution. Concentrated ammonium paramolybdate solution is made from $60.0 \mathrm{~g}$ of ammonium paramolybdate $\left.\left(\mathrm{NH}_{4}\right) 6 \mathrm{Mo}_{7} \mathrm{O}_{24} * 4 \mathrm{H}_{2} \mathrm{O}\right), 1.455 \mathrm{~g}$ antimony potassium tartrate $\left(\mathrm{KSbOC}_{4} \mathrm{H}_{4} \mathrm{O}_{6}\right)$ and $700 \mathrm{~mL}$ of concentrated sulfuric acid $\left(\mathrm{H}_{2} \mathrm{SO}_{4}\right)$ diluted to $1 \mathrm{~L}$ with DDI. The second reagent is the ascorbic acid solution. It is made by dissolving $132 \mathrm{~g}$ of ascorbic acid in $1 \mathrm{~L}$ of DDI. Daily, a working reagent is made by adding $25 \mathrm{~mL}$ of the concentrated ammonium paramolybdate solution with $10 \mathrm{~mL}$ of the ascorbic acid solution and diluting 
to volume to $1 \mathrm{~L}$ with DDI. A $2 \mathrm{~mL}$ aliquot of soil extract is transferred in to $15 \mathrm{~mL}$ microcenterfuge tube and mixed with $8 \mathrm{~mL}$ of the working reagent. The solution is allowed to stand for 20 minutes and the color change is read at $882 \mathrm{~nm}$. High pH extractants $\left(\mathrm{NaHCO}_{3}\right.$ and $\left.\mathrm{NaOH}\right)$ extract some acid insoluble organic acids. These acids precipitate when $\mathrm{pH}$ is lowered by the ammonium molybdate-ascorbic acid colorimetric method. These organic acids were eliminated by pipetting $10 \mathrm{~mL}$ of these extractions into a $50 \mathrm{~mL}$ centrifuge tube and lowering the $\mathrm{pH}$ to about 1.5 by adding $6 \mathrm{~mL}$ to the $0.5 \mathrm{M} \mathrm{NaHCO}_{3}$ and $1.6 \mathrm{~mL}$ of $0.9 \mathrm{M} \mathrm{H}_{2} \mathrm{SO}_{4}$ to the $0.1 \mathrm{M} \mathrm{NaOH}$ (Tiessen and Moir, 1993). The precipitated samples were centrifuged, made to volume, and analyzed accordingly.

\section{Statistical Analysis}

Prior to analysis the data were examined to evaluate univariate normality using the Ryan - Joiner method and identify potential outliers identified by the Dixon's Q test (Minitab 16, 2010). Statistical outliers were examined and considered for eliminated. With removal of outliers the data more closely fit the assumptions associated with the analysis. The experimental design dictated that the data were independent; however, the homogeneity of the covariance matrices were not examined, as the requirement for the covariance of each cell to every other cell results in numerous opportunities for the assumption of homogeneity to fail and in practice it is rarely satisfied in real research data (Lehman et al., 2005).

Data analysis began with multivariate analysis of variance (MANOVA). This looked for significant difference within the $\mathrm{P}$ fractions collectively relative to management history, differing sources of $\mathrm{P}$ used in the incubations, and the presence or absence of vegetation. Essentially, MANOVA was used to determine which independent variables had significant effects on the $P$ fractions prior to univariate analysis. The univariate ANOVA determines if the effects of the independent variables were significant within each dependent variable. Some research assumes a significant MANOVA controls family error rate (Minitab 16 Statistical Software, 2010) while others indicate this is incorrect (Weinfurt, 1995). Multiple comparisons within the ANOVA between the levels of fertilizer treatments were examined by Tukey's Honestly Significant Differences (Tukey's HSD) test (Dowdy et al., 2004).

\section{Results and Discussion}

Poultry manure as a fertilizer has the ability to accelerate the transformation and mineralization of less labile P forms (Waldrip et al., 2011). The question is how this impacts the ultimate distribution of $P$ under real world conditions. Samples were collected at two locations with very different histories of management but from very similar locations (Table 2.1). As expected, the results of this research 
indicated significant effects for main factor History $\mathrm{P}=0.000$ (Table 2.2). For example, Fox and Kamprath (1970) noted increases in soluble P were related to initial soil test P levels. Specifically, Fox and Kamprath (1970) found greater increases in soils with higher initial soil test P levels. Similarly, Pote et al. (2003) and Bond et al. (2006) found higher levels of water soluble P in experimental trials was strongly correlated to the initial levels of water soluble $P$. This is in direct agreement the identified significance related to the factor History.

Additionally, results indicated significant effects for main factors Source $\mathrm{P}=0.005$ (Table 2.2). However, there is some degree of disagreement among previously published results regarding the potential impact of $\mathrm{P}$ source on $\mathrm{P}$ distribution and fractionation. Some studies noted livestock manures were equivalent to inorganic P sources relative to their availability (Eghball et al. 2005; Sikora and Enkiri 2005; Zvomuya et al. 2006; Sneller and Laboski 2009). Conversely, others have found livestock manures and inorganic P do not have the same availability (Gracy 1984; Motavalli et al. 1989; Sharpley and Sisak 1997; Griffin et al. 2003; Miller et al. 2010), whereas these findings indicate not only a significant effect for Source, but a significant interaction between History and Source $\mathrm{P}=0.003$ (Table 2.3) This data indicates that change in the distribution of $\mathrm{P}$ is related to the $\mathrm{P}$ status of soil prior to the additions. In similar work, Waldrip et al. (2011) noted increases in specific $P$ fractions over time in soils amended with poultry manure, but did not necessarily find evidence that single applications created significant differences in specific fractions over time.

Miller et al (2010) indicated experimental conditions such as incubation periods, animal species, and inorganic $P$ types could explain some of the conflicting findings among the literature. Similarly, Rumi et al. (2012) noted changes in soil test $P$ was rate and time dependent. The observed interaction between Source and History means the significance of the independent variable Source is dependent upon the level of the independent variable History. Under these experimental conditions (one soil with very low STP levels vs. one with an extensive history of manure $P$ additions and high STP levels) the ability to identify changes in soil test $\mathrm{P}$ levels relative to $\mathrm{P}$ source is related to the management history. It is reasonable to assume that the effect of that management paradigm has led to an elevated initial soil test P level (Scalenghe et al. 2002) and the changes from such management alters the soil properties and soil P dynamics (Hao et al., 2008). As a result, continual additions of poultry manure shift $P$ from binding with Fe and Al products to binding with Ca (Sharpley et al., 2004).

No significant differences in $\mathrm{P}$ levels relative to the factor Vegetation $\mathrm{P}=0.494$ were identified (Table 2.2). Strictly in terms of plant use, Goss and Stewart (1979) found plants grown in soil fertilized with 
inorganic $\mathrm{P}$ removed soil $\mathrm{P}$ at higher rates than those grown in soil fertilized with manure. Later research examined poultry liter compost and compared it to inorganic fertilizer and found no significant differences in plant uptake (Sikora and Enkiri, 2003). Yet, luxury consumption of $P$ and elevated initial soil test $\mathrm{P}$ levels could be contributing factors to inconsistent plant utilization of P (Goss and Stewart, 1979; Sikora and Enkiri, 2003; Miller et al. 2010). However, one would assume the uptake of P from the plants would change P levels, leading to significant differences between samples incubated with and without vegetation. Yet in soils with significant pools of $P$, the transformation and redistribution of $P$ between could buffer minimal losses during short term incubation. In this experiment $\mathrm{P}$ additions were nominal (equivalent to 60 pounds per acre). Typically, acidic upland soils like berks have a significant $P$ sorption capacity (Sekhon et al., 2014) and the location with a long history of poultry manure applications should have a higher degree of $\mathrm{P}$ saturation. Assuming soils are capable of replenishing the labile P pools; limited change in STP levels relative to any plant uptake would be expected. Similarly, soil for the location with limited to no know history of poultry manure fertilization would have extensive unused $\mathrm{P}$ sorption capabilities and would retain the majority of the $\mathrm{P}$ applied and may not reflect change due to plant uptake. Combined the availability of $P$ from manure applications, the effect of microbial and chemical properties of the soil and the composition of the manure (Waldrip et al. 2011) make a simple explanation of findings is unlikely. Additionally, the vegetation in this experiment was minimal given the appropriate samples were seeded with $0.1 \mathrm{~g}$ of tall fescue and its growth did not exceed $8 \mathrm{~cm}$ in height. Given these conditions and factors, the lack of significance relative to the factor Vegetation was not unexpected as its inclusion as an experimental factor was not about plant uptake as much as it was to establish if the soil-root interactions significantly impacted P distribution within these operationally defined pools.

After examining the main factors and identifying a significant interaction between the dependent variables History and Treatment, (Table 2.3 ) the dependent variable were analyzed individually. The differences between the levels of History were significant across all dependent variables (Tables 2.4, 2.5, 2.6, and 2.7). The main factor Treatment was only significant 2 of 4 sequentially extracted fractions. A closer examination identified significant effects for treatment at the $\mathrm{p}<0.1$ level in the $\mathrm{H}_{2} \mathrm{O}$-Organic (Table 2.4) and $\mathrm{NaOH}-O r g a n i c$ fractions (Table 2.6). Typically following brief incubations (4 weeks) the majority of the sequentially extracted $\mathrm{P}_{\mathrm{o}}$ is found in the $\mathrm{NaOH}$ extractable fraction with the least extractable $P_{0}$ in the most labile fractions (Waldrip et al., 2014). Following longer incubations (8 weeks) more $\mathrm{P}$ is retained in the $\mathrm{NaOH}$ extractable fraction. Likewise, Fox and Kamprath (1970) identified greater increases in soils $P$ fractions when soils were examined with higher initial soil test $P$ levels. 
The Tukey HSD multiple comparisons procedure was applied to the $\mathrm{H}_{2} \mathrm{O}$-Organic (Table 2.8) and $\mathrm{NaOH}$ Organic (Table 2.10) fractions, but the only significant difference identified were between the poultry manure leachate and the control in the $\mathrm{NaOH}-O r g a n i c$ fraction and the Organic and Inorganic $\mathrm{P}$ fractions and the control in the $\mathrm{H}_{2} \mathrm{O}$ extracted fractions. In general, $\mathrm{NaOH}$ extracted organic fractions are considered immobile and are often phytic acid sorbed onto clay minerals or precipitated with various metals oxides (Gagnon et al. 2012). Po can be described or assigned in to one of two generic pools (the slow cycling and the fast cycling pools) and this is related to the form of the $\mathrm{P}_{\mathrm{o}}$ and the associated process by which the $P_{o}$ is retained within the soil (Dodd and Sharpley, 2015). The more stable, slow cycling pool consists of dead microbial cells, organic matter, and plant materials where the faster cycling pool consists of P contained within the microbial biomass (Dodd and Sharpley, 2015). Others (Negassa and Leinweber, 2009) indicated that in short-term studies, changes in P fractions depended on the amount of applied $\mathrm{P}$ regardless of $\mathrm{P}$ source. Similarly, sequential-P-fractionation schemes can be insensitive to detect small changes in $\mathrm{P}$ fractions following incubation with little or no $\mathrm{P}$ additions to agricultural soils (Qian and Schoenau, 2000; Hylander and Siman, 2006). One possible explanation would be the leaching of very labile $P$ forms and related enzymes that facilitate the transfer of sorbed $P$ into the fast cycling $P_{\mathrm{o}}$ pool over time.

The data identified significant interactions between History and Treatment in the $\mathrm{HCl}$-Inorganic (Table 2.7), and $\mathrm{H}_{2} \mathrm{O}$-Organic fractions (Table 2.4) at the $\mathrm{p}<0.1$ level. The $\mathrm{HCl}$ extracted inorganic $\mathrm{P}$ is typically associated with Ca compounds and the water extractable fraction are the most labile fractions (Negassa and Leinweber 2009; Gagnon et al. 2013). Organic P when incorporated in soil can be transformed into labile inorganic $P$ forms (Waldrip et al. 2011). Long-term additions of $P$ even at low rates should increases the level of $P_{0}$ in all extractable $P$ o fractions (Negassa and Leinweber 2009). While in general, $P$ additions in any form tend to follow a progression outline by Walker and Syers (1976) that predicts the gradual conversion of $\mathrm{P}$ additions toward occluded $\mathrm{P}$, more specifically it appears over time $\mathrm{P}$ from labile or moderately labile fractions can be transformed into the stable more recalcitrant forms (Negassa and Leinweber 2009). The interactions seen here indicate a likely hood that the most recalcitrant pools and the most labile pools seem to be dependent upon the management history i.e. the degree of $P$ saturation, size of the active $\mathrm{P}$ pool in solution, and change in organic matter, and cations associated with long-term manure applications. Clearly these changes could impact how $\mathrm{P}$ additions would behave and what forms of $P$ if any would remain in solution following weeks of incubation. 


\section{Conclusions}

There were no significant effects from the actively growing plants on the disposition of $\mathrm{P}$ within the sequentially extracted factions. While 16 week incubations may be sufficient for sorption-desorption studies, there are limits to the amount of vegetation that can be generated under these experimental conditions. It is possible more prolific vegetation and increased sample numbers could lead to statistically significant differences. However, based on the lack of effect from vegetation in this experiment, any significant differences in $\mathrm{P}$ distribution because of vegetation in additional research seem unlikely. As such, any previous research involving incubation of $\mathrm{P}$ and soil without actively growing vegetation can be assumed representative of $\mathrm{P}$ sorption-desorption dynamics typical of pasture settings.

It was noted that $\mathrm{P}$ additions contribute to $\mathrm{P}$ pools in somewhat predictable ways. The changes in extractable soil P pools are consistent with the basic premise of the conceptual model of Walker and Syers (1976), whereby inorganic $P$ in the labile pool become occluded. In theory as $P$ becomes occluded, it is replenished via P cycling between labile and non-labile and organic and inorganic forms. As such, it appears the majority the $\mathrm{P}$ added to these samples became sorbed or occluded to the extent that the sequential extraction failed to identify any significant differences between the various sources. The literature indicates water-soluble P levels stabilize as quickly as 3 weeks after fertilization (Bond, et.al, 2006) or could continue to increasing in availability for up to 13 weeks before leveling off and stabilizing for up to 6 month (Gagnon and Simard, 1999). The length of incubation (16 week) and the repeated wetting and drying of the soil would have facilitated P cycling and provided time for P level to equilibrate.

It is understood that additions of some P compounds such as inositol hexaphosphate (IP6) can cause other forms of sorbed $\mathrm{P}$ to desorb causing temporary spikes in the more labile $\mathrm{P}$ pools such as water soluble inorganic $P$ (Berg and Joern, 2006). Additionally, consider the conceptual model of Walker and Syers (1976) and its' conclusion that, over time, P becomes occluded and it is known that continual additions of poultry manure shift P from binding with Fe and Al products to binding with Ca (Sharpley et al., 2004). Given the experimental design with soil from locations with extensive histories of manure application the likelihood of the soil-P dynamics changing due to shifts in binding mechanisms is high. Likewise, soil from locations with low soil test P levels should have ample sorption capacity. It is assumed these factors contribute to the modest $\mathrm{P}$ additions not inducing significant changes in $\mathrm{P}$ levels. 
Combined with the fact that is not unexpected that $\mathrm{P}$ additions from one source may elevate seeming unrelated P pools none of these results should be viewed as entirely unexpected.

Following these lines of reasoning and these findings, it seems reasonable to support the use of existing research independent of the $P$ source and the presence or absence of vegetation in the incubation process, for the development of $\mathrm{P}$ management strategies and risk assessments. However, it is also clear that long-term additions of poultry manure change the fundamental aspects of how $\mathrm{P}$ additions interact with the soil. It is paramount to remember that while a great deal of $\mathrm{P}$ is retained in these soils, the interaction of the most labile forms is fundamental affected by the management history. Moving forward much caution should be observed when anticipating the fate of new $P$ additions with any degree of specificity. Clearly there are more opportunities to examine the impacts of management history on $\mathrm{P}$ and how remediation strategies could impact that relationship over time.

The first research hypothesis ( $\mathrm{H} 1 \mathrm{a}$ ) states that an addition of $\mathrm{P}$ causes a significant difference in operationally defined sequentially extracted $P_{0}$ fractions relative to the source of the $P$ addition and the fertilization history of the sample at the $p \leq 0.1$ level. The null hypothesis ( $\mathrm{HOa}$ ) states that additions of $\mathrm{P}$ does not cause a significant difference in operationally defined sequentially extracted $P_{o}$ fractions relative to the source of the $P$ addition and the fertilization history of the sample at the $p \leq 0.1$ level. Results of the MANOVA identified significant difference between $\mathrm{P}$ levels in the samples relative to History and Treatment. A detailed examination identified that while there are differences in some instances but not for all sequentially extracted fractions but not in the samples with soils with limited histories of $\mathrm{P}$ additions, thus rejecting the null hypothesis.

The third hypothesis $\left(\mathrm{H}_{\mathrm{b}}\right)$ states that the presence of active growing vegetation can affect sequentially extracted $\mathrm{P}_{\mathrm{o}}$ fractions in incubated soil samples at the $\mathrm{p} \leq 0.1$ level. The null hypothesis $\left(\mathrm{HO}_{\mathrm{c}}\right)$ states, that the presence of active growing vegetation does not affect sequentially extracted $P_{0}$ fractions in incubated soil samples at the $p \leq 0.1$ level. There was no evidence that the presence of actively growing plants had any impact on the sequentially extracted $\mathrm{P}_{\mathrm{o}}$ level. Thus the null hypothesis was confirmed. 


\section{References}

Beck, M.A., L.W. Zelazny, W.L. Daniels, and G.L. Mullins. 2004. Using the mehlich-1 extract to estimate soil phosphorus saturation for environmental risk assessment. Soil Science Society of America Journal 68:1762-1771.

Berg, A.S. and B.C. Joren. 2006 Sorption dynamics of organic and inorganic phosphorus compounds in soil. J. Environ. Qual. 35:1855-1862.

Bond, R., R.O. Maguire, and J. L. Havlin. 2006. Change in soluble phosphorus in soils following fertilization is dependent on initial mehlich-3 phosphorus. J. Environ. Qual. 35:1818-1824.

Bowman, R.A., and C.V. Cole. 1978. An exploratory method for fractionation of organic phosphorus from grassland soils. Soil Sci. 125, 95-101.

Cassel, D.K., and D.R. Nielsen. 1986. Field capacity and available water capacity. In A. Klute (ed.) Methods of soils analysis. Part 1. 2nd ed. Agron. Monogr. 9. SSSA, Madison, WI.

Chang, S.C., and M.L. Jackson. 1957. Fraction of soil phosphorus. Soil Sci. 84:133-144.

Cross, A.F., and W.H. Schlesinger. 1995. A literature review and evaluation of the Hedley fractionation: applications to the biogeochemical cycle of soil phosphorus in natural ecosystems. Geoderma 64, 197-214.

Crouse, D.A., H. Sierzputowska-Gracz, R.L. Mikkelson, and A.G. Wollum. 2002. Monitoring phosphorus mineralization from poultry manure using phosphatase assays and phosphorus-31 nuclear magnetic resonance spectroscopy. Commun. Soil Sci. Plant Anal. 33:1205-1217.

Dodd, R.J., A.N. Sharpley. 2015. Recognizing the role of soil organic phosphorus in soil fertility and water quality. Resour. Conserv. Recy. 105:282-293.

Dowdy, S.M., S. Wearden, and D. Chilko. 2004. Statistics for research. 3rd Edition. John Wiley and Sons. Hoboken, New Jersey.

Ebeling, A.M., L. Cooperband, L.G. Bundy. 2003. Phosphorus source effects on soil test phosphorus and forms of phosphorus in soil. Communications in Soil Science and Plant Analysis. Vol. 34, Nos. 13 \& 14, pp. 1897-1917. 
Eghball, B., B. J. Wienhold, B. L. Woodbury, and R. A. Eigenberg. 2005. Plant availability of phosphorus in swine slurry and cattle feedlot manure. Agronomy Journal, vol. 97, no. 2, pp. 542-548.

Erich, M.S., C.B. Fitzgerald, G.A. Porter. 2002 The effect of organic amendments on phosphorus chemistry in a potato cropping system. Agric Ecosyst Environ 88:79-88.

Estepp, R. 1989. Soil Survey of Grant and Hardy Counties, West Virginia. United States Department of Agriculture, Soil Conservation Service.

Fox, R.L., and E.J. Kamprath. 1970. Phosphorus sorption isotherms for evaluating the phosphate requirement of soils. Soil Sci. Soc. Am. Proc. 34:902-907.

Gagnon, B., I. Demers, N. Ziadi, M.H. Chantigny, L.E. Parent, T.A, Forge, F.J. Larney, and K.E. Buckley. 2012. Forms of phosphorus in composts and in compost-amended soils following incubation. Can. J. Soil Sci. 92: 711_721.

Gagnon, B., and R.R. Simard. 1999. Nitrogen and phosphorus release from on-farm and industrial composts. Can. J. Soil Sci. 79:481-489.

Gracey, H.I. 1984. Availability of phosphorus in organic manures compared with monoammonium phosphate. Agricultural Wastes, vol. 11, no. 2, pp. 133-141.

Griffin, T.S., C. W. Honeycutt, Z. He. 2003. Changes in soil phosphorus from manure application. Soil Science Society of America Journal, vol. 67, no. 2, pp. 645-653.

Goss, D. W., and B. A. Stewart. 1979. Efficiency of phosphorus utilization by alfalfa from manure and superphosphate. Soil Sci. Soc. Am. J. 43:523-528

Guppy, C.N., N.W. Menzies, P.W. Moody, B.L. Compton, F.P.C. Blamey. 2000. A simplified, sequential, phosphorus fractionation method. Communications in soil science and plant analysis vol: 31 $1981-1991$.

Hao, X., F. Godlinski, C. Chang. 2008. Distribution of phosphorus forms in soil following long-term continuous and discontinuous cattle manure applications. Soil Sci. Soc. Am. J. 72:90-97.

Harman, M.B., J.A. Thompson, E.M. Pena-Yewtukhiw, L.M. McDonald, and J. Beard. 2011. Preferential flow in pastures on benchmark soils in West Virginia. Soil Science, 176: 509-519. 
Harman, M.B., J.A. Thompson, L.M. McDonald, E.M. Pena-Yewtukhiw, J. Beard. 2013. Phosphorus translocation in pastures on benchmark soils in West Virginia. Soil Horizons Vol.54 - No.3.

He, Z., C.W. Honeycutt, B.J. Cade-Menun, Z.N. Senwo, and I.A. Tazisong. 2008. Phosphorus in poultry litter and soil: enzymatic and nuclear magnetic resonance characterization. Soil Sci. Soc. Am. J. 72:1425-1433.

He, Z., C. W. Honeycutt, and T. S. Griffin. 2003. Comparative investigation of sequentially extracted phosphorus fractions in a sandy loam soil and a swine manure. Communications in soil science and plant analysis. Vol. 34, Nos. 11 \& 12, pp. 1729-1742.

He, Z., T.S. Griffin, and C.W. Honeycutt. 2004. Evaluation of soil phosphorus transformations by sequential fractionation and phosphatase hydrolysis. Soil Sci. 169:515-527.

Hedley, M.J., J.W.B. Stewart, and B.S. Chauhan. 1982. Changes in inorganic and organic soil phosphorus fractions induced by cultivation practices and by laboratory incubations. Soil. Sci. Soc. Am. J. 46, 970-976.

Hill, J.E., and B.J. Cade-Menun. 2009. Phosphorus-31 Nuclear Magnetic Resonance Spectroscopy Transect Study of Poultry Operations on the Delmarva Peninsula. J. Environ. Qual. 38:130-138.

Hylander, L. D., G. Siman. 2006. Phosphorus fractionation in soils and wastewater sorbent materials as an indicator of material specific and storage-dependent availability. Commun. Soil Sci. Plant Anal. 37, 1013-1030.

Iyamuremye, F., R.P. Dick, and J. Baham. 1996. Organic amendments and soil phosphorus dynamics: I. Phosphorus chemistry and sorption. Soil Sci. 161:426-435.

Knudsen, D. and D. Beegle. 1988. Recommended phosphorus tests. p. 12-15, In: W.C. Dahnke (ed.) Recommended Chemical Soil Tests Procedures for the North Central Region. Bulletin No. 499 (Revised). North Dakota Agric. Exp. Sta., Fargo, North Dakota.

Laboski, C.A.M., and J.A. Lamb. 2003. Changes in soil test phosphorus concentration after application of manure or fertilizer. Published in Soil Sci. Soc. Am. J. 67:544-554.

Leytem, A.B., J.T. Sims, and F.J. Coale. 2004. Determination of phosphorus source coefficients for organic phosphorus sources: laboratory studies. J. Environ. Qual. 33:380-388. 
Lehman, A., N. O’Rourke, L. Hatcher, and E.J. Stephans. 2005. JMP for Basic Univariate and Multivariate Statistics. SAS Institute, Cary, NC.

Maguire, R.O. and J.T. Sims. 200s. Soil testing to predict phosphorus leaching. J. Environ. Qual. 31:16011609.

Maguire, R.O., J.T. Sims, S.K. Dentel, F.J. Coale, and J.T. Mah. 2001. Relationships between biosolids treatment process and soil phosphorus availability. J. Environ. Qual. 30:1023-1033.

Miller, J.C., T. Astatkie, A. Madani. 2010. Soil test phosphorus from livestock manures compared with inorganic fertilizers in soil incubations. Applied and Environmental Soil Science. 2010:1-6.

Minitab 16 Statistical Software. 2010. [Computer software]. State College, PA: Minitab, Inc. (www.minitab.com)

Motavalli, P.P., K. A. Kelling, and J. C. Converse. 1989. First-year nutrient availability from injected dairy manure. Journal of Environmental Quality, vol. 18, no. 2, pp. 180-185.

Negassa W. and P. Leinweber. 2009. How does the hedley sequential phosphorus fractionation reflect impacts of land use and management on soil phosphorus: a review. J Plant Nutr. Soil Sci. 172:305-325.

Pote, D.H., J.A. Lory, and H. Zhang. 2003. Does initial soil P level affect water-extractable soil P response to applied P? Adv. Environ. Res. 7:503-509.

Qian, P., and J.J. Schoenau. 2000. Fractionation of $\mathrm{P}$ in soil as influenced by a single addition of liquid swine manure. Can. J. Soil Sci. 80:561-566.

Rumi, F., M.A. Kashem, K.T. Osman. 2012. Recovery of soil test phosphorus from an acidic soil amended with organic and inorganic phosphorus. Open Journal of Soil Science. Vol. 2. pp. 382-388.

Scalenghe, R., A. C. Edwards, F. A. Marsan and E. Barberis. 2002. The effect of reducing conditions on the solubility of phosphorus in a diverse range of european agricultural soils. Eur. J. Soil Sci. 53:439447.

Schroeder, P.D., and J.L. Kovar. 2006. Comparison of organic and inorganic phosphorus fractions in an established buffer and adjacent production field. Communications in Soil Science and Plant Analysis, 37: 1219-1232. 
Sekhon, B.S., D.K. Bhumbla, J. Sencindiver, L.M. McDonald. 2014. Using soil survey data for series-level environmental phosphorus risk assessment. Environ. Earth Sci. 72:2345-2356.

Sharpley, A.N., R.W. McDowell, P.J.A. Kleinman. 2004. Amounts, forms, and solubility of phosphorus in soils receiving manure. Soil Sci. Soc. Am. J. 68:2048-2057.

Sharpley, A.N. and I. Sisak. 1997. Differential availability of manure and inorganic sources of phosphorus in soil. Soil Science Society of America Journal, vol. 61, no. 5, pp. 1503-1508.

Sikora, L.J., and N. K. Enkiri. 2005. Comparison of phosphorus uptake from poultry litter compost with triple superphosphate in codorus soil. Agronomy Journal, vol. 97, no. 3, pp. 668-673.

Sneller, E.G., and C. A.M. Laboski. 2009. Phosphorus source effects on corn utilization and changes in soil test. Agronomy Journal, vol. 101, no. 3, pp. 663-670.

Sui, Y., M.L. Thompson, and C. Shang. 1999. Fractionation of phosphorus in a Mollisol with biosolids. Soil Sci. Soc. Am. J. 63: 1174-1180.

Toor, G.S., L.M. Condron, H.J. Di, K.C. Cameron, B.J. Cade-Menun. 2003. Characterization of organic phosphorus in leachate from a grassland soil. Soil Biology \& Biochemistry 35: pp. 1317-1323.

Tiessen, H. and J.O. Moir. 1993. Characterization of available P by sequential extraction. In: Carter, M.R., (Ed.). Soil sampling and methods of analysis. pp. 75-86. Canadian Society of Soil Science.

Waldrip, H.M., Z. He, M.S. Erich. 2011. Effects of poultry manure amendment on phosphorus uptake by ryegrass, soil phosphorus fractions and phosphatase activity. Biol. Fertil. Soils. Volume 47, Issue 4, pp 407-418.

Waldrip-Dail, H., Z. He, M.S. Erich, C.W. Honeycutt. 2009. Soil phosphorus dynamics in response to poultry manure amendment. Soil Sci 174:195-201.

Walker, T. and J. Syers. 1976. The fate of phosphorus during pedogenesis. Geoderma, 15, 1-19.

Warren, J.G., C.J. Penn, J.M. McGrath, K. Sistani. 2008. The impact of alum addition on organic $p$ transformations in poultry litter and litter-amended soil. J. Environ. Qual. 37:469-476. 
Weinfurt, K.P. 1995. Multivariate analysis of variance. In: Grimm, L.G., P.R. Yarnold (Eds.). Reading and Understanding Multivariate Statistics. 245-247. American Psychological Association. Washington, DC, U.S.A.

Whalen, J.K., and C. Chang. 2001. Phosphorus accumulation in cultivated soils from long-term annual application of cattle feedlot manure. J. Environ. Qual. 30:229-237.

Yang, J.E., C.A. Jones, H.J. Kim, and J.S. Jacobsen. 2002. Soil inorganic phosphorus fractions and Olsen-P in phosphorus-responsive calcareous soils: Effects of fertilizer amount and incubation time. Commun. Soil Sci. Plant Anal. 33:855-871.

Ylivainio, K., R. Uusitalo E. Turtola. 2008. Meat bone meal and fox manure as P sources for ryegrass (Lolium multiflorum) grown on a limed soil. Nutr Cycl Agroecosyst 81:267-278.

Zvomuya, F., B. L. Helgason, F. J. Larney, H. H. Janzen, O. O. Akinremi, B. M. Olson. 2006. Predicting phosphorus availability from soil-applied composted and non-composted cattle feedlot manure. Journal of Environmental Quality, vol. 35, no. 3, pp. 928-937. 


\section{Tables}

Table 2.1 Soil map unit information from locations where soil was collected for benchtop experiments.

Location Map Unit Name

Size

\begin{tabular}{ccc}
\hline & & Acers \\
\hline *Fertilized & Berks-Weikert channery silt loams, 8 to 15 percent slopes & 4.7 \\
$* *$ Unfertilized & Berks-Weikert channery silt loams, 15 to 25 percent slopes & 1.2 \\
\hline
\end{tabular}

*Fertilized location received annual or near annual applications of animal (poultry) manure as a source of $\mathrm{N}$ fertilizer for a minimum of 10 years.

**Unfertilized locations are similar but had no significant manure applications within the last 10 years.

Table 2.2 MANOVA Test Criteria and F approximations for history treatment vegetation

Effect Test Statistic Approximate Numerator Denominator P value

\begin{tabular}{|c|c|c|c|c|c|c|}
\hline & & & F statistic & DF & DF & \\
\hline \multirow[t]{3}{*}{ History } & Wilks' & 0.00384 & 1201.273 & 8 & 37 & $\leq 0.000^{*}$ \\
\hline & Lawley - Hotelling & 259.73474 & 1201.273 & 8 & 37 & $\leq 0.000^{*}$ \\
\hline & Pillai's & 0.99616 & 1201.273 & 8 & 37 & $\leq 0.000^{*}$ \\
\hline
\end{tabular}

\begin{tabular}{lllllll}
\hline Treatment & Wilks' & 0.20420 & 1.804 & 40 & 164 & $0.005^{*}$ \\
& Lawley - Hotelling & 1.99458 & 1.765 & 40 & 177 & $0.007^{*}$ \\
& Pillai's & 1.29632 & 1.794 & 40 & 205 & $0.005^{*}$ \\
\cline { 2 - 7 } & & $\mathrm{S}=5$ & $\mathrm{M}=1.0$ & $\mathrm{~N}=17.5$ & \\
\hline \multirow{2}{*}{ Vegetation } & Wilks' & 0.83067 & 0.943 & 8 & 37 & 0.494 \\
& Lawley - Hotelling & 0.20385 & 0.943 & 8 & 37 & 0.494 \\
& Pillai's & 0.16933 & 0.943 & 8 & 37 & 0.494 \\
\cline { 2 - 6 } & & & $\mathrm{S}=1$ & $\mathrm{M}=3.0$ & $\mathrm{~N}=17.5$ &
\end{tabular}

* indicates $p$ value less than or equal to 0.05 , Wilks' test is the most commonly used test because it was the first derived and has a well-known F approximation, the Lawley-Hotelling is based on a T statistic. Pillai's trace will give similar to the Wilks' and Lawley-Hotelling's tests. S, M, and N are used to calculate the various statistics. If $\mathrm{S}=1$ or 2 , the $\mathrm{F}$ is exact, otherwise it's an approximation. 
Table 2.3 MANOVA Test Criteria and F approximations for interactions

\begin{tabular}{|c|c|c|c|c|c|c|}
\hline Effect & Test & Statistic & $\begin{array}{l}\text { Approximate } \\
\text { F statistic }\end{array}$ & $\begin{array}{l}\text { Numerator } \\
\text { DF }\end{array}$ & $\begin{array}{l}\text { Denominator } \\
\text { DF }\end{array}$ & $P$ value \\
\hline History X & Wilks' & 0.19293 & 1.881 & 40 & 164 & $0.003 *$ \\
\hline \multirow{3}{*}{ Treatment } & Lawley - Hotelling & 2.21027 & 1.956 & 40 & 177 & $0.002 *$ \\
\hline & Pillai's & 1.28431 & 1.771 & 40 & 205 & $0.006 *$ \\
\hline & & & $S=5$ & $M=1.0$ & $N=17.5$ & \\
\hline History X & Wilks' & 0.67905 & 2.186 & 8 & 37 & 0.051 \\
\hline \multirow{3}{*}{ Vegetation } & Lawley - Hotelling & 0.47264 & 2.186 & 8 & 37 & 0.051 \\
\hline & Pillai's & 0.32095 & 2.186 & 8 & 37 & 0.051 \\
\hline & & & $S=5$ & $M=1.0$ & $N=17.5$ & \\
\hline Treatment X & Wilks' & 0.50667 & 0.692 & 40 & 164 & 0.914 \\
\hline \multirow{3}{*}{ Vegetation } & Lawley - Hotelling & 0.82902 & 0.734 & 40 & 177 & 0.876 \\
\hline & Pillai's & 0.57072 & 0.660 & 40 & 205 & 0.941 \\
\hline & & & $S=5$ & $M=1.0$ & $N=17.5$ & \\
\hline History X & Wilks' Lambda & 0.46420 & 0.790 & 40 & 164 & 0.808 \\
\hline \multirow{3}{*}{$\begin{array}{l}\text { Treatment X } \\
\text { Vegetation }\end{array}$} & Hotelling - Lawley & 0.88306 & 0.782 & 40 & 177 & 0.820 \\
\hline & Pillai's Trace & 0.67342 & 0.798 & 40 & 205 & 0.801 \\
\hline & & & $S=5$ & $M=1.0$ & $\mathrm{~N}=17.5$ & \\
\hline
\end{tabular}

* indicates $p$ value less than or equal to 0.05 , Wilks' test is the most commonly used test because it was the first derived and has a well-known F approximation, the Lawley-Hotelling is based on a T statistic.

Pillai's trace will give similar to the Wilks' and Lawley-Hotelling's tests. S, M, and N are used to calculate the various statistics. If $\mathrm{S}=1$ or 2 , the $\mathrm{F}$ is exact, otherwise it's an approximation.

Table 2.4 Analysis of Variance for $\mathrm{H}_{2} \mathrm{O}$-Organic, using Adjusted SS for Tests

\begin{tabular}{lllllll} 
Source & DF & Seq SS & Adj SS & Adj MS & F & P \\
\hline History & 1 & 17162.8 & 17173.6 & 17173.6 & 280.27 & $\leq 0.000^{*}$ \\
Treatment & 5 & 702.8 & 696.4 & 139.3 & 2.27 & $0.060^{*}$ \\
History * Treatment & 5 & 696.6 & 696.6 & 139.3 & 2.27 & $0.059^{*}$ \\
Error & 56 & 3431.4 & 3431.4 & 61.3 & & \\
Total & 67 & 21993.6 & & & & \\
\hline
\end{tabular}

$\mathrm{S}=7.82783 \quad \mathrm{R}-\mathrm{Sq}=84.40 \% \quad \mathrm{R}-\mathrm{Sq}(\mathrm{adj})=81.33 \%$

* indicates $p$ value less than or equal to $0.05, *$ indicates $p$ value less than or equal to 0.10

Table 2.5 Analysis of Variance for $\mathrm{NaHCO}_{3}$-Organic, using Adjusted SS for Tests

\begin{tabular}{lllllll} 
Source & DF & Seq SS & Adj SS & Adj MS & F & P \\
\hline History & 1 & 23500.7 & 23913.6 & 23913.6 & 190.26 & $0.000^{*}$ \\
Treatment & 5 & 706.0 & 784.1 & 156.8 & 1.25 & 0.299
\end{tabular}




\begin{tabular}{lllllll} 
History * Treatment & 5 & 690.0 & 690.0 & 138.0 & 1.10 & 0.372 \\
Error & 56 & 7038.6 & 7038.6 & 125.7 & & \\
Total & 67 & 31935.3 & & & \\
\hline $\mathrm{S}=11.2111$ & $\mathrm{R}-\mathrm{Sq}=77.96 \%$ & $\mathrm{R}-\mathrm{Sq}(\mathrm{adj})=73.63 \%$ &
\end{tabular}

* indicates $p$ value less than or equal to $0.05, *$ indicates $p$ value less than or equal to 0.10

Table 2.6 Analysis of Variance for NaOH-Organic, using Adjusted SS for Tests

\begin{tabular}{lllllll} 
Source & DF & Seq SS & Adj SS & Adj MS & F & P \\
\hline History & 1 & 469495 & 475973 & 475973 & 509.54 & $\leq 0.000^{*}$ \\
Treatment & 5 & 8620 & 9333 & 1867 & 2.00 & $0.093^{*}$ \\
History * Treatment & 5 & 8048 & 8048 & 1610 & 1.72 & 0.144 \\
Error & 56 & 52310 & 52310 & 934 & & \\
Total & 67 & 538473 & & & & \\
\hline
\end{tabular}

$\mathrm{S}=30.5633 \quad \mathrm{R}-\mathrm{Sq}=90.29 \% \quad \mathrm{R}-\mathrm{Sq}(\mathrm{adj})=88.38 \%$

* indicates $p$ value less than or equal to $0.05, *$ indicates $p$ value less than or equal to 0.10

Table 2.7 Analysis of Variance for HCl-Organic, using Adjusted SS for Tests

\begin{tabular}{lllllll} 
Source & DF & Seq SS & Adj SS & Adj MS & F & P \\
\hline History & 1 & 24056.5 & 23899.5 & 23899.5 & 2662.55 & $\leq 0.000^{* *}$ \\
Treatment & 5 & 79.9 & 75.4 & 15.1 & 1.68 & 0.154 \\
History * Treatment & 5 & 97.7 & 97.7 & 19.5 & 2.18 & $0.070^{*}$ \\
Error & 56 & 502.7 & 502.7 & 9.0 & & \\
Total & 67 & 24736.8 & & & & \\
\hline S $=2.99603$ & R-Sq $=97.97 \%$ & R-Sq (adj) $=97.57 \%$ & &
\end{tabular}

* indicates $p$ value less than or equal to $0.05,{ }^{*}$ indicates $p$ value less than or equal to 0.10 


\begin{tabular}{|c|c|c|c|c|c|c|}
\hline History & Treatment & Count & $\begin{array}{l}\text { Mean } \\
\mathrm{mg} / \mathrm{kg}\end{array}$ & Standard Error & Standard Deviation & Grouping \\
\hline \multirow{6}{*}{ 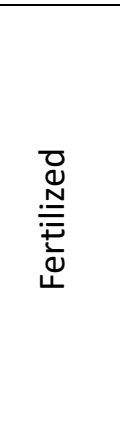 } & Control & 6 & 25.4 & 1.63 & 4.0 & $A$ \\
\hline & Leached Manure & 6 & 39.2 & 5.71 & 13.98 & $A B$ \\
\hline & Manure & 6 & 33.6 & 5.34 & 13.09 & $A B$ \\
\hline & Manure Leachate & 5 & 29.3 & 0.88 & 1.97 & $A B$ \\
\hline & $P_{0}$ & 6 & 41.2 & 6.42 & 15.74 & B \\
\hline & $P_{i}$ & 6 & 26.0 & 3.29 & 8.06 & B \\
\hline \multirow{6}{*}{ 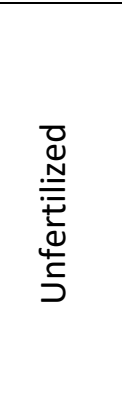 } & Control & 6 & 0.5 & 0.21 & 0.51 & C \\
\hline & Leached Manure & 6 & 0.4 & 0.23 & 0.56 & C \\
\hline & Manure & 6 & 1.0 & 0.31 & 0.75 & C \\
\hline & Manure Leachate & 6 & 0.9 & 0.31 & 0.75 & C \\
\hline & $P_{0}$ & 5 & 1.1 & 0.29 & 0.64 & C \\
\hline & $P_{i}$ & 6 & 1.0 & 0.34 & 0.84 & C \\
\hline
\end{tabular}

Treatments with same grouping letter are not significantly different 


\begin{tabular}{|c|c|c|c|c|c|c|}
\hline History & Treatment & Count & $\begin{array}{l}\text { Mean } \\
\mathrm{mg} / \mathrm{kg}\end{array}$ & Standard Error & Standard Deviation & Grouping \\
\hline \multirow{6}{*}{ 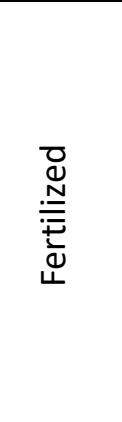 } & Control & 6 & 48.4 & 7.65 & 18.74 & $A$ \\
\hline & Leached Manure & 6 & 50.0 & 5.94 & 13.27 & A \\
\hline & Manure & 6 & 47.3 & 7.20 & 17.63 & $A$ \\
\hline & Manure Leachate & 5 & 64.5 & 1.74 & 3.88 & A \\
\hline & $P_{0}$ & 6 & 45.9 & 1.77 & 19.03 & $A$ \\
\hline & $P_{i}$ & 6 & 46.6 & 5.49 & 13.45 & $A$ \\
\hline \multirow{6}{*}{ 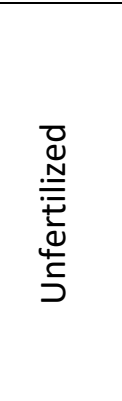 } & Control & 6 & 11.5 & 0.30 & 0.75 & B \\
\hline & Leached Manure & 6 & 11.7 & 0.26 & 0.64 & B \\
\hline & Manure & 6 & 11.9 & 0.14 & 0.32 & B \\
\hline & Manure Leachate & 6 & 13.7 & 1.86 & 4.56 & B \\
\hline & $\mathrm{P}_{\mathrm{o}}$ & 5 & 11.5 & 0.23 & 0.51 & B \\
\hline & $P_{i}$ & 6 & 16.6 & 2.14 & 5.25 & B \\
\hline
\end{tabular}

Treatments with same grouping letter are not significantly different 


\begin{tabular}{|c|c|c|c|c|c|c|}
\hline History & Treatment & Count & $\begin{array}{l}\text { Mean } \\
\mathrm{mg} / \mathrm{kg}\end{array}$ & Standard Error & Standard Deviation & Grouping \\
\hline \multirow{6}{*}{ 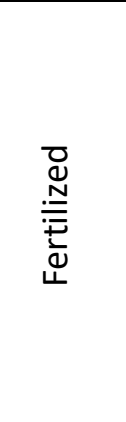 } & Manure Leachate & 5 & 264 & 5.22 & 11.7 & $A$ \\
\hline & Leached Manure & 6 & 243 & 13.9 & 34.0 & $A B$ \\
\hline & Manure & 6 & 208 & 15.7 & 38.5 & $A B$ \\
\hline & $\mathrm{P}_{\mathrm{i}}$ & 6 & 223 & 27.6 & 67.7 & $A B$ \\
\hline & $\mathrm{P}_{\mathrm{o}}$ & 6 & 217 & 17.3 & 42.5 & $A B$ \\
\hline & Control & 6 & 199 & 11.7 & 28.6 & B \\
\hline \multirow{6}{*}{ 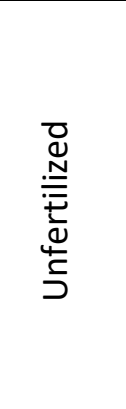 } & Control & 6 & 53.6 & 3.60 & 8.81 & C \\
\hline & Leached Manure & 6 & 56.7 & 0.98 & 2.41 & C \\
\hline & Manure & 6 & 62.0 & 4.97 & 12.2 & C \\
\hline & Manure Leachate & 6 & 58.9 & 4.52 & 11.1 & C \\
\hline & $\mathrm{P}_{\mathrm{o}}$ & 5 & 56.2 & 4.19 & 9.36 & C \\
\hline & $\mathrm{P}_{\mathrm{i}}$ & 6 & 65.6 & 5.73 & 14.0 & C \\
\hline
\end{tabular}

Treatments with same grouping letter are not significantly different 


\begin{tabular}{|c|c|c|c|c|c|c|}
\hline History & Treatment & Count & $\begin{array}{l}\text { Mean } \\
\mathrm{mg} / \mathrm{kg}\end{array}$ & Standard Error & Standard Deviation & Grouping \\
\hline \multirow{6}{*}{ 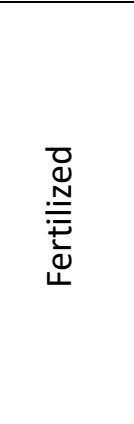 } & Control & 6 & 25.4 & 1.63 & 4.00 & $A$ \\
\hline & Leached Manure & 6 & 39.2 & 5.71 & 13.98 & $A$ \\
\hline & Manure & 6 & 33.6 & 5.34 & 13.09 & $A$ \\
\hline & Manure Leachate & 5 & 29.3 & 0.88 & 1.97 & $A$ \\
\hline & $P_{0}$ & 6 & 41.2 & 6.42 & 15.75 & $A$ \\
\hline & $P_{i}$ & 6 & 26.0 & 3.29 & 8.06 & $A$ \\
\hline \multirow{6}{*}{ 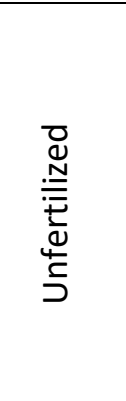 } & Control & 6 & 0.5 & 0.21 & 0.51 & B \\
\hline & Leached Manure & 6 & 0.4 & 0.23 & 0.56 & B \\
\hline & Manure & 6 & 1.0 & 0.31 & 0.75 & B \\
\hline & Manure Leachate & 6 & 0.9 & 0.31 & 0.75 & B \\
\hline & $\mathrm{P}_{\mathrm{o}}$ & 5 & 1.1 & 0.29 & 0.64 & B \\
\hline & $P_{i}$ & 6 & 1.0 & 0.34 & 0.84 & B \\
\hline
\end{tabular}

Treatments with same grouping letter are not significantly different 


\section{Chapter 3. Identifying the Effects of Space on the Distribution of Sequential Extracted Organic Phosphorus Fractions in Hay and Grass Pastures of Eastern West Virginia Following Long-Term Nitrogen-based Manure Applications.}

\section{Abstract}

While $\mathrm{P}$, in general, is strongly sorbed by soil, $\mathrm{P}$ applied to the soil surface may not necessarily remain in place. Not all forms of $P$ are equal in terms of the strength with which the forms are sorbed. There is also variability in terms of ability of different soils to sorb P. Furthermore, surface applications of manure or fertilizer are not necessarily uniform across the landscape. All of these factors play some role in the physical distribution of various $\mathrm{P}$ compounds within any managed unit. When $\mathrm{P}$ at landscape scales is examined to evaluate potential movement or loss one must account for these effects prior to determining if a true pattern exists. To determine if $P$ has moved over time, multiple $P$ fractions were sequentially extracted and analyzed for significant spatial structure. Statistical techniques were applied to identify soil properties that could explain significant portions of the P variability while controlling for the effect of those variables while examining the residual variability for spatial structure. Thus it was concluded that in some instances the $0.5 \mathrm{M} \mathrm{NaHCO}_{3}$ extractable organic $\mathrm{P}\left(\mathrm{P}_{\mathrm{o}}\right)$ fraction and the $1.0 \mathrm{M} \mathrm{HCl}$ extractable $\mathrm{P}$ fraction exhibited identifiable spatial structure (residual spatial autocorrelation) not associated with changes in soil properties. Conversely the more stable $0.1 \mathrm{M} \mathrm{NaOH}$ extractable P fraction and the very transient $\mathrm{H}_{2} \mathrm{O}$ extractable fractions did not exhibit such patterns. These results are consistent with a hypothesis of extractable $P$ fractions behaving uniquely at landscape scales.

\section{Introduction}

Whether practicing sustainable agriculture, protecting sensitive watersheds or understanding the longterm implication of specific management paradigms is critically important. In some locations, due to capacity to generate manure and how that manure is utilized on farms, have a greater potential to influence water quality. The poultry-producing region of West Virginia is one such location. For example, Grant, Hardy, and Pendleton Counties in eastern West Virginia produce approximately $14 \%$ of the state's cattle sales and $85 \%$ of the state's meat type chicken sales (USDA-NASS, 2009). This regionally dense food animal agriculture production has the potential to generate in excess of 200,000 tons of dry manure per year (Wang et al., 2007). Significant portions of animal manure in these counties are used as fertilizers (Basden et al., 1994) on grain crops, grass hay, and pasturelands. When concentrated animal agriculture and $\mathrm{N}$-based manure management occur together, $\mathrm{P}$ saturation and elevated risks to water 
quality are potential outcomes (Beck et al., 2004; Miller et al. 2010). If a given location in these counties received animal manure applications on a $\mathrm{N}$ basis, these locations will accumulate $\mathrm{P}$ as the $\mathrm{P}$ levels on the manures are in excess of plant removal or requirement rates when applied to meet the $\mathrm{N}$ needs of the crops. This should prohibit further manure applications. In the coming years the efforts to reduce the $\mathrm{P}$ saturation of these sites and prevent $\mathrm{P}$ loss will be a greater priority. As such, a greater understanding of the fate of surface applied P on these agricultural lands becomes even more critical.

Historically, most research on P sorption and availability has focused on inorganic sources, with significantly less attention given to organic species of P (Laboski and Lamb, 2003; Anderson and Magdoff, 2005). Some researchers have hypothesized that this is, in part, be due to (i) a perception that $\mathrm{P}_{\mathrm{i}}$ is the dominant form of $\mathrm{P}$, (ii) $\mathrm{P}_{\mathrm{i}}$ is the plant available form, and (iii) the analysis of organic $\mathrm{P}$ is simply too problematic (Jansson et al., 1988; Turner and Haygarth, 2000; Anderson and Magdoff, 2005). Between 29 to $65 \%$ of the total P (Harrison, 1987) and perhaps greater than $90 \%$ of the soil solution phase P could be in an organic form (Helal and Dressler, 1989; Shand et al., 1994; Turner and Haygarth, 2000; Anderson and Magdoff, 2005). Only considering $P_{\mathrm{i}}$ in risk assessment is to potentially overlook a large portion of the total P pool. Such oversight could undermine the conservation and restoration efforts of regulators, the agricultural community, and conservation professionals by invalidating the basic assumptions used in developing their $\mathrm{P}$ loss control strategies.

In terms of $\mathrm{P}$ composition in soil, the $\mathrm{P}_{\mathrm{o}}$ pool is typically composed of inositol phosphates, phospholipids, nucleic acids, phosphoproteins, and unidentified P compounds (Schroeder and Kovar, 2006). To date, the only significant examination of $\mathrm{P}_{\mathrm{o}}$ in West Virginia soils was produced by the West Virginia University Agricultural Experiment Station in the 1960's (Jencks et al., 1964). This research measured total P, total $P_{0}$, phytin, available $P$, organic matter, and $\mathrm{pH}$ in several soils. $P_{0}$ accounted for between 7 and $66 \%$ of the total $\mathrm{P}$ in the surface horizons, and from 13 to $55 \%$ in the subsurface horizons (Jencks et al., 1964). Phytin or phytic acid (an inositol phosphate) accounted for between 13 and $63 \%$ of the total $P$ in the surface horizons, and from 10 to $48 \%$ in the subsurface horizons (Jencks et al., 1964). This corroborates the assertions of others (Harrison, 1987; Helal and Dressler, 1989; Shand et al., 1994; Turner and Haygarth, 2000; Anderson and Magdoff, 2005) that significant portions of the total soil P pool may, in fact, be $P_{0}$. Given any $P$ loss is potentially damaging to the environment, resource managers need a better understanding of how $P_{0}$ responds relative to management, movement, and soil interaction (Condron et al., 2005). 
One way to examine differing $\mathrm{P}$ forms in soil is sequential extraction. There are numerous examples of research that has utilized this technique to separate the total P pool into operational defined fractions (Bowman and Cole 1978; Hedley et al., 1982; Tiessen et al., 1984; Schoenau et al., 1989; Cross and Schlesinger, 1995; lyamuremye et al., 1996; Sui et al., 1999; Guppy et al., 2000; Qian and Schoenau, 2000; Yang et al., 2002; He et al., 2004; Schroeder and Kovar, 2006). A sequential P extraction integrates a collection of chemical extractions so as to characterize $\mathrm{P}$ by the type and strength of their physicochemical interactions with soil components (Bowman and Cole 1978; Hedley et al., 1982; Cross and Schlesinger, 1995). An individual fraction in a sequential extraction is conceptually different but not necessarily pure or unique. The most common extractions used in these sequential fractionations are water $\left(\mathrm{H}_{2} \mathrm{O}\right)$, anion exchange resin, sodium bicarbonate $\left(\mathrm{NaHCO}_{3}\right)$, hydrochloric acid $(\mathrm{HCl})$, and sodium hydroxide (NaOH) (Guppy et al., 2000; Schroeder and Kovar, 2006).

In soil, P extracted with any hydroxide solution is typically bound to Al and Fe (Sharpley et al., 2004). The P extracted with acid is typically bound to Ca (Sharpley et al., 2004). The P extracted with bicarbonate, ion exchange resin, and or $\mathrm{H}_{2} \mathrm{O}$ are characteristically the weakest attached, most labile, and easily exchangeable or plant available forms of $\mathrm{P}$ (Sharpley et al., 2004). The dominant forms of $\mathrm{P}$ in poultry manure (the primary animal manure used in these study areas) are orthophosphate and phytate (Warren et al., 2008). The majority of the $\mathrm{P}$ in poultry liter can be extracted from the manure with $\mathrm{H}_{2} \mathrm{O}$ and $\mathrm{NaHCO}_{3}$ (Codling, 2006; Dou et al., 2000; Dail et al., 2007) due in part to phytate is the principal form of $\mathrm{P}$ in the grain-based diets of non-ruminants being passed along into the feces undigested (Harland and Morris, 1995; Sharpley, 2000). The $\mathrm{P}_{\mathrm{i}}$ percentage is typically highest in the $\mathrm{H}_{2} \mathrm{O}$ extractable fraction (Codling, 2006). However, some reports indicate that $72-83 \%$ of $\mathrm{H}_{2} \mathrm{O}$-extractable $\mathrm{P}$ in poultry manure is in an organic form (Sistani et al., 2001).

Poultry manure can raise $\mathrm{P}, \mathrm{N}$, and Ca levels in soil, as well as elevate the levels of bicarbonates and organic acids with carboxyl and phenolic hydroxyl groups (Sharpley et al., 2004). This provides new reactive surfaces, changes the constitution of the soil solution, and can alter basic chemical properties such as $\mathrm{pH}$ and ionic strength; which can, over time, shift $\mathrm{P}$ from binding with Fe and $\mathrm{Al}$ to binding with Ca (Sharpley et al., 2004). With continued manure application, more and more P ends up in the easily extractable, labile fractions (Blake et al., 2003). Ultimately, the number and type of sorbtive surfaces in the soil determines the fate of $\mathrm{P}$ and how it is described by a sequential extraction procedure (Blake et al., 2003). Accordingly, when analyzing spatial distributions of $P$ across a landscape it is important to consider how changes in soils properties across the landscape could alter the distribution. 
While, in a general sense, $\mathrm{P}$ is limited in its mobility, it can move through soil profiles (Smeck and Runge, 1971; Smeck, 1973; Harman et al. 2013) and across landscapes (Smeck, 1973). Most P loss or movement is attributed to one of two processes-leaching or erosion. Leaching occurs when P from fertilizer or manure moves through the soil into the groundwater or surface water. Erosion losses occur when overland flow moves $\mathrm{P}$ from fertilizer and manures or $\mathrm{P}$ enriched soil materials across the soil surface and into surface waters. $P_{i}$ leaching is generally considered a minimal risk (Anderson and Magdoff, 2005). However, soils receiving large quantities of $P$ fertilizer, deep sandy soils, organic soils, well structure soils, and soils with high rock fragment contents can be at risk of P leaching (Harman et al., 2013; Anderson and Magdoff, 2005). Smeck (1973) and Smeck and Runge (1971) proposed that P can move laterally in a landscape, and will accumulate in lower landscape positions. The more important questions are: do all forms of P move similarly, and are changes in P levels an indication of movement or an indication of changes in soil properties that shift or modify P retention dynamics?

Measured P levels at any location is the product of the soils properties, $\mathrm{P}$ additions over time, and any landscape scale process that could move P over or through the soil. Research on P sorption capacity of riparian wetlands soils has highlighted the importance of changes in soil properties relative to the soils ability to retain P (Bruland and Richardson, 2004). Bruland and Richardson (2004) found significant portion of the variability in $\mathrm{P}$ levels were related to changes in the P sorption capacity. In most instances, within a defined management area such as a hayfield, an attempt to achieve a somewhat uniform application of nutrients over time can be assumed. Thus if one accounts for the effect of changing soil properties across a management area and assume a uniform application of nutrients over time, any pattern in measure $\mathrm{P}$ at that scale must be related to the space itself, or the physical process that are dependent upon that space. Similarly, operational defined $\mathrm{P}$ fractions can have differing characteristics and sorb at differing rates to soil particles (Anderson and Magdoff, 2005). Thus some sequentially extracted $\mathrm{P}$ fractions may be more or less responsive to these spatial effects and manifest some degree of spatial dependence.

One way to measure spatial dependence is the Mantel test (Mantel, 1967). The Mantel test is a permutation-based correlations analysis where one matrix is a difference matrix and the other a distance matrix. A correlation coefficient is calculated between these matrices. The values of distance matrix are randomly reassigned to another location, and the analysis repeated. After many permutations, a distribution of the correlation coefficients is generated. Thus the significance of the correlations can be estimated from the permutated distribution (Bonnet and Van de Peer. 2002). 
A further adaptation of the Mantel test is the partial Mantel test. A partial Mantel test uses three matrices. Rossi (1997) stated, "Once the existence of a relationship between two variables has been demonstrated, one can wonder if it is a true correlation or if it is only a spurious correlation due to common spatial (or temporal) pattern". A partial Mantel test, tests the correlation of two matrices while controlling the effect of a third matrix (Bonnet and Van de Peer, 2002; Smouse et al., 1986). When looking at a P distribution across a landscape, one such spurious correlation could be changes in P sorption capacity via changes in soil properties. The partial Mantel test allows for control for the effect of changes in soil properties while determining if any remaining patterns of spatial dependence exist within the P data.

This research consists of field scale experiments designed to examine the possible movement of sequentially extracted $\mathrm{P}_{\mathrm{o}}$ fractions in typical hay or pasture setting on marginal soil in the poultryproducing region of West Virginia. The purpose of this research is to determine if there is an unidentified spatial component to the field-scale distribution of sequentially extracted $\mathrm{P}_{\mathrm{o}}$ beyond what can be explained by changes in soil properties across the study area.

The first research hypothesis $\left(H 1_{a}\right)$ states that over time sequentially extracted $\mathrm{P}_{\mathrm{o}}$ fractions in typical hay or pasture setting on marginal soil in the poultry-producing region of West Virginia will exhibit spatial dependence among the sequentially extracted $\mathrm{P}_{\mathrm{o}}$ fractions. The null hypothesis $\left(\mathrm{HO}_{\mathrm{a}}\right)$ states that in typical hay or pasture settings on marginal soil in the poultry-producing region of West Virginia will not exhibit spatial dependence among the sequentially extracted $P_{o}$ fractions. The second hypothesis $\left(H 1_{b}\right)$ states that there is spatial dependence among sequentially extracted $\mathrm{P}_{\mathrm{o}}$ fractions after removing potential spatial dependence associated with changes in soil properties. The null hypothesis $\left(\mathrm{HO}_{\mathrm{b}}\right)$ states, states that there is no spatial dependence among sequentially extracted $\mathrm{P}_{\mathrm{o}}$ fractions after removing potential spatial dependence associated with changes in soil properties.

\section{Materials \& Methods}

\section{Site selection and Sampling}

The selected study sites were typical hay or grass pasture fields in eastern West Virginia. The study sites consisted of one set of fertilized locations (High 1 and High 2), with lengthy histories (approximately 10+ yrs.) of annual N-based manure applications and one set of unfertilized locations (Low 1 and Low 2) with very infrequent manure applications (approximately one application every 5-10 yrs.). 
Sample points sere selected in a stratified random design (Thompson et al., 2006), with the strata being the topographic wetness index (TWI) at each location. For all locations, TWI was calculated from a 3-m digital elevation model (DEM) from the WV State Address Mapping Board (SAMB) aerial imagery. All determinations were made from a DEM free of sinks or voids. TWI is defined as the $\ln (A / \tan B)$ where $A$ is the local upslope contributing area for that point and B is the local slope gradient (Beven and Kirkby, 1979). The flow directions used in the TWI calculation was the simplest design. It specifies flow direction from each raster cell into one of the eight neighboring cells based on the steepest downward slope gradient (O'Callaghan and Mark, 1984). Specific catchment area is estimated by $A / L$, with $A$ being the number of pixels draining into a pixel, multiplied by the area of a pixel, and $\mathrm{L}$ is the pixel width (Moore et al., 1991b). At each location TWI was classified into three equal-sized classes based on the TWI score. Ten samples locations were selected at random within each class, for a total of 30 samples locations at each study area. From each sample point the first mineral horizon (surface horizon) and the $10 \mathrm{~cm}$ below that horizon (subsurface horizon) were sampled.

\section{Sample Preparation}

All samples were air dried, ground, sieved (2-mm sieve), and thoroughly mixed to make individual samples as homogenous as possible (Laboski and Lamb, 2003). Dried and ground samples were stored in sealed centrifuge tubes at $4^{\circ} \mathrm{C}$ until one day prior to analysis. All soil samples were analyzed in duplicate.

$\mathrm{pH}$

The $\mathrm{pH}$ of the soil samples was measured as described by Eckert and Sims (1995) in the recommended soil testing procedures for the northeastern United States. A $5 \mathrm{~cm}^{3}$ sample of dried and sieved soil was mixed with $5 \mathrm{~mL}$ of distilled deionized water (DDI), stirred vigorously for 15 seconds and allowed to sit for 30 minutes. The $\mathrm{pH}$ was measured with a calibrated $\mathrm{pH}$ meter. This procedure was then repeated using $0.01 \mathrm{M} \mathrm{CaCl}_{2}$ in place of DDI.

\section{Sequential Fractionation}

This method of sequential P fractionation is based on a suggested modification (Sui et al., 1999) of the Hedley method (Hedley et al., 1982) as described by He et al. (2003). For each sample, $1.0 \mathrm{~g}$ of soil and $25 \mathrm{~mL}$ of extractant was placed in a centrifuge tube in a reciprocal shaker at 180 oscillations per minute for $16 \mathrm{~h}$ at room temperature. The samples were centrifuged for $15 \mathrm{~min}$ at $3500 \mathrm{~g}$ and the supernatant filtered (Whatman No. 2 or equivalent). This process was repeated sequentially with the following extractants: distilled deionized water, $0.5 \mathrm{M} \mathrm{NaHCO}, 0.1 \mathrm{M} \mathrm{NaOH}$, and $1 \mathrm{M} \mathrm{HCl}$. Duplicates of each 
sample were fractionated in this manner. Water, 0.5M NaHCO3, and 0.1M NaOH extracts were acidified and filtered (Whatman No. 2 or equivalent) prior to analysis for $\mathrm{P}_{\mathrm{i}}$.

$P_{i}$ was determined by the ammonium molybdate-ascorbic acid method (Knudsen and Beegle, 1988). The ammonium molybdate-ascorbic acid method is a single reagent orthophosphate colorimetric method. There are two stock solutions: the concentrated ammonium paramolybdate solution and the ascorbic acid solution. The concentrated ammonium paramolybdate solution was made by adding $60 \mathrm{~g}$ of ammonium paramolybdate $\left.\left(\mathrm{NH}_{4}\right)_{6} \mathrm{Mo}_{7} \mathrm{O}_{24} \cdot 4 \mathrm{H}_{2} \mathrm{O}\right)$ to approximately $200 \mathrm{~mL}$ of distilled water in a $1 \mathrm{~L}$ volumetric flask, along with $1.455 \mathrm{~g}$ of antimony potassium tartrate $\left(\mathrm{KSbO} \cdot \mathrm{C}_{4} \mathrm{H}_{4} \mathrm{O}_{6}\right)$. Then $700 \mathrm{~mL}$ of concentrated sulfuric acid was added and the solution was allowed to cool to room temperature, diluted to volume with distilled water, and stored in a dark glass bottle in the refrigerator. The ascorbic acid solution was made by dissolving $132 \mathrm{~g}$ of ascorbic acid in distilled water diluted to $1 \mathrm{~L}$ in a volumetric flask. The single colorimetric working solution was made daily by adding $25 \mathrm{~mL}$ of concentrated ammonium paramolybdate solution to approximately $800 \mathrm{~mL}$ distilled water, with $10 \mathrm{~mL}$ of the ascorbic acid solution and diluting to volume with distilled deionized water in a $1 \mathrm{~L}$ volumetric flask.

To determine P content, $2 \mathrm{~mL}$ of the sample solution was transferred to a test tube with $8 \mathrm{~mL}$ of the colorimetric working solution and mixed thoroughly. After 20 minutes for color development, percent transmittance was read at $882 \mathrm{~nm}$. Total $P\left(P_{t}\right)$ was determined with a Perkin Elmer P4000 Inductively Coupled Plasma Optical Emission Spectrometer (ICP-OES). $\mathrm{P}_{\mathrm{o}}$ was calculated for each fraction as the mathematical difference between the reactive $P_{t}$ and $P_{i}$.

\section{Mehlich-1}

Mehlich-1 is a soil test with a 5:1 ratio of Mehlich-1 solution $\left(0.025 \mathrm{~N} \mathrm{H}_{2} \mathrm{SO}_{4}+0.05 \mathrm{~N} \mathrm{HCl}\right)$ to soil. The mixture is shaken for five minutes on a reciprocating shaker set at a minimum of 180-200 oscillations per minute (Nelson et al., 1953). The extractant is filtered through a medium-porosity filter paper (Whatman No. 2 or equivalent) and analyzed for Al, Ca, Fe, and P content (Nelson et al., 1953). Total P, $\mathrm{Fe}, \mathrm{Al}$ and $\mathrm{Ca}$ levels were determined by ICP-OES.

\section{Total Soil Carbon}

Total soil carbon was measured in a LECO TruSpec CHN elemental analyzer (LECO Corp., St Joseph, MI), where a sample was weighed into foil cups and combusted at $950^{\circ} \mathrm{C}$ and the $\mathrm{CO}_{2}$ gas produced was measured by infrared gas spectrometer (Keene, 2010). 


\section{Particle Size Distribution}

Particle size distribution was determined by the pipette method (Gee and Bauder, 1986), with only A horizon samples pretreated to remove organic matter. Five grams of soil and $25 \mathrm{ml}$ of $\mathrm{H}_{2} \mathrm{O}$ were placed in a tared $250 \mathrm{~mL}$ fleaker with $5 \mathrm{~mL}$ of $\mathrm{H}_{2} \mathrm{O}_{2}$. After the reaction ceased, additional $\mathrm{H}_{2} \mathrm{O}_{2}$ was added until the reactivity stopped and the mixture appeared to be fully oxidized (little reaction and a gleyed appearance). When oxidation of organic $\mathrm{C}$ was complete, the sample and container were oven dried at $90^{\circ} \mathrm{C}$ and reweighed.

The samples were dispersed in sodium hexametaphosphate solution (HMP) overnight on a mechanical shaker, in a solution at a concentration of $0.5 \mathrm{~g} / \mathrm{L} \mathrm{HMP}$. The sample was then made to volume ( $250 \mathrm{ml})$ shaken for 30 seconds, and positioned to allow time for differential settling of the sand and silt size particles, prior to extracting a $25 \mathrm{~mL}$ sample and transferring it into a tared container and dried at $90^{\circ} \mathrm{C}$, cooled, and reweighed. The remaining sample was filtered through a 270-mesh sieve into a tared container and the sand size particles dried at $90^{\circ} \mathrm{C}$, cooled, and reweighed. A blank of the HMP was sampled in the same manner to determine salt content from the HMP. The clay content was calculated from the sample minus the HMP blank. Sand content was calculated from the direct measurement of sieved sand. Silt will be determined mathematically as the difference between the sample mass after any pretreatments and the sum of the sand and clay (Gee and Bauder, 1986).

\section{Statistical Analysis}

The initial characterization of the soil samples from each location began by preforming a multivariate analysis of variance (MANOVA) on the soil test data from each horizon independently to determine if there were significant differences between locations, followed by a Bonferroni corrected one-way analysis of variance (ANOVA) on each soil test parameter. Spatial dependence in the sequentially extracted $\mathrm{P}_{\mathrm{o}}$ data was assessed with Mantel and partial Mantel tests. The Mantel tests (Mantel, 1967) were used to determine if the differences between $\mathrm{P}$ measures and the distances between sample locations were significantly correlated, thus spatially dependent (Bonnet and Van de Peer, 2002). The Mantel test is a permutation based correlations analysis. One matrix was the difference between $\mathrm{P}_{\mathrm{o}}$ values of each pair of points, the other a distance matrix between points. A correlation coefficient was calculated between these matrices. The values on one matrix randomly reassigned to another location, and the analysis repeated. After many permutations, a distribution of the correlation coefficients would be generated. Probabilities would then be estimated based on the data's position within the permutated distribution (Bonnet and Van de Peer. 2002). 
A stepwise regression was used to identify measured soil properties that could explain a significant portion of the variability seen in STP levels. Alpha to enter and leave values of 0.15 were selected and the Mehlich 1 extractable Fe, Al, and Ca; soil carbon; sand, silt, and clay percentages; surface horizon thickness; and $\mathrm{pH}$ in water and in $\mathrm{CaCl}$ for the surface horizon samples were examined. For the subsurface horizon samples, similarly the Mehlich 1 extractable Fe, Al, and Ca; the soil carbon; sand, silt, and clay percentages; surface horizon thickness; $\mathrm{pH}$ in water and in $\mathrm{CaCl}$; and STP levels of the surface horizon samples were examined.

The extension of the Mantel techniques is the partial Mantel test. A partial Mantel test uses more difference or distance matrices. In a partial Mantel test, two variables are compared while fixing for the effect of a third matrix of a third variable or group of variables. Similarly, after permutation the probabilities can be estimated based on the data's position within the generated distribution (Bonnet and Van de Peer. 2002). Accordingly, a two tailed permutation Mantel and partial Mantel tests with 10,000 permutations were performed.

\section{Results and Discussion}

The Mehlich 1 soil test results, $\mathrm{pH}$, particle size distribution, and surface horizon thickness were used to characterize each fertilized and unfertilized location. The MANOVA of the soil test levels was used to determine if there were significant differences between the unfertilized and fertilized locations (Table 3.1). The MANOVA results indicated significant differences $(p \leq 0.001)$ between the soil test values from the surface horizons of the fertilized and unfertilized locations. Similarly, the MANOVA of the subsurface soil test values indicated significant differences $(p \leq 0.001)$ between the fertilized and unfertilized locations (Table 3.2.). This result was explored in further detail by individually examining each soil test parameter via one-way ANOVA using Tukey's multiple comparison procedure to evaluate the significance of the different locations.

The one-way ANOVA of surface soil test $P$ values indicated a significant difference between locations (Table 3.3). The mean soil test P levels ranged from $1020 \mathrm{mg} / \mathrm{L}$ at High 2 to a mean low of $12.9 \mathrm{mg} / \mathrm{L}$ at Low 2 (Table 3.4). The grouping information using Tukey's multiple comparisons procedure identified three groups: (i) High 1, (ii) High 2, and (iii) a group comprised of Low 1 and Low 2 (Table 3.4).

Subsurface STP levels were significantly different between locations (Table 3.3), with values ranging from a high of $982 \mathrm{mg} / \mathrm{L}$ at High 2 to a low of $4.9 \mathrm{mg} / \mathrm{L}$ at Low 1 (Table 3.4). The grouping Information from the Tukey's multiple comparisons procedure followed the same pattern as the STP levels of the 
surface horizon (Table 3.5). The elevated STP levels at the fertilized locations are consistent with Nbased manure applications (Beck et al., 2004) and P translocation into the soil profile (Harman et al., 2013).

The one-way ANOVA of surface and subsurface soil test Ca (STCa) levels indicated a significant difference between locations (see Table 3.3). The mean surface horizon STCa levels ranged from a high of 4170 $\mathrm{mg} / \mathrm{L}$ at High 2 to a low of 745 at Low 2, while mean subsurface STCa levels ranged from $1620 \mathrm{mg} / \mathrm{L}$ at High 1 to $365 \mathrm{mg} / \mathrm{L}$ at Low 2 (Table 3.4). The grouping information for the subsurface STCa levels using the Tukey's multiple comparisons procedure identified three groups: (i) High 1, (ii) High 2, and (iii) a group comprised of Low 1 and Low 2 (Table 3.5) following the same pattern as the surface and subsurface STP levels, and surface STCa levels. Poultry manure can raise $\mathrm{P}, \mathrm{N}$, and Ca levels in soil, as well as elevate the levels of bicarbonates and organic acids with carboxyl and phenolic hydroxyl groups (Sharpley et al., 2004). Based on STP levels, the effects of long term N-based poultry manure applications, and the Tukey groupings it appears the High fertilization locations were managed significantly different from each other, with one receiving more frequent applications leading to higher STP levels.

Soil test Fe and Al (STFe and STAl) results do not follow this pattern. The one-way ANOVA of STAI indicated a significant difference between locations (see Table 3.3). The mean STAI levels ranged from a high of $277 \mathrm{mg} / \mathrm{L}$ at High 2 to a low of 120 at Low 1 (Table 3.4). The grouping information using Tukey multiple comparisons procedure identified three groups. STAl levels at High 1 and Low 2 were not significantly different forming one group while High 2 and Low 1 were significantly different from each other and from High 1 and Low 2 (Table 3.5). The one-way ANOVA of STFe indicated a significant difference between locations (see Table 3.3). The mean soil test Fe levels ranged from a high of 57.2 $\mathrm{mg} / \mathrm{L}$ at Low 1 to a low of 16.1 at High 2 (Table 3.4). The grouping Information from the Tukey multiple comparisons procedure identified two groups. Only Low 1 was significantly different from the other locations (see Table 3.5). This indicates differences in STFe and STAI are not related to management practices, i.e., the differences are pedogenic. However, these differences are potentially important because as soils weather and acidify, the formation of Fe and Al phosphates and $\mathrm{P}_{\mathrm{o}}$ is favored (Smech, 1985; Pierzynski et. al 2005). Thus, differences in concentrations of extractable Fe and Al could impact retention mechanisms.

Changes in $\mathrm{Fe}, \mathrm{Al}$, and $\mathrm{Ca}$ concentrations and soil texture have the potential to be important factors in the translocation of P across a landscape. Specifically, Sharpley et al. (2004) described sequentially 
extracted $\mathrm{P}$ as typically bound to $\mathrm{Al}, \mathrm{Fe}$, and $\mathrm{Ca}$, or weakly attached, most labile, and easily exchangeable. Blake et al. (2003) stated that continued additions of poultry manure would increase the more easily extractable labile fraction of soil P. Additionally it is known that concentrations of various $\mathrm{P}$ fractions can be affected by slope position (Heilmann et al., 2005, Kistner et al., 2013). Thus it seems likely that, even if applied uniformly over a lengthy period of time, $\mathrm{P}$ accumulation and distribution would not remain uniform. As such, there could be patterns in the P distributions related to changes in these properties or changes dependent on the landscape itself. When combined, the physical distances between locations and the significant differences in STP, STFe, STAI, and STCa justifies examining each location independently.

The Mantel test for correlation between dissimilarity matrices was applied to each location for each sequential fraction. In brief, this test identifies significant correlation between dissimilarity matrices of data. The partial Mantel test was applied to examine the data in greater detail. The partial mantel test fixes for the effect of selected data while comparing the correlation of dissimilarity matrices of the other data sets. The identification of a significant correlation between the dissimilarity matrices is an indication of an underlying spatial structure within the data.

To identify other factors that could explain the distribution of $\mathrm{P}$ across the landscape a stepwise regression of the response STP was used for the surface and subsurface horizons and identified multiple properties related to STP levels (Tables 3.6 and 3.7). These properties were fixed while evaluating the correlation between the dissimilarity matrices in sequentially extracted $\mathrm{P}$ fractions using the partial Mantel test. This approach is similar to Bruland and Richardson (2004), who used these techniques to measure partial correlations between soil properties and $\mathrm{P}$ sorption while controlling for the effect of spatial autocorrelation. In this instance the procedure controlled for the effects of soil properties when evaluating the probability of spatial structure in the data. In this example each sequential fraction at each location was examined for spatial autocorrelation. The Mantel tests identified spatial structure among multiple $P_{o}$ fractions (Table 3.8). For any location-sequential fraction combination with identified spatial structure the effects of the select soil properties as identified via stepwise regression were held constant and the remaining variability was examined via the partial Mantel test to determine if the underlying spatial structure was intact. Initial observation of the data seemed to indicate that the locations with the higher STP and the lower STP levels do not behave consistently. Specifically, locations High 1 and High 2 each have $P_{0}$ fractions exhibited spatial structure after fixing for the effects of changing soil properties, but not the same fractions. Management can be an important factor in how $\mathrm{P}$ 
is distributed between sequentially extracted pools. P availability post manure application can be influenced by microbial and chemical properties of the soil, the makeup of the manure, and the complex interactions between these components (Waldrip et al. 2011). Lilientein et al. (2000) determined that changes in landuse strongly influence available $\mathrm{P}$ fractions relative to $\mathrm{Ca}$, Fe, and Al-bounded $\mathrm{P}$ fractions. The location with the highest STP levels shows spatial dependence in the $\mathrm{HCl}$ extracted fraction. Low 2 has a lower mean STP level (approximately $20 \%$ of High 1 ). This location has a significant spatially autocorrelated $\mathrm{NaHCO}_{3}$ extracted fraction. It is not uncommon for $\mathrm{P}$ additions on fertilized pastures to lead to elevated $\mathrm{NaHCO}_{3}$ and $\mathrm{NaOH}$ fractions (Haynes and Williams, 1992) and it is possible due to the higher STP levels at $\mathrm{High} 1$ that the $\mathrm{HCl}$ extractable fraction is behaving as a sink for the more labile $\mathrm{P}$ forms. Specifically, Sharpley et al. (2004) found that long term applications of manures shifted P fractions into the $\mathrm{HCl}$ extractable fractions. Thus it seems likely that there are differing mechanisms of retention between High 1 and High 2.

Similarly, the location Low 1 also exhibited spatial dependence in the $\mathrm{NaHCO}_{3}$ fraction. Waldrip et al. (2011) hypothesized that stable P forms from poultry manure would steadily replenish plant available forms of $\mathrm{P}$ in the soil solution. Additionally, it is known that $\mathrm{NaHCO}_{3}$ extractable $\mathrm{P}_{\mathrm{o}}$ is labile and in some instances is considered plant available (Johnson et al. 2003, Dieter et al. 2010). As a labile to moderately labile fraction it is not unexpected to find spatial differentiation of this $\mathrm{P}$ fraction. However, while there was no statistical difference between the STP levels of the unfertilized plots, there were differences in terms of which extractable fractions exhibited spatial dependence after fixing for the effects of soil properties. At location Low 1 the $\mathrm{NaHCO}_{3}$ extracted fraction was spatially autocorrelated and at Low 2 the $\mathrm{HCl}$ extracted fraction was spatially autocorrelated. This finding is inconsistent with what is expected.

When examining the subsurface horizons data there were no spatially autocorrelated fractions in the High locations. Given the frequency and pedologiclly diverse conditions where preferential flow occurs in pasture of this region (Harman et al., 2011) one would expect to find a great deal of variability in the subsurface data. However, given the elevated STP level of the fertilized sites and the modest depths of the subsurface samples the soil could be more fully saturated than the subsurface samples from the unfertilized locations. Likewise, the number and diversity of fractions exhibiting spatial dependence in the unfertilized location could be a product of preferential flow. In similar pasture soils, Harman et al. (2013) identified $P$ translocation through multiple soil profiles. 


\section{Conclusions}

$P$ availability following manure application can be influenced by the microbial communities and chemical properties of the soil, the makeup of the manure, and any number of complex interactions between these components (Waldrip et al. 2011). Among the chemical properties influencing P availability is soil surface chemistry, reactivity, Fe and Al content, clay content, and pH (Barrow, 1984; Fox, 1985; McGechan and Lewis, 2002). As these soil properties change, the strength of the interactions between $\mathrm{P}$ and the soil changes. The changes in these interactions affects soil solution P concentrations (Brady and Weill, 2002; Blake et al., 2003; Pierzynski et al., 2005). Knowing that $P$ from animal manures is a mixture of $\mathrm{P}$ forms of various solubility (Harland and Morris, 1995; Schroeder and Kovar, 2006; Warren et al., 2008), not all P forms are equally labile (Pierzynski et. al 2005), and concentrations of various P fractions can be affected by slope position (Heilmann et al., 2005; Kistner et al., 2013). The logical conclusion is a differential distribution of all P forms across a landscape.

However, if inferring risk of $P_{0}$ loss from over-fertilized landscapes based in patterns seen in the $P$ distribution, the first step in determining if $P_{o}$ loss and leaching is occurring is identifying how much of the changes in $\mathrm{P}_{\mathrm{o}}$ concentrations are related to soil properties and how much is related to the landscape. Water movement in a landscape is often an indication of the potential P distribution (Smeck and Runge, 1971).

Given the dynamic relationships between the soil, the fertilizers, and the landscape one would assume several specific occurrences within the spatial distribution of $\mathrm{P}_{\mathrm{o}}$. The first logical assumption would be to expect relatively low and or constant levels of water soluble $P_{o}$ due to the transient nature of the pool and constant replenishment from other $\mathrm{P}$ fractions. A second assumption would be the labile but more recalcitrant $\mathrm{NaHCO}_{3}$ extractable $\mathrm{P}$ fractions would potentially be mobile enough to redistribute yet recalcitrant enough to accumulate. As metal oxide sorption sites become saturated with $\mathrm{P}$, the $\mathrm{NaOH}$ extractable fraction would essentially mimic the distribution of metal oxides and be explained by the changes in particle size distribution and the Fe and Al concentrations. Lastly, one would expect the $\mathrm{HCl}$ extractable $\mathrm{P}_{\mathrm{o}}$ fractions should be closely matched to the concentrations of $\mathrm{Ca}$ in the soil.

The data collected was consistent with a sequential saturation of progressively stronger sorption sites. At the fertilized location with the highest STP levels, the variability in the transient and labile fractions were fully explained by the changes in soil properties (Table 3.8). However, the $\mathrm{HCl}$ extracted fraction in this location continued to exhibit spatial dependence beyond that explained by changes in soil 
properties (Table 3.8). It is not uncommon for soils with high levels of $P$ to show evidence of $P$ movement even if the respective P levels in deeper horizons are very low (Nelson, et al., 2005). Similarly, at the fertilized location with lower STP levels, there was variability unexplained by changes in soil properties but it was identified in the more labile fractions (Table 3.8). The location Low 1 also exhibited spatial dependence in theNaHCO3 fraction (Table 3.8). Waldrip et al. (2011) hypothesized that stable P forms from poultry manure would steadily replenish plant available forms of $P$ in the soil solution. Additionally, it is known that $\mathrm{NaHCO}$ extractable $\mathrm{P}_{\mathrm{o}}$ is labile and in some instances is considered as plant available (Johnson et al. 2003, Dieter et al. 2010). While there was no statistical difference between the STP levels of the unfertilized plots (Table 3.5), there were differences in terms of which extractable fractions exhibited spatial dependence after fixing for the effects of soil properties (Table 3.8). At location Low 1 the $\mathrm{NaHCO} 3$ extracted fraction was spatially autocorrelated and at Low 2 the $\mathrm{HCl}$ extracted fraction was spatially autocorrelated (Table 3.8).

At Low 2 several fractions in the subsurface exhibit spatial dependence (Table 3.8). While somewhat unclear as to why, there is obvious evidence of landscape factors leading to $P_{0}$ redistribution. As such it is very apparent there is in fact an unidentified spatial component to the field scale distribution of sequentially extracted $\mathrm{P}_{\mathrm{o}}$ beyond what can be explained by changes in soil properties. In the future, detailed exploratory spatial data analysis and geovisualization techniques could be applied to formulate specific hypotheses related to the apparent spatial structure within this data. While the likely cause of the variability is the landform itself, by examining the data and its structure, it should be possible to develop specific hypothesis related to how pedogenic processes and management factors could contribute to controlling the ultimate distribution of the itinerant $P_{0}$ fractions. These hypotheses, when tested, should be the next step in the progression of identifying spatial significance, determining the cause of that significance, and using that understanding to more efficiently model $\mathrm{P}_{\mathrm{o}}$ distributions across landscapes.

After reviewing the data collected it became apparent spatial dependence among some sequentially extracted $\mathrm{P}_{\mathrm{o}}$ fractions was confirmed at multiple locations, conforming $\left(\mathrm{H} 1_{\mathrm{a}}\right)$. This outcome was in contradiction to $\left(\mathrm{HO}_{\mathrm{a}}\right)$. $\mathrm{H}_{\mathrm{b}}$ states that there is spatial dependence among sequentially extracted $\mathrm{P}_{\mathrm{o}}$ fractions after removing potential spatial dependence associated with changes in soil properties. Likewise $\mathrm{H} 1_{b}$ was confirmed. 


\section{References}

Anderson, B.H. and F.R. Magdoff. 2005. Relative movement and soil fixation of soluble organic and inorganic phosphorus. J. Environ. Qual. 34:2228-2233.

Barrow, N.J. 1984. Modelling the effects of $\mathrm{pH}$ on phosphate sorption by soils. Journal of Soil Science, 35, 283-297.

Basden T., A. Walker, and C. Ritz. 1994. West Virginia Poultry Production Survey: A Report on Implementation of Water Quality Improvement Practices in the Five Eastern Panhandle Poultry Producing Countries. West Virginia University Extension Service, Morgantown, WV.

Beck, M.A., L.W. Zelazny, W.L. Daniels, and G.L. Mullins. 2004. Using the mehlich-1 extract to estimate soil phosphorus saturation for environmental risk assessment. Soil Science Society of America Journal 68:1762-1771.

Beven, K. J. and M.J. Kirkby. 1979. A physically based, variable contributing area model of basin hydrology. Hydrol. Sci. Bull., 24, 43-69.

Blake, L., A.E. Johnston, P.R. Poulton and K.W.T. Goulding. 2003. Changes in soil phosphorus fractions following positive and negative phosphorus balances for long periods. Plant and Soil 254: 245261.

Bonnet, E. and Y. Van de Peer. 2002. ZT: a software tool for simple and partial Mantel tests. J. Statist. Software 7(10): 1-12.

Bowman, R.A., and C.V. Cole. 1978. An exploratory method for fractionation of organic phosphorus from grassland soils. Soil Sci. 125, 95-101.

Brady, N. C., and R.R. Weill. 2002. The Nature and Properties of Soils; Prentice Hall: Englewood Cliffs, NJ.

Bruland, G.L., and C.J. Richardson. 2004. A spatially explicit investigation of phosphorus sorption and related soil properties. J. Environ. Qual. 33:785-794.

Condron, L.M., B.L. Turner, and B.J. Cade-Menun. 2005. The chemistry and dynamics of soil organic phosphorus. p. 87-121. In J.T. Sims and A.N. Sharpley (ed.) Phosphorus: Agriculture and the environment. Agron. Monogr. 46. ASA, CSSA, and SSSA, Madison, WI. 
Cross, A.F., and W.H. Schlesinger. 1995. A literature review and evaluation of the Hedley fractionation: applications to the biogeochemical cycle of soil phosphorus in natural ecosystems. Geoderma 64, 197-214.

Codling, E.E. 2006. Laboratory characterization of extractable phosphorus in poultry litter and poultry litter ash. Soil Sci. Vol. 171 No. 11. 854 - 864.

Dail, H.W., Z. He, M.S. Erich, and C. Wayne. 2007. Effect of drying on phosphorus distribution in poultry manure. Communications in Soil Science and Plant Analysis, 38: 1879-1895.

Dieter, D., H. Elsenbeer, B.L. Turner. 2010. Phosphorus fractionation in lowland tropical rainforest soils in central Panama. Cantena 82, 118-125.

Dou, Z., J.D. Toth, D.T. Galligan, C.F. Ramberg Jr., and J.D. Ferguson. 2000. Laboratory procedures for characterizing manure phosphorus. J. Environ. Qual. 2000, 29, 508-514.

Eckert, D., and J.T. Sims. 1995. Recommended soil pH and lime requirement tests. p. 11-16. In J.T. Sims and A. Wolf (ed.) Recommended soil testing procedures for the northeastern United States. Northeast Regional Bull. 493. Agric. Exp. Stn., Univ. of Delaware, Newark, DE.

Fox, R.L. 1985. External phosphorus requirements of crops. In: Stelly, M., D.M. Kral, and M.K. Cousin (eds). Chemistry of the Soil Environment. 223-259. ASA Special Publ. No. 40. Madison, W.I., U.S.A.

Gee, G.W., and J.W. Bauder. 1986. Particle-size Analysis. p. 383-411. In A. Klute (ed.) Methods of Soil Analysis Part 1. 2nd ed. Agron. Monogr. 9. ASA and SSSA, Madison, WI.

Guppy, C.N., N.W. Menzies, P.W. Moody, B.L. Compton, F.P.C. Blamey. 2000. A simplified, sequential, phosphorus fractionation method. Communications in soil science and plant analysis vol: 31 $1981-1991$.

Harland, B.F., and E.R. Morris. 1995. Phytate- a good or a bad food component. Nutr. Res. 15:733-754.

Harman, M.B., J.A. Thompson, E.M. Pena-Yewtukhiw, L.M. McDonald, and J. Beard. 2011. Preferential flow in pastures on benchmark soils in West Virginia. Soil Science, 176: 509-519.

Harman, M.B., J.A. Thompson, L.M. McDonald, E.M. Pena-Yewtukhiw, J. Beard. 2013. Phosphorus translocation in pastures on benchmark soils in West Virginia. Soil Horizons Vol.54 - No.3. 
Harrison, A.F. 1987. Soil organic phosphorus. A review of world literature. CAB International, Oxon.

Haynes, R. J., P.H. Williams. 1992. Long-term effect of superphosphate on accumulation of soil phosphorus and exchangeable cations on a grazed, irrigated pasture site. Plant Soil 142, $123-$ 133.

He, Z., C. W. Honeycutt, and T. S. Griffin. 2003. Comparative investigation of sequentially extracted phosphorus fractions in a sandy loam soil and a swine manure. Communications in soil science and plant analysis. Vol. 34, Nos. 11 \& 12, pp. 1729-1742.

He, Z., T.S. Griffin, and C.W. Honeycutt. 2004. Evaluation of soil phosphorus transformations by sequential fractionation and phosphatase hydrolysis. Soil Sci. 169:515-527.

Hedley, M.J., J.W.B. Stewart, and B.S. Chauhan. 1982. Changes in inorganic and organic soil phosphorus fractions induced by cultivation practices and by laboratory incubations. Soil. Sci. Soc. Am. J. 46, 970-976.

Heilmann, E., Leinweber, P., Ollesch, G., Meissner, R., 2005. Spatial variability of sequentially extracted P fractions in a silty loam. J. Plant Nutrit. Soil Sci. 168(3), 307-315.

Helal, H.M., and A. Dressler. 1989. Mobilization and turnover of phosphorus in the rhizosphere. Z. Pflanzenernahr. Bodenkunde. 152:175-180.

Iyamuremye, F., R.P. Dick, and J. Baham. 1996. Organic amendments and soil phosphorus dynamics: I. Phosphorus chemistry and sorption. Soil Sci. 161:426-435.

Jansson, M., H. Olsson, and K. Pettersson. 1988. Phosphatase: Origin, characteristics and function in lakes. Hydrobiologia 170:157-175.

Jencks, E.M., J.T. Raese, and C.D. Reese. 1964. Organic phosphorus content of some West Virginia soils. Bulletin of the. West Virginia University Agricultural Experimental Station 489.

Johnson, A.H., Frizano, J., Vann, D.R., 2003. Biogeochemical implications of labile phosphorus in forest soils determined by the Hedley fractionation procedure. Oecologia 135, 487-499.

Keene, T. 2010. Switchgrass establishment and growth for biofuels and carbon sequestration of reclaimed mine lands in Appalachia. M.S, Thesis West Virginia Univ., Morgantown. 
Kistner, I. G. Ollesch, R. Meissner, M. Rode. 2013. Spatial-temporal dynamics of water soluble phosphorus in the topsoil of a low mountain range catchment. Agriculture, Ecosystems and Environment 176 (2013) 24- 38.

Knudsen, D. and D. Beegle. 1988. Recommended phosphorus tests. p. 12-15, In: W.C. Dahnke (ed.) Recommended Chemical Soil Tests Procedures for the North Central Region. Bulletin No. 499 (Revised). North Dakota Agric. Exp. Sta., Fargo, North Dakota.

Laboski, C.A.M., and J.A. Lamb. 2003. Changes in soil test phosphorus concentration after application of manure or fertilizer. Published in Soil Sci. Soc. Am. J. 67:544-554.

Lilientein, J., W. Wilcke, M. A. Ayarza, L. Vilela, S. C. Lima, and W. Zech. 2000. Chemical fractions of phosphorus, sulphur and molybdenum in Brazilian Savannah Oxisols under different land use. Geoderma 96:31-46.

Mantel, N. 1967. The detection of disease clustering and a generalized regression approach. Cancer Res. 27: 209-220.

McGechan, M.B., and D.R. Lewis. 2002. Sorption of phosphorus by soil, part 1: principles, equations and models. Biosystems Engineering 82 (1), 1-24.

Miller, J.C., T. Astatkie, A. Madani. 2010. Soil test phosphorus from livestock manures compared with inorganic fertilizers in soil incubations. Applied and Environmental Soil Science. 2010:1-6.

Moore, I.D., R. B. Grayson and A. R. Ladson. 1991 "Digital terrain modelling: A review of hydrological, geomorphological, and biological applications. Hydrological Processes, 5, 1: pp. 3-30.

Nelson W.L., A. Mehlich, E. Winters. 1953. The development, evaluation, and use of soil tests for phosphorus availability. In: Pierre, W.H., and A.G. Norman. Editors. Soil and fertilizer phosphorus. New York (NY): Academic Press, Inc. (Agronomy monograph series; 4). pp. 153-88.

Nelson, N.O., J.E. Parsons, and R.L. Mikkelson. 2005. Field-scale evaluation of phosphorus leaching in acid sandy soils receiving swine waste. J. Environ. Qual. 34(6): 2024-2035.

O'Callaghan, J. F. and D. M. Mark. 1984. The extraction of drainage networks from digital elevation data. Computer Vision, Graphics and Image Processing. 28: 328-344. 
Pierzynski, G.M., RW McDowell, J.T. Sims. 2005. Chemistry, cycling, and potential movement of inorganic phosphorus in soils. in J.T. Sims and A.N. Sharpley. 2005. Phosphorus: Agriculture and the Environment. Soil Science Society of America. Madison Wisconsin, USA. pp53-87.

Qian, P., and J.J. Schoenau. 2000. Fractionation of $\mathrm{P}$ in soil as influenced by a single addition of liquid swine manure. Can. J. Soil Sci. 80:561-566.

Rossi, J.P. 1996. Statistical tools for soil biology. XI. Autocorrelogram and Mantel test. Eur. J. Soil Biol. 32:4 p 195-203.

Schoenau, J.J., J.W.B. Stewart, and J.R. Bettany. 1989. Forms and cycling of phosphorus in prairie and boreal forest soils. Biogeochemistry 8:223-237.

Schroeder, P.D., and J.L. Kovar. 2006. Comparison of organic and inorganic phosphorus fractions in an established buffer and adjacent production field. Communications in Soil Science and Plant Analysis, 37: 1219-1232.

Shand, C.A., A.E.S. Macklon, A.C. Edwards, and S. Smith. 1994. Inorganic and organic P in soil solutions from three upland soils: I. Effect of soil solution extraction conditions, soil type and season. Plant Soil 159:255-264.

Sharpley, A.N. 2000. Agriculture and phosphorus management: The Chesapeake Bay. Lewis Publishers, Boca Raton, FL. p. 3-5.

Sharpley, A.N., R.W. McDowell, P.J.A. Kleinman. 2004 Amounts, forms, and solubility of phosphorus in soils receiving manure. Soil Sci. Soc. Am. J. 68:2048-2057.

Sistani, K.R., D.M. Miles, D.E. Rowe, G.E. Brink, and S.L. McGowen. 2001. Impact of drying method, dietary phosphorus levels, and methodology on phosphorus chemistry of broiler manure. Communications in Soil Science and Plant Analysis, 32: 2783-2793.

Smeck, N.E. 1973. Phosphorus: and indicator of pedogenetic weathering processes. Soil Sci. 115: 199206.

Smeck, N.E., 1985. Phosphorus dynamics in soils and landscapes. Geoderma, 36:185-199.

Smeck, N.E. and E.C.A. Runge. 1971. Phosphorus availability and redistribution in relation to soil profile development in an Illinois landscape segment. Soil Sci. Soc. Am. Proc. 35: 952-959. 
Smouse P.E., J.C. Long, R.R. Sokal. 1986. Multiple regression and correlation extensions of the Mantel test of matrix correspondence. Systeinatic Zoology, 35, 627-632.

Sui, Y., M.L. Thompson, and C. Shang. 1999. Fractionation of phosphorus in a Mollisol with biosolids. Soil Sci. Soc. Am. J. 63: 1174-1180.

Thompson, J.A. E.M. Pena-Yewtukhiw, J.H. Grove. 2006. Soil-landscape modelling across a physiographic region: Topographic patterns and model transportability. Geoderma 133: pp. 57-70

Tiessen, H, J.W.B. Stewart, C.V. Cole. 1984. Pathways of phosphate transformations in soils of differing pedogenesis. Soil Sci. Soc. Amer. J. 48: 853-858.

Turner, B.L., and P.M. Haygarth. 2000. Phosphorus forms and concentrations in leachate from four grassland soil types. Soil Sci. Soc. Am. J. 64:1090-1097.

USDA-NASS. 2009. 2007 Census of Agriculture West Virginia State and County Data. Vol. 1 Pt. 48. http://www.agcensus.usda.gov/Publications/2007/Full_Report/Volume_1,_Chapter_2_County_ Level/West_Virginia/wvv1.pdf (accessed 24 Jan. 2013).

Warren, J.G., C.J. Penn, J.M. McGrath, K. Sistani. 2008. The impact of alum addition on organic $p$ transformations in poultry litter and litter-amended soil. J. Environ. Qual. 37:469-476.

Waldrip, H.M., Z. He, M.S. Erich. 2011. Effects of poultry manure amendment on phosphorus uptake by ryegrass, soil phosphorus fractions and phosphatase activity. Biol. Fertil. Soils. Volume 47, Issue 4, pp 407-418.

Wang, J., S. Grushecky, J. McNeel. 2007. Biomass resources, uses, and opportunities in West Virginia. West Virginia University Biomaterials and Wood Utilization Research Center. Morgantown West Virginia.

Yang, J.E., C.A. Jones, H.J. Kim, and J.S. Jacobsen. 2002. Soil inorganic phosphorus fractions and Olsen-P in phosphorus-responsive calcareous soils: Effects of fertilizer amount and incubation time. Commun. Soil Sci. Plant Anal. 33:855-871. 


\section{Tables}

Table 3.1 MANOVA for fertility levels surface samples

\begin{tabular}{|c|c|c|c|c|c|}
\hline Criterion & Test Statistic & $\mathrm{F}$ & Numerator & Denominator & $\mathrm{P}$ \\
\hline & & & \multicolumn{2}{|c|}{ Degree Freedom } & \\
\hline Wilks' & 0.43631 & 37.143 & 4 & 115 & $\leq 0.000^{*}$ \\
\hline Lawley-Hotelling & 1.29193 & 37.143 & 4 & 115 & $\leq 0.000^{*}$ \\
\hline Pillai's & 0.56369 & 37.143 & 4 & 115 & $\leq 0.000^{*}$ \\
\hline Roy's & 1.29193 & & & & \\
\hline$s=1$ & & $m=1.0$ & & $N=56.5$ & \\
\hline
\end{tabular}

* indicates $p$ value less than or equal to $0.05, *$ indicates $p$ value less than or equal to 0.10

Table 3.2 MANOVA for fertility levels subsurface samples

\begin{tabular}{|c|c|c|c|c|c|}
\hline Criterion & Test Statistic & $\mathrm{F}$ & Numerator & Denominator & $\mathrm{P}$ \\
\hline & & \multicolumn{4}{|c|}{ Degree Freedom } \\
\hline Wilks' & 0.41976 & 39.742 & 4 & 115 & $\leq 0.000^{*}$ \\
\hline Lawley-Hotelling & 1.38234 & 39.742 & 4 & 115 & $\leq 0.000^{*}$ \\
\hline Pillai's & 0.58024 & 39.742 & 4 & 115 & $0.000 *$ \\
\hline Roy's & 1.38234 & & & & \\
\hline$s=1$ & & $\mathrm{~m}=1.0$ & & $N=56.5$ & \\
\hline
\end{tabular}

* indicates $p$ value less than or equal to $0.05, *$ indicates $p$ value less than or equal to 0.10

Table 3.3 Summary of Bonferroni corrected one-way ANOVA of soil test values

\begin{tabular}{lllll} 
Horizon & STP & STCa & STAI & STFe \\
\hline Surface & $\leq 0.005$ & $\leq 0.005$ & $\leq 0.005$ & $\leq 0.005^{*}$ \\
Subsurface & $\leq 0.005$ & $\leq 0.005$ & $\leq 0.005$ & $\leq 0.005^{*}$
\end{tabular}

* indicates $p$ value less than or equal to $0.05, *$ indicates $p$ value less than or equal to 0.10 


\section{Table 3.4 Descriptive statistics}

\begin{tabular}{|c|c|c|c|c|c|c|}
\hline Variable & Location & $\mathrm{N}$ & Mean & SE Mean & St Dev & Median \\
\hline & High 1 & 30 & 5.85 & 0.342 & 1.87 & 5 \\
\hline Surface Horizon & High 2 & 30 & 9.58 & 0.833 & 4.56 & 9 \\
\hline \multirow[t]{2}{*}{ Thickness } & Low 1 & 30 & 7.17 & 0.254 & 1.39 & 7 \\
\hline & Low 2 & 30 & 4.72 & 0.203 & 1.11 & 4.75 \\
\hline Surface Horizon & High 2 & 30 & 152 & 6.18 & 33.8 & 158 \\
\hline \multirow[t]{3}{*}{ STAI } & Low 1 & 30 & 120 & 4.54 & 24.9 & 117 \\
\hline & Low 2 & 30 & 168 & 7.48 & 41.0 & 163 \\
\hline & High 1 & 30 & 4170 & 229 & 1260 & 3750 \\
\hline Surface Horizon & High 2 & 30 & 1980 & 66.3 & 363 & 1940 \\
\hline \multirow{2}{*}{ STCa } & Low 2 & 30 & 743 & 35.3 & 194 & 715 \\
\hline & High 1 & 30 & 1020 & 58.4 & 320 & 962 \\
\hline Surface Horizon & High 2 & 30 & 229 & 13.4 & 73.6 & 228 \\
\hline \multirow[t]{3}{*}{ STP } & Low 1 & 30 & 15.2 & 1.92 & 10.5 & 12.7 \\
\hline & Low 2 & 30 & 12.9 & 0.985 & 5.39 & 12.1 \\
\hline & High 1 & 30 & 0.248 & 0.005 & 0.0290 & 0.250 \\
\hline Surface Horizon & High 2 & 30 & 0.258 & 0.009 & 0.051 & 0.252 \\
\hline \multirow[t]{2}{*}{ \% Sand } & Low 1 & 30 & 0.412 & 0.026 & 0.1402 & 0.430 \\
\hline & Low 2 & 30 & 0.193 & 0.006 & 0.032 & 0.195 \\
\hline Surface Horizon & High 2 & 30 & 29.4 & 4.90 & 26.8 & 17.6 \\
\hline \multirow[t]{2}{*}{ STFe } & Low 1 & 30 & 16.2 & 1.52 & 8.32 & 14.7 \\
\hline & Low 2 & 30 & 57.2 & 7.29 & 38.6 & 45.3 \\
\hline \multirow{3}{*}{$\begin{array}{c}\text { Subsurface } \\
\text { Horizon }\end{array}$} & High 1 & 30 & 1620 & 62.8 & 344 & 1630 \\
\hline & High 2 & 30 & 3680 & 257 & 1410 & 3020 \\
\hline & Low 1 & 30 & 523 & 35.2 & 193 & 482 \\
\hline STCa & Low 2 & 30 & 365 & 40.9 & 224 & 308 \\
\hline \multirow{4}{*}{$\begin{array}{c}\text { Subsurface } \\
\text { Horizon } \\
\mathrm{pH}\left(\mathrm{CaCl}_{2}\right)\end{array}$} & High 1 & 30 & 5.7 & 0.059 & 0.323 & 5.70 \\
\hline & High 2 & 30 & 5.97 & 0.060 & 0.326 & 6.04 \\
\hline & Low 1 & 30 & 4.97 & 0.043 & 0.234 & 4.98 \\
\hline & Low 2 & 30 & 4.51 & 0.053 & 0.292 & 4.52 \\
\hline \multirow{2}{*}{ Subsurface } & High 1 & 30 & 162 & 8.03 & 43.96 & 148 \\
\hline & High 2 & 30 & 329 & 12.8 & 70.0 & 332 \\
\hline Horizon & Low 1 & 30 & 136 & 6.54 & 35.8 & 126 \\
\hline STAI & Low 2 & 30 & 221 & 18.3 & 100 & 199 \\
\hline \multirow{2}{*}{ Subsurface } & High 1 & 30 & 0.259 & 0.011 & 0.059 & 0.271 \\
\hline & High 2 & 30 & 0.278 & 0.008 & 0.046 & 0.278 \\
\hline Horizon & Low 1 & 30 & 0.428 & 0.021 & 0.115 & 0.475 \\
\hline \% Sand & Low 2 & 30 & 0.208 & 0.007 & 0.038 & 0.211 \\
\hline Subsurface & High 1 & 30 & 18.7 & 0.931 & 5.10 & 18.0 \\
\hline
\end{tabular}




\begin{tabular}{|c|c|c|c|c|c|c|}
\hline Variable & Location & $\mathrm{N}$ & Mean & SE Mean & St Dev & Median \\
\hline Horizon & High 2 & 30 & 26.4 & 5.12 & 28.1 & 15.1 \\
\hline \multirow[t]{3}{*}{ STFe } & Low 1 & 30 & 12.0 & 1.29 & 7.04 & 9.48 \\
\hline & Low 2 & 30 & 43.6 & 5.02 & 26.5 & 35.8 \\
\hline & High 1 & 30 & 2.06 & 0.111 & 0.608 & 2.04 \\
\hline \multirow{2}{*}{$\begin{array}{c}\text { Subsurface } \\
\text { Horizon } \\
\text { \% Carbon }\end{array}$} & Low 1 & 30 & 1.83 & 0.117 & 0.642 & 1.66 \\
\hline & Low 2 & 30 & 1.50 & 0.103 & 0.564 & 1.36 \\
\hline
\end{tabular}

Table 3.5 Summary groupings from one-way ANOVA of soil test values

\begin{tabular}{|c|c|c|c|c|c|}
\hline Horizon & Location & STP & STCa & STAI & STFe \\
\hline \multirow{5}{*}{ Surface } & & Group & Group & Group & Group \\
\hline & High 1 & B & B & B & B \\
\hline & High 2 & A & A & A & B \\
\hline & Low 1 & C & C & C & A \\
\hline & Low 2 & C & C & B & B \\
\hline \multirow{4}{*}{ Subsurface } & High 1 & B & B & C & B \\
\hline & High 2 & A & A & A & $\mathrm{BC}$ \\
\hline & Low 1 & C & C & C & $\mathrm{C}$ \\
\hline & Low 2 & C & C & B & A \\
\hline
\end{tabular}

Treatments with same grouping letter are not significantly different 
Table 3.6 Stepwise regression of soil properties for surface samples with STP as the response, and Mehlich 1 extractable Fe, Al, and Ca; \% soil carbon; \% sand, silt, and clay; surface horizon thickness; and $\mathrm{pH}$ in water and in $\mathrm{CaCl}$ as the predictors

Alpha-to-enter: 0.15 Alpha-to-remove: 0.15 Response is STP, 10 predictors, $n=120$

\begin{tabular}{lllll} 
Step & 1 & 2 & 3 & 4 \\
Constant & -215.2 & -349.5 & -268.7 & -337.6 \\
\hline STCa & 0.2762 & 0.2398 & 0.2464 & 0.2467 \\
T-Value & 34.90 & 23.64 & 23.94 & 24.31 \\
P-Value & $\leq 0.000^{* *}$ & 0.000 & 0.000 & 0.000 \\
\hline STAl & & 1.14 & 0.96 & 1.04 \\
T-Value & 5.08 & 4.13 & 4.48 \\
P-Value & & $\leq 0.000^{* *}$ & 0.000 & 0.000 \\
\hline Thickness & & -8.9 & -9.4 \\
T-Value & & -2.46 & -2.63 \\
P-Value & & & $0.015^{* *}$ & 0.010 \\
\hline \% Sand & & & & 207 \\
T-Value & & & & 2.09 \\
P-Value & & & 118 & $0.038^{* *}$ \\
\hline S & 133 & 121 & 93.13 & 116 \\
R-Sq & 91.17 & 92.77 & 92.95 & 93.38 \\
R-Sq (adj) & 91.09 & 92.64 & 93.15 \\
\hline
\end{tabular}

** indicates $p$ value less than or equal to $0.05, *$ indicates $p$ value less than or equal to 0.10 . The adjusted R-squared compares the explanatory power of regression models. The predicted R-squared indicates how well a regression model predicts responses for new observations. S represents the average distance that the observed values fall from the regression line 
Table 3.7 Stepwise regression of soil properties for subsurface samples with STP as the response, and Mehlich 1 extractable $\mathrm{Fe}, \mathrm{Al}$, and $\mathrm{Ca}$; the soil carbon; sand, silt, and clay percentages; surface horizon thickness; $\mathrm{pH}$ in water and in $\mathrm{CaCl}$; and STP levels of the surface horizon as predictors Alpha-to-enter: 0.15 Alpha-to-remove: 0.15 Response is STP, 11 predictors, $n=120$

\begin{tabular}{|c|c|c|c|c|c|c|c|}
\hline Step & 1 & 2 & 3 & 4 & 5 & 6 & 7 \\
\hline Constant & -18.97 & -56.69 & 367.23 & 187.45 & 139.52 & 80.09 & 98.01 \\
\hline Surface STP & 0.977 & 0.736 & 0.687 & 0.577 & 0.561 & 0.537 & 0.515 \\
\hline T-Value & 56.00 & 13.43 & 13.82 & 10.69 & 10.89 & 10.42 & 9.87 \\
\hline P-Value & $\leq 0.000 * *$ & $\leq 0.000^{* *}$ & $\leq 0.000 * *$ & $\leq 0.000 * *$ & $\leq 0.000 * *$ & $\leq 0.000 * *$ & $\leq 0.000^{* *}$ \\
\hline STCa & & 0.074 & 0.118 & 0.129 & 0.135 & 0.136 & 0.146 \\
\hline T-Value & & 4.60 & 7.20 & 8.26 & 9.06 & 9.28 & 9.50 \\
\hline P-Value & & $\leq 0.000^{* *}$ & $\leq 0.000 * *$ & $\leq 0.000 * *$ & $\leq 0.000 * *$ & $\leq 0.000 * *$ & $\leq 0.000 * *$ \\
\hline $\mathrm{pH}$ in $\mathrm{CaCl}_{2}$ & & & -90 & -67 & -71 & -51 & -50 \\
\hline T-Value & & & -5.56 & -4.11 & -4.60 & -2.92 & 2.90 \\
\hline P-Value & & & $\leq 0.000 * *$ & $\leq 0.000^{* *}$ & $\leq 0.000 * *$ & $0.004^{* *}$ & $0.005^{* *}$ \\
\hline STAI & & & & 0.353 & 0.393 & 0.379 & 0.411 \\
\hline T-Value & & & & 4.03 & 4.69 & 4.59 & 4.95 \\
\hline P-Value & & & & $\leq 0.000^{* *}$ & $\leq 0.000 * *$ & $\leq 0.000 * *$ & $\leq 0.000 * *$ \\
\hline$\%$ Sand & & & & & 199 & 189 & 204 \\
\hline T-Value & & & & & 3.67 & 3.56 & 3.84 \\
\hline P-Value & & & & & $\leq 0.000 * *$ & $0.001^{* *}$ & $\leq 0.000^{* *}$ \\
\hline Thickness & & & & & & -5.2 & -6.1 \\
\hline T-Value & & & & & & -2.35 & -2.74 \\
\hline P-Value & & & & & & $0.021^{* *}$ & $0.007^{* *}$ \\
\hline \% Carbon & & & & & & & -18.5 \\
\hline T-Value & & & & & & & -1.95 \\
\hline P-Value & & & & & & & $0.053 *$ \\
\hline $\mathrm{S}$ & 84.6 & 78.2 & 69.8 & 65.6 & 62.3 & 61.1 & 60.3 \\
\hline $\mathrm{R}-\mathrm{Sq}$ & 96.37 & 96.93 & 97.58 & 97.88 & 98.10 & 98.19 & 98.25 \\
\hline R-Sq (adj) & 96.34 & 96.88 & 97.51 & 97.80 & 98.02 & 98.09 & 98.14 \\
\hline
\end{tabular}

** indicates $p$ value less than or equal to $0.05, *$ indicates $p$ value less than or equal to 0.10 . The adjusted R-squared compares the explanatory power of regression models. The predicted R-squared indicates how well a regression model predicts responses for new observations. S represents the average distance that the observed values fall from the regression line. 
Table 3.8 Mantel and Partial Mantel tests for spatial structure in surface samples

\begin{tabular}{|c|c|c|c|c|c|c|c|c|}
\hline & & & & & & & & \\
\hline \multirow{2}{*}{$\mathrm{DDI} \mathrm{H}_{2} \mathrm{O} \mathrm{P}_{\mathrm{o}}$} & Surface & Subsurface & Surface & Subsurface & Surface & Subsurface & Surface & Subsurface \\
\hline & 0.28047 & 0.65123 & 0.78742 & 0.53695 & 0.89601 & 0.61504 & 0.68513 & 0.33227 \\
\hline \multirow{2}{*}{$0.5 \mathrm{M} \mathrm{NaHCO}_{3} \mathrm{P} 。$} & \multirow{2}{*}{0.41676} & \multirow{2}{*}{0.63874} & 0.02040 & \multirow{2}{*}{0.36716} & 0.00060 & 0.00030 & \multirow{2}{*}{0.75682} & \multirow[t]{2}{*}{0.64454} \\
\hline & & & $0.01940 * *$ & & $0.00170 * *$ & $0.00910 * *$ & & \\
\hline \multirow{2}{*}{$0.1 \mathrm{M} \mathrm{NaOH} \mathrm{P}_{\mathrm{o}}$} & \multirow{2}{*}{0.76712} & \multirow{2}{*}{0.15368} & 0.02620 & \multirow{2}{*}{0.41696} & \multirow{2}{*}{0.69003} & 0.00010 & \multirow{2}{*}{0.95960} & \multirow[t]{2}{*}{0.68943} \\
\hline & & & 0.48215 & & & $0.02640 * *$ & & \\
\hline \multirow{2}{*}{$1.0 \mathrm{M} \mathrm{HCl} \mathrm{P}_{0}$} & 0.03920 & \multirow{2}{*}{0.57274} & \multirow{2}{*}{0.10739} & \multirow{2}{*}{0.13719} & 0.05859 & 0.00290 & 0.01560 & 0.05749 \\
\hline & $0.03790 * *$ & & & & 0.26907 & $0.01270 * *$ & $0.01550 * *$ & 0.36746 \\
\hline
\end{tabular}

Values in bold indicate significant mantel correlations, values identified with ** indicate a significant

$(P \leq 0.05)$ after controlling for the contribution of soil properties identified by stepwise regression. 


\section{Chapter 4. Topographic Influence on the Movement and Transformation of Organic Phosphorus in Hay and Grass Pastures of Eastern West}

\section{Virginia}

\section{Abstract}

This study was conceived to investigate the fate of organic $P\left(P_{o}\right)$ in typical hay and grass pasture of eastern West Virginia following long-term annual applications of animal manure, often on a $\mathrm{N}$ basis. Over the past decade, P management has evolved on many West Virginia farms from N-based manure management towards using tools such as a $\mathrm{P}$ index. At present, many hay and grass pastures in the region have a high degree of $\mathrm{P}$ saturation and, at some locations, additional application may be occurring. As environmental regulations tighten there are expectations that remediation and interception strategies at some locations may be needed. Given that most P research focuses on P loss via surface erosion, on tile drained land, and rarely on $\mathrm{P}_{\mathrm{o}}$ there is a clear deficit in knowledge. The capacity to predict how $\mathrm{P}_{\mathrm{o}}$ moves is a potentially useful tool in evaluating risk of loss and for developing remediating strategies. Sequentially extracted $\mathrm{P}$ fractions derived from spatially explicit samples can be used to better understand $\mathrm{P}_{\mathrm{o}}$ movement at field scales. In this research a Pearson's product-moment correlation matrix was used to determine what, if any, topographic variables were significantly correlated to selected sequentially extracted $P_{0}$ fractions. Stepwise regression was further used to identify variables specific to each location and each fraction. Partial Mantel tests were then used to determine if the remaining variability could be explained. Specifically, it was hypothesized that the pure spatial portion of the variability in sequentially extracted $P_{o}$ fractions could be explained by topographic variables. This only proved to be the case in locations with histories of long-term $\mathrm{N}$-based manure applications. However, identifying explanatory topographic variables can still be a strategic component in developing field-scale predictive models of $\mathrm{P}_{\mathrm{o}}$ distributions that could prove invaluable in risk assessment, remediation, and model development.

\section{Introduction}

Plant nutrients applied in excess of crop removal rates allow some nutrients to accumulate (Sims et al., 2002; Johnson et al., 2005). When concentrated animal agriculture occurs and $P$ is applied at rates in excess of plant needs, the soil becomes saturated with $\mathrm{P}$ and may pose a risk to water quality (Beck et al., 2004). As more fields become saturated with $P$, efforts of lower saturation and prevent $P$ loss may 
become a greater priority. To effectively address this situation, it will require strategies that incorporate topographic data to effectively model field scale P movement.

Conceptually, the idea of relating soil properties to terrain can be traced to the catena concept (Milne 1935) and the belief that soils differentiate in predictable ways along toposequences. This concept was refined by Jenny (1941) who developed the idea of factors of soil formation. Jenny (1941) concluded that soil properties were related to a series of factors: climate, organisms, relief, parent material, and time. In particular, topography directs the movement of water. Jenny (1941) believed relief or topography was responsible the majority of the variability seen in soils at landscape scale. Today, many studies have included topographic elements when modeling soil moisture and other properties (Moore et al., 1991; Hornberger \& Boyer, 1995; Iverson et al., 1997; Famiglietti et al. 1998; Boerner et al., 2000; Gessler et al., 2000; Western et al. 2001; Mohanty and Skaggs 2001; Case et al., 2005). Accordingly, there is reasonable expectation of changes in soil properties directly related to the changes in the mechanistic process that occur differentially across the landform.

When examining P distributions one must consider the possible effects of changing soil properties. If the ability of the soil profile to retain $\mathrm{P}$ is, in part, related to changes in soil properties, then as these properties change so changes the $P$ exchange dynamics of the soil. A soil's ability to retain $P$ is related to the soil surface chemistry, reactivity, Fe and Al content, clay content, and pH (Barrow, 1984; Fox, 1985; McGechan and Lewis, 2002). Over time, management can modify soil properties and, by extension, $\mathrm{P}$ sorption characteristics, which may increase P translocation, through the soil profile (Hao et al., 2008). Specifically, the continual additions of poultry manure shifts $P$ from binding with Fe and Al products to binding with Ca (Sharpley et al., 2004). The soluble nature of some of these Ca-P complexes under some conditions could contribute to potential P translocation within the soil profile (Holford et al., 1997; Siddique and Robinson, 2003). As such, it is critical to consider the variability in soil properties within a management unit when evaluating the mobility of any portion of the $\mathrm{P}$ pool.

Much of the P-soil-environment research has focused on $\mathrm{P}_{\mathrm{i}}$ or total P (Laboski, and Lamb, 2003; Anderson and Magdoff, 2005; Loria and Sawyer, 2005; Casson, et al., 2006; Haden et al., 2007). However, $P_{0}$ is a significant part of the total soil P pool. For example, Jencks et al. (1964) examined various $P$ fractions in a selection of soils across West Virginia and found $P_{0}$ accounted for between 7 and $66 \%$ of the total $P$ in the surface horizons, and from 13 to $55 \%$ in the subsurface horizons. While $P_{i}$ leaching is generally considered of minimal risk, soils receiving large quantities of $P$ fertilizer, sandy soils, organic soils, well structure soils, and soils with high rock fragment content can be at risk of $\mathrm{P}$ leaching 
(Anderson and Magdoff, 2005; Harman et al., 2013). A greater understanding of potential $\mathrm{P}_{\mathrm{o}}$ movement and soil interactions is needed (Condron et al., 2005).

In terms of water movement, it is known that soils with high percentages of rock fragments can rapidly infiltrate to some depth via preferential flow processes (Harman et al. 2011). Likewise, research has shown that in this environment (hay and pasture lands of eastern West Virginia) there is $P$ translocation within the soil profile (Harman et al. 2013). The literature indicates that downslope receiving positions can in some conditions soils test considerably higher for $\mathrm{P}$ than stable upland positions due to the movement of P downslope (Porder et al. 2005). This is consistent with the assertions of Smeck (1973) and Smeck and Runge (1971) when they proposed that P can move latterly within a landscape, and will accumulate in lower landscape positions. This is an indication of the importance of understanding the landscape, water movement, and topographic data.

Quantitative topographic data for use in soil-landscape analysis and modeling is most often obtained from digital elevation models (DEM). These DEM-derived land surface parameters can be classified as primary or secondary (sometimes called compound) terrain attributes (Moore et al., 1991; Thompson et al., 1997; Bishop and Minasny 2006). Using a computer, the most easily estimated primary attributes would include slope gradient, slope aspect, slope curvature, drainage direction, and drainage area (Moore at al. 1991). A complete list of primary terrain attributes was published by Speight $(1974,1980)$. The most common secondary attribute is the topographic wetness index (TWI) (Bishop and Minasny 2006; Grundwald 2006). Secondary attributes are often more useful than primary attributes for predicting soil properties (Bell et al. 1994; Gessler et al., 1995; McBratney et al., 2000; Bishop and Minasny 2006). TWI describes the tendency of a cell to accumulate water (Gruber and Peckham, 2009). TWI is defined as the $\ln (A / \tan B)$ where $A$ is the local upslope contributing area for that point and $B$ is the local slope (Beven and Kirkby, 1979). Up slope contributing area is estimated by a/L, with a being the number of pixels draining into a pixel, multiplied by the area of a pixel, and $L$ as the pixel width (Moore et al., 1991). A similar secondary terrain attribute, stream power index, was developed to be used to describe erosion and related landscape processes, and is defined as A × (tan B) (Moore et al., 1991).

There are many techniques that can be used to determine flow direction and each has the potential to calculate a unique outcome. Flow direction determines flow accumulation, which establishes the upslope contributing area. The earliest and simplest flow direction calculation is the deterministic 8 (D8) of O'Callaghan and Mark (1984). D8 specifies a single flow direction from each raster cell into one of the eight neighboring cells based on the steepest downward slope (O'Callaghan and Mark, 1984). Another 
method is the multiple flow direction (MFD) method (Quinn et al., 1991). MFD divides flow between all down slope cells based on slope gradient (Tarbonton, 1997). A third method, which is a compromise between D8 and MFD, is the deterministic infinity method ( $D \infty$ ) of Tarboton (1997). The D $\infty$ method divides a $3 \times 3$ grid into eight triangular facets, and allocates flow to the steepest direction, where by allocating flow solely to one cell or dividing it based on slope gradient between the cells that define the downslope facet (Tarbonton, 1997).

$P_{\mathrm{o}}$ fractions move through the soil at different rates (Anderson and Magdoff, 2005), and soil P fixation varies with changes in soil properties as soils vary across the landscape (Daniels et al., 2001; Borling et al., 2004; Herlihy and McGrath, 2007). Thus $\mathrm{P}_{\mathrm{o}}$ levels at any location are the product of the soils properties, $\mathrm{P}_{\mathrm{o}}$ additions, $\mathrm{P}_{\mathrm{o}}$ transformations and any landscape-scale process that move $\mathrm{P}$ or soil over or through the landscape. In fact, compound topographic variables have been successfully used to explaining variability in STP data at field scale (Moore et al., 1993). If accepted that water can move $P_{\circ}$ and erode surface soils while statistically accounting for the variability in the $\mathrm{P}_{\mathrm{o}}$ levels associated with changes in soil properties, any residual pattern must be related to space or a physical process dependent upon the configuration of that space such as the movement of water. This necessitates not only the consideration of topographic variables when modeling $P_{0}$ fractions across a landform or management unit, but closer attention to the location of high and low values during data processing.

It is assumed that spatial dependence identified in selected $P_{0}$ fractions not explained by changes in management practices, soil properties or sub field level management units are primarily due to water movement. Thus the research hypothesis (Ha) states: Spatial dependence in sequentially extracted $\mathrm{P}_{\mathrm{o}}$ fractions can be sufficiently explained via compound topographic variables, TWI and SPI such that the remaining variability will be randomly distributed across management units. The null hypothesis (Ho) states with the inclusion of compound topographic variables, TWI and SPI will not render the remaining spatial variability randomly distributed across the management units.

\section{Materials and Methods}

\section{Site Selection}

The study sites were hay or grass pasture fields typical of eastern West Virginia. There were two fertilized locations with histories of annual N-based manure applications (High 1 and High 2), and two unfertilized locations with very infrequent manure applications (Low 1 and Low 2). The unfertilized 
locations typically received manure application approximately once every 5 to $10 \mathrm{yr}$. For more information on the composition of these locations see Table 4.1.

\section{Compound Topographic Indices}

All terrain attributes were calculated from 3-m resolution (DEM) data from United States Geologic Survey (USGS) using SAGA GIS (Bock et al., 2008). The DEM was extracted for each field, and was preprocessed to remove any sinks or voids (Wang and Liu, 2006). From these DEM, three flow direction grids were calculated: A D8 grid (O'Callaghan \& Mark, 1984), a MFD grid (Quinn et al., 1991), and a D grid (Tarboton, 1997). From each of these grids, upslope contributing area grids were developed using the recursive upslope method and then both TWI and SPI grids were created. In addition to these six compound indices (MFD TWI, D8 TWI, D $\infty$ TWI, MFD SPI, D8 SPI, and D $\infty$ SPI), two additional indices were constructed, SAGA wetness index $\left(\mathrm{TWI}_{\mathrm{s}}\right)$ and modified $\mathrm{SPI}\left(\mathrm{SPI} \mathrm{I}_{\mathrm{m}}\right)$. TWI $\mathrm{s}$ uses a modified catchment area calculation to better represent water dispersions in low slope areas (Boehner et al., 2002). SPI $\mathrm{m}_{\mathrm{m}}$ the same SPI calculation but it is generated using the modified catchment area calculation of the $\mathrm{TWI}_{s}$.

\section{Sample Locations}

A stratified random design was used to select sample points (Thompson et al., 2006). The stratification variable was the most basic TWI the D8-based TWI (Moore et al., 1991). Three equal sized TWI classes were specified and ten samples locations were selected randomly within each class. In the field, two soil samples were collected at each sample location: one sample the surface A or Ap horizon and one from the $10 \mathrm{~cm}$ immediately below. Samples were air dried, ground, sieved (2-mm sieve), and thoroughly mixed (Laboski and Lamb, 2003).

\section{Laboratory Methods}

The $\mathrm{pH}$ of the soil samples was measured in distilled deionized water (DDI) and $0.01 \mathrm{M} \mathrm{CaCl}_{2}$ (Eckert and Sims, 1995). Samples were sequential fractioned based on a suggested modification (Sui et al., 1999) of the Hedley method (Hedley, et al., 1982) as described by He et al (2003). Mehlich-1 extractable Al, Ca, Fe, and P content (Nelson et al., 1953) were determined with a Perkin Elmer P4000 Inductively Coupled Plasma Optical Emission Spectrometer (ICP-OES). Particle size distribution was determined by the pipette method (Gee and Bauder, 1986). Total soil carbon was measured in a LECO TruSpec CHN elemental analyzer (LECO Corp., St Joseph, MI), where soil carbon total is measured by dry combustion (Keene, 2010). 


\section{Data Analysis}

Values for all terrain attributes were extracted for each of the sample locations. The combined data was than exported as .DBF files for analysis in Minitab version 16 (Minitab Inc. 2012) and PASSaGes version 2.0 (Rosenburg and Anderson, 2011).

Unforeseen spatial factors can contribute to the data variability. To reduce these likelihood elements of exploratory spatial data analysis (ESDA) and geovisualization (GV) techniques were incorporated to identify spatial outliers and enhance the understanding of this data (ESRI, 2011). ESDA was used to visualize spatial distributions of data and identify potential unforeseen spatial factors leading to atypical locations, spatial clusters, spatial regions, or forms of spatial instability or non-stationary within the data (Anselin 1996, 1998a, 1998b). In brief, the STP levels were analyzed for spatial clusters, particularly hotspots (locations with clusters of high values) using the Getis-Ord Gi* statistic (Getis and Ord, 1992). This analysis examines the Z-scores of the variables relative to the surrounding data points and compared to the entire data set (Mitchell, 2005). When hotspots were identified the aerial images of the locations were reviewed along with the history of the sample locations. If there was a possibility of an external factor contributing to the elevated values, the data in the hot spot was considered a spatial outlier and excluded. Additionally, each location was examined in 2D to determine if there was a need to be subdivided or separated based on the complexity of the landform. Accordingly, the sample points were categorized (as landform units) within each location by any landscape position or change in slope aspect that dramatically inhibits uniform downslope movement of nutrients.

Following the ESDA, any sequentially extracted fraction-horizon-location combinations with spatial outliers were re-examined. Specifically, stepwise regression was used to identify measured soil properties that could explain a significant portion of the variability. Using alpha to enter and leave values of 0.15 the Mehlich 1 extractable Fe, Al, and Ca; soil carbon; sand, silt, and clay percentages; surface horizon thickness; and $\mathrm{pH}$ in water and in $\mathrm{CaCl}$ of the surface horizon samples were examined. For the subsurface horizon samples, the Mehlich 1 extractable $\mathrm{Fe}, \mathrm{Al}$, and $\mathrm{Ca}$; the soil carbon; sand, silt, and clay percentages; surface horizon thickness; $\mathrm{pH}$ in water and in $\mathrm{CaCl}$; and STP levels of the surface horizon samples were examined. Next the data was examined to determine if the data retained a purely spatial component in the data variability. Subsequently all reaming sequentially extracted fractionhorizon-location combinations with a purely spatial component in their data variability were examined in detail. Specifically, compound topographic variables were selected to include in a stepwise regression based on a Pearson's product-moment correlation matrix. S selected soil properties and the compound 
topographic variable with the strongest correlation were entered into a stepwise regression with $p$ values to enter and to remove of 0.05 to determine what if any soil and compound topographic properties explained a significant portion of the data variability.

To examine the role of space in the structure of the data variability, Mantel and partial Mantel tests were used to fix for the effects of soil and topographic variables. The Mantel test is a permutation based correlations analysis with one matrix being the difference between $\mathrm{P}_{\mathrm{o}}$ values of each pair of points, the other a distance matrix between points. A correlation coefficient is calculated between these matrices. The values of one matrix are randomly reassigned to another spatial location, and the analysis repeated. After 10,000 permutations, a distribution of correlation coefficients is generated. Probabilities can be estimated, based on the data's position within the permutated distribution (Bonnet and Van de Peer. 2002). One extension of the Mantel techniques is the partial Mantel test. A partial Mantel test uses more difference or distance matrices. In a partial Mantel test, two variables are compared while fixing for the effect of a third matrices of a third variable or group of variables. Similarly, after permutation the probabilities can be estimated, based on the data's position within the generated distribution (Bonnet and Van de Peer. 2002). Selected sequentially extracted fraction-horizon-location combinations were examined with a series of Mantel tests to determine if the selected sequentially extracted fractionhorizon-location combinations exhibited spatial structure in the data variability after fixing for the effect of soil properties, compound topographic indices, and sub field level delineations.

\section{Results and Discussion}

Of the 32 possible combinations of horizon, location, and sequential extracted $P_{\mathrm{o}}$ fraction examined in chapter 3, seven had significant partial mantel correlations indicating spatial structure beyond that explained by changes in soil properties identified as explaining a significant portion of the variability in STP data (Table 4.1). The next analysis included a review of the data using ESDA techniques. Next each location was examined using the Getis-Ord Gi* technique (Figs. 4.1, 4.2, 4.3 and 4.4), which identified multiple hotspots among the locations. Each hotspot was examined in detail to determine if the hotspots could be attributed to additional management factors.

At location Low 2, it was determined that three sample points (Fig. 4.5) near the entrance to the pasture formed a hotspot potentially associated with land use and management. When viewed against the field imagery, it seemed apparent the two data points located closest to the entrance were potentially spatial outliers. Two of the three data points were very near the entrance. It is possible this location was a 
natural bottleneck in cattle traffic and this location has been used as a winter feeding area. The third data point that made up the hotspot while having a higher STP value, it was farther away from the entrance to the pasture. Thus the two data points nearest the entrance were considered spatial outliers and excluded them from the analysis. When the location was reexamined, it no longer exhibited the underlying spatial dependence noted in chapter 3. Hence moving forward only the remaining six possible combinations of horizon, location, and sequential extracted $\mathrm{P}_{\mathrm{o}}$ fraction were examined.

When reviewed it became apparent there was a need for additional division of the management units (the fields) at each location. At location High 1, it became apparent the field had three distinct regions, a summit position, and a sub field drainage exiting the field midslope. (Fig. 4.6). Sample points were categorized accordingly. Location High 2 also had a complex configuration. At High 2 the field was composed of two basic elements, a very flat footslope and a series of convex and concave backslopes. Most of the data points appeared hydrologically connected (based on the topography) however a sub set of the data that appear to drain away from the majority of the data. Accordingly, the field was into two groups (Fig. 4.7). At location Low 1 the field was composed of four basic elements, a summit, two backslopes and a footslope position. The sample points in the summit drained into one of two backslopes, which converged at the footslope of the landscape. The field was divided into three parts. The first two parts were the two backslopes with the associated points at the summit/shoulder area. The remaining data points at the footslope were grouped together (Fig. 4.8).

Initially, the Pearson product-moment correlations were calculated between the compound topographic indices (Table 4.3) and each of the six unique combination (UC) of horizon-location- $\mathrm{P}_{\mathrm{o}}$ fraction identified in chapter 3 (Table 4.2). Stepwise regression of each UC was used to identify the variables that best explained the $\mathrm{P}_{\mathrm{o}}$ data. Next, partial Mantel tests were used to determine if the soil variables explained all the spatial variability in the data to an extent that it eliminated the correlation of the dissimilarity matrices and void of identifiable spatial structure. The partial Mantel test was performed again fixing for the effect of soil properties and the compound topographic indices with the strongest linear relationship to each UC. Similarly, partial Mantel tests were calculated including a variable of infield division (IFD), and with the combination of compound topographic indices and IFD.

Location Fertilized 1 is a pasture and hay field that has received annual poultry manure applications on a $\mathrm{N}$-basis for more than $30 \mathrm{yr}$. Long-term manure application has been documented to cause total $\mathrm{P}$ concentration in the top $5 \mathrm{~cm}$ to increase as much as 2.8 to 5.5 times (Koopmans et al., 2007). Location Fertilized 1-surface horizon-1.0 M HCl extractable $P_{0}$ fraction has a significant partial Mantel correlation 
indicating an underlying spatial structure within the data (Table 4.1). P fertilization mostly increases the labile and moderately labile inorganic soil P fractions (Oniani et al., 1973; Blake et al., 2003) with minimal effect on $\mathrm{P}_{\mathrm{o}}$ levels except the most labile $\mathrm{P}_{\mathrm{o}}$ fraction, such as the $\mathrm{NaHCO}_{3}$ extractable $\mathrm{P}_{\mathrm{o}}$ fraction (Pätzold 2013). Pedogenic transport processes can govern the distribution and forms of $P$ at field scale (Heilmann et al., 2005). As such, recognizing connectivity within a complex landform is important given significance of movement mechanisms when evaluating P loss and movement (Davies et al 2006). As such the subdivision of data points in to three subsets for analysis seems prudent.

The Mantel correlation from the $1.0 \mathrm{M} \mathrm{HCl}$ extractable $P_{0}$ fraction of Fertilized 1 was $p=0.038$ (Table 4.2). The Pearson's product-moment correlation analysis identified $T W I_{s}$ as the topographic index with the strongest linear relationship to the $1.0 \mathrm{M} \mathrm{HCl}$ extractable $P_{0}$ fraction (see Table 4.3), with a correlation of -0.576 and a $\mathrm{p}$ value $=0.001$. The stepwise regression of 11 predictors $\left(\mathrm{TWI}_{\mathrm{s}}\right.$, horizon thickness, STAl, STFe, STCa, \% Carbon, \% Sand, \% Silt, \% Clay, pH in $\mathrm{H}_{2} \mathrm{O}$ and pH in $0.01 \mathrm{M} \mathrm{CaCl}_{2}$ ) for 1.0M $\mathrm{HCl}$ extracted $\mathrm{P}_{\mathrm{o}}$ identified STCa and $\mathrm{TWI}_{\mathrm{S}}$ as the only predictors that explained a significant portion of the variability (Table 4.4). Poultry manure can raise $\mathrm{P}, \mathrm{N}$, and $\mathrm{Ca}$, levels in soil, as well as elevate the levels of bicarbonates and organic acids with carboxyl and phenolic hydroxyl groups (Sharpley et al., 2004). P bound to Ca can be a significant fraction within some soil (Amaizah et al., 2012). STCa explained $55.9 \%$ of the variability. Together, STCa and $\mathrm{TWI}_{\mathrm{s}}$ explained $61.6 \%$ of the variability in the data. The partial Mantel tests indicated significant spatial structure (Table 4.5) in the $1.0 \mathrm{M} \mathrm{HCl}$ extractable $\mathrm{P}_{\mathrm{o}}$ fraction when fixing for the effects of soil properties ( $p=0.038)$, soil properties with $\operatorname{TWI}_{s}(p=0.037)$, and soil properties with IFD ( $p=0.090)$. When fixed for the effect of STCa, TWI $s$, and IFD, the residuals were no longer spatially autocorrelated $(p=0.133)$ indicating the identifiable patterns of $P$ distribution were likely related to changes in soil properties and water movement / soil moister conditions.

Location Fertilized 2 is a pasture and hay field that has received annual poultry manure applications on a $\mathrm{N}$-basis for more than $30 \mathrm{yr}$. Location Fertilized 2-surface horizon-0.5 $\mathrm{M} \mathrm{NaHCO}_{3}$ extractable $\mathrm{P}_{\mathrm{o}}$ fraction has a significant partial Mantel correlation indicating an underlying spatial structure within the data (Table 4.2). P losses are often driven by fast transport processes such as surface runoff, shallow interflow, and macropore flow in close interaction with $\mathrm{P}$ enriched topsoil layers resulting in high $\mathrm{P}$ concentrations in along these rapid pathways, particularly in permanent grassland with histories of $\mathrm{P}$ accumulation (Schärer et al. 2007). P extracted with $\mathrm{NaHCO}_{3}$ is a labile $\mathrm{P}$ fraction can contribute to the nutrient supply to plants and can be transferred to the surrounding environment by moving through the soil profile (Pizzeghello et al., 2011; Schmitt et al., 2014). 
The Mantel correlation from the $0.5 \mathrm{M} \mathrm{NaHCO}_{3}$ extractable $\mathrm{P}_{\mathrm{o}}$ fraction from the surface horizon of Fertilized 2 was $p=0.019$ (Table 4.2). The Pearson's product-moment correlation analysis identified TWI as the topographic index with the strongest linear relationship to the $0.5 \mathrm{M} \mathrm{NaHCO}_{3}$ extractable $\mathrm{P}_{\mathrm{o}}$ fraction (Table 4.6) with a correlation of 0.450 and a $p$ value $=0.014$. The stepwise regression of 11 predictors $\left(\mathrm{TWI}_{\mathrm{s}}\right.$, horizon thickness, STAI, STFe, STCa, \% Carbon, \% Sand, \% Silt, \% Clay, pH in $\mathrm{H}_{2} \mathrm{O}$, and pH in $0.01 \mathrm{M} \mathrm{CaCl}_{2}$ ) for the $0.5 \mathrm{M} \mathrm{NaHCO}_{3}$ extractable $\mathrm{P}_{\mathrm{o}}$ fraction identified $\mathrm{TWI}_{\mathrm{s}}$ as the only predictor that explained a significant portion of the variability, with $\mathrm{TWI}_{\mathrm{s}}$ explaining $17.26 \%$ of the variability in the data (Table 4.7). While $17.26 \%$ would seem to be a small percentage of the total variability, the compound topographic variable in location High 1 only accounted for $5.7 \%$. While that model accounted for $61.4 \%$. The partial Mantel tests indicated a significant correlation between the dissimilarity matrices (Table 4.5) in the $0.5 \mathrm{M} \mathrm{NaHCO}_{3}$ extractable $\mathrm{P}_{\mathrm{o}}$ fraction when fixing for the effects of $\mathrm{TWI}_{\mathrm{s}}(\mathrm{p}=0.01350)$, and for IFD ( $p=0.09749)$. When fixed for the effect of $T W I_{s}$ and IFD the residuals were no longer exhibited spatial structure $(p=0.12479)$. Any number of factors (slope position, soil order, management, and weather condition) can affect the concentration and proportions of P fractions (Wagar et al., 1986; Heilmann et al., 2005; Negassa and Leinweber, 2009).

The Mantel correlation from the $0.5 \mathrm{M} \mathrm{NaHCO}_{3}$ extractable $\mathrm{P}_{\mathrm{o}}$ fraction from the surface horizon of Unfertilized 1 was $p=0.002$ (Table 4.2). The Pearson's product-moment correlation analysis identified D8 SPI as the topographic index with the strongest linear relationship to the $0.5 \mathrm{M} \mathrm{NaHCO}_{3}$ extractable $P_{0}$ fraction (Table 4.8) with a correlation of 0.341 and $p$ value $=0.065$. The Mantel correlation from the $0.5 \mathrm{M} \mathrm{NaHCO}_{3}$ extractable $P_{\mathrm{o}}$ fraction from the subsurface horizon of Unfertilized 1 was $p=0.00910$ (Table 4.2). In general it is expected to find elevated $\mathrm{NaHCO} 3$ extractable P levels when soils are fertilized (Haynes and Williams, 1992) and the NaHCO3 fraction is labile and under some conditions can be considered plant available (Johnson et al. 2003, Dieter et al. 2010).The Pearson's product-moment correlation analysis identified MFD SPI and $\mathrm{SPI}_{\mathrm{m}}$ as the topographic indices with the strongest linear relationships to the $0.5 \mathrm{M} \mathrm{NaHCO}_{3}$ extractable $\mathrm{P}_{\mathrm{o}}$ fraction (Table 4.8) with a correlation of 0.451 and $p$ value $=0.012$. Given the labile nature of $\mathrm{NaHCO}_{\text {fraction }}$ this was not unexpected.

The Mantel correlation from the $0.1 \mathrm{M} \mathrm{NaOH}$ extractable $P_{\mathrm{o}}$ fraction from the subsurface horizon of Unfertilized 1 was $p=0.026$ (Table 4.1). The Pearson's product-moment correlation analysis identified $\mathrm{TWI}_{\mathrm{s}}$ as the topographic index with the strongest linear relationship to the $0.1 \mathrm{M} \mathrm{NaOH}$ extractable $\mathrm{P}_{\mathrm{o}}$ fraction (Table 4.8) with a correlation of 0.290 and $p$ value $=0.121$. In general, $\mathrm{NaOH}$ extracted organic fractions are immobile sorbed onto clay minerals or precipitated with metals oxides (Gagnon et al. 
2012). As such, under conditions with minimal $\mathrm{P}$ saturation, it is less likely the $\mathrm{NaOH}$ extractable fractions would be strongly correlated with metrics for water movement. However, the Mantel correlation from the $1.0 \mathrm{M} \mathrm{HCl}$ extractable $P_{\mathrm{o}}$ fraction from the subsurface horizon of Unfertilized 1 was $p=0.013$ (Table 4.1). The Pearson's product-moment correlation analysis identified D8 SPI as the topographic index with the strongest linear relationship to the $1.0 \mathrm{M} \mathrm{HCl}$ extractable $\mathrm{P}_{\mathrm{o}}$ fraction (Table 4.8) with a correlation of 0.540 and $p$ value $=0.004$.

$P$ availability following manure application can also be influenced by microbial properties of the soil, the makeup of the manure, and any number of complex interactions between these components (Waldrip et al. 2011). Stepwise regression was used to determine the variables that explained a significant portion of the variability in each fraction-horizon combination with known spatial correlation. The stepwise regression of 11 predictors (TWI, horizon thickness, STAI, STFe, STCa, \% Carbon, \% Sand, \% Silt, \% Clay, $\mathrm{pH}$ in $\mathrm{H}_{2} \mathrm{O}$ and $\mathrm{pH}$ in $0.01 \mathrm{M} \mathrm{CaCl}_{2}$ ) identified horizon thickness as significant for the $0.5 \mathrm{M} \mathrm{NaHCO}_{3}$ extractable $P_{\mathrm{o}}$ fraction from the surface (Table 4.9) and subsurface (Table 4.10) horizons of Unfertilized 1. Likewise, via regression depth of horizon, \% carbon, STAI, STFe, \% silt, and pH that explained significant portions of the variability in the $0.1 \mathrm{M} \mathrm{NaOH}$ extractable $\mathrm{P}_{\mathrm{o}}$ fraction from the subsurface horizon of Unfertilized 1 (Table 4.11) were determined. The more labile nature of some of these Ca-P complexes following long-term manure applications could contribute to potential P translocation within the soil profile (Holford et al., 1997; Siddique and Robinson, 2003). It is believed this is likely due in part to the elevated organic matter concentration, the formation of dissolved organic P species, and colloid mediated transport facilitated by association dissolved organic carbon (Gerke, 1992; Dolfing et al., 1999; Ilg et al., 2005; Koopmans et al 2007). Similarly, horizon depth was the only variable that explained a significant portions of the variability $1.0 \mathrm{M} \mathrm{HCl}$ extractable $P_{\mathrm{o}}$ fraction from the subsurface horizon of Unfertilized 1 (Table 4.12).

\section{Conclusions}

Understanding how topographic variables and sequential extracted $\mathrm{P}_{\mathrm{o}}$ fractions relate is important to the understanding of landscape-scape scale P movement. While P is generally relatively insoluble in soil, considerable movement can occur over time (Smeck, 1973). P inputs elevate labile organic $P$ pools regardless of the type of $\mathrm{P}$ input (Guggenberger et al) and $\mathrm{P}_{\mathrm{o}}$ fractions can be as much as $20-30 \%$ of the total P (Amaizah et al., 2012). The primary objective of this research was to identify an optimal topographic variable to explain the variability in $\mathrm{P}_{\mathrm{o}}$ levels not explained by management practices, changes in soil properties, or sub field level delineations. The relationship between $\mathrm{P}$ fractions and 
environmental loss is related to the susceptibility to runoff and the distance to waterways (Negassa and Leinweber 2009), and reducing elevated P concentrations to more environmentally acceptable levels by cession of $\mathrm{P}$ applications could take decades or more (Dodd et al., 2012). To facilitate an immediate response or reduce imminent loss, the use of these topographic variables could be fundamental to the predictive capabilities needed to identify potential points of $\mathrm{P}$ egress.

The results from the locations with lengthy histories of poultry manure applications were different but explainable. Smeck and Runge (1971) indicated that the distribution of P across a landscape was a good indicator of past water movement. Logically this relationship should prove useful when looking for patterns in $\mathrm{P}$ distribution. Very different behaviors between TWI and the $1.0 \mathrm{M} \mathrm{HCl}$ extractable $\mathrm{P}_{\mathrm{o}}$ fractions (a negative correlation) and the more labile 0.5M NaHCO3 $\mathrm{P}_{\mathrm{o}}$ fraction (positive correlation) at locations with histories of $\mathrm{N}$-based manure applications were identified. One would expect to find the labile $P_{\mathrm{o}}$ fractions will be highest in the lower slope positions (Heilmann et al., 2005) and following continual additions of poultry manure one would expect $\mathrm{P}$ to shift from binding with Fe and $\mathrm{Al}$ to binding with Ca (Sharpley et al., 2004). Additionally, one would expect the soluble nature of some of these Ca-P complexes to be subject to loss relative to water movement (Holford et al., 1997; Siddique and Robinson, 2003). Overall this is what was confirmed. Topography is guiding the distribution and to some extent the composition of the $\mathrm{P}_{\mathrm{o}}$ pool and the determining threshold appears to be relative $\mathrm{P}$ status.

The unfertilized location was very different. The unfertilized location had multiple fractions across the surface and subsurface horizons that contained a pure spatial component in their data structure. The same fractions exhibited differing behaviors between horizons and overall there seems to be no definite trend. Still it is interesting that in situations where $\mathrm{P}$ is scarce and sorption and consumption is expected to render the collective $\mathrm{P}$ distribution somewhat fixed in place, yet some patterns, particularly at depth were still identified. The analysis was able to explain some of these patterns via topographic means. As the unfertilized locations have had poultry manure applications in the past, it could lead one to speculate that these locations may have had significantly higher ST levels at some point in time causing these relict spatial patterns that are not easily interpreted.

Specifically, the research hypothesis $(\mathrm{Ha})$ states: Spatial dependence in sequentially extracted $\mathrm{P}_{\mathrm{o}}$ fractions can be sufficiently explained via compound topographic variables, TWI and SPI such that the remaining variability will be randomly distributed across management units. This only proved to be the case in locations with histories of long-term N-based P applications. Dieter et al. (2010) pointed out that the interpretation of all P fractionation results is complicated and of limited practical utility, however 
there may be significant utility in some fractions at some locations. The null hypothesis (Ho) states with the inclusion of compound topographic variables, TWI and SPI will not render the remaining spatial variability randomly distributed across the management units. Thus $\mathrm{Ha}$ is accepted and Ho rejected.

Ultimately it appears the determining factor in which extractable P fraction is subject to movement and redistribution in accordance with spatially predictable parameters is the degree or level of $\mathrm{P}$ at the location. Additionally, in several instances a purely spatial component in the data variability was identified. These insights lend themselves to speculation about field scale process of $\mathrm{P}_{\mathrm{o}}$ movement. Many soil properties like soil carbon, clay content, and STP have been shown to be strongly correlated with TWI, in particular. As such, it is very likely that TWI alone or in conjunction with a metric for local field-scale P status could directly-and through collinearity with other important variables-explains a significant portion of the spatial variability seen in sequentially extracted $\mathrm{P}_{\mathrm{o}}$ fractions.

Unlike the initial analysis in chapter 3 that sought to identify spatial patterns in sequentially extracted $P$ fractions, this chapter's intent was to go one step further and look for the specific soil properties that explain variability in each of the fraction-location combinations and fully describe the sources of the variability. In doing so it became obvious, water related metrics were capable of modeling the spatial variability in the soils with lengthy histories of fertilization with animal manures, primarily poultry manure. This distinction indicates that these terms could be beneficial for modeling these relationships.

Future research should focus on additional compound topographic variables that could prove useful for modeling $\mathrm{P}_{\mathrm{o}}$ movement, determining the threshold where $\mathrm{P}$ makes the transition from spatial relationships between $0.5 \mathrm{NaHCO}_{3}$ extractable $\mathrm{P}_{\mathrm{o}}$ and soil properties, to $1.0 \mathrm{M} \mathrm{HCl}$ extractable $\mathrm{P}_{\mathrm{o}}$ fractions and $\mathrm{Ca}$ levels in the soil, and selecting optimal metrics for local field scale P assessment. As agricultural fields in similar landscape to those investigated become saturated with $\mathrm{P}$, the ability to predict or model $\mathrm{P}_{\mathrm{o}}$ movement will become critically important, particularly to the poultry producing region of West Virginia. At a minimum, this research supports the use of TWI as a risk assessment tool, and as supporting information for focused remediation. With TWI resource managers could select fields that pose a greater risk for $\mathrm{P}_{\mathrm{o}}$ leaching or movement, and target funding for conservation or remediation efforts. In the years to come as environmental regulations tighten and policies change, the ability to effect meaningful change with minimal resources on an immediate time scale will become a necessity. This sort of soil landscape modeling technique could allow a greater portion of the limited financial resources available to be focused on locations with the greatest potential to pollute and by extension generate the greatest savings per unit of funding. 


\section{References}

Amaizah, N.R., D. Cakmak, E. Saljnikov, G. Roglic, V. Mrvic, R. Krgovic, D. Manojlovic, 2012. Fractionation of soil phosphorus in a long-term phosphate fertilization. J. Serb. Chem. Soc. 77(7):971-981.

Anderson, B.H. and F.R. Magdoff. 2005. Relative movement and soil fixation of soluble organic and inorganic phosphorus. J. Environ. Qual. 34:2228-2233.

Anselin, L. 1996. The Moran scatterplot as an ESDA tool to assess local instability in spatial association. In: Fisher M, Scholten HJ, Unwin D (Eds) Spatial analytical perspectives on GIS. Taylor \& Francis, London

Anselin, L.1998a. Interactive techniques and exploratory spatial data analysis. In: Longley PA, Goodchild MF, Maguire DJ, Wind DW (eds) Geographical information systems: principles, techniques, management and applications. Wiley, New York

Anselin, L. 1998b. Exploratory spatial data analysis in a geocomputational environment. In: Longley PA, Brooks SM, McDonnell R, Macmillan B (Eds) Geocomputational, a primer. Wiley, New York

Barrow, N.J. 1984. Modelling the effects of pH on phosphate sorption by soils. Journal of Soil Science, $35,283-297$.

Beck, M.A., L.W. Zelazny, W.L. Daniels, and G.L. Mullins. 2004. Using the mehlich-1 extract to estimate soil phosphorus saturation for environmental risk assessment. Soil Science Society of America Journal 68:1762-1771.

Bell, J.C., C.A. Butler, J.A. Thompson. 1994. Soil-terrain modelling for site specific agricultural management. In Site specific management for agricultural systems, P.C. Robert, R.H. Rust, W.E. Larson, Eds. ASA-CSSA-SSSA, Madison WI, pp 209-228.

Beven, K. J. and M.J. Kirkby. 1979. A physically based, variable contributing area model of basin hydrology. Hydrol. Sci. Bull., 24, 43-69.

Bishop, T.F.A., and B. Minasny. 2006. Digital soil-terrain modeling: the predictive potential and uncertainty. In: Grunwald, S. (Ed.), Environmental Soil-Landscape Modeling - Geographic Information Technologies and Pedometrics. CRC Press, New York, pp. 185-214. 
Blake, L., A.E. Johnston, P.R. Poulton and K.W.T. Goulding. 2003. Changes in soil phosphorus fractions following positive and negative phosphorus balances for long periods. Plant and Soil 254: 245261.

Bock, M., J. Bohner, O. Conrad, R. Kothe, and A. Ringeler. 2008. SAGA: System for the Automated Geoscientific Analysis. Dept. of Physical Geography, Hamburg, Germany. URL http://www.sagagis.org/en/index.html/ (verified 29 March 2013).

Boehner, J., R. Koethe, O. Conrad, J. Gross, A. Ringeler, T. Selige. 2002. Soil Regionalization by Means of Terrain Analysis and Process Parameterization. In: Micheli, E., Nachtergaele, F., Montanarella, L. [Ed.]: Soil Classification 2001. European Soil Bureau, Research Report No. 7, EUR 20398 EN, Luxembourg. pp. 213-222.

Boerner, R.E.J., Morris, S.J., Sutherland, E.K. \& Hutchinson, T.F. 2000. Spatial variability in soil nitrogen dynamics after prescribed burning in Ohio mixed-oak forests. Landscape Ecology, 15, 425- 439.

Bonnet, E. and Y. Van de Peer. 2002. ZT: a software tool for simple and partial Mantel tests. J. Statist. Software 7(10): 1-12.

Borling, K., E. Otabbong, E. Barberis. 2004. Soil variables for predicting potential phosphorus release in Swedish non calcareous soils. J. Environ. Qual. 33:99-106.

Case, B.S., Meng, F.-R. \& Arp, P.A. 2005. Digital elevation modelling of soil type and drainage within small forested catchments. Canadian Journal of Soil Science, 85, 127-137.

Casson, J.P., D.R. Bennett, S.C. Nolan, B.M. Olson, G.R. Ontkean. 2006. Degree of phosphorus saturation thresholds in manure-amended soils of Alberta. J. Environ. Qual. 35:2212-2221.

Condron, L.M., H. Tiessen. 2005. Interactions of organic phosphorus in terrestrial ecosystems. In: Turner, B.L., Frossard, E., Baldwin, D.S. (Eds.), Inositol Phosphates: Linking Agriculture and the Environment. CAB International, Wallingford, UK, pp. 295-308.

Daniels, M.B., P. Delaune, P.A. Moore, Jr., A. Mauromoustakos, S.L. Chapman, and J.M. Langston. 2001. Soil phosphorus variability in pastures: implications for sampling and environmental management strategies. J. Environ. Qual. 30:2157-2165. 
Davies, P.J., J.W. Cox, N.K. Fleming, W.J. Dougherty, D.M. Nash, J.L. Hutson. 2006. Predicting runoff and phosphorus loads from variable source areas: A terrain-based spatial modelling approach. Journal of Spatial Hydrology Vol.6, No.2.

Dieter, D., H. Elsenbeer, B.L. Tuner. 2010. Phosphorus fractionation in lowland tropical rainforest soils in central Panama. Catena 82 (2010) 118-125.

Dodd, R.J., R.W. McDowell, L.M. Condron. 2012. Predicting the changes in environmentally and agronomically significant phosphorus forms following the cessation of phosphorus fertilizer applications to grassland. Soil Use Manag. 28, 135-147.

Dolfing, J., W.J. Chardon, and J. Japenga. 1999. Association between colloidal iron, aluminum, phosphorus, and humic acids. Soil Sci. 164:171-179.

Eckert, D., and J.T. Sims. 1995. Recommended soil pH and lime requirement tests. p. 11-16. In J.T. Sims and A. Wolf (ed.) Recommended soil testing procedures for the northeastern United States. Northeast Regional Bull. 493. Agric. Exp. Stn., Univ. of Delaware, Newark, DE.

ESRI 2011. ArcGIS Desktop: Release 10.2 Redlands, CA: Environmental Systems Research Institute.

Famiglietti, J. S., J.W. Rudnicki, M. Rodell. 1998. Variability in surface moisture content along a hillslope transect: Rattlesnake Hill, Texas, Journal of Hydrology, 210, 259-281.

Fox, R.L. 1985. External phosphorus requirements of crops. In: Stelly, M., D.M. Kral, and M.K. Cousin (Eds). Chemistry of the Soil Environment. 223-259. ASA Special Publ. No. 40. Madison, W.I., U.S.A.

Gee, G.W., and J.W. Bauder. 1986. Particle-size Analysis. p. 383-411. In A. Klute (ed.) Methods of Soil Analysis Part 1. 2nd ed. Agron. Monogr. 9. ASA and SSSA, Madison, WI.

Gessler, P.E., I.D. Moore, N.J. McKenzie, P.J. Ryan. 1995. Soil-landscape Modelling soil-and spatial prediction of soil attributes. Int. J Geogr. Inf. Syst. 9: 421-432.

Gerke, J. 1992. Orthophosphate and organic phosphate in the soil solution of four sandy soils in relation to $\mathrm{pH}$-evidence for humic-Fe-(Al-) phosphate complexes. Commun. Soil Sci. Plant Anal. 23:601612. 
Gessler, P.E., O.A., Chadwick, F. Chamran, L. Althouse, and K. Holmes. 2000. Modelling soil-landscape and ecosystem properties using terrain attributes. Soil Science Society of America Journal, 64, 2046- 2056.

Getis, A. and J.K. Ord. 1992. The analysis of spatial association by use of distance statistics. Geographical Analysis. 24:3 189-206.

Gruber, S. and S. Peckham. 2009. Land-surface parameters and objects in hydrology. In: Hengl, T., and Reuter H.I. (Eds.): Geomorphometry: concepts, software, applications (Vol. 33). Elsevier Science.

Grunwald, S. (Ed.), 2006. Environmental Soil-landscape Modeling - Geographic Information Technologies and Pedometrics. CRC Press, New York

Guggenberger, G., B.T. Christensen, G.H. Rubaek. 2000. Isolation and characterization of labile organic phosphorus pools in soils from the Askov long-term field experiments. Journal of Plant Nutrition and Soil Science. Vol. 163, No. 2: 151-155.

Haden, V.R., Q.M. Ketterings, J.E. Kahabka. 2007. Factors affecting change in soil test phosphorus following manure and fertilizer application. Soil Sci. Soc. Am. J. 71:1225-1232.

Hao, X., F. Godlinski, C. Chang. 2008. Distribution of phosphorus forms in soil following long-term continuous and discontinuous cattle manure applications. Soil Sci. Soc. Am. J. 72:90-97.

Harman, M.B., J.A. Thompson, E.M. Pena-Yewtukhiw, L.M. McDonald, and J. Beard. 2011. Preferential flow in pastures on benchmark soils in West Virginia. Soil Science, 176: 509-519.

Harman, M.B., J.A. Thompson, L.M. McDonald, E.M. Pena-Yewtukhiw, J. Beard. 2013. Phosphorus translocation in pastures on benchmark soils in West Virginia. Soil Horizons Vol.54 - No.3.

He, Z., C. W. Honeycutt, and T. S. Griffin. 2003. Comparative investigation of sequentially extracted phosphorus fractions in a sandy loam soil and a swine manure. Communications in soil science and plant analysis. Vol. 34, Nos. 11 \& 12, pp. 1729-1742.

Hedley, M.J., J.W.B. Stewart, and B.S. Chauhan. 1982. Changes in inorganic and organic soil phosphorus fractions induced by cultivation practices and by laboratory incubations. Soil. Sci. Soc. Am. J. 46, 970-976. 
Heilmann, E., P. Leinweber, G. Ollesch, R. Meissner. 2005. Spatial variability of sequentially extracted P fractions in a silty loam. J. Plant Nutrit. Soil Sci. 168(3): 307-315.

Herlihy, M., D. McGrath. 2007. Phosphorus fractions and adsorption characteristic in grassland soils of varied soil phosphorus status. Nutrient Cycling in Agroecosystems. 77:15-27.

Holford, I.C.R., C. Hird, and R. Lawrie. 1997. Effects of animal effluents on the phosphorus sorption characteristics of soils. Aust. J. Soil Res. 35:365-374.

Hornberger, G.M. \& Boyer, E.W. 1995. Recent advances in watershed modelling. Review of Geophysics, 33, 949-957.

Ilg, K., J. Siemens, and M. Kaupenjohann. 2005. Colloidal and dissolved phosphorus in sandy soils as affected by phosphorus saturation. J. Environ. Qual. 34:926-935.

Iverson, L.R., Dale, M.E., Scott, C.T. \& Prasad, A. 1997. A GIS-derived integrated moisture index to predict forest composition and productivity of Ohio forests (U.S.A). Landscape Hydrology, 12, 331-348.

Jencks, E.M., J.T. Raese, and C.D. Reese. 1964. Organic phosphorus content of some West Virginia soils. Bulletin of the. West Virginia University Agricultural Experimental Station 489.

Jenny, H., 1941. Factors of Soil Formation, A System of Quantitative Pedology. Dover publications, New York.

Johnson, A.M., D.L. Osmond, and S.C. Hodges. 2005. Predicted impact and evaluation of North Carolina's phosphorus indexing tool. J. Environ. Qual. 34:1801-1810.

Keene, T. 2010. Switchgrass establishment and growth for biofuels and carbon sequestration of reclaimed mine lands in Appalachia. M.S, Thesis West Virginia Univ., Morgantown.

Koopmans, G. F., W. J. Chardon, and R. W. McDowell. 2007. Phosphorus movement and speciation in a sandy soil profile after long-term animal manure applications. J. Environ. Qual. 36:305-315.

Laboski, C.A.M., and J.A. Lamb. 2003. Changes in soil test phosphorus concentration after application of manure or fertilizer. Published in Soil Sci. Soc. Am. J. 67:544-554.

Loria, E.R., J.E. Sawyer. Extractable soil phosphorus and inorganic nitrogen following application of raw and anaerobically digested swine manure. Agron. J. 97:879-885. 
McBratney, A. B., M.L. Mendonca Santos, B. Minasny. 2003. On digital soil mapping. Geoderma 117, 352.

McBratney, A.B., I.O.A. Odeh, T.F.A. Bishop, M.S. Dunbar, T.M. Shatar. 2000. An overview of pedometric techniques for use in soil survey. Geoderma 97: 293-327.

McGechan, M.B., and D.R. Lewis. 2002. Sorption of phosphorus by soil, part 1: principles, equations and models. Biosystems Engineering 82 (1), 1-24.

Milne, G., 1935. Some suggested units of classification and mapping particularly for East African soils. Soil Res. 4, 183-198.

Minitab Inc. 2012. Minitab 16 Statistical Software. State College, PA (www.minitab.com)

Mitchell, A. 2005. The ESRI guide to GIS analysis: Spatial measurements and statistics (Vol. 2). Redlands, CA: ESRI Press.

Mohanty, B. P., and T. H. Skaggs. 2001. Spatio-temporal evolution and time-stable characteristics of soil moisture within remote sensing footprints with varying soil, slope, and vegetation. Advances in Water Resources. 24. 1051-1067.

Moore, I.D., R. B. Grayson and A. R. Ladson. 1991 "Digital terrain modelling: A review of hydrological, geomorphological, and biological applications. Hydrological Processes, 5, 1: pp. 3-30.

Moore, I.D., P.E. Gessler, G.A. Nielsen, G.W. Peterson. 1993. Soil attribute prediction using terrain analysis. Soil Science Society of America Journal 57, 443- 452.

Negassa, W., and P. Leinweber. 2009. How does the Hedley sequential phosphorus fractionation reflect impacts of land use and management on soil phosphorus: a review. J Plant Nutr. Soil Sci. 172:305-325.

Nelson W.L., A. Mehlich, E. Winters. 1953. The development, evaluation, and use of soil tests for phosphorus availability. In: Pierre, W.H., and A.G. Norman. Editors. Soil and fertilizer phosphorus. New York (NY): Academic Press, Inc. (Agronomy monograph series; 4). pp. 153-88.

O'Callaghan, J. F. and D. M. Mark. 1984. The extraction of drainage networks from digital elevation data. Computer Vision, Graphics and Image Processing. 28: 328-344. 
Oniani, O.G., M. Chater, G. E. G. Mattingly. 1973. Some effects of fertilizers and farmyard manure on the organic phosphorus in soils. J. Soil Sci. 24, 1-9.

Pätzold, S., M. Hejcman, J. Barej, J. Schellberg. 2013. Soil phosphorus fractions after seven decades of fertilizer application in the Rengen Grassland Experiment. J. Plant Nutr. Soil Sci. Vol. 176, No. 6: 910-920.

Pizzeghello, D., A. Berti, S. Nardi, F. Morari. 2011. Phosphorus forms and P-sorption properties in three alkaline soils after long-term mineral and manure applications in north-eastern Italy. Agriculture, Ecosystems and Environment, v.141, p.58-66.

Porder, S., G.P. Asner, and P.M. Vitousek, 2005. Ground-based and remotely sensed nutrient availability across a tropical landscape, Proceedings of the National Academy of Sciences of the United States of America, 102 (31):10909-10912

Quinn, P., K. Beven, P. Chevallier, and O. Planchon. 1991. The prediction of hillslope flow paths for distributed hydrological modeling using digital terrain models, Hydrol. Proc., 5, 59-80.

Rosenberg, M.S., and C.D. Anderson. 2011. PASSaGE: Pattern Analysis, Spatial Statistics, and Geographic Exegesis. Version 2. Methods in Ecology and Evolution 2(3):229-232.

Schärer, M., C. Stamm, T. Vollmer, E. Fossard, A. Oberson, H. Fluhler, S. Sinaj. 2007. Reducing phosphorus losses from over-fertilized grassland soils proves difficult in the short term. Soil Use and Management, 23 (Suppl. 1), 154-164.

Schmitt, D.E., L.C. Gatiboni, E. Girotto., F. Lorensini, G.W.B. Melo, G. Brunetto. 2014. Phosphorus fractions in the vineyard soil of the Serra Gaucha of Rio Grande do Sul, Brazil. R. Bras. Eng. Agríc. Ambiental, Vol.18 No. 2: 134-140.

Sharpley, A.N., R.W. McDowell, P.J.A. Kleinman. 2004. Amounts, forms, and solubility of phosphorus in soils receiving manure. Soil Sci. Soc. Am. J. 68:2048-2057.

Siddique, M.T., and J.S. Robinson. 2003. Phosphorus sorption and availability in soils amended with animal manures and sewage sludge. J. Environ. Qual. 32:1114-1121. 
Sims, J.T., R.O. Maguire, A.B. Leytem, K.L. Gartley, and M.C. Pautler. 2002. Evaluation of Mehlich-3 as an agri-environmental soil phosphorus test for the mid-Atlantic United States of America. Soil Sci. Soc. Am. J. 66:2016-2032.

Smeck, N.E. 1973. Phosphorus: and indicator of pedogenetic weathering processes. Soil Sci. 115: 199206.

Smeck, N.E. and E.C.A. Runge. 1971. Phosphorus availability and redistribution in relation to soil profile development in an Illinois landscape segment. Soil Sci. Soc. Am. Proc. 35: 952-959.

Speight, J.G. 1974. A parametric approach to landform regions. Special Publication Institute of British Geographers. 7: 213-230.

Speight, J.G. 1980. The role of topography in controlling throughflow generation: a discussion. Earth Surface Processes and Landforms. 5: 187-191.

Sui, Y., M.L. Thompson, and C. Shang. 1999. Fractionation of phosphorus in a Mollisol with biosolids. Soil Sci. Soc. Am. J. 63: 1174-1180.

Tarboton, D.G. 1997. A new method for the determination of flow directions and upslope areas in grid digital elevation models. Water Resource Research. Vol.33, No.2 pp. 309-319.

Thompson, J.A. E.M. Pena-Yewtukhiw, J.H. Grove. 2006. Soil-landscape modeling across a physiographic region: Topographic patterns and model transportability. Geoderma 133: pp. 57-70

Wagar, B.I., J.W.B. Stewart, and J.L. Henry. 1986. Comparison of single large broadcast and small annual seed-placed phosphorus treatments on yield and phosphorus and zinc content of wheat on Chernozemic soils. Can. J. Soil Sci. 66:237-248.

Waldrip, H.M., Z. He, M.S. Erich. 2011. Effects of poultry manure amendment on phosphorus uptake by ryegrass, soil phosphorus fractions and phosphatase activity. Biol. Fertil. Soils 47:407-418.

Wang, L. \& H. Liu. 2006. An efficient method for identifying and filling surface depressions in digital elevation models for hydrologic analysis and modelling. International Journal of Geographical Information Science, Vol. 20, No. 2: 193-213.

Western A., G. Bloschl and R. Grayson. 2001. Toward capturing hydrologically significant connectivity in spatial patterns, Water Resources Research, 37, 83-97, 2001. 


\section{Tables}

Table 4.1Soil Map Units by Study Site

\begin{tabular}{|c|c|c|c|c|}
\hline Location & Map Unit Name & Slope Range & Acres & Percent Total \\
\hline \multirow[t]{3}{*}{ High 1} & Berks-Weikert channery silt loams & $8-15 \%$ & 4.7 & 44.9 \\
\hline & Berks-Weikert channery silt loams & $15-25 \%$ & 5.5 & 51.8 \\
\hline & Berks-Weikert channery silt loams & $25-55 \%$ & 0.3 & 3.3 \\
\hline \multirow[t]{4}{*}{ High 2} & Berks channery silt loam & $8-15 \%$ & 1.4 & 21.4 \\
\hline & Berks-Weikert channery silt loams & $22-55 \%$ & 1.1 & 17.3 \\
\hline & Ernest silt loam & $3-8 \%$ & 2.9 & 46.1 \\
\hline & Lobdell loam & $0-3 \%$ & 1.0 & 15.2 \\
\hline \multirow[t]{2}{*}{ Low 1} & Blackthorn channery sandy loam & $8-15 \%$ & 8.6 & 85.8 \\
\hline & Toms silt loam & $3-8 \%$ & 1.4 & 14.2 \\
\hline \multirow[t]{2}{*}{ Low 2} & Berks-Weikert channery silt loams & $15-25 \%$ & 1.2 & 23.1 \\
\hline & Berks-Weikert channery silt loams & $25-55 \%$ & 4.2 & 76.6 \\
\hline
\end{tabular}

Table 4.2 Location - horizon - fraction combinations with a significant spatial component to the data variability

\begin{tabular}{|c|c|c|c|c|c|c|c|c|c|}
\hline Location \& & Fertilized 1 & Fertilized 2 & Unfertilized 1 & Unfertilized 1 & Unfertilized & \multicolumn{2}{|c|}{ Unfertilized } & \multicolumn{2}{|c|}{ Unfertilized } \\
\hline Horizon* & Surface & Surface & Surface & Subsurface & 1 Subsurface & 1 Subs & rface & \multicolumn{2}{|c|}{2 Surface } \\
\hline $\mathrm{P}_{\mathrm{o}}$ Fraction & $1.0 \mathrm{M} \mathrm{HCl}$ & $0.5 \mathrm{M} \mathrm{NaHCO} 3$ & 0.5 M NaHCO3 & $0.5 \mathrm{M} \mathrm{NaHCO} 3$ & $0.1 \mathrm{M} \mathrm{NaOH}$ & $1.0 \mathrm{M}$ & $\mathrm{HCl}$ & $1.0 \mathrm{M}$ & $\mathrm{HCl}$ \\
\hline Two-tailed p & 0.038 & 0.019 & 0.002 & 0.009 & 0.026 & \multicolumn{2}{|c|}{0.013} & \multicolumn{2}{|c|}{$0.016 * *$} \\
\hline
\end{tabular}


significantly related to STP data. ${ }^{* *}$ After removing spatial outliers this location - horizon - fraction combination was no longer spatially significant. 
Table 4.3 Pearson's product-moment correlation matrix for sequential extracted $\mathrm{P}_{\mathrm{o}}$ fractions from location Fertilized 1

\begin{tabular}{|c|c|c|c|c|c|c|c|c|}
\hline & $1.0 \mathrm{M} \mathrm{HCl}$ & MFD TWI & MFD SPI & $\mathrm{D} \infty \mathrm{TWI}$ & $\mathrm{D} \infty \mathrm{SPI}$ & D8 TWI & D8 SPI & $\mathrm{TWI}_{\mathrm{s}}$ \\
\hline \multirow{2}{*}{ MFD TWI } & 0.071 & & & & & & & \\
\hline & 0.710 & & & & & & & \\
\hline \multirow{2}{*}{ MFD SPI } & -0.345 & -1.519 & & & & & & \\
\hline & $0.062 * *$ & $0.003^{* *}$ & & & & & & \\
\hline \multirow{2}{*}{ D $\infty$ TWI } & 0.054 & 0.997 & -0.505 & & & & & \\
\hline & 0.778 & $0.000 * *$ & $0.004^{* *}$ & & & & & \\
\hline \multirow{2}{*}{$\mathrm{D} \infty \mathrm{SPI}$} & -0.338 & -0.490 & 0.988 & -0.472 & & & & \\
\hline & $0.068^{*}$ & $0.006 * *$ & $0.000 * *$ & $0.008^{* *}$ & & & & \\
\hline \multirow{2}{*}{ D8 TWI } & 0.060 & 0.973 & -0.468 & 0.971 & -0.441 & & & \\
\hline & 0.752 & $0.000 * *$ & $0.009 * *$ & $0.000 * *$ & $0.015^{* *}$ & & & \\
\hline \multirow{2}{*}{ D8 SPI } & -0.374 & -0.482 & 0.990 & -0.467 & 0.989 & -0.427 & & \\
\hline & 0.042 & $0.007^{* *}$ & $0.000^{* *}$ & $0.009 * *$ & $0.000^{* *}$ & $0.019 * *$ & & \\
\hline \multirow{2}{*}{$\mathrm{TWI}_{\mathrm{s}}$} & -0.576 & -0.020 & 0.522 & -0.001 & 0.504 & 0.012 & 0.509 & \\
\hline & $0.001^{* *}$ & 0.914 & $0.003^{* *}$ & 0.994 & $0.005^{* *}$ & 0.950 & $0.004^{* *}$ & \\
\hline \multirow{2}{*}{$\mathrm{SPI}_{\mathrm{m}}$} & -0.345 & -0.521 & 1.000 & -0.507 & 0.988 & -0.470 & 0.990 & 0.524 \\
\hline & $0.062^{*}$ & $0.003^{* *}$ & $0.000 * *$ & $0.004 * *$ & $0.000 * *$ & $0.009 * *$ & $0.000 * *$ & $0.003^{* *}$ \\
\hline
\end{tabular}

** indicates $p$ value less than or equal to $0.05, *$ indicates $p$ value less than or equal to 0.10 
Table 4.4 Stepwise regression of surface horizon from location Fertilized 1 with 1.0M HCl extracted $\mathrm{P}_{\mathrm{o}}$ as the response and Mehlich 1 extractable $\mathrm{Fe}, \mathrm{Al}$, and Ca; the soil carbon; sand, silt, and clay percentages; surface horizon thickness; $\mathrm{pH}$ in water and in $\mathrm{CaCl}$; and $\mathrm{TWI}_{\mathrm{s}}$ as the predictors

\begin{tabular}{|c|c|c|}
\hline Step & 1 & 2 \\
\hline Constant & -259 & 2900 \\
\hline STCa & 0.504 & 0.370 \\
\hline T-Value & 6.14 & 3.83 \\
\hline P-Value & $\leq 0.000 * *$ & $0.001 * *$ \\
\hline $\mathrm{TWI}_{\mathrm{s}}$ & & -505 \\
\hline T-Value & & -2.27 \\
\hline P-Value & & $0.031^{* *}$ \\
\hline $\mathrm{S}$ & 560 & 518 \\
\hline $\mathrm{R}-\mathrm{Sq}$ & 57.4 & 64.2 \\
\hline R-Sq (adj) & 55.9 & 61.6 \\
\hline \multicolumn{3}{|c|}{ Alpha to enter or remove $=\mathrm{P} \leq 0.05$ Response $=1.0 \mathrm{M} \mathrm{HCl}$ extracted $\mathrm{P}_{0}$, predictors $=11, \mathrm{n}=30$} \\
\hline \multirow{2}{*}{\multicolumn{3}{|c|}{$\begin{array}{l}* * \text { indicates } p \text { value less than or equal to } 0.05, * \text { indicates } p \text { value less than or equal to } 0.10 . \text { The } \\
\text { adjusted R-squared compares the explanatory power of regression models. The predicted R-square }\end{array}$}} \\
\hline & & \\
\hline \multicolumn{3}{|c|}{ indicates how well a regression model predicts responses for new observations. S represents the } \\
\hline
\end{tabular}


Table 4.5 Mantel and partial Mantel correlations all unique combinations with a spatial component in the data variability

\begin{tabular}{|c|c|c|c|c|c|c|c|c|}
\hline \multicolumn{2}{|c|}{ Location \& Horizon } & $\begin{array}{c}\text { Fertilized } 1 \\
\text { Surface }\end{array}$ & $\begin{array}{c}\text { Fertilized } 2 \\
\text { Surface }\end{array}$ & $\begin{array}{c}\text { Unfertilized } 1 \\
\text { Surface }\end{array}$ & \multicolumn{2}{|c|}{$\begin{array}{l}\text { Unfertilized } 1 \\
\text { Subsurface }\end{array}$} & $\begin{array}{l}\text { Unfertilized } 1 \\
\text { Subsurface }\end{array}$ & $\begin{array}{l}\text { Unfertilized } 1 \\
\text { Subsurface }\end{array}$ \\
\hline \multicolumn{2}{|l|}{ Po Fraction } & $1.0 \mathrm{M} \mathrm{HCl}$ & $\begin{array}{c}0.5 \mathrm{M} \\
\mathrm{NaHCO} 3\end{array}$ & $0.5 \mathrm{M} \mathrm{NaHCO} 3$ & \multicolumn{2}{|c|}{$0.5 \mathrm{M} \mathrm{NaHCO} 3$} & $0.1 \mathrm{M} \mathrm{NaOH}$ & $1.0 \mathrm{M} \mathrm{HCl}$ \\
\hline $\begin{array}{l}\text { Stepwise select } \\
(P \leq 0.05)\end{array}$ & variables & $\begin{array}{l}\text { STCa } \\
\mathrm{TWI}_{\mathrm{s}}\end{array}$ & $\mathrm{TWI}_{\mathrm{s}}$ & $\begin{array}{l}\text { Horizon } \\
\text { Thickness }\end{array}$ & \multicolumn{2}{|c|}{ Depth to Horizon } & $\begin{array}{c}\text { Depth to } \\
\text { Horizon, \%C, } \\
\text { STAl, STFe, } \\
\text { \%Silt, pH }\end{array}$ & $\begin{array}{l}\text { Depth to } \\
\text { Horizon }\end{array}$ \\
\hline \multirow{2}{*}{$\begin{array}{l}\text { Partial Mantel } \\
\text { test }\end{array}$} & correlation & 0.174 & -na- & 0.254 & \multicolumn{2}{|c|}{0.184} & 0.163 & 0.235 \\
\hline & $\mathrm{t}$ & 2.21 & -na- & 3.30 & & & 2.43985 & 2.95 \\
\hline Soil properties & Two-tailed $p$ & $0.038^{* *}$ & -na- & $0.003^{* *}$ & \multicolumn{2}{|c|}{$0.012^{* *}$} & $0.01570^{* *}$ & $0.010^{* *}$ \\
\hline \multirow{2}{*}{$\begin{array}{l}\text { Partial Mantel } \\
\text { test }\end{array}$} & correlation & 0.176 & 0.168 & 0.205 & 0.094 & 0.093 & 0.16661 & 0.123 \\
\hline & $\mathrm{t}$ & 2.20 & 2.68 & 2.98 & 1.46 & 1.44 & 2.48767 & 1.842 \\
\hline Soil and TI & Two-tailed $p$ & $0.037^{* *}$ & $0.014^{* *}$ & $0.007^{* *}$ & 0.155 & 0.157 & $0.01601^{* *}$ & $0.094 *$ \\
\hline \multirow{2}{*}{$\begin{array}{l}\text { Partial Mantel } \\
\text { test }\end{array}$} & correlation & 0.136 & 0.104 & 0.262 & \multicolumn{2}{|c|}{0.233} & 0.20830 & 0.301 \\
\hline & $\mathrm{t}$ & 1.78 & 1.66 & 2.84 & \multicolumn{2}{|c|}{2.63} & 2.75 & 3.14 \\
\hline Soil and IFD & Two-tailed $p$ & $0.090^{*}$ & 0.097* & $0.007^{* *}$ & \multicolumn{2}{|c|}{$0.009 * *$} & $0.008^{* *}$ & $0.007^{* *}$ \\
\hline \multirow{2}{*}{$\begin{array}{l}\text { Partial Mantel } \\
\text { test }\end{array}$} & correlation & 0.120 & 0.102 & 0.198 & 0.121 & 0.119 & 0.206 & 0.157 \\
\hline & $\mathrm{t}$ & 1.55 & 1.57 & 2.38 & 1.58 & 1.56 & 2.73 & 1.98 \\
\hline Soil, TI, and IFD & Two-tailed $p$ & 0.133 & 0.125 & $0.022 * *$ & 0.135 & 0.138 & $0.010^{* *}$ & $0.081^{*}$ \\
\hline
\end{tabular}

$* *$ indicates $p$ value less than or equal to $0.05, *$ indicates $p$ value less than or equal to 0.10 
Table 4.6 Pearson's product-moment correlation matrix for sequential extracted $\mathrm{P}_{\mathrm{o}}$ fractions from location Fertilized 2

\begin{tabular}{|c|c|c|c|c|c|c|c|c|}
\hline & $0.5 \mathrm{M} \mathrm{NaHCO} 3$ & MFD TWI & MFD SPI & $D \infty \mathrm{TWI}$ & DळSPI & D8 TWI & D8 SPI & $\mathrm{TWI}_{\mathrm{s}}$ \\
\hline \multirow{2}{*}{ MFD TWI } & 0.155 & & & & & & & \\
\hline & 0.421 & & & & & & & \\
\hline \multirow{2}{*}{ MFD SPI } & 0.195 & -0.201 & & & & & & \\
\hline & 0.311 & 0.295 & & & & & & \\
\hline \multirow{2}{*}{ D $\infty$ TWI } & 0.142 & 0.994 & -0.210 & & & & & \\
\hline & 0.464 & $0.000^{* *}$ & 0.275 & & & & & \\
\hline \multirow{2}{*}{ D $\infty S P I$} & 0.198 & -0.213 & 0.999 & -0.220 & & & & \\
\hline & 0.304 & 0.266 & $0.000^{* *}$ & 0.251 & & & & \\
\hline \multirow{2}{*}{ D8 TWI } & 0.169 & 0.956 & -0.155 & 0.952 & -0.164 & & & \\
\hline & 0.380 & $0.000^{* * *}$ & 0.423 & $0.000^{* *}$ & 0.394 & & & \\
\hline \multirow{2}{*}{ D8 SPI } & 0.201 & -0.189 & 0.999 & -0.196 & 0.999 & -0.141 & & \\
\hline & 0.297 & 0.327 & $0.000^{* *}$ & 0.309 & $0.000^{* *}$ & 0.467 & & \\
\hline \multirow{2}{*}{$\mathrm{TWI}_{\mathrm{S}}$} & 0.450 & 0.330 & 0.575 & 0.319 & 0.569 & 0.338 & 0.576 & \\
\hline & $0.014^{*}$ & $0.080^{*}$ & $0.001 * *$ & $0.092^{*}$ & $0.001 * *$ & $0.072^{*}$ & $0.001^{* *}$ & \\
\hline \multirow{2}{*}{$\mathrm{SPI}_{\mathrm{m}}$} & 0.193 & -0.232 & 0.999 & -0.240 & 0.990 & -0.184 & 0.997 & 0.565 \\
\hline & 0.315 & 0.226 & $0.000^{* *}$ & 0.210 & $0.000^{* *}$ & 0.339 & $0.000^{* * *}$ & $0.001^{* *}$ \\
\hline
\end{tabular}

** indicates $p$ value less than or equal to $0.05, *$ indicates $p$ value less than or equal to 0.10 
Table 4.7 Stepwise regression of soil properties for surface horizons of location fertilized 2 with $0.5 \mathrm{M} \mathrm{NaHCO}_{3}$ as the response and Mehlich 1 extractable $\mathrm{Fe}, \mathrm{Al}$, and Ca; the soil carbon; sand, silt, and clay percentages; surface horizon thickness; $\mathrm{pH}$ in water and in $\mathrm{CaCl}$; and $\mathrm{TWI}_{\mathrm{s}}$ as the predictors

\begin{tabular}{lc} 
Step & 1 \\
Constant & 133 \\
\hline $\mathrm{TWI}_{\mathrm{s}}$ & 20.9 \\
$\mathrm{~T}-\mathrm{V}$ alue & 2.62 \\
$\mathrm{P}-\mathrm{V}$ alue & 0.014 \\
$\mathrm{~S}$ & 43.8 \\
$\mathrm{R}-\mathrm{Sq}$ & 20.2 \\
$\mathrm{R}-\mathrm{Sq}$ (adj) & 17.3 \\
\hline Alpha to enter or remove $=\mathrm{P} \leq 0.05 \quad$ Response $=0.5 \mathrm{M}$ NaHCO${ }_{3}$ extracted $\mathrm{P}_{\mathrm{o}}$, predictors $=11, \mathrm{n}=29$ \\
\hline$* *$ indicates $\mathrm{p}$ value less than or equal to $0.05,{ }^{*}$ indicates $\mathrm{p}$ value less than or equal to 0.10. The \\
adjusted R-squared compares the explanatory power of regression models. The predicted $\mathrm{R}$-squared \\
indicates how well a regression model predicts responses for new observations. S represents the \\
average distance that the observed values fall from the regression line.
\end{tabular}


Table 4.8 Pearson's product-moment correlation matrix for sequential extracted $\mathrm{P}_{\mathrm{o}}$ fractions from location Unfertilized 1

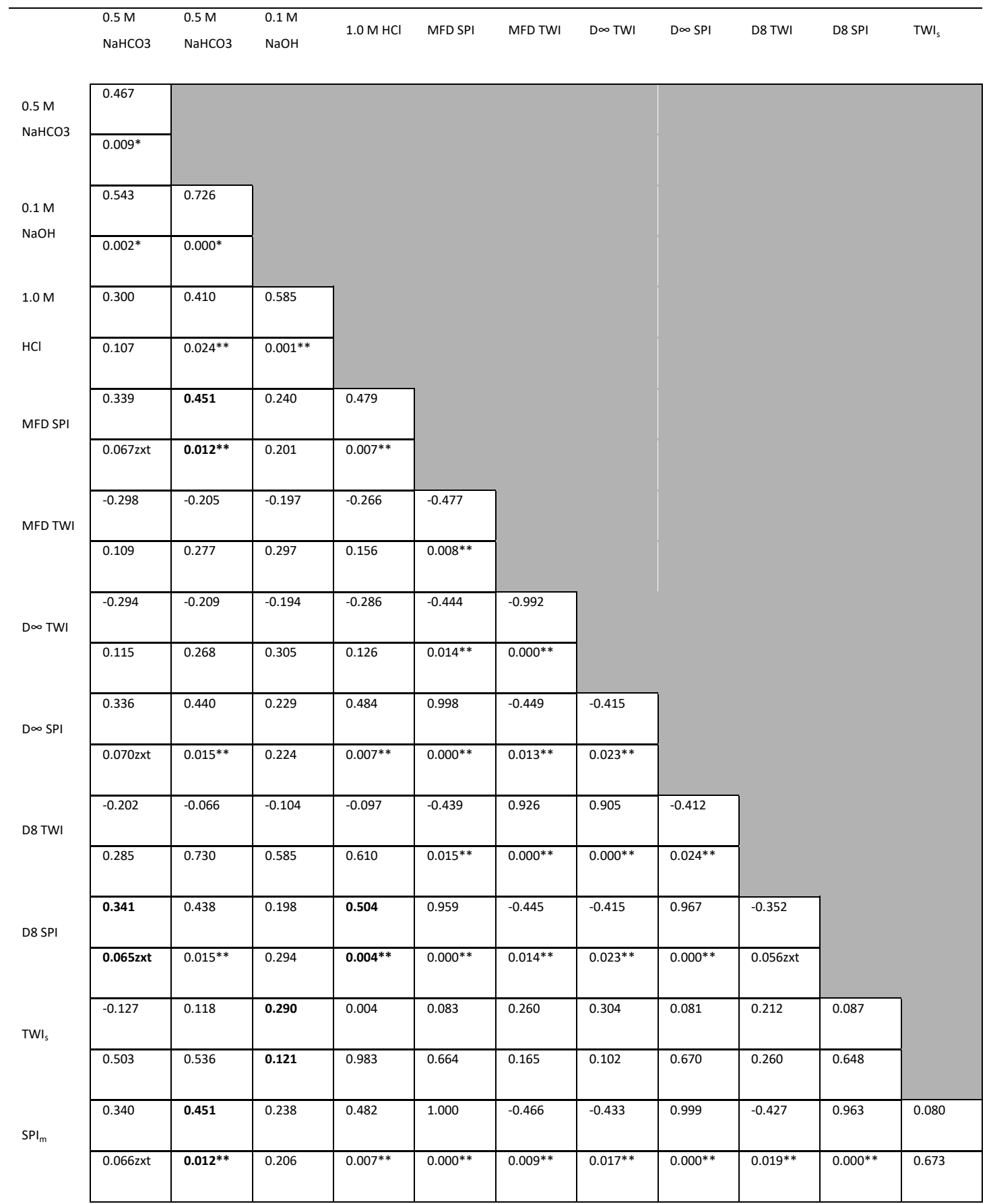

** indicates $p$ value less than or equal to $0.05, *$ indicates $p$ value less than or equal to 0.10 
Table 4.9 Stepwise regression of soil properties for surface horizon of location Unfertilized 1 with $0.5 \mathrm{M} \mathrm{NaHCO}_{3}$ as the response and Mehlich 1 extractable $\mathrm{Fe}, \mathrm{Al}$, and Ca; the soil carbon; sand, silt, and clay percentages; surface horizon thickness; $\mathrm{pH}$ in water and in $\mathrm{CaCl}$; and $\mathrm{TWI}_{\mathrm{s}}$ as the predictors

\begin{tabular}{lc}
\hline Step & 1 \\
Constant & 129 \\
\hline Horizon Thickness & -4.7 \\
T-Value & -2.06 \\
P-Value & 0.049 \\
\hline $\mathrm{S}$ & 17.0 \\
$\mathrm{R}-\mathrm{Sq}$ & 13.1 \\
$\mathrm{R}-\mathrm{Sq}$ (adj) & 10.0 \\
\hline Alpha to enter or remove $=\mathrm{P} \leq 0.05$ Response $=0.5 \mathrm{M}$ NaHCO $_{3}$ extracted $\mathrm{P}_{\mathrm{o}}$, predictors $=11, \mathrm{n}=30$ \\
\hline$* *$ indicates $\mathrm{p}$ value less than or equal to $0.05,{ }^{*}$ indicates $\mathrm{p}$ value less than or equal to 0.10. The \\
adjusted R-squared compares the explanatory power of regression models. The predicted $\mathrm{R}$-squared \\
indicates how well a regression model predicts responses for new observations. S represents the \\
average distance that the observed values fall from the regression line.
\end{tabular}

Table 4.10 Stepwise regression of soil properties for subsurface horizon of location low one with Mehlich 1 extractable $\mathrm{Fe}, \mathrm{Al}$, and Ca; the soil carbon; sand, silt, and clay percentages; surface horizon thickness; pH in water and in $\mathrm{CaCl}$; and STP levels of the surface horizon as predictors

Step 1

Constant 132

\begin{tabular}{lc}
\hline Depth to Horizon & -12.3 \\
T-Value & -5.38 \\
P-Value & $\leq 0.000^{* *}$ \\
\hline S & 17.2 \\
R-Sq & 50.8 \\
R-Sq (adj) & 49.1 \\
\hline
\end{tabular}

Alpha to enter or remove $=\mathrm{P} \leq 0.05$ Response is $0.5 \mathrm{M} \mathrm{NaHCO}_{3}$ predictors $=12, \mathrm{n}=30$

** indicates $p$ value less than or equal to $0.05, *$ indicates $p$ value less than or equal to 0.10 . The adjusted R-squared compares the explanatory power of regression models. The predicted R-squared indicates how well a regression model predicts responses for new observations. S represents the average distance that the observed values fall from the regression line. 
Table 4.11 Stepwise regression of soil properties for subsurface horizon of location Unfertilized 1 with Mehlich 1 extractable $\mathrm{Fe}, \mathrm{Al}$, and $\mathrm{Ca}$; the soil carbon; sand, silt, and clay percentages; surface horizon thickness; $\mathrm{pH}$ in water and in $\mathrm{CaCl}$; $\mathrm{TWI}_{s}$; and STP levels of the surface horizon as predictors

\begin{tabular}{|c|c|c|c|c|c|c|}
\hline Step & 1 & 2 & 3 & 4 & 5 & 6 \\
\hline Constant & 820 & 649 & 427 & 354 & 114 & 726 \\
\hline Depth & -63 & -53 & -42 & -38 & -49 & -39 \\
\hline T-Value & -5.61 & -4.50 & -3.42 & -3.40 & -4.72 & -3.75 \\
\hline P-Value & 0.000 & 0.000 & 0.002 & 0.002 & 0.000 & 0.001 \\
\hline$\%$ Carbon & & 53 & 65 & 95 & 97 & 95 \\
\hline T-Value & & 2.09 & 2.63 & 3.81 & 4.50 & 4.86 \\
\hline P-Value & & 0.046 & 0.014 & 0.001 & 0.000 & 0.000 \\
\hline STAI & & & 0.90 & 1.31 & 1.76 & 1.74 \\
\hline T-Value & & & 2.07 & 3.13 & 4.48 & 4.86 \\
\hline P-Value & & & 0.048 & 0.004 & 0.000 & 0.000 \\
\hline STFe & & & & -5.6 & -6.9 & -7.3 \\
\hline T-Value & & & & -2.68 & -3.70 & -4.24 \\
\hline P-Value & & & & 0.013 & 0.001 & 0.000 \\
\hline \%Silt & & & & & 581 & 478 \\
\hline T-Value & & & & & 3.01 & 2.66 \\
\hline P-Value & & & & & 0.006 & 0.014 \\
\hline $\mathrm{pH}$ & & & & & & -114 \\
\hline T-Value & & & & & & -2.46 \\
\hline$p$-Value & & & & & & 0.022 \\
\hline $\mathrm{S}$ & 84.4 & 79.8 & 75.3 & 67.7 & 58.8 & 53.5 \\
\hline $\mathrm{R}-\mathrm{Sq}$ & 52.9 & 59.5 & 65.2 & 73.0 & 80.4 & 84.5 \\
\hline $\mathrm{R}-\mathrm{Sq}$ (adj) & 51.2 & 56.5 & 61.2 & 68.7 & 76.3 & 80.4 \\
\hline
\end{tabular}

Alpha to enter or remove $=\mathrm{P} \leq 0.05$ Response $=0.1 \mathrm{M} \mathrm{NaOH}$ extracted $\mathrm{P}_{\mathrm{o}}$, predictors $=12, \mathrm{n}=30$ ** indicates $p$ value less than or equal to $0.05, *$ indicates $p$ value less than or equal to 0.10 . The adjusted R-squared compares the explanatory power of regression models. The predicted R-squared indicates how well a regression model predicts responses for new observations. S represents the average distance that the observed values fall from the regression line. 


\begin{tabular}{lc} 
Step & 1 \\
Constant & 88.8 \\
\hline Depth to Horizon & -9.2 \\
T-Value & -2.38 \\
P-Value & $0.024^{* *}$ \\
\hline S & 29.1 \\
R-Sq & 16.9 \\
R-Sq (adj) & 13.9 \\
\hline A-to-enter: 0.15 A-to-remove: 0.15 Response is $1.0 \mathrm{M} \mathrm{HCl}$ extracted P 11 predictors, $\mathrm{n}=30$
\end{tabular}

A-to-enter: 0.15 A-to-remove: 0.15 Response is $1.0 \mathrm{M} \mathrm{HCl}$ extracted $\mathrm{P}_{0}, 11$ predictors, $\mathrm{n}=30$ $* *$ indicates $p$ value less than or equal to $0.05, *$ indicates $p$ value less than or equal to 0.10 . The adjusted R-squared compares the explanatory power of regression models. The predicted R-squared indicates how well a regression model predicts responses for new observations. S represents the average distance that the observed values fall from the regression line. 


\section{Figures}

Figure 4.1 Hot spot analysis of Mehlich 1 soil test phosphorus data at location fertilized 1where locations with high value, surrounded by other features with high values are identified and hot spots and locations with low value, surrounded by other features with low values are identified and cold spots

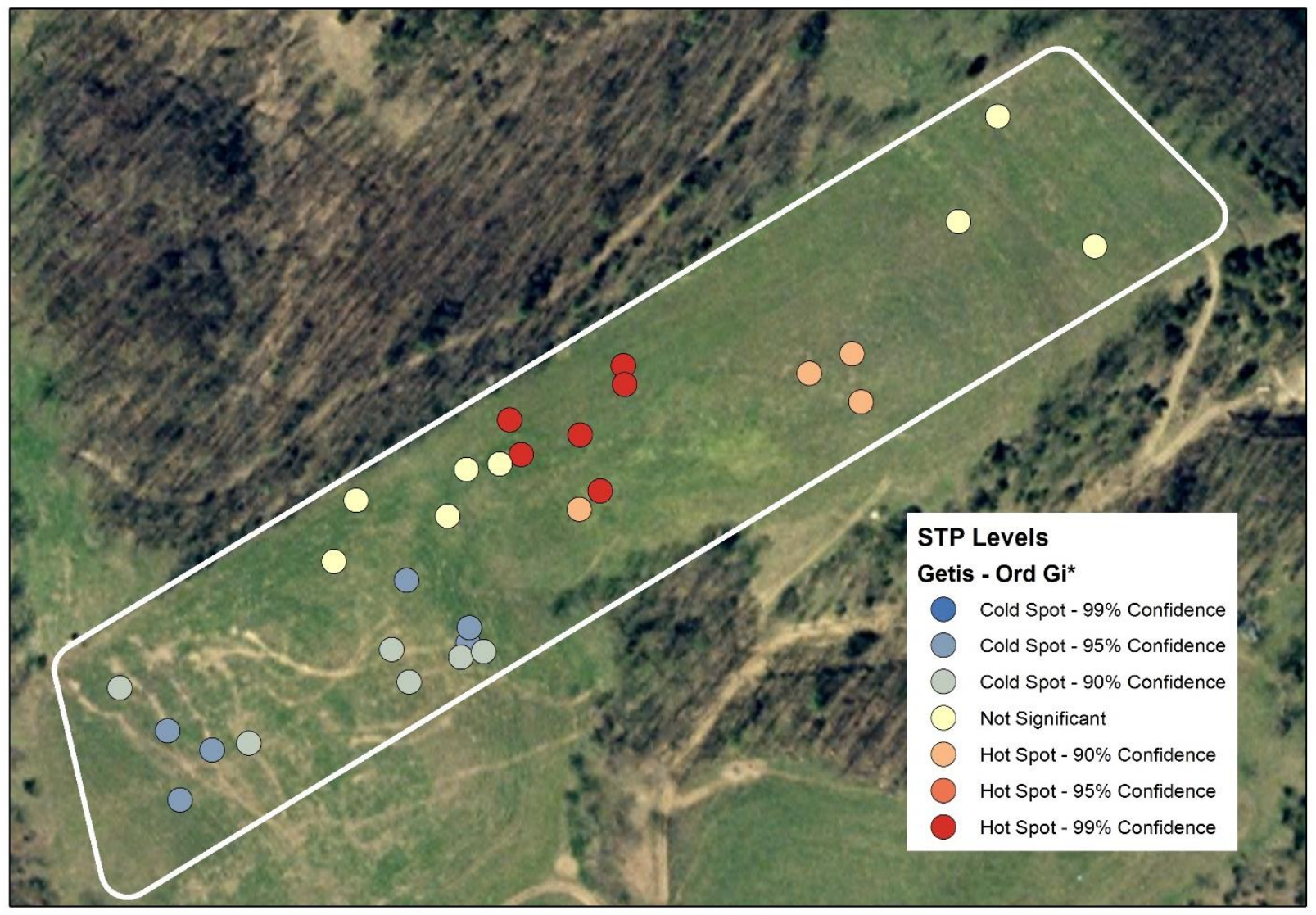


Figure 4.2 Hot spot analysis of Mehlich 1 soil test phosphorus data at location fertilized 2where locations with high value, surrounded by other features with high values are identified and hot spots and locations with low value, surrounded by other features with low values are identified and cold spots

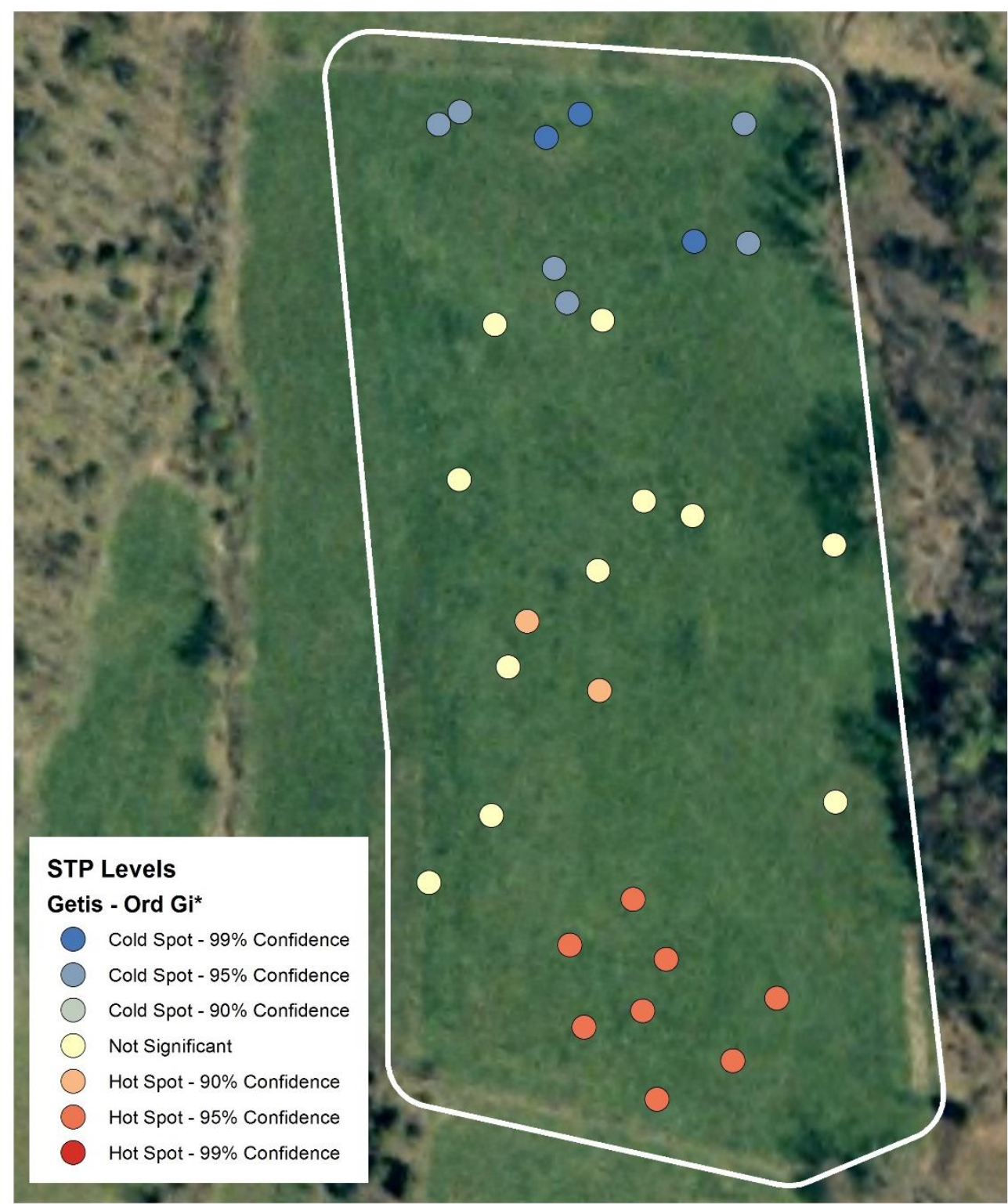


Figure 4.3 Hot spot analysis of Mehlich 1 soil test phosphorus data at location unfertilized 1where locations with high value, surrounded by other features with high values are identified and hot spots and locations with low value, surrounded by other features with low values are identified and cold spots

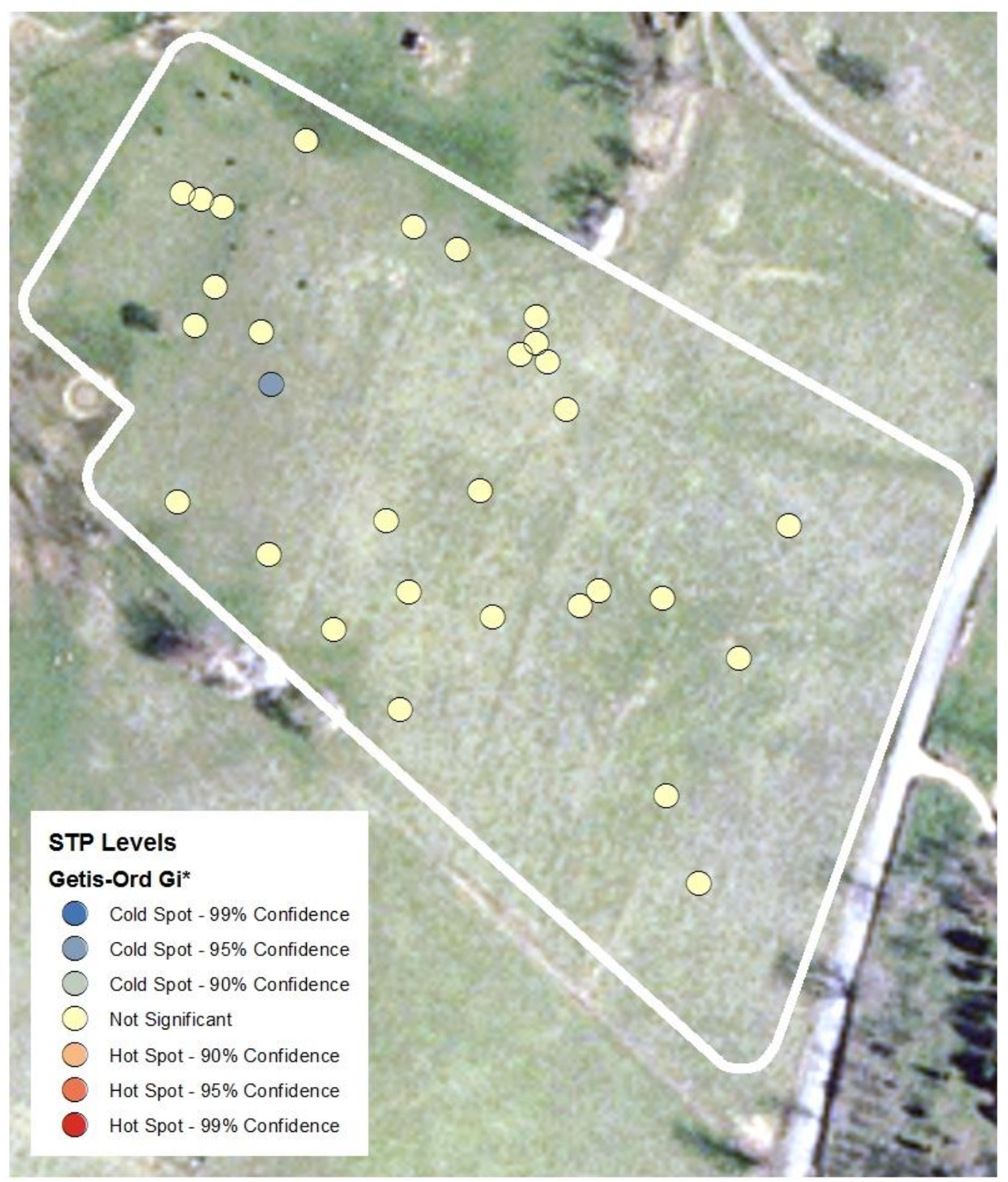


Figure 4.4 Hot spot analysis of Mehlich 1 soil test phosphorus data at location unfertilized 2 where locations with high value, surrounded by other features with high values are identified and hot spots and locations with low value, surrounded by other features with low values are identified and cold spots

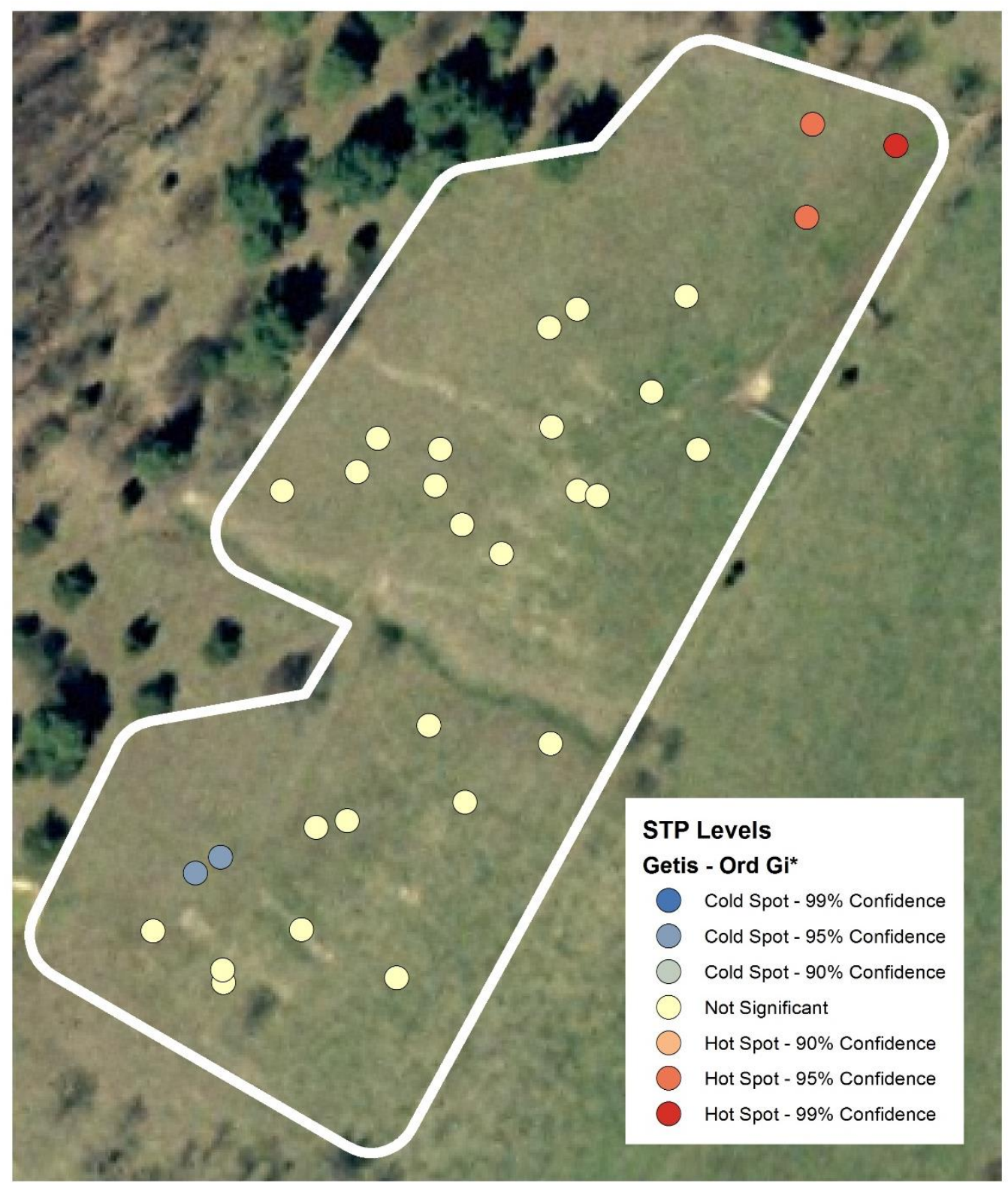


Figure 4.5 Hot spots near former gated entrance and winter feeding area at entrance of the pasture area at location unfertilized 2 where locations with high value, surrounded by other features with high values are identified and hot spots and locations with low value, surrounded by other features with low values are identified and cold spots

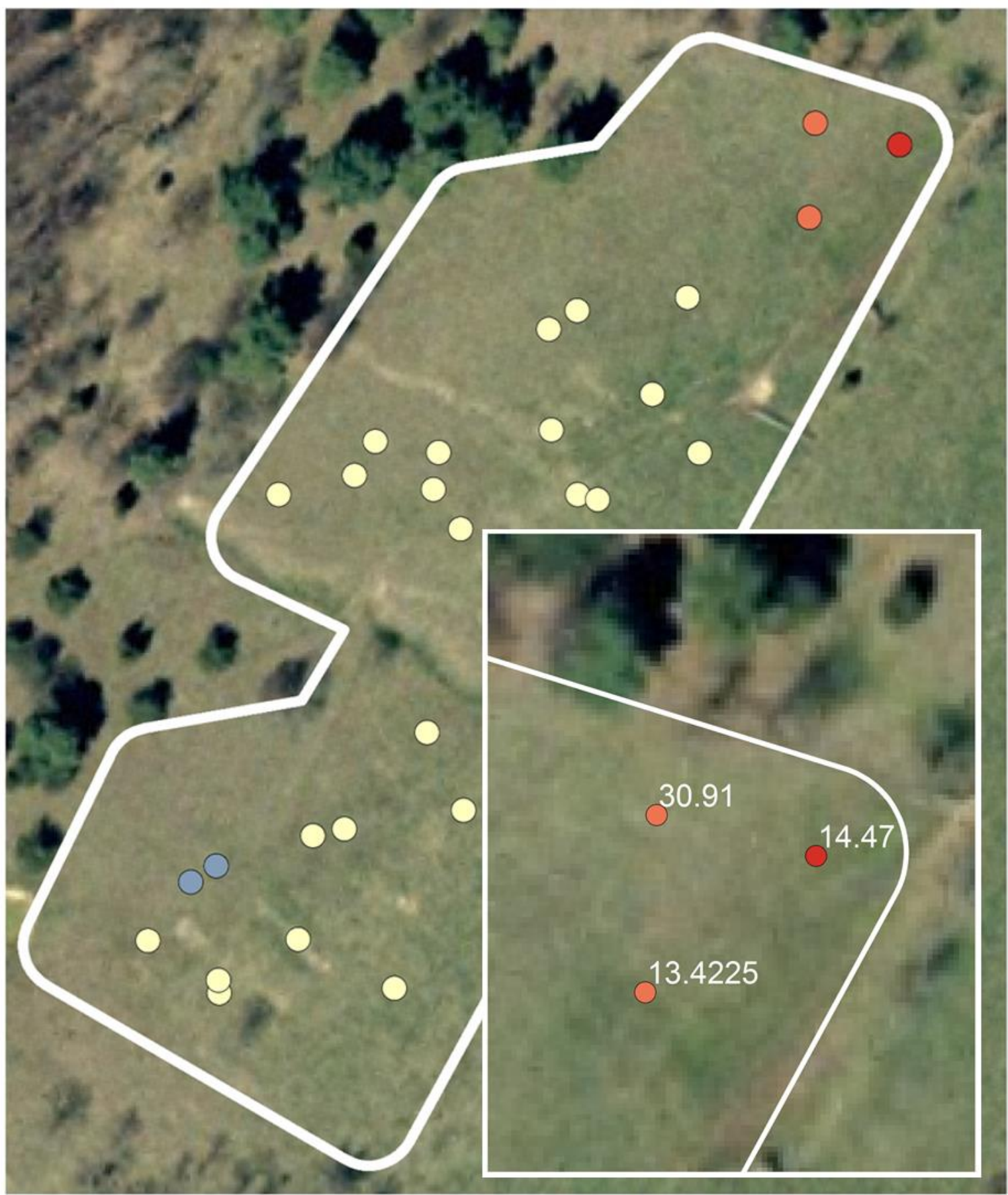


Figure 4.6 Isolines of location fertilized 1 with sample points divided into three distinct subsets with the sample points located in the summit position (blue), the sample points contributing to a midfield concave feature draining out of the field (yellow), and the remaining points (red).

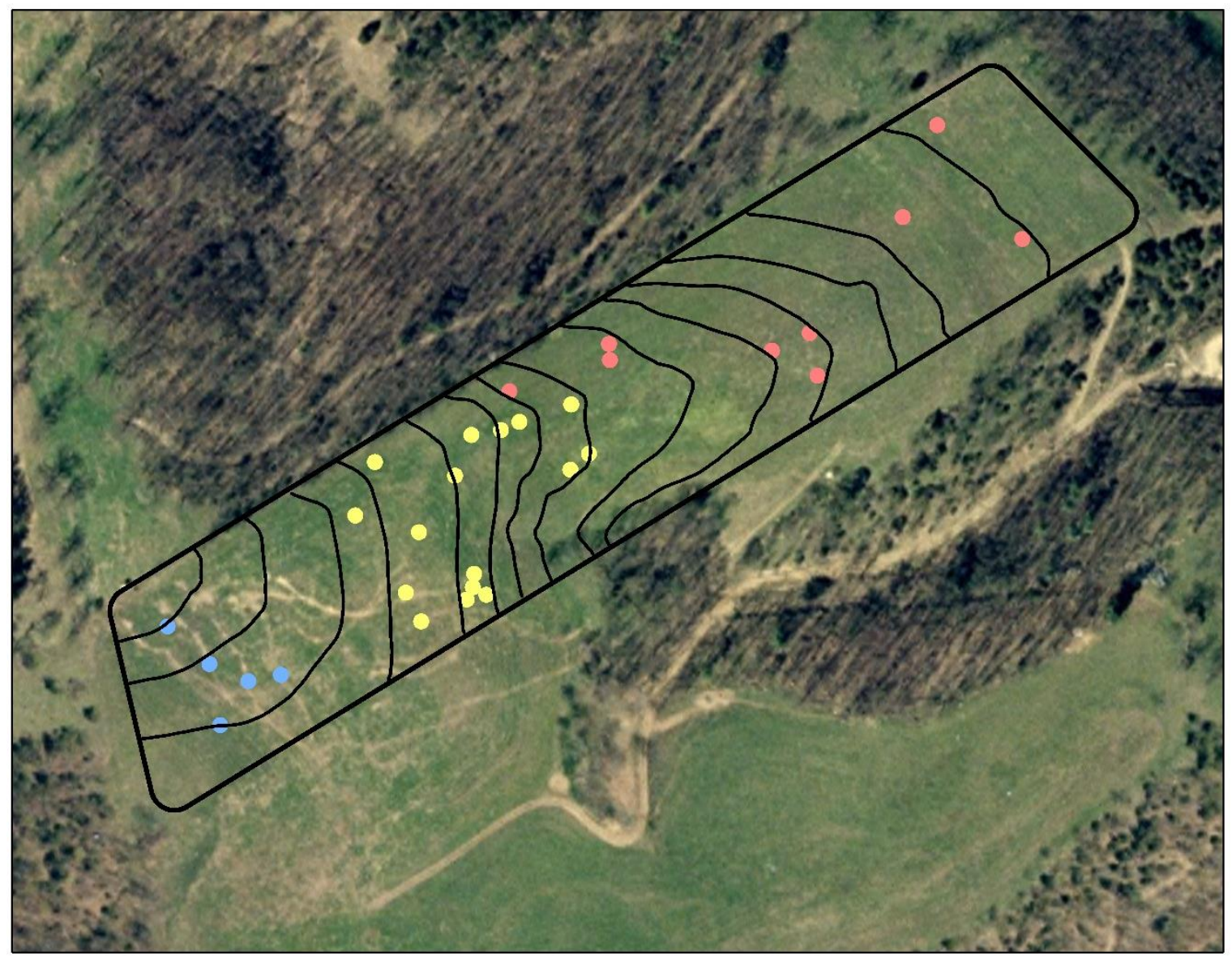


Figure 4.7 Isolines of location fertilized 2 with sample points divided into two subsets: a limited subset of sample points located on the higher landscape positons in the foot slope that appear to be hydrologically isolated from the remaining data points (blue) and the remaining data points (yellow).

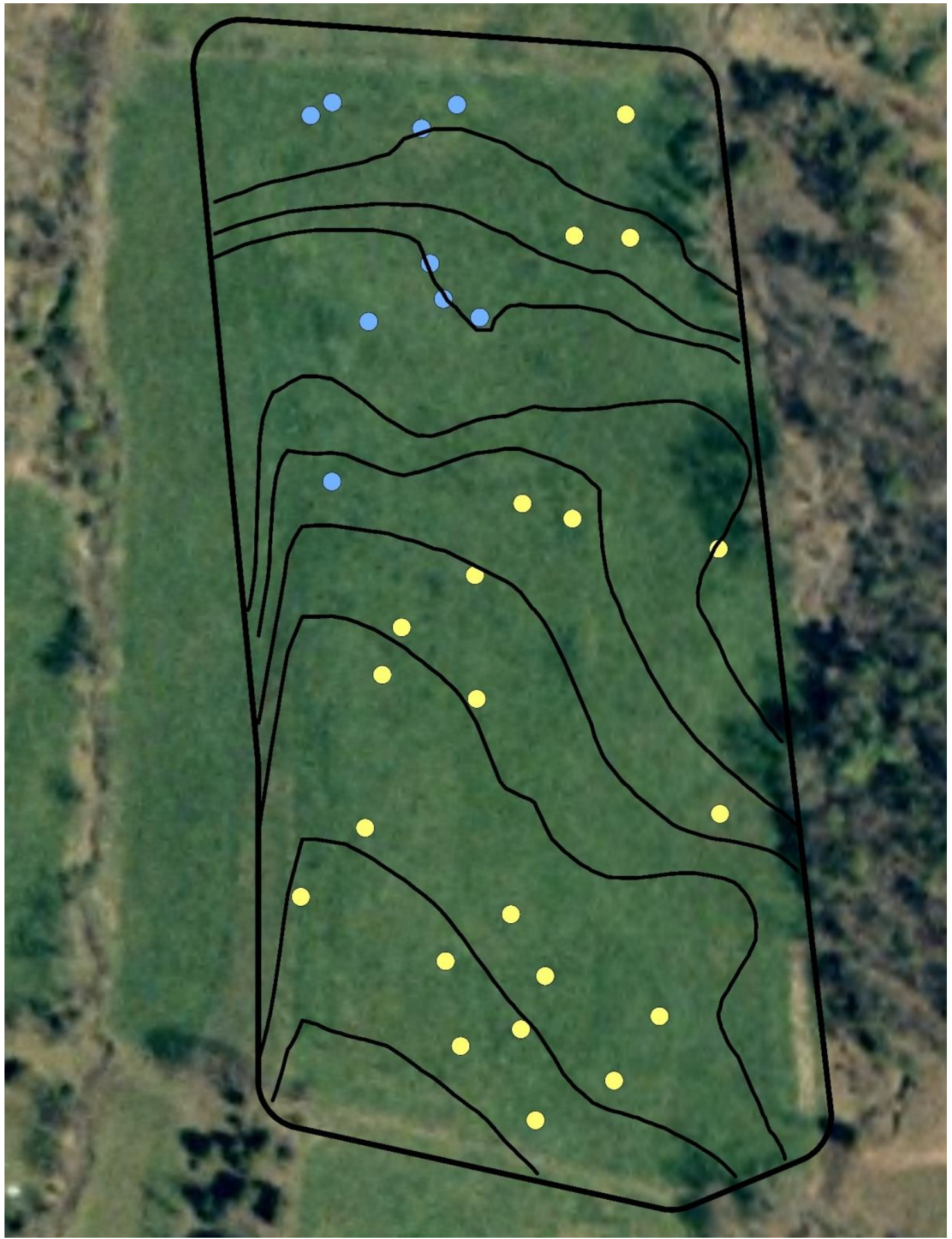


Figure 4.8 Isolines of location unfertilized 1 is composed of four basic elements, a summit, two back slopes and a foot slope position. The sample points in the summit drained into one of two back slopes, who converged at the foot slope of the landscape. The data points are divided into three parts: the two back slopes (red and blue) and data points at the foot slope position (yellow).

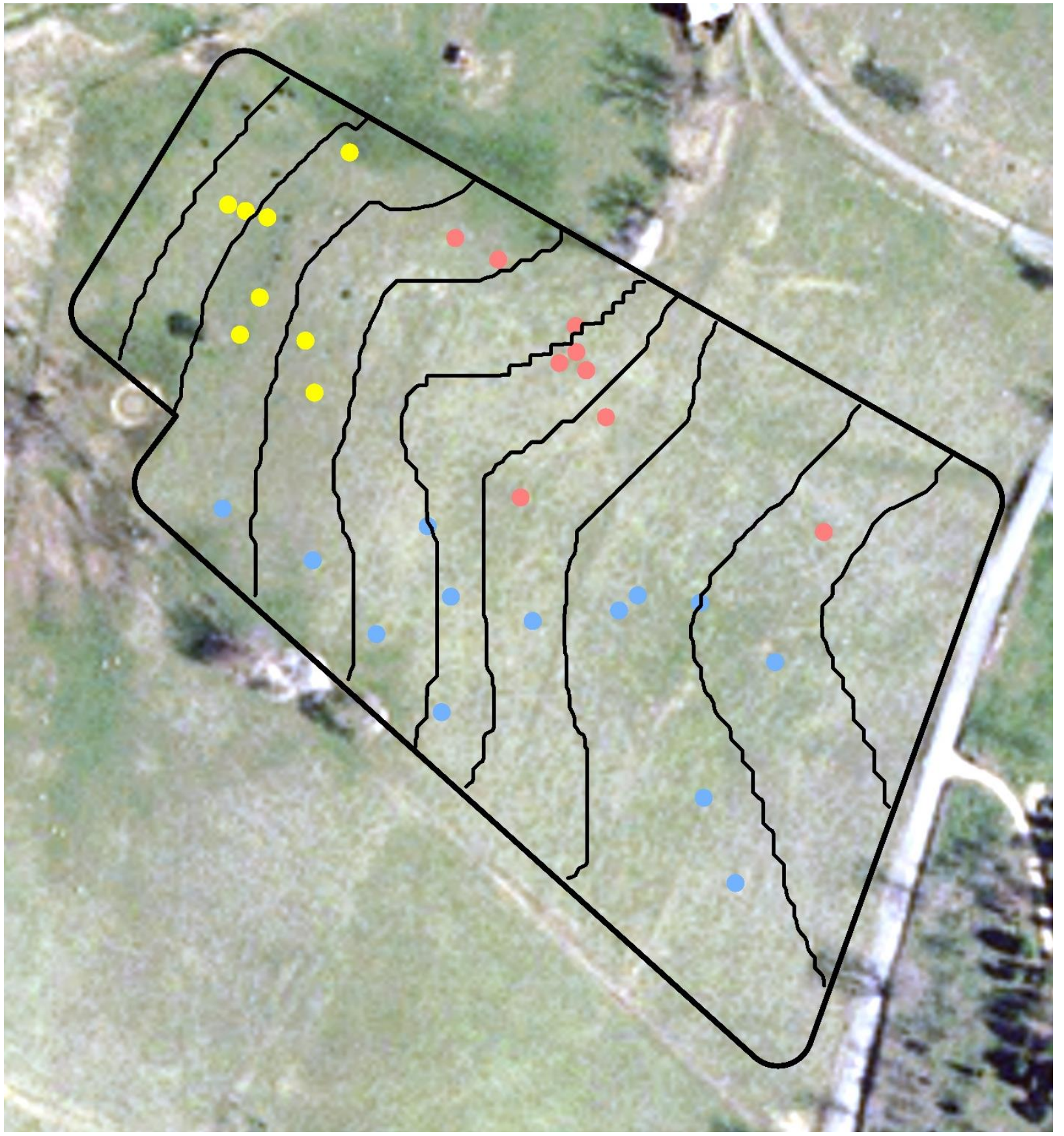




\section{Chapter 5. Modeling Sequentially Extracted Organic Phosphorus Fractions from Soil Test Phosphorus and Topographic Data}

\section{Abstract}

In locations with significant food animal agriculture and historic $\mathrm{N}$-based manure applications, $\mathrm{P}$ accumulation is a significant environmental concern. As efforts to evaluate risk associated with additional manure applications evolve, tools to improve the ability of conservation professionals to make such determinations become more critical. When locations are identified with a degree of $P$ saturation that poses a risk of environmental loss, any tools that assist conservation professionals in developing remediation strategies are equally utilitarian. However, the resources to manage risk and develop remediation strategies are often at a premium. By utilizing readily available topographic data and routine soil test data, $\mathrm{P}$ distributions in locations with lengthy histories of animal manure applications can be modeled without the costs associated with additional sampling and elaborate multistep laboratory procedures. As such, when sequential extracted $\mathrm{P}$ fractions were modeled using Mehlich 1 (M1) and Mehlich 3 (M3) soil test data and various topographic data it explained between 43.2 and $97.9 \%$ of the variability in the data. This has the potential to allow resource managers to utilize basic soil test results and topographic data to predict multiple organic and inorganic $P$ fractions providing a useful tool for risk assessment and remediation at a fraction of normal cost.

\section{Introduction}

Historically, there have been multi-step fractionation procedures developed to describe and categorize soil P (Chang and Jackson, 1957; Bowman and Cole 1978; Hedley et al. 1982) and countless

modifications to these methods. The most commonly cited and modified method in soil P research is the Hedley et al. (1982) fractionation (Guppy et al., 2000). The Hedley et al. (1982) fractionation partitions the $\mathrm{P}$ pool into soluble, aluminum/iron-bound, calcium-bound, and residual forms. Most research on $\mathrm{P}$ has focused on inorganic $P\left(P_{i}\right)$, with significantly less attention given to organic species of $P$ (Laboski, and Lamb, 2003; Anderson and Magdoff, 2005). Some researchers hypothesize that this is in part due to a perception that $\mathrm{P}_{\mathrm{i}}$ is the dominant form of $\mathrm{P}$, it is the plant available form, and the analysis of organic forms was simply too problematic (Jansson et al., 1988; Turner and Haygarth, 2000; Anderson and Magdoff, 2005).

In general, P mobility is dependent upon hydrological and chemical processes (Galeone, 1996; Easton et al., 2009). P movement follows the direction of surface and subsurface water movement (Smeck and 
Runge, 1971). The research of Smeck (1973) and Smeck and Runge (1971) documented lateral P movement and accumulate in lower landscape positions. Smeck (1985) identified multiple examples where soils sampled from lower positions in a toposequence had higher total P levels.

Multiple researchers have reported subsurface transport of P (Turner and Haygarth, 2000; Kleinman et al., 2004; Nelson et al., 2005; Andersen and Kronvang, 2006). Using a topographic wetness index (TWI) Moore et al. (1993) explained $48 \%$ of the variability within STP extractions at a field scale. Similarly, McKenzie and Ryan (1999) found climate, terrain, and parent material to explain as much as $78 \%$ of total $P$ variation within a catchment. As sediments and any dissolved materials move with water, it effectively generates vertical and lateral differentiation in the soil or its properties (Ziadat, 2005; Pachepsky et al., 2001; Young and Hammer, 2000; Girgin and Frazier, 1996). Water and material movement at field scale is strongly influenced by slope configuration (Huggett, 1975). However, the specific factors that control surface and subsurface hydrology may change with scale (Park and Vlek, 2002; Kirkby et al., 1996).

Phosphorus fractionation procedures can provide insight into how $\mathrm{P}$ exists within a soil and across a landscape. The strength of the P-soil bonds affects soil solution concentrations (Brady and Weil, 2002; Blake et al., 2003; Pierzynski et al., 2005). In terms of P composition in soil, the $P_{0}$ pool in soil is typical composed of inositol phosphates, phospholipids, nucleic acids, phosphoproteins and other unidentified P compounds (Schroeder and Kovar, 2006). $P_{\mathrm{i}}$ in soils typically comes from the weathering of apatite (Pierzynski et. al 2005). If multiple $P_{\circ}$ fractions are applied to packed soil columns, different classes of $P_{0}$ fractions will move through the soil at different rates (Anderson and Magdoff, 2005). For example, orthophosphate diesters are more likely to leach in soils than monoesters or $\mathrm{P}_{\mathrm{i}}$ (Anderson and Magdoff, 2005). Based on the principals of soil landscape modeling, if one can model the water movement within a landscape and that water moves one or more fractions of $P$, one could develop a quantitative method to predict the redistribution of $\mathrm{P}$ across the same landscape.

While effective at describing the distribution of $P$ within a sample, sequential extractions are time consuming and may not be practical for routine soil analysis. Yet at a landscape scale, knowledge of the labile $P$ fractions is of importance in assessing risk of $P$ loss (Negassa and Leinweber, 2009). The proposed solution is to predict $\mathrm{P}$ fractions from more readily available data. In recent years there has been research on predicting and assessing the spatial distribution of soil P (Wang et al., 2009; Liu et al., 2013; Rubaek et al., 2013; Roger et al., 2014), but little effort to predict spatially explicit sequentially extracted $\mathrm{P}$ fractions from landscape data. This may be in part related to the perception that terrain attributes do not adequately explain the variability seen in P distributions. Roger et al. (2014) noted the 
poor performance of terrain attributes at spatially predicting various $\mathrm{P}$ forms and the overwhelming influence of land use and management on P levels. Similarly, Sarmadian et al. (2014) indicated only a moderate influence of terrain attributes on P levels in Iran. However, if landscape variables are only part of the model and landscape variables are combined with other metrics for P status, field level spatial prediction is not unreasonable.

As concerns over pending P regulation mount, strategic long-term solutions to localized P saturation will become more necessary. Locations currently applying animal manure on a $\mathrm{N}$ basis or locations subject to new more restrictive $P$ indices will soon be prohibited further $P$ application. In the coming years, the efforts of reduce the P saturation at these sites and prevent $\mathrm{P}$ loss will become more critical. Similarly, the ability to model $\mathrm{P}$ movement within these sites and develop spatially-based $\mathrm{P}$ interception strategies will be dependent on basic, accurate, and cost-effective modeling of $\mathrm{P}$ distributions at the field level. Soil-landscape modeling can provide that capability.

There are two primary objectives of this research. The first is to establish a series of statistical soillandscape models that best explain the spatial distributions of sequential extracted $P$ fractions across hay and grass pastures in West Virginia. The second is to determine which soil test extraction (Mehlich 1 or Mehlich 3) is best suited for modeling sequential extracted $\mathrm{P}$ fractions. As such, these models could serve as a guide for resource allocations, as a component in remediation strategies, and have the potential to improve regional risk assessments of $\mathrm{P}$ loss.

The first research hypothesis $\left(\mathrm{Ha}_{1}\right)$ states that soil landscape data and soil test $\mathrm{P}$ data will be significant $(p \leq 0.05)$ terms in sequentially extracted $\mathrm{P}_{\mathrm{o}}$ models at landscape scales. The null hypothesis $\left(\mathrm{Ho}_{1}\right)$ states that soil landscape data and soil test $P$ data will not be significant $(p \leq 0.05)$ terms in sequentially extracted $\mathrm{P}_{\mathrm{o}}$ models at landscape scales. The second research hypothesis $\left(\mathrm{Ha}_{2}\right)$ states Mehlich 1 soil test phosphorus data based models will have higher $\mathrm{R}^{2}$ values than Mehlich 3 soil test phosphorus data based models. The second null hypothesis $\left(\mathrm{Ho}_{2}\right)$ states Mehlich 3 soil test phosphorus data based models will have higher $\mathrm{R}^{2}$ values than Mehlich 1 soil test phosphorus data based models. 


\section{Materials and Methods}

\section{Study Sites and Sample Locations}

The selected study sites were typical hay or grass pasture fields in eastern West Virginia. The study sites consisted of four fields. Two fields had lengthy histories (approximately $10+\mathrm{yrs}$.) of annual N-based manure applications. Two fields had very infrequent applications of animal manure (once every 4 or 5 yrs.). Within each field a stratified random sampling design (Thompson et al., 2006) was used to select sample points. The topographic wetness index (TWI) of each location was used as the basis for the stratification. TWI was calculated from a 3-m DEM (SAMB) made free of sinks or voids. TWI is defined as the $\ln (A / \tan B)$ where $A$ is the local upslope contributing area for that point and $B$ is the local slope gradient (Beven and Kirkby, 1979). Flow direction was calculated for TWI by determining the specific flow direction from each cell into one of the eight neighboring cells based on the steepest downward slope (O'Callaghan and Mark, 1984). Specific catchment area is estimated by $A / L$, with $A$ being the number of pixels draining into a pixel multiplied by the area of a pixel, and $\mathrm{L}$ as the pixel width (Moore et al., 1991). TWI was grouped into three classes of equal area. Ten samples locations were selected at random within each class. From each sample point the first mineral horizon (surface horizon) and the 10 $\mathrm{cm}$ below that horizon (subsurface horizon) were sampled.

\section{Sample Preparation}

All samples were air dried, ground, sieved (2-mm sieve), and thoroughly mixed to make individual samples as homogenous as possible (Laboski and Lamb, 2003). Dried and ground samples were stored in sealed centrifuge tubes at $4^{\circ} \mathrm{C}$ until 1 day prior to analysis.

\section{Sequential Fractionation}

The method of sequential P fractionation is based on a suggested modification (Sui et al., 1999) of the Hedley method (Hedley et al., 1982) as described by He et al. (2003). From each sample, $1.0 \mathrm{~g}$ of soil and $25 \mathrm{~mL}$ of extractant was placed in a centrifuge tube in a reciprocal shaker at 180 oscillations per minute for $16 \mathrm{~h}$ at room temperature. The samples were centrifuged for $15 \mathrm{~min}$ at 2,800 $\mathrm{Xg}$ and the supernatant filtered (Whatman No. 2 or equivalent). This process was repeated sequentially with the following extractants: (i) distilled deionized water, (ii) $0.5 \mathrm{M} \mathrm{NaHCO}_{3}$, (iii) $0.1 \mathrm{M} \mathrm{NaOH}$, and (iv) $1.0 \mathrm{M} \mathrm{HCl}$. Duplicates of each sample were fractionated in this manner. Water, $0.5 \mathrm{M} \mathrm{NaHCO}_{3}$, and $0.1 \mathrm{M} \mathrm{NaOH}$ extracts were acidified and filtered prior to analysis for $\mathrm{P}_{\mathrm{i}} . \mathrm{P}_{\mathrm{i}}$ was determined by the ammonium molybdate-ascorbic acid method (Knudsen and Beegle, 1988). The ammonium molybdate-ascorbic acid method is a single reagent orthophosphate colorimetric method with two stock solutions, the 
concentrated ammonium paramolybdate solution and the ascorbic acid solution. The concentrated ammonium paramolybdate solution consists of $60 \mathrm{~g}$ of ammonium paramolybdate $\left.\left(\mathrm{NH}_{4}\right) 6 \mathrm{Mo}_{7} \mathrm{O}_{24} \cdot 4 \mathrm{H}_{2} \mathrm{O}\right)$ and approximately $200 \mathrm{~mL}$ of distilled water in a $1 \mathrm{~L}$ volumetric flask, along with $1.455 \mathrm{~g}$ of antimony potassium tartrate $\mathrm{K}_{2} \mathrm{Sb}_{2}\left(\mathrm{C}_{4} \mathrm{H}_{2} \mathrm{O}_{6}\right)_{2}$. These compounds are added to $700 \mathrm{~mL}$ of concentrated sulfuric acid and allowed to cool to room temperature, diluted to volume with distilled water, and stored in a dark glass bottle in the refrigerator. The ascorbic acid solution was made by dissolving $132 \mathrm{~g}$ of ascorbic acid in distilled water and diluted to $1 \mathrm{~L}$ in a volumetric flask. The single colorimetric working solution was made daily by adding $25 \mathrm{~mL}$ of concentrated ammonium paramolybdate solution to approximately 800 $\mathrm{mL}$ distilled water, with $10 \mathrm{~mL}$ of the ascorbic acid solution and diluting to volume with distilled deionized water in a $1 \mathrm{~L}$ volumetric flask. To determine $\mathrm{P}$ content, $2 \mathrm{~mL}$ of the soil extract or $\mathrm{P}$ standard was transferred to a test tube with $8 \mathrm{~mL}$ of the colorimetric working solution and mixed thoroughly. After 20 minutes for color development, the percent transmittance was read at $882 \mathrm{~nm}$. Total $P\left(P_{t}\right)$ was determined with a Perkin Elmer P4000 Inductively Coupled Plasma-Optical Emission Spectrometer (ICPOES). $P_{o}$ was calculated for each fraction as the mathematical difference between the reactive $P_{i}$ and $P_{t}$.

\section{Mehlich-1}

Mehlich-1 (M1) is a soil test with a 5:1 ratio of Mehlich-1 solution $\left(0.025 \mathrm{~N} \mathrm{H}_{2} \mathrm{SO}_{4}+0.05 \mathrm{~N} \mathrm{HCl}\right)$ to soil. The mixture is shaken for five minutes on a reciprocating shaker set at a minimum of $180-200$ oscillations per minute (Nelson et al., 1953). The extractant is filtered through a medium-porosity filter paper (Whatman No. 2 or equivalent) and analyzed for $P$ content (Nelson et al., 1953). $P_{t}$ was determined with a Perkin Elmer P4000 Inductively Coupled Plasma Optical Emission Spectrometer (ICPOES). For modeling purposes, a mean M1 P levels was calculated for each field.

\section{Mehlich-3}

Mehlich-3 (M3) is a 10:1 ratio of Mehlich-3 solution $\left(0.2 \mathrm{~N} \mathrm{CH}_{3} \mathrm{COOH}+0.25 \mathrm{~N} \mathrm{NH}_{4} \mathrm{NO}_{3}+0.015 \mathrm{~N} \mathrm{NH}_{4} \mathrm{~F}+\right.$ $0.013 \mathrm{~N} \mathrm{HNO}_{3}+0.001 \mathrm{M} \mathrm{EDTA}$ ) to soil. The mixture is shaken for five minutes on a reciprocating shaker set at a minimum of 180-200 oscillations per minute (Mehlich, 1984). The extractant is filtered through a medium-porosity filter paper (Whatman No. 2 or equivalent) and analyzed for P content (Mehlich, 1984). $P_{t}$ level was determined with a Perkin Elmer P4000 ICP-OES. For modeling purposes, a mean M3 $P$ levels was calculated for each field.

\section{Modeling Parameters}

Terrain attributes from 3-m resolution United States Geologic Survey (USGS) DEM were calculated. The elevation model was converted and exported as an ASCII files using ArcGIS 10.3. The ASCII files were 
imported into SAGA GIS (Bock et al., 2008). In SAGA, each DEM was examined for and filled any sinks or voids (Wang and Liu, 2006). Primary terrain attributes slope gradient, profile curvature, plan curvature, and tangential curvature were calculated (SAGA). Based on multiple flow direction (MFD), deterministic

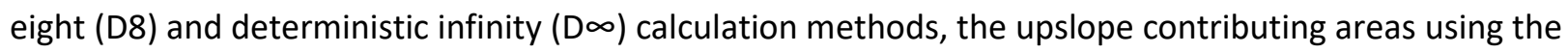
recursive upslope method, were calculated for use when calculating the compound topographic indices TWI and SPI. In addition to these six compound indices three additional indices, a SAGA wetness index $\left(\mathrm{TWI}_{\mathrm{s}}\right)$, modified SPI $\left(\mathrm{SPI}_{\mathrm{m}}\right)$ and convergence index $(\mathrm{Cl})$ were constructed. $\mathrm{Cl}$ is a terrain parameter that examines the aspect of surrounding cells and determines the degree to which those aspects point toward or away from a given cell (Koethe and Lehmeier, 1996). $\mathrm{TWI}_{\mathrm{s}}$ uses a modified catchment area calculation to better represent water dispersions in low slope areas (Boehner et al., 2002). The $\mathrm{SPI}_{\mathrm{m}}$ is the same SPI calculation but it is generated using the modified catchment area calculation of the $\mathrm{TWI}_{\mathrm{s}}$. All compound indices were exported as ESRI Grid files using SAGA 2.0. Lastly, the data was imported into Arc Map 10.2 and the respective TWI and SPI values attached to the sample point data. The combined data was than exported as .DBF files for analysis in Minitab version 17 (Minitab, 2012).

While the 3M DEM was the basis for all topographic data in this research, it is likely there is a local optimal resolution. Clearly there is some potential for a variation on the modifiable areal unit problem related to the artificial selection of $\mathbf{3 0}$ meter dimensionality. Specifically a DEM at another resolution or scale could generate different results. However a multi scale assessment to optimize DEM resolution to the study sites or the region is beyond the scope of this research. Additionally 30 meters is a resolution that is available statewide and is less resource dependent in terms of processing the DEM.

\section{Statistical Analysis and Modeling}

Surface and subsurface models were developed. All models included a STP term (individual data points or field averages). Stepwise regression was used to identify topographic variables that explain a significant portion of the variability in the sequential extracted $P$ fractions across all study sites. Alpha to enter and leave values of 0.05 were selected. Each $\mathrm{P}_{\mathrm{o}}$ and $\mathrm{P}_{\mathrm{i}}$ fraction for the surface and subsurface horizons relative to the modeling parameters S TWI, CI, ELE, MFD, Z Slope, D8 SPI, D8 TWI, DINF SPI, PRC, and TANC were examined. To determine final model parameters, the initial models with multiple landscape variables were reexamined. Where models were generated with multiple terms measuring the same phenomena and or spatial model terms were significantly correlated $(p \leq 0.05)$, selected model terms were removed. Model terms selected for removal were based on variance inflation factors, $p$ values, frequency of occurrence in other models, and expert knowledge. 
Randomly $30 \%$ of the data was selected for the purpose of model validation. After selecting model terms, the regression equations were applied to the validation data, and modeled the predicted values against the real data and measured the fit $\left(r^{2}\right)$ for each equation. Next field level averages were calculated from the sample data for M1 and M3 STP values in place of individual sample STP values and evaluated these predicted values against validation data and measured the fit $\left(R^{2}\right)$ for each equation. Lastly the fit of the M1 and M3 STP models was measured across all samples to determine which STP method explained the greatest portion of variability in the test data. This step was developed to determine how well each soil test data set did respectively when modeling the sequentially extracted $\mathrm{P}$ fractions over the landscape.

\section{Results and Discussion}

To facilitate the development of these models an extensive set spatially explicit sequentially extracted $\mathrm{P}$ data was used to develop and test a series of multiple regression models based on initial stepwise regression models. When the stepwise procedure was applied to the model dataset the predicted $\mathbf{r}^{2}$ ranged from a low of .528 for the subsurface $\mathrm{P}_{\mathrm{i}} \mathrm{M} 3-0.5 \mathrm{M} \mathrm{NaHCO}$ model to a high of .962 for the surface $P_{0}$ M1-1.0M HCl model (Table 5.1). However, when examined closer, several models contained terms that were potentially collinear and the lack of fit with some models could be an indication of inaccuracy and bias in the models (Minitab, 2012). Of the 18 initial landscape variables considered by the stepwise procedure, ten variables were included in at least one model (Table 5.2). The Pearson product moment correlation (Table 5.3) identified 16 significant $(p \leq 0.05)$ correlations between various landscape terms. Inclusion of multiple collinear model terms violates the basic assumptions inherent with regression models and thereby reducing the predictive utility of the model (Thompson et al., 1997). Two of more landscape variables were included in 14 of the regression models. In some instances, (Surface $\mathrm{P}_{\mathrm{i}} \mathrm{M} 1-\mathrm{DDI}$ $\mathrm{H}_{2} \mathrm{O}$ and Subsurface $\mathrm{P}_{\mathrm{o}} \mathrm{M1}-0.5 \mathrm{M} \mathrm{NaHCO}$ ) models had Mallows' $\mathrm{Cp}$ values more than double the number of model terms (Table 5.1) an indication of collinearity. In other instances, potential collinearity was identified when models contained compound terrain variables as well as some of their component primary terrain variable components. Thompson et al. (1997) point out how several of the models generated by Moore et al. (1993) used regression models with slope gradient and TWI to predict soil properties. The primary terrain variable slope gradient is a component in the TWI and using both has the potential to reduce the predictive utility of the model (Thompson et al., 1997).

To view selected model terms, see (Table $5.4 \& 5.5$ ). In general, model terms were selected that had lower variance inflation factors, lower $p$ values, and terms that occurred frequently in other models 
(Table 5.6). For example, the model for the surface inorganic $\mathrm{P}$ fraction extracted with $0.5 \mathrm{M} \mathrm{NaHCO}_{3}$, contained a slope gradient term and a compound terrain variable in which slope is a component (Table 5.4), and the subsurface inorganic $P$ fraction extracted with $D D I \mathrm{H}_{2} \mathrm{O}$, contained another compound terrain variable, and upslope contributing area term (Table 5.5). While not a component of the compound variable, the up slope contributing area term is another calculation of a component term. In both instance, there were significant correlations between the terms (Table 5.3), similar variance inflation factors (Table $5.4 \& 5.5$ ). The complete list of final regression models is provided in Table 5.7.

Among the models for the sequentially extracted $P_{i}$ fractions from the surface horizon samples, the term $\mathrm{TWI}_{\mathrm{s}}$ was included in six of eight models (Table 5.6). Among compound terrain variables, $\mathrm{TWI}$ is a good indicator of soil moisture (Pei et al., 2010) and TWI has been suggested as a tool to identify critical source areas (CSA) (Endreny and Wood 2003; Page et al., 2005). "The strong influence of terrain parameters on the soil spatial variation is now a well-known principle" (Park and Vlek 2002). Overall, in seven of eight models the terrain parameter model term (TWI or $\mathrm{Cl}$ ) was selected. Terrain parameters tend to be very effective soil predictors at the hillslope or field scale (Huggett, 1975; McKenzie and Austin, 1993; Gessler et al., 1995; Thompson et al., 1997; McBratney et al., 2000; Park and Vlek 2002). This is consistent with the way P movement was described by Smeck and Runge (1971) when they indicated P movement follows the direction of surface and subsurface water movement. The frequent inclusion of these terms reinforces the notion that hydrologic data needs to be integrated when identifying CSA, predicting P loss, and developing P management strategies (Collick et al., 2015).

The sequentially extracted $P_{0}$ fractions from the surface horizon samples behaved somewhat similar to the $P_{i}$ fractions. However, unlike the inorganic fractions where only M3 models did not contain the term $\mathrm{TWI}_{\mathrm{s}}$, the two models without $\mathrm{TWI}_{\mathrm{s}}$ in this group were in the same extractable fraction in both the M1 and M3 STP models. It would appear that $1.0 \mathrm{M} \mathrm{HCl}$ extracted $\mathrm{P}_{\mathrm{o}}$ fractions may be controlled by other factors. For example, as $\mathrm{pH}$ and other the concentrations of other ions change the forms of soil phosphorus also change (Smeck, 1973). In general, as pH drops less soluble and more occluded forms of P dominate (Smeck, 1973). In general, the $\mathrm{HCl}$ extractable pools are the non-available and or recalcitrant P pools (Ziadi et al 2013). It may be the relative stability of this fraction does not lend to downslope movement as seen in the other fractions. Similarly, others have indicated the $\mathrm{HCl}$ extractable fraction may be a sink for P (Haynes and Williams, 1992; Patzold et al. 2013). The continual and excessive additions of $\mathrm{P}$ to soils in temperate climates causes elevated levels of the most labile $\mathrm{P}$ fractions (Negassa and Leinweber 2009). Perhaps over time these mobile fraction satiate the sorption sites 
typically extracted by the stronger components in the sequential extraction and the spatial variability of that factor is adequately expressed by the variability in the routine soil test data.

The subsurface sequentially extracted inorganic $P$ fractions did not display the consistency in selected model terms found in the surface samples. Traditionally P transfer by subsurface pathways has been perceived as negligible (Turner and Haygarth, 2000). However, P does bypass much of the soil matrix via preferential flow (Kleinman et al., 2004; Harman et al., 20130. Clearly subsurface P movement is a less understood transport mechanism (Turner and Haygarth, 2000). As such, unlike the majority of the surface samples, within the inorganic fractions, only two of the eight models used the combination of $\mathrm{TWI}_{\mathrm{s}}$ and STP. Three models include other topographic variables (profile curvature, elevation, and SPI). This is consistent with the idea that topography can have an indirect effect on soil properties, and the distribution of P (Seibert et al. 2007; Vasques et al. 2010), but as a whole, the more mobile fraction (DDI $\mathrm{H}_{2} \mathrm{O}$, and $0.5 \mathrm{M} \mathrm{NaHCO}_{3}$ ) models tend to not have topographic components while the models for the less mobile fractions do include topographic components. This is consistent with mobile fractions moving rapidly away via subsurface flow and less mobile fractions persisting. As Rittenburger et al. (2015) pointed out, in subsurface pathways, strongly adsorbed chemicals tend to adhere to the soil matrix and become somewhat immobile. In the literature there are ample examples of $\mathrm{P}$ accumulating in the sub surface horizons of agricultural soils (Eghball et al., 1996; Hountin et al., 1997; Oehl et al., 2002; Stephenson and Chapman, 1931; Harman et al., 2013).

In the subsurface horizon, sequentially extracted $\mathrm{P}_{\mathrm{o}}$ fractions behaved in a pattern more consistent with the surface organic fractions. $\mathrm{TWI}_{\mathrm{s}}$ was a model tem in six of eight models. $\mathrm{P}$ applied with animal manure is generally more prone to leaching than inorganic fertilizer (Chardon et al., 1997; Eghball et al., 1996; Glæsner et al., 2011). As such the ability to model these fractions similarly to their surface counterparts is not unexpected. The only sequentially extracted fraction models not to include the term $\mathrm{TWI}_{\mathrm{s}}$ were the $1.0 \mathrm{M} \mathrm{HCl}$ fractions with the $\mathrm{M} 1$ and $\mathrm{M} 3$ model terms. Given the similarity of extraction mechanisms (strong acid and dilute double acid) it is it is understandable that such a model could explain $94.26 \%$ of the variability. The M3 model did not include a spatial term similar to its corresponding surface model. The models for the $1.0 \mathrm{M} \mathrm{HCl}$ fraction in the $\mathrm{M} 1 \mathrm{P}_{\mathrm{o}}$ subsurface, $\mathrm{M} 1 \mathrm{P}_{\mathrm{i}}$ subsurface, and the $\mathrm{M} 1 \mathrm{P}_{\mathrm{o}}$ surface models all contained the same model terms (list those model terms in parentheses here).

Overall, M1 models explained $89.35 \%$ of the variability in the validation data set, while the M3 models only explained $69.08 \%$ (Table 5.8). This may be an important distinction, as terrain variables are poorly correlated to various P forms across multiple land uses (Roger et al., 2014; Sarmadian et al., 2014), but 
have proven highly useful at identifying CSA and predicting $\mathrm{P}$ loss at field and sub field levels. While $\mathrm{P}$ variability can be substantial between fields, among land uses, and within fields (Page et al., 2005), the combination of actual soil test $P$ data and topographic data can adequately describe said variability and generate useful knowledge. When examined by soil test type (M1 vs. M3) some broad generalizations about the appropriateness of each soil test for the purpose of modeling sequentially extracted $P$ fractions could be made. For example, the $\mathrm{M} 1$ and $\mathrm{M} 3$ models were examined across all sample data by various grouping intervals (surface, subsurface, $\mathrm{P}_{\mathrm{o}}$ and $\mathrm{P}_{\mathrm{i}}$ ) to determine which soil test had the best overall fit. Among the surface samples, point value M1 STP data had an overall fit $\left(R^{2}\right)$ of $92.44 \%$ compared to the M3 STP data fit of $84.56 \%$. Among the subsurface models those numbers dropped to $84.13 \%$ and $54.56 \%$, respectively. Accordingly, it is critical to utilize a soil test parameter that is the best compromise between availability of data and simple fit of the predictive model. Overall, the M1 STP models yielded a higher $\mathrm{R}^{2}$, but in many instances both models have the ability to improve understanding and enhance the decision making processes.

Given the global frequency of $\mathrm{P}$ application in excess of removal (Kronvang et al., 2009), the acceleration of $P$ redistribution by agricultural practices (Rubaek et al., 2013) and need for models that reflect $P$ fate and transport (Kleinman et al., 2015) it is reasonable to expect such models may find practical application. Given this, it is prudent to consider how a model may be used as opposed to how it was intended to be used. While terrain variables are extensive in number and scope, and while terrain variables provide a great deal of important information about the various physical process that occur at a given location (Pei et al., 2010), discrete STP data for any or all fields or sub-field units of management in a region are generally not available. Often in agriculture producers sample at coarser scales than researchers may prefer for modeling P fate and or transport. Thus the best available STP data may at times be a single field value from a composite sample.

If applied in practice regionally in the poultry producing region of West Virginia, a single field average is likely the only data that would be available. While not specifically modeled for this use, it is likely that would be how these models would be applied. To understand the impact of using the incorrect data for these models, the field average STP data was utilized in place of the point data values. When this substitution was made for the surface models the $R^{2}$ values dropped (Table 5.8). However, when the same substitution was applied to the subsurface models the M3 model dropped but the M1 model improved slightly. Overall, the point data out performed field averages, but in many instances both models have the ability to improve understanding and decision making. 


\section{Conclusions}

The goal of these models was to develop a simple, affordable, and utilitarian approach for predicting sequentially extracted $\mathrm{P}$ fractions across complex landforms utilizing the best available data. Such models could facilitate frugality and equitableness in allocation of resources to identify locations for targeted mediation. Historically soil-landscape relationships have been used successfully at numerus scales to model many soil properties and characteristics (Moore et al. 1993; Gessler et al., 1995; Gessler et al., 2000; Omran, 2012). However, for such models to be successfully applied to the management of $\mathrm{P}$, soil-P- landscape models must accurately capture the impact of the various important processes controlling the distribution of $P$ at a given scale (Kleinman et al., 2015). In the context of these models, that means not only selecting the proper terrain variables, but also selecting the STP method that yields the greatest predictive power. The data is suggestive of an ability to adequately model the spatial distribution of sequentially extracted $\mathrm{P}$ data within individual fields from routine soil test data and readily available terrain data. Thus confirming $\mathrm{Ha}_{1}$ as soil landscape data and soil test $\mathrm{P}$ data were successfully used to model sequentially extracted $\mathrm{P}_{\mathrm{o}}$ models at landscape scales thus rejecting the $\mathrm{Ho}_{1}$. Likewise when the Mehlich 1 and Mehlich 3 soil test $P$ levels were used to model sequentially extracted $\mathrm{P}_{\mathrm{o}}$ fraction the Mehlich 1 models generally yielded models with higher $\mathrm{R}^{2}$ vales, thus rejecting $\mathrm{Ho}_{2}$.

In most cases a single field average from a typical agronomic soil test and the associated $\mathrm{TWI}_{\mathrm{s}}$ for that field would generate a map of highly labile, labile, moderately labile, and somewhat non-labile P for the field in question. From this data, conservation professionals could evaluate the infield area that is most likely to contribute significant $\mathrm{P}$ loss. In addition to a basic evaluation of potential loss, environmental and conservation professionals could in theory apply some sort of economic metric in terms of P loss prevented per dollar spent and spatially model competing scenarios for how to allocate resources. Clearly this model may not have adequate exportability to be useful at larger national scales, but in terms of grassland in the poultry producing region of West Virginia this may prove to be very useful.

Given the political climate in the Chesapeake Bay watershed, some locations with significant P accumulation could ultimately face mandatory mitigation. At that time $P$ loss assessment tools will be needed to implement mediation strategies. It is safe to assume there will never be adequate funding to pay for full implementation, and it is very unlikely that all producers would voluntarily make every desired remediation effort given the elevated $\mathrm{P}$ levels may have occurred while operating under previously acceptable management practices. This makes targeted remediation using available funding not only sensible, but a reasonable first step in a long term plan to eliminate much of the current P loss. 


\section{References}

ArcGIS. 2014. ArcGIS 10.3. ESRI Redlands CA.

Anderson, B.H. and F.R. Magdoff. 2005. Relative movement and soil fixation of soluble organic and inorganic phosphorus. J. Environ. Qual. 34:2228-2233.

Andersen, H.E., and B. Kronvang. 2006. Modifying and evaluating a P index for Denmark. Water Air and Soil Poll. 174(1-4): 341-353.

Beven, K. J. and M.J. Kirkby. 1979. A physically based, variable contributing area model of basin hydrology. Hydrol. Sci. Bull., 24, 43-69.

Blake, L., A.E. Johnston, P.R. Poulton and K.W.T. Goulding. 2003. Changes in soil phosphorus fractions following positive and negative phosphorus balances for long periods. Plant and Soil 254: 245261.

Bock, M., J. Bohner, O. Conrad, R. Kothe, and A. Ringeler. 2008. SAGA: System for the Automated Geoscientific Analysis. Dept. of Physical Geography, Hamburg, Germany. URL http://www.sagagis.org/en/index.html/ (verified 29 March 2013).

Boehner, J., R. Koethe, O. Conrad, J. Gross, A. Ringeler, T. Selige. 2002. Soil Regionalization by Means of Terrain Analysis and Process Parameterization. In: Micheli, E., Nachtergaele, F., Montanarella, L. [Ed.]: Soil Classification 2001. European Soil Bureau, Research Report No. 7, EUR 20398 EN, Luxembourg. pp. 213-222.

Bowman, R.A., and C.V. Cole. 1978. An exploratory method for fractionation of organic phosphorus from grassland soils. Soil Sci. 125, 95-101.

Brady, N. C., and R.R. Weill. 2002. The Nature and Properties of Soils; Prentice Hall: Englewood Cliffs, NJ.

Chang, S.C., and M.L. Jackson. 1957. Fraction of soil phosphorus. Soil Sci. 84:133-144.

Chardon, W., O. Oenema, P. del Castilho, R. Vriesema, J. Japenga, D. Blaauw, D., 1997. Organic phosphorus in solutions and leachates from soils treated with animal slurries. Journal of Environmental Quality. 26: 372-378. 
Collick, A., D. Fuka, P. Kleinman, A. Buda, J. Weld, M. White, T. Veith, R. Bryant, C. Bolster, Z. Easton. 2015. Predicting phosphorus dynamics in complex terrains using a variable source area hydrology model. Hydrol. Process. 29: 588-601.

Easton, Z.M., M.T. Walter, M. Zion, E.M. Schneiderman, T.S. Steenhuis. 2009. Including source-specific phosphorus mobility in a nonpoint source pollution model for agricultural watersheds. Journal of Environmental Engineering, ASCE 135(1): 25-35.

Eghball, B., G.D. Binford, D.D. Baltensperger. 1996. Phosphorus movement and adsorption in a soil receiving long-term manure and fertilizer application. Journal of Environmental Quality 25: 1339-1343.

Endreny, T.A., E.F. Wood. 2003. Watershed weighting of export coefficients to map critical phosphorus loading areas. J. Am. Water Resour. Assoc. 39: 165-181.

Galeone, D.G. 1996. Factors affecting phosphorus transport at a conventionally-farmed site in Lancaster County, Pennsylvania. 1992-95. U.S. Geological Survey Water-Resources Investigations Report 96-4168.

Gessler, P.E., O.A., Chadwick, F. Chamran, L. Althouse, and K. Holmes. 2000. Modelling soil-landscape and ecosystem properties using terrain attributes. Soil Science Society of America Journal, 64, 2046- 2056.

Gessler, P.E., I.D. Moore, N.J. McKenzie, P.J. Ryan. 1995. Soil-landscape Modelling soil-and spatial prediction of soil attributes. Int. J Geogr. Inf. Syst. 9: 421-432.

Girgin, B.N., and B.E. Frazier. 1996. Landscape position and surface curvature effects on soils developed in the Palouse area, WA. Washington State University, Department of Crop and Soil Sciences, Pullman, WA.

Glaesner, N., C. Kjaergaard, G.H. Rubaek, J. Magid. 2011. Interactions between soil texture and placement of dairy slurry application: II. Leaching of phosphorus forms. Journal Environmental Quality 40: 344-351.

Guppy, C.N., N.W. Menzies, P.W. Moody, B.L. Compton, F.P.C. Blamey. 2000. A simplified, sequential, phosphorus fractionation method. Communications in soil science and plant analysis. 31: $1981-$ 1991. 
Harman, M. B., J.A. Thompson, L.M. McDonald, E.M. Pena-Yewtukhiw, J. Beard. 2013. Phosphorus Translocation in Pastures on Benchmark Soils in West Virginia. Soil Horizons, 54(3).

Haynes, R. J., P.H. Williams. 1992. Long-term effect of superphosphate on accumulation of soil phosphorus and exchangeable cations on a grazed, irrigated pasture site. Plant Soil 142: 123133.

He, Z., C. W. Honeycutt, and T. S. Griffin. 2003. Comparative investigation of sequentially extracted phosphorus fractions in a sandy loam soil and a swine manure. Communications in soil science and plant analysis. Vol. 34, Nos. 11 \& 12, pp. 1729-1742.

Hedley, M.J., J.W.B. Stewart, and B.S. Chauhan. 1982. Changes in inorganic and organic soil phosphorus fractions induced by cultivation practices and by laboratory incubations. Soil. Sci. Soc. Am. J. 46, 970-976.

Hountin, J., D. Couillard, A. Karam. 1997. Soil carbon, nitrogen and phosphorus contents in maize plots after 14 years of pig slurry applications. Journal of Agricultural Science. 129: 187-191.

Huggett, R.J., 1975. Soil landscape systems: a model of soil genesis. Geoderma 13, 1- 22.

Jansson, M., H. Olsson, and K. Pettersson. 1988. Phosphatase: Origin, characteristics and function in lakes. Hydrobiologia 170:157-175.

Kirkby, M.J., Imeson, A.C., Bergkamp, G., Cammeraat, L.H., 1996. Scaling up processes and models from the field plot to the watershed and regional scale. Journal of Soil and Water Conservation 51, 391-396.

Kleinman, P.J.A., D.R. Smith, C.H. Bolster, Z.M. Easton. 2015. Phosphorus fate, management, and modeling in artificially drained systems. J. Environ. Qual. 44:460-466.

Kleinman, P.J.A., B.A. Needelman, A.N. Sharpley, and R.W. McDowell. 2004. Using soil phosphorus profile data to assess phosphorus leaching potential in manured soils. Soil Sci. Soc. Am. J. 67 (1): 215-224.

Knudsen, D. and D. Beegle. 1988. Recommended phosphorus tests. p. 12-15, In: W.C. Dahnke (ed.) Recommended Chemical Soil Tests Procedures for the North Central Region. Bulletin No. 499 (Revised). North Dakota Agric. Exp. Sta., Fargo, North Dakota. 
Koethe, R. \& F. Lehmeier. 1996. SARA - System zur Automatischen Relief-Analyse. User Manual, 2. Edition [Dept. of Geography, University of Goettingen, unpublished].

Kronvang, B., G.H. Rubaek, G. Heckrath. 2009. International phosphorus workshop: diffuse phosphorus loss to surface water bodies - risk assessment, mitigation options and ecological effects in river basins. Journal of Environmental Quality 38: 1924-1929.

Laboski, C.A.M., and J.A. Lamb. 2003. Changes in soil test phosphorus concentration after application of manure or fertilizer. Published in Soil Sci. Soc. Am. J. 67:544-554.

Liu, Z.P., M.A. Shao, Y.Q. Wang. 2013. Spatial patterns of soil total nitrogen and soil total phosphorus across the entire Loess Plateau region of China. Geoderma 197-198: 67-78.

McBratney, A.B., I.O.A. Odeh, T.F.A. Bishop, M.S. Dunbar, T.M. Shatar. 2000. An overview of pedometric techniques for use in soil survey. Geoderma 97, 293-327.

McKenzie, N.J., M.P. Austin. 1993. A quantitative Australian approach to medium and small scale surveys based on soil stratigraphy and environmental correlation. Geoderma 57, 329- 355.

McKenzie, N.J., and P.J. Ryan. 1999. Spatial prediction of soil properties using environmental correlation. Geoderma 89, 67-94.

Mehlich, A. 1984. Mehlich 3 soil test extractant: A modification of the Mehlich 2 extractant. Commun. Soil Sci. Plant Anal. 15(12):1409-1416.

Minitab. 2012. MINITAB 17. Minitab, State College, PA.

Moore, I.D., R. B. Grayson and A. R. Ladson. 1991 "Digital terrain modelling: A review of hydrological, geomorphological, and biological applications. Hydrological Processes, 5, 1: pp. 3-30.

Moore, I.D., P.E. Gessler, G.A. Nielsen, G.A. Peterson. 1993. Soil attribute prediction using terrain analysis. Soil Sci. Soc. Am. J. 57:443-452.

Negassa, W., P. Leinweber. 2009. How does the Hedley sequential phosphorus fractionation reflect impacts of land use and management on soil phosphorus: A review J. Plant Nutr. Soil Sci. 172: 305-325. 
Nelson W.L., A. Mehlich, E. Winters. 1953. The development, evaluation, and use of soil tests for phosphorus availability. In: Pierre, W.H., and A.G. Norman. Editors. Soil and fertilizer phosphorus. New York (NY): Academic Press, Inc. (Agronomy monograph series; 4). p 153-88.

Nelson, N.O., J.E. Parsons, and R.L. Mikkelson. 2005. Field-scale evaluation of phosphorus leaching in acid sandy soils receiving swine waste. J. Environ. Qual. 34(6): 2024-2035.

O'Callaghan, J. F. and D. M. Mark. 1984. The extraction of drainage networks from digital elevation data. Computer Vision, Graphics and Image Processing. 28: 328-344.

Oehl, F., A. Oberson, H.U. Tagmann, J.M. Besson, D. Dubois, P. Mader, H.R. Roth, E. Frossard. 2002. Phosphorus budget and phosphorus availability in soils under organic and conventional farming. Nutrient Cycling in Agroecosystems 62: 25-35.

Omran El, E., 2012. On-the-go digital soil mapping for precision agriculture. Int. J. Remote Sensing Appl. 2 (3): 1-18.

Park, S.J., and P.L.G. Vlek. 2002. Environmental correlation of three-dimensional soil spatial variability: a comparison of three adaptive techniques. Geoderma 109 (2002) 117- 140.

Pachepsky, Y.A., D.J. Timlin, and W.J. Rawls. 2001. Soil water retention as related to topographic variables. Soil Sci. Soc. Am. J. 65: 1787-1795.

Page T. P.M. Haygarth, K.J. Beven, A. Joynes, T. Butler, C. Keeler, J. Freer, P.N. Owens, and G.A. Wood. 2005. Spatial variability of soil phosphorus in relation to the topographic index and critical source areas: sampling for assessing risk to water quality. J. Environ. Qual. 34:2263-2277.

Park, S.J.; P.L.G. VLEK. 2002. Environmental correlation of three-dimensional soil spatial variability: comparison of three adaptive techniques. Geoderma 109: 117-140.

Patzold S., M. Hejcman, J. Barej, J. Schellberg. 2013. Soil phosphorus fractions after seven decades of fertilizer application in the Rengen Grassland Experiment. Journal of Plant Nutrition and Soil Science 176: 910-920.

Pei, T., C.Z. Qin, A.X. Zhu, L. Yang, M. Luo, B. Li, C. Zhou. 2010. Mapping soil organic matter using the topographic wetness index: A comparative study based on different flow-direction algorithms and kriging methods Ecological Indicators. 10: 610-619. 
Pierzynski, G.M., RW McDowell, J.T. Sims. 2005. Chemistry, cycling, and potential movement of inorganic phosphorus in soils. in J.T. Sims and A.N. Sharpley. 2005. Phosphorus: Agriculture and the Environment. Soil Science Society of America. Madison Wisconsin, USA. pp53-87.

Rittenburg, R.A., A.L. Squires, J. Boll, E.S. Brooks, Z.M. Easton, T. Steenhuis. 20145. Agricultural BMP effectiveness and dominant hydrological flow paths: concepts and a review. Journal of the American Water Resources Association 51(2): 305-329.

Roger, A., Z. Libohova, N. Rossier, S. Joost, A. Maltas, E. Frossard, S. Sinaj. 2004. Spatial variability of soil phosphorus in the Fribourg canton, Switzerland. Geoderma 217-218: 26-36.

Rubaek, G.H., K. Kristensen, S.E. Olesen, H.S. Ostergaard, G. Heckrath. 2013. Phosphorus accumulation and spatial distribution in agricultural soils in Denmark. Geoderma 209-210: 241-250.

Sarmadian, F. A. Keshavarzi, A. Rooien, M. Iqbal, G. Zahedi, H. Javadikia. 2014. Digital mapping of soil phosphorus using multivariate geostatistics and topographic information. AJCS 8(8):1216-1223.

Schroeder, P.D., and J.L. Kovar. 2006. Comparison of organic and inorganic phosphorus fractions in an established buffer and adjacent production field. Communications in Soil Science and Plant Analysis, 37: 1219-1232.

Seibert J, J. Stendahl, R. Sorensen. 2007. Topographical Influences on soil properties in Boreal Forests. Geoderma 141: 139-148.

Smeck, N.E. 1985. Phosphorus dynamics in soils and landscapes. Geoderma 36: 185-199.

Smeck, N.E. 1973. Phosphorus: and indicator of pedogenetic weathering processes. Soil Sci. 115: 199206.

Smeck, N.E. and E.C.A. Runge. 1971. Phosphorus availability and redistribution in relation to soil profile development in an Illinois landscape segment. Soil Sci. Soc. Am. Proc. 35: 952-959.

Stephenson, R.E., H.D. Chapman. 1931. Phosphate penetration in field soils. Journal of the American Society of Agronomy 23: 759-770.

Sui, Y., M.L. Thompson, and C. Shang. 1999. Fractionation of phosphorus in a Mollisol with biosolids. Soil Sci. Soc. Am. J. 63: 1174-1180. 
Thompson, J.A. E.M. Pena-Yewtukhiw, J.H. Grove. 2006. Soil-landscape modelling across a physiographic region: Topographic patterns and model transportability. Geoderma 133: pp. 57-70

Turner, B.L., and P.M. Haygarth. 2000. Phosphorus forms and concentrations in leachate from four grassland soil types. Soil Sci. Soc. Am. J. 64 (3):1090-1097.

U.S. Geological Survey (USGS) and West Virginia Statewide Addressing and Mapping Board (SAMB). 2003. West Virginia statewide digital elevation models. URL: http://wvgis.wvu.edu/data/dataset.php?ID=261 (verified May 15th 2016).

Vasques, G.M., S. Grunwald, N.B. Comerford, J.O. Sickman. 2010. Regional modelling of soil carbon at multiple depths within a subtropical watershed. Geoderma 156: 326-336.

Wang, L. \& H. Liu. 2006. An efficient method for identifying and filling surface depressions in digital elevation models for hydrologic analysis and modelling. International Journal of Geographical Information Science. 20 (2): 193-213.

Wang, Y., X. Zhang, C. Huang. 2009. Spatial variability of soil total nitrogen and soil total phosphorus under different land uses in a small watershed on the Loess Plateau, China. Geoderma 150 (1-2): 141-149.

Young, F.J., and R.D. Hammer. 2000. Soil-landform relationships on a loess-mantled, upland landscape in Missouri. Soil Sci. Soc. Am. J. 64:1443-1454.

Ziadat, F.M. 2005. Analyzing digital terrain attributes to predict soil attributes for a relatively large area. Soil Sci. Soc. Am. J., 69: 1590-1599.

Ziadi, N., J.K Whalen, A.J. Messiga, C. Morel. 2013. Assessment and modeling of soil available phosphorus in sustainable cropping systems. Adv. Agron. 122: 85-126. 


\section{Tables}

Table 5.1 Initial regression models using stepwise procedure with adjusted $\mathrm{R}^{2}$ - a modified version of R-squared that has been adjusted for the number of predictors in the model, Mallow's CP - when close to the number of predictors in a model indicates unbiased in estimating the true regression coefficients and predicting future responses and $\mathrm{S}$ the standard error of the regression

\begin{tabular}{|c|c|c|c|c|}
\hline & & \multirow{2}{*}{$\begin{array}{l}\text { Model } \\
\text { Adj. } \mathrm{R}^{2}\end{array}$} & \multicolumn{2}{|l|}{ Mallow's } \\
\hline Model & Stepwise regression equation & & $\mathrm{CP}$ & $\mathrm{s}$ \\
\hline Surface $P_{i} M 1$ DDI H2O & $\mathrm{Y}=-40.0+21.89 \mathrm{Z}$ Slope $+16.03 \mathrm{~S} \mathrm{TWI}+0.12151 \mathrm{M} 1 \mathrm{~S}$ & 85.04 & 15.56 & 22.3 \\
\hline Surface $P_{i}$ M1 0.5M NaHCO3 & $Y=-150.1+40.4$ Z Slope $+68.63 \mathrm{~S} \mathrm{TWI}+0.2866 \mathrm{M} 1 \mathrm{~S}$ & 85.60 & 16.48 & 48.6 \\
\hline Surface $P_{i} M 10.1 \mathrm{M} \mathrm{NaOH}$ & $Y=-388.2-0.4325 \mathrm{MFD}+230.5 \mathrm{~S}$ TWI $-8.65 \mathrm{D} 8 \mathrm{TWI}-0.0696 \mathrm{DINF}$ SPI + $0.6462 \mathrm{M} 1 \mathrm{~S}$ & 87.26 & 1.77 & 110 \\
\hline 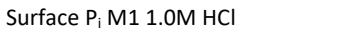 & $Y=-105.6-7663$ TANC $+60.2 \mathrm{STWI}+1.5076 \mathrm{M} 1 \mathrm{~S}$ & 95.52 & 1.19 & 140 \\
\hline Surface $P_{i} M 3$ DDI H2O & $Y=8.65+1.743 \mathrm{~m} 3 \mathrm{~s}$ & 60.20 & 7.94 & 34.7 \\
\hline Surface $P_{i} M 3 \quad 0.5 \mathrm{M} \mathrm{NaHCO}$ & $Y=-91.1+4.348 \mathrm{~m} 3 \mathrm{~s}+48.5 \mathrm{STWI}$ & 63.50 & 9.54 & 77.4 \\
\hline Surface $P_{\mathrm{i}} \mathrm{M} 3 \quad 0.1 \mathrm{M} \mathrm{NaOH}$ & $Y=-438.3+11.157 \mathrm{~m} 3 \mathrm{~s}-0.224 \mathrm{MFD}+202.6 \mathrm{~S}$ TWI & 78.23 & 4.25 & 144 \\
\hline 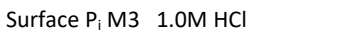 & $\mathrm{Y}=28.0+25.80 \mathrm{~m} 3 \mathrm{~s}-7.71 \mathrm{Cl}$ & 76.25 & 0.14 & 322 \\
\hline Surface $\mathrm{P}_{\mathrm{o}} \mathrm{M} 1 \mathrm{DDI} \mathrm{H} 2 \mathrm{O}$ & $\mathrm{Y}=-24.2+22.60 \mathrm{~S} \mathrm{TWI}+0.18152 \mathrm{M} 1 \mathrm{~S}$ & 85.23 & -1.0 & 32.9 \\
\hline Surface $\mathrm{P}_{0} \mathrm{M} 10.5 \mathrm{M}$ NaHCO3 & $\mathrm{Y}=-46.3+1.668 \mathrm{Cl}+59.2 \mathrm{~S} \mathrm{TWI}+0.2812 \mathrm{M} 1 \mathrm{~S}$ & 73.76 & -4.30 & 75.5 \\
\hline Surface $P_{0} \mathrm{M} 10.1 \mathrm{M} \mathrm{NaOH}$ & $\mathrm{Y}=-263+7.53 \mathrm{Cl}+319.4 \mathrm{~S} \mathrm{TWI}+0.9823 \mathrm{M} 1 \mathrm{~S}$ & 69.58 & 8.34 & 299 \\
\hline Surface $\mathrm{P}_{\mathrm{o}} \mathrm{M} 1$ 1.0M HCl & $\mathrm{Y}=-21.2-44.2 \mathrm{Z}$ ELEVATIO $+1.8775 \mathrm{M} 1 \mathrm{~S}$ & 96.18 & 3.50 & 166 \\
\hline Surface $P_{\circ} M 3$ DDI H2O & $Y=-12.5+2.986 \mathrm{~m} 3 \mathrm{~s}+17.02 \mathrm{~S}$ TWI & 72.38 & 3.92 & 43.7 \\
\hline Surface $\mathrm{P}_{0} \mathrm{M} 30.5 \mathrm{M}$ NaHCO3 & $\mathrm{Y}=-4.9+5.380 \mathrm{~m} 3 \mathrm{~s}+38.8 \mathrm{~S} \mathrm{TWI}$ & 74.22 & -3.58 & 74.9 \\
\hline Surface $P_{0} \mathrm{M} 30.1 \mathrm{M} \mathrm{NaOH}$ & $Y=-50+18.67 m 3 s+227.3 s$ TWI & 65.87 & 3.05 & 316 \\
\hline Surface $P_{0} M 31.0 M ~ H C l$ & $Y=-57.4+30.89 \mathrm{~m} 3 \mathrm{~s}$ & 80.03 & -1.35 & 379 \\
\hline Subsurface $P_{\mathrm{i}} \mathrm{M} 1 \mathrm{DDI} \mathrm{H} 2 \mathrm{O}$ & $\mathrm{Y}=0.50+0.08461 \mathrm{M} 1 \mathrm{~S}$ & 86.94 & -3.70 & 14.5 \\
\hline Subsurface $P_{i} M 10.5 \mathrm{M}$ NaHCO3 & $Y=42.8-4359 P R C+0.2665 \mathrm{M} 1 \mathrm{~S}$ & 70.07 & -1.70 & 74.6 \\
\hline Subsurface $P_{i} M 10.1 \mathrm{M} \mathrm{NaOH}$ & $\mathrm{Y}=-378.2+4.00 \mathrm{Cl}+162.9 \mathrm{~S} \mathrm{TWI}+0.5942 \mathrm{M} 1 \mathrm{~S}$ & 83.5 & 1.96 & 120 \\
\hline Subsurface $\mathrm{P}_{\mathrm{i}} \mathrm{M} 11.0 \mathrm{M} \mathrm{HCl}$ & $Y=4.9-37.3$ Z_ELEVATIO + 1.2702 M1S & 94.26 & -2.02 & 139 \\
\hline Subsurface $P_{\mathrm{i}} \mathrm{M} 3 \mathrm{DDI} \mathrm{H} 2 \mathrm{O}$ & $\mathrm{Y}=0.01+1.324 \mathrm{~m} 3 \mathrm{~s}$ & 65.70 & 1.49 & 23.5 \\
\hline Subsurface $P_{i} M 30.5 \mathrm{M} \mathrm{NaHCO} 3$ & $\mathrm{Y}=43.6+4.054 \mathrm{~m} 3 \mathrm{~s}$ & 52.83 & 0.61 & 93.7 \\
\hline Subsurface $P_{i} M 30.1 \mathrm{M} \mathrm{NaOH}$ & $Y=-254.2+10.985 \mathrm{~m} 3 \mathrm{~s}+110.5 \mathrm{~S} \mathrm{TWI}$ & 76.43 & 2.10 & 144 \\
\hline Subsurface $\mathrm{P}_{\mathrm{i}} \mathrm{M} 31.0 \mathrm{M} \mathrm{HCl}$ & $Y=-36.3+22.36 \mathrm{~m} 3 \mathrm{~s}-5.72 \mathrm{Cl}+0.1441 \mathrm{D} 8 \mathrm{SPI}$ & 77.63 & -1.28 & 274 \\
\hline Subsurface $P_{0} M 1$ DDI H2O & $Y=-36.7-0.0440 \mathrm{MFD}+24.69 \mathrm{~S} \mathrm{TWI}+0.15711 \mathrm{M} 1 \mathrm{~S}$ & 86.98 & 6.57 & 26.1 \\
\hline Subsurface $P_{0} \mathrm{M} 1 \quad 0.5 \mathrm{M}$ & $\mathrm{Y}=-101.4+2.175 \mathrm{Cl}+54.7 \mathrm{~S} \mathrm{TWI}+0.3218 \mathrm{M} 1 \mathrm{~S}$ & 84.62 & -6.81 & 63.2 \\
\hline Subsurface $\mathrm{P}_{\mathrm{o}} \mathrm{M} 1 \quad 0.1 \mathrm{M} \mathrm{NaOH}$ & $\mathrm{Y}=-587+11.00 \mathrm{Cl}+339.6 \mathrm{~S} \mathrm{TWI}+0.8370 \mathrm{M} 1 \mathrm{~S}$ & 71.85 & 3.23 & 261 \\
\hline Subsurface $\mathrm{P}_{\mathrm{o}} \mathrm{M} 1 \quad 1.0 \mathrm{M} \mathrm{HCl}$ & $Y=-42.8-48.0$ Z_ELEVATIO + $1.3785 \mathrm{M} 1 \mathrm{~S}$ & 90.99 & -5.66 & 193 \\
\hline Subsurface $P_{0}$ M3 DDI H2O & $Y=-43.2+2.739 \mathrm{~m} 3 \mathrm{~s}+32.3 \mathrm{ZSlope}+21.65 \mathrm{~S} \mathrm{TWI}$ & 75.76 & 5.94 & 35.6 \\
\hline Subsurface $\mathrm{P}_{\circ} \mathrm{M} 30.5 \mathrm{M}$ NaHCO3 & $Y=-52.8+6.134 \mathrm{~m} 3 \mathrm{~s}+30.9 \mathrm{STWI}+0.0297 \mathrm{D} 8 \mathrm{SPI}$ & 74.22 & 3.00 & 67.0 \\
\hline Subsurface $P_{0} M 30.1 \mathrm{M} \mathrm{NaOH}$ & $Y=-304+17.24 \mathrm{~m} 3 \mathrm{~s}+221.5 \mathrm{STWI}$ & 68.31 & 6.52 & 277 \\
\hline Subsurface $\mathrm{P}_{\mathrm{o}} \mathrm{M} 3$ 1.0M HCl & $Y=-69.3+22.80 \mathrm{~m} 3 \mathrm{~s}$ & 76.21 & 0.15 & 313 \\
\hline
\end{tabular}


Table 5.2 All topographic variables considered \& selected by the initial stepwise regression procedure

\section{Potential model terms Selected Variable type}

\begin{tabular}{|c|c|c|}
\hline Deterministic 8 up slope contributing area (D8) & & primary terrain variable \\
\hline Deterministic infinity up slope contributing area (INF) & & primary terrain variable \\
\hline Multiple flow direction up slope contributing area (MFD) & - & primary terrain variable \\
\hline Profile curvature (PRC) & $\bullet$ & primary terrain variable \\
\hline Plan curvature (PLC) & & primary terrain variable \\
\hline Tangential curvature (TANC) & - & primary terrain variable \\
\hline Z score of individual study site aspects (Z Aspect) & & primary terrain variable \\
\hline Z score of individual study site aspects slope (Z Slope) & - & primary terrain variable \\
\hline Z score individual study site aspects (Z Elevation) & - & primary terrain variable \\
\hline Convergence index $(\mathrm{Cl})$ & $\bullet$ & Compound terrain variable \\
\hline SPI from D8 up slope contributing area (D8 SPI) & - & Compound terrain variable \\
\hline TWI from D8 up slope contributing area (D8 TWI) & $\bullet$ & Compound terrain variable \\
\hline SPI from INF up slope contributing area (DINF SPI) & $\bullet$ & Compound terrain variable \\
\hline TWI from INF up slope contributing area (DINF TWI) & & Compound terrain variable \\
\hline SPI from saga modified contributing area (MC SPI) & & Compound terrain variable \\
\hline SPI from MFD up slope contributing area (MFD SPI) & & Compound terrain variable \\
\hline TWI from MFD up slope contributing area MFD TWI) & & Compound terrain variable \\
\hline Saga topographic wetness index (S TWI) & - & Compound terrain variable \\
\hline
\end{tabular}


Table 5.3 Pearson product moment correlation of topographic model terms selected by initial stepwise regression procedure.

\begin{tabular}{|c|c|c|c|c|c|c|c|c|c|}
\hline & 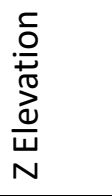 & $\begin{array}{l}\frac{\searrow}{O} \\
\frac{0}{n} \\
N\end{array}$ & $\begin{array}{l}\text { U } \\
a\end{array}$ & $\underset{⿱}{\longleftarrow}$ & $\stackrel{0}{\stackrel{0}{\Sigma}}$ & $\bar{\cup}$ & $\underset{\sim}{\sum}$ & 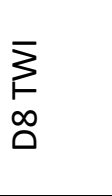 & $\begin{array}{l}\bar{a} \\
\tilde{n} \\
u \\
\stackrel{\Sigma}{\Delta}\end{array}$ \\
\hline \multirow{2}{*}{ Z Slope } & 0.221 & & & & & & & & \\
\hline & 0.052 & & & & & & & & \\
\hline \multirow{2}{*}{ PRC } & -0.027 & -0.063 & & & & & & & \\
\hline & 0.816 & 0.582 & & & & & & & \\
\hline \multirow{2}{*}{ TANC } & 0.007 & -0.067 & 0.465 & & & & & & \\
\hline & 0.955 & 0.561 & 0.000 & & & & & & \\
\hline \multirow{2}{*}{ MFD } & -0.176 & -0.289 & 0.012 & -0.356 & & & & & \\
\hline & 0.123 & 0.010 & 0.981 & 0.001 & & & & & \\
\hline \multirow{2}{*}{$\mathrm{Cl}$} & 0.236 & -0.030 & 0.167 & 0.453 & -0.597 & & & & \\
\hline & 0.038 & 0.792 & 0.144 & 0.000 & 0.000 & & & & \\
\hline \multirow{2}{*}{ S TWI } & -0.198 & -0.395 & -0.084 & -0.379 & 0.483 & -0.554 & & & \\
\hline & 0.083 & 0.000 & 0.465 & 0.001 & 0.000 & 0.000 & & & \\
\hline \multirow{2}{*}{ D8 TWI } & 0.034 & -0.033 & -0.027 & -0.043 & 0.193 & -0.102 & -0.001 & & \\
\hline & 0.767 & 0.774 & 0.816 & 0.712 & 0.091 & 0.376 & 0.993 & & \\
\hline \multirow{2}{*}{ DINF SPI } & 0.076 & 0.151 & 0.011 & 0.153 & -0.514 & 0.104 & -0.171 & -0.491 & \\
\hline & 0.509 & 0.186 & 0.927 & 0.181 & 0.000 & 0.367 & 0.135 & 0.000 & \\
\hline \multirow{2}{*}{ D8 SPI } & 0.061 & 0.113 & 0.019 & 0.111 & -0.363 & 0.049 & -0.120 & -0.559 & 0.822 \\
\hline & 0.599 & 0.322 & 0.868 & 0.335 & 0.001 & 0.671 & 0.296 & 0.000 & 0.000 \\
\hline
\end{tabular}


Table 5.4 Summary model data for surface stepwise regression models with potentially collinear model terms

Surface $\mathrm{P}_{\mathrm{i}} \mathrm{M} 1 \mathrm{DDI} \mathrm{H}_{2} \mathrm{O}$

\begin{tabular}{llllll}
\hline Term & Coef & SE Coef & T-Value & P-Value & VIF \\
Constant & -40.0 & 12.9 & -3.11 & 0.003 & \\
Z Slope & 21.89 & 8.20 & 2.67 & 0.009 & 1.24 \\
M1S & 16.03 & 4.12 & 3.89 & 0.000 & 1.15 \\
S TWI & 0.12151 & 0.00588 & 20.67 & 0.000 & 1.35 \\
\hline
\end{tabular}

Surface $\mathrm{P}_{\mathrm{i}} \mathrm{M} 10.5 \mathrm{M}$ NaHCO3

\begin{tabular}{llllll}
\hline Term & Coef & SE Coef & T-Value & P-Value & VIF \\
Constant & -150.0 & 29.4 & -5.11 & 0.000 & \\
Z Slope & 40.4 & 18.7 & 2.16 & 0.034 & 1.24 \\
S TWI & 68.63 & 9.42 & 7.28 & 0.000 & 1.35 \\
M1S & 0.2866 & 0.0134 & 21.34 & 0.000 & 1.15 \\
\hline
\end{tabular}

Surface $P_{i} \mathrm{M} 10.1 \mathrm{M} \mathrm{NaOH}$

\begin{tabular}{llllll}
\hline Term & Coef & SE Coef & T-Value & P-Value & VIF \\
Constant & -388.2 & 70.2 & -5.53 & 0.000 & \\
MFD & -0.4325 & 0.0881 & -4.91 & 0.000 & 1.76 \\
S TWI & 230.5 & 21.7 & 10.63 & 0.000 & 1.39 \\
D8 TWI & -8.65 & 3.89 & -2.22 & 0.029 & 1.33 \\
DINF SPI & -0.0696 & 0.0199 & -3.50 & 0.001 & 1.75 \\
M1S & 0.6462 & 0.0300 & 21.56 & 0.000 & 1.11 \\
\hline
\end{tabular}

Surface $\mathrm{P}_{\mathrm{i}} \mathrm{M} 11.0 \mathrm{M} \mathrm{HCl}$

\begin{tabular}{|c|c|c|c|c|c|}
\hline Term & Coef & SE Coef & T-Value & P-Value & VIF \\
\hline Constant & -105.6 & 80.5 & -1.31 & 0.194 & \\
\hline TANC & -7663 & 3614 & -2.12 & 0.037 & 1.21 \\
\hline STWI & 60.2 & 25.8 & 2.34 & 0.022 & 1.23 \\
\hline M1S & 1.5076 & 0.0384 & 39.22 & 0.000 & 1.14 \\
\hline \multicolumn{6}{|c|}{ Surface $P_{i} M 3 \quad 0.1 \mathrm{M} \mathrm{NaOH}$} \\
\hline Term & Coef & SE Coef & T-Value & P-Value & VIF \\
\hline Constant & -483.3 & 80.0 & -5.48 & 0.000 & \\
\hline M3S & 11.157 & 0.701 & 15.91 & 0.000 & 1.10 \\
\hline MFD & -0.224 & 0.100 & -2.24 & 0.028 & 1.33 \\
\hline S TWI & 202.6 & 27.9 & 7.27 & 0.000 & 1.35 \\
\hline
\end{tabular}


Table 5.5 Summary model data for subsurface stepwise regression models with potentially collinear model terms

\begin{tabular}{llllll}
\multicolumn{2}{l}{ Subsurface $\mathrm{P}_{\mathrm{i}} \mathrm{M} 1$} & $0.1 \mathrm{M} \mathrm{NaOH}$ & & & \\
\hline Term & Coef & SE Coef & T-Value & P-Value & VIF \\
Constant & -378.2 & 73.7 & -5.13 & 0.000 & 1.67 \\
Cl & 4.00 & 1.24 & 3.22 & 0.002 & 1.45 \\
S TWI & 162.9 & 24.1 & 6.77 & 0.000 & 1.27 \\
M1S & 0.5942 & 0.0349 & 17.00 & 0.000 & \\
\hline
\end{tabular}

Subsurface $\mathrm{P}_{\mathrm{i}} \mathrm{M} 3$ 1.0M HCl

\begin{tabular}{llllll}
\hline Term & Coef & SE Coef & T-Value & P-Value & VIF \\
Constant & -36.3 & 42.8 & -0.85 & 0.400 & 1.48 \\
M3S & 22.36 & 1.54 & 14.48 & 0.000 & 1.48 \\
Cl & -5.72 & 2.67 & -2.14 & 0.036 & 0.015 \\
D8 SPI & 0.1441 & 0.0578 & 2.49 & 00 & 1.00 \\
\hline
\end{tabular}

Subsurface $\mathrm{P}_{\mathrm{o}} \mathrm{M} 1 \mathrm{DDI} \mathrm{H}_{2} \mathrm{O}$

\begin{tabular}{llllll}
\hline Term & Coef & SE Coef & T-Value & P-Value & VIF \\
Constant & -36.7 & 14.5 & -2.52 & 0.014 & 1.31 \\
MFD & -0.0440 & 0.0180 & -2.44 & 0.017 & 1.38 \\
S TWI & 24.69 & 5.10 & 4.84 & 0.000 & 1.11 \\
M1S & 0.15711 & 0.00709 & 22.17 & 0.000 & \\
\hline
\end{tabular}

Subsurface $\mathrm{P}_{\mathrm{o}} \mathrm{M} 10.5 \mathrm{M} \mathrm{NaHCO} 3$

\begin{tabular}{|c|c|c|c|c|c|}
\hline Term & Coef & SE Coef & T-Value & P-Value & VIF \\
\hline Constant & -101.4 & 38.8 & -2.61 & 0.011 & \\
\hline $\mathrm{Cl}$ & 2.175 & 0.653 & 3.33 & 0.001 & 1.67 \\
\hline S TWI & 54.7 & 12.7 & 4.32 & 0.000 & 1.45 \\
\hline M1S & 0.3218 & 0.0184 & 17.50 & 0.000 & 1.27 \\
\hline \multicolumn{6}{|c|}{ Subsurface $\mathrm{P}_{\mathrm{o}} \mathrm{M} 10.1 \mathrm{M} \mathrm{NaOH}$} \\
\hline Term & Coef & SE Coef & T-Value & P-Value & VIF \\
\hline Constant & -587 & 160 & -3.66 & 0.000 & \\
\hline $\mathrm{Cl}$ & 11.00 & 2.70 & 4.08 & 0.000 & 1.67 \\
\hline S TWI & 339.6 & 52.3 & 6.49 & 0.000 & 1.45 \\
\hline M1S & 0.8370 & 0.0759 & 11.02 & 0.000 & 1.27 \\
\hline \multicolumn{6}{|c|}{ Subsurface $\mathrm{P}_{\mathrm{o}} \mathrm{M} 3 \mathrm{DDI} \mathrm{H}_{2} \mathrm{O}$} \\
\hline Term & Coef & SE Coef & T-Value & P-Value & VIF \\
\hline Constant & -43.2 & 21.8 & -1.98 & 0.052 & \\
\hline M3M & 2.739 & 0.178 & 15.38 & 0.000 & 1.16 \\
\hline Z Slope & 32.3 & 13.9 & 2.31 & 0.023 & 1.28 \\
\hline S TWI & 21.65 & 6.92 & 3.13 & 0.002 & 1.36 \\
\hline \multicolumn{6}{|c|}{ Subsurface $\mathrm{P}_{0} \mathrm{M} 3$ 0.5M NaHCO3 } \\
\hline Term & Coef & SE Coef & T-Value & P-Value & VIF \\
\hline Constant & -52.8 & 36.9 & -1.43 & 0.156 & \\
\hline M3M & 6.134 & 0.323 & 18.98 & 0.000 & 1.08 \\
\hline S TWI & 30.9 & 11.7 & 2.64 & 0.010 & 1.10 \\
\hline D8 SPI & 0.0297 & 0.0142 & 2.09 & 0.040 & 1.02 \\
\hline
\end{tabular}


Table 5.6 Frequency of terms across all initial stepwise regression models

\begin{tabular}{lcc}
\multicolumn{1}{c}{ Model Terms } & $\begin{array}{c}\text { Number of } \\
\text { Occurrences }\end{array}$ & $\begin{array}{c}\text { \% of models } \\
\text { including term }\end{array}$ \\
\hline Saga topographic wetness index (S TWI) & 20 & 62.5 \\
Convergence index (CI) & 7 & 21.9 \\
Z score individual study site elevation (ELE) & 3 & 9.4 \\
Multiple flow direction up slope contributing area (MFD) & 3 & 9.4 \\
Z score of individual study site slope (Z Slope) & 3 & 9.4 \\
SPI from D8 up slope contributing area (D8 SPI) & 2 & 6.3 \\
TWI from D8 up slope contributing area (D8 TWI) & 1 & 3.1 \\
SPI from INF up slope contributing area (DINF SPI) & 1 & 3.1 \\
Profile curvature (PRC) & 1 & 3.1 \\
Tangential curvature (TANC) & 1 & 3.1 \\
\hline
\end{tabular}


Table 5.7 Final regression models for sequentially extracted $\mathrm{P}$ fractions with adjusted $\mathrm{R}^{2}$ - a modified version of R-squared that has been adjusted for the number of predictors in the model, $\mathrm{R}^{2}$ fit 1 - fit against the validation set using point STP data, $\mathrm{R}^{2}$ fit 2 - fit against the validation set using field average STP data and S the standard error of the regression

Mode

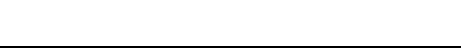

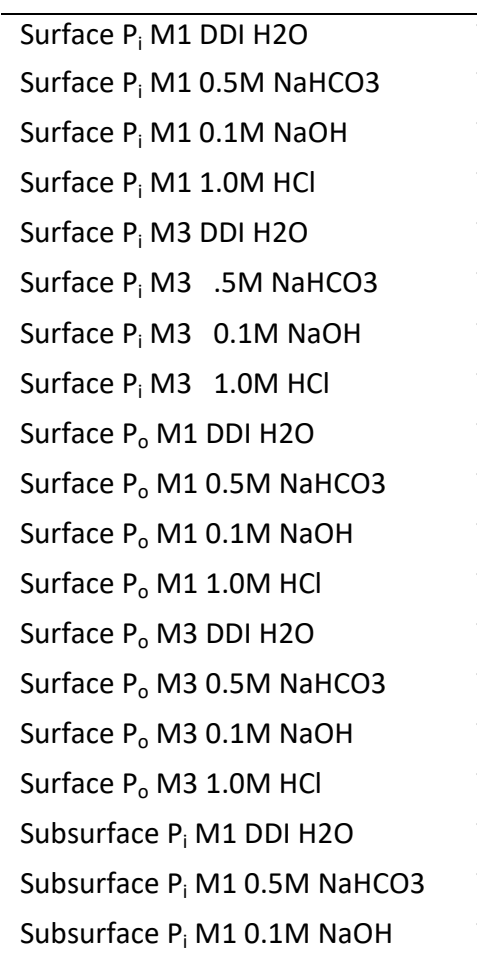

Subsurface $\mathrm{P}_{\mathrm{i}} \mathrm{M} 11.0 \mathrm{M} \mathrm{HCl}$

Subsurface $P_{i} M 3$ DDI H2O

Subsurface $\mathrm{P}_{\mathrm{i}} \mathrm{M} 30.5 \mathrm{M} \mathrm{NaHCO} 3$

Subsurface $\mathrm{P}_{\mathrm{i}} \mathrm{M} 30.1 \mathrm{M} \mathrm{NaOH}$

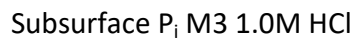

Subsurface $P_{0} M 1$ DDI H2O

Subsurface $\mathrm{P}_{\mathrm{O}} \mathrm{M} 10.5 \mathrm{M} \mathrm{NaHCO} 3$

Subsurface $P_{0} M 10.1 \mathrm{M} \mathrm{NaOH}$

Subsurface $P_{0} M 11.0 \mathrm{M} \mathrm{HCl}$

Subsurface $P_{\circ} M 3 D D I H 2 O$

Subsurface $\mathrm{P}_{\mathrm{O}} \mathrm{M} 30.5 \mathrm{M} \mathrm{NaHCO} 3$

Subsurface $P_{0} M 30.1 \mathrm{M} \mathrm{NaOH}$

Subsurface $\mathrm{P}_{\mathrm{o}} \mathrm{M} 31.0 \mathrm{M} \mathrm{HCl}$
Stepwise regression equation
Model

Adj. R2

$Y=-25.1+0.11832 \mathrm{M} 1 \mathrm{~S}+11.25 \mathrm{~S}$ TWI

$Y=-122.6+0.2807 \mathrm{M} 1 \mathrm{~S}+59.81 \mathrm{~S}$ TWI

$Y=-422.3+0.6617 \mathrm{M} 1 \mathrm{~S}+190.4 \mathrm{~S}$ TWI

$\mathrm{Y}=-161.6+1.4928 \mathrm{M} 1 \mathrm{~S}+77.9 \mathrm{~S}$ TWI

$\mathrm{Y}=8.65+1.743 \mathrm{~m} 3 \mathrm{~s}$

$Y=-91.1+4.348 m 3 s+48.5 \mathrm{~S}$ TWI

$Y=-404.2+11.371 \mathrm{~m} 3 \mathrm{~s}+174.8 \mathrm{~S}$ TWI

$Y=28.0+25.80 \mathrm{~m} 3 \mathrm{~s}-7.71 \mathrm{Cl}$

$Y=-24.2+0.18152 \mathrm{M} 1 \mathrm{~S}+22.60 \mathrm{~S}$ TWI

$Y=-0.6+0.2985 \mathrm{M} 1 \mathrm{~S}+43.3 \mathrm{~S}$ TWI

$Y=-56+1.0604 \mathrm{M} 1 \mathrm{~S}+247.7 \mathrm{~S}$ TWI

$Y=-21.2+1.8775 \mathrm{M} 1 \mathrm{~S}-44.2 \mathrm{Z}$ Elevation

$Y=-12.5+2.986 m 3 s+17.02 \mathrm{~S}$ TWI

$\mathrm{Y}=-4.9+5.380 \mathrm{~m} 3 \mathrm{~s}+38.8 \mathrm{STWI}$

$Y=-50+18.67 m 3 s+227.3 \mathrm{~S}$ TWI

$Y=-57.4+30.89 \mathrm{~m} 3 \mathrm{~s}$

$\mathrm{Y}=0.50+0.08461 \mathrm{M} 1 \mathrm{~S}$

$\mathrm{Y}=42.8+0.2665 \mathrm{M} 1 \mathrm{~S}-4359 \mathrm{PRC}$

$Y=-268.6+0.6357 \mathrm{M} 1 \mathrm{~S}+124.8 \mathrm{~S}$ TWI

$Y=4.9+1.2702 \mathrm{M} 1 \mathrm{~S}-37.3$ Z Elevation

$Y=0.01+1.324 \mathrm{~m} 3 \mathrm{~s}$

$Y=43.6+4.054 \mathrm{~m} 3 \mathrm{~s}$

$Y=-254.2+10.985 \mathrm{m3s}+110.5 \mathrm{~S}$ TWI

$Y=-36.3+22.36 \mathrm{~m} 3 \mathrm{~s}-5.72 \mathrm{Cl}$

$Y=-29.2+0.15856 \mathrm{M} 1 \mathrm{~S}+19.10 \mathrm{~S}$ TWI

$Y=-41.8+0.3444 \mathrm{M} 1 \mathrm{~S}+34.0 \mathrm{~S}$ TWI

$Y=-285+0.9512 \mathrm{M} 1 \mathrm{~S}+235.0 \mathrm{~S}$ TWI

$Y=-42.8+1.3785 \mathrm{M} 1 \mathrm{~S}$ -

$Y=-20.0+2.629 \mathrm{~m} 3 \mathrm{~s}+14.44 \mathrm{~S}$ TWI

$Y=-42.2+6.114 m 3 s+27.8 S$ TWI

$Y=-304+17.24 \mathrm{~m} 3 \mathrm{~s}+221.5 \mathrm{~S}$ TWI

$Y=-69.3+22.80 \mathrm{~m} 3 \mathrm{~s}$

\begin{tabular}{llll}
$83.8 \%$ & $73.4 \%$ & $78.3 \%$ & 22.1 \\
$84.9 \%$ & $89.0 \%$ & $81.2 \%$ & 49.8 \\
$82.9 \%$ & $78.0 \%$ & $81.3 \%$ & 128 \\
$95.3 \%$ & $95.7 \%$ & $89.3 \%$ & 143 \\
$60.2 \%$ & $55.6 \%$ & $63.7 \%$ & 34.7 \\
$63.5 \%$ & $74.0 \%$ & $69.1 \%$ & 77.4 \\
$77.1 \%$ & $69.9 \%$ & $79.3 \%$ & 148 \\
$76.3 \%$ & $81.1 \%$ & $82.2 \%$ & 322 \\
$85.2 \%$ & $75.0 \%$ & $80.1 \%$ & 32.0 \\
$72.5 \%$ & $78.6 \%$ & $66.6 \%$ & 77.3 \\
$67.6 \%$ & $61.3 \%$ & $62.9 \%$ & 308 \\
$96.2 \%$ & $95.5 \%$ & $77.5 \%$ & 166 \\
$72.4 \%$ & $77.1 \%$ & $78.4 \%$ & 43.7 \\
$74.2 \%$ & $84.3 \%$ & $66.0 \%$ & 74.9 \\
$65.9 \%$ & $61.1 \%$ & $61.8 \%$ & 316 \\
$80.0 \%$ & $80.9 \%$ & $67.2 \%$ & 379 \\
$86.9 \%$ & $58.4 \%$ & $72.0 \%$ & 14.5 \\
$70.1 \%$ & $75.8 \%$ & $71.0 \%$ & 74.6 \\
$81.5 \%$ & $65.3 \%$ & $75.9 \%$ & 128 \\
$94.3 \%$ & $95.3 \%$ & $92.6 \%$ & 139 \\
$65.7 \%$ & $43.7 \%$ & $63.9 \%$ & 23.5 \\
$52.8 \%$ & $64.4 \%$ & $62.6 \%$ & 93.7 \\
$76.4 \%$ & $62.4 \%$ & $75.4 \%$ & 144 \\
$77.6 \%$ & $37.0 \%$ & $32.3 \%$ & 274 \\
$86.1 \%$ & $65.6 \%$ & $76.0 \%$ & 27.0 \\
$82.6 \%$ & $76.2 \%$ & $80.8 \%$ & 67.3 \\
$66.0 \%$ & $32.5 \%$ & $48.1 \%$ & 287 \\
$74.0 \%$ & $93.5 \%$ & $81.8 \%$ & 192 \\
\hline $71.9 \%$ & $81.1 \%$ & $80.2 \%$ & 68.5 \\
\hline $78.3 \%$ & $34.2 \%$ & $48.2 \%$ & 277 \\
\hline $74.5 \%$ & $75.5 \%$ & 313
\end{tabular}


Table 5.8 Mean fit of Mehlich $1 \& 3$ models using point and field average soil test P values for surface, subsurface, and all data

\begin{tabular}{|c|c|c|}
\hline Modeled P fractions & Soil test model term & $\mathrm{R}^{2}$ \\
\hline \multirow{4}{*}{ Surface } & Mehlich 1 point test values & $92.4 \%$ \\
\hline & Mehlich 1 field average & $85.2 \%$ \\
\hline & Mehlich 3 point test values & $84.6 \%$ \\
\hline & Mehlich 3 field average & $81.4 \%$ \\
\hline \multirow{4}{*}{ Subsurface } & Mehlich 1 point test values & $84.1 \%$ \\
\hline & Mehlich 1 field average & $84.6 \%$ \\
\hline & Mehlich 3 point test values & $54.6 \%$ \\
\hline & Mehlich 3 field average & $52.4 \%$ \\
\hline \multirow{4}{*}{ All } & Mehlich 1 point test values & $89.4 \%$ \\
\hline & Mehlich 1 field average & $85.1 \%$ \\
\hline & Mehlich 3 point test values & $69.1 \%$ \\
\hline & Mehlich 3 field average & $66.0 \%$ \\
\hline
\end{tabular}




\section{Chapter 6. Summary}

\section{Summary of Findings}

$\mathrm{P}$ management is more than a scientific endeavor; it is an issue of science, economics, and politics. As such, evolving technology, changing socioeconomic factors and the current political will generates an elastic target in terms of what is or is not an acceptable level of $P$ saturation in soils and dissolved $P$ in surface waters. This evolving target does place some agriculturalists in some locations between the proverbial rock and a hard place. The availability of low cost P-rich sources of $\mathrm{N}$ places economic pressures to apply said $\mathrm{N}$ sources liberally at the expenses of over application of $\mathrm{P}$. As the impacts of excessive $\mathrm{P}$ accumulation become more apparent, the availability of low-cost animal manure fertilizers decline, and the political will to regulate agriculture increases, acceptable levels of $P$ will likely be lowered. It is very likely producers and conservation professionals will soon face difficult management decisions. How scientists, environmental mangers, conservationists, and members of the production agriculture community deal with this will become critical in the near future. Thus, the issues which have the most relevance not only in terms of best management practices moving forward but in terms of how environmental professionals address the problems associated with management strategies from the past must be addressed. This research in part addresses several of these issues.

\section{Bench Top Experiments}

Understanding the interactions between soils, fertilizers, and management practices is critical for sustainable agriculture and environmental protection (Harman et al., 2013). However, much of what is known in terms of such interactions comes from controlled laboratory experiments and field trials. Furthermore, the conditions in the lab experiments are often different from the conditions in the field. In particular, field trials lack the controls in place in bench top experiments. One aspect of this research focused on applying experimental conditions that more closely resemble field conditions to a traditional incubation experiment, and then characterizing the fate of that $\mathrm{P}$ via a sequential $\mathrm{P}$ extraction procedure.

A sequential $P$ fractionation is a series of chemical extractions to characterize $P$ by the type and/or strength of the assumed physicochemical interactions with the soil (Bowman and Cole 1978; Hedley et al., 1982; Cross and Schlesinger, 1995; Negassa and Leinweber 2009; Gagnon et al., 2012). Soil from locations with differing management histories were incubated over a period of time following one of several $\mathrm{P}$ treatments both with and without the presence of actively growing plants. During the course 
of this research it was determined there were significant differences between several fractions relative to $\mathrm{P}$ source and fertilization history, but no difference relative the presence of vegetation. This is a somewhat common approach to define changes in soil P pools (Warren et al., 2008; He et al., 2004; Qian and Schoenau, 2000; Yang et al., 2002; Negassa and Leinweber 2009; Gagnon et al., 2012). In general, the results of this research agree with other results in terms of the effect of management history (Fox and Kamprath, 1970; Pote et al., 2003; Bond et al., 2006). In other aspects (impact of P source on P distribution and fractionation) there are conflicting results. One collection of papers (Eghball et al. 2005; Sikora and Enkiri 2005; Zvomuya et al. 2006; Sneller and Laboski 2009) indicate source of P was not important in terms of $\mathrm{P}$ distribution and fractionation while another (Gracy 1984; Motavalli et al. 1989; Sharpley and Sisak 1997; Griffin et al. 2003; Miller et al. 2010) indicated it was. These results concur with the second group. However, results did not indicate and effect from actively growing vegetation.

\section{Identifying Actual Patterns in Sequentially Extracted P Fractions}

Organic $P\left(P_{0}\right)$ in soil is the lesser studied part of the total $P$ pool. Understanding $P_{0}$ is critical in managing potential $\mathrm{P}$ loss to the environment. If one were to assume $\mathrm{P}_{\mathrm{o}}$ moves across and within landscapes, it would be expected that evidence of that movement would be identified when the sequentially extracted $\mathrm{P}_{\mathrm{o}}$ fractions are examined across management units. However, a pattern is not always indicative of what is assumed to be causing it. Thus, to make that distinction clearer, it requires a deeper examination of the data. To determine if $\mathrm{P}_{\mathrm{o}}$ has moved over time on these research sites, sequentially extracted $P$ fractions were analyzed for spatial significance (an indication that the $P_{0}$ levels seen across the landscape were not random). Next statistical techniques were used to identify soil properties that could explain some of the patterns seen in the $P_{0}$ data, and other techniques were used to determine if the remaining variability in the $\mathrm{P}_{\mathrm{o}}$ data still exhibited spatial significance (a nonrandom pattern across the landscape).

To address the issue of true spatial significance, regression and Mantel tests (Bruland and Richardson, 2004) were used to identify those soil properties that explained a significant portion of the $P_{0}$ variability, then fixed the effect of those variables and examined the residual variability for spatial dependence. Results identified $0.5 \mathrm{M} \mathrm{NaHCO}_{3}$ and $1.0 \mathrm{M} \mathrm{HCl}$ extractable $\mathrm{P}_{\mathrm{o}}$ fractions as exhibiting a pure spatial component in their distribution (real spatial pattern not explained by changes in soil properties). Other extractable fractions did not exhibit such spatial structure. 


\section{Explaining Spatially Significant Patterns in Sequentially Extracted P Fractions}

The next logical step after determining a spatially significant pattern in sequentially extracted $\mathrm{P}_{\mathrm{o}}$ fractions across the study sites has occurred is to try and understand why. The initial assumption is the differentiation in $\mathrm{P}_{\mathrm{o}}$ fractions is related to redistribution of $\mathrm{P}_{\mathrm{o}}$ via the movement of water. There are numerous examples of using topographic data to model moisture, water movement, and soil properties (e.g., Moore et al., 1991; Hornberger \& Boyer, 1995; Iverson et al., 1997; Famiglietti et al. 1998; Boerner et al., 2000; Gessler et al., 2000; Western et al. 2001; Mohanty and Skaggs 2001; Case et al., 2005). Thus, one can reasonably expect there to be some topographic metric that relates to water movement that will explain the variability seen in the $\mathrm{P}_{\mathrm{o}}$ data, assuming the distribution is, in fact, related to the movement of water.

Among topographic data, the variables can be generally described as primary or secondary (sometimes called compound) attributes (Bishop and Minasny 2006). Common primary attributes are slope gradient, slope aspect, and slope curvature. One of the most common secondary attributes is the topographic wetness index (TWI) (Bishop and Minasny 2006). In general, secondary attributes tend to be more useful than primary attributes for predicting soil properties (Bell et al. 1994; Gessler et al., 1995; McBratney et al., 2000; Bishop and Minasny 2006). In particular, TWI describes the likelihood of a location to accumulate water due to its surrounding topography (Gruber and Peckham, 2009). Another compound attribute related to water movement is the stream power index (SPI), which describes erosion and related landscape processes (Moore et al., 1991). These compound attributes utilize variables that can be calculated multiple ways. In this research, the common primary and compound terrain attributes and the multiple ways terrain attributes can be calculated were examined to determine if terrain attributes explained the residual variability in $\mathrm{P}_{\mathrm{o}}$ distributions not explained by changes in soil properties.

It is reasonable to assume one would be able to explain the $P_{o}$ distribution using these variables. In fact, Moore et al. (1993) successfully used to TWI to explain STP data at field scale. When this approach was applied to this data, the variability not explained by changes in soil properties was adequately explained by terrain attributes. Specifically, in the location with the longest history of manure applications, a spatial pattern in the $1.0 \mathrm{M} \mathrm{HCl}$ extractable $P_{\mathrm{o}}$ fraction in the surface samples was identified, the combination of Mehlich 1 extractable $\mathrm{Ca}$, field subdivision and topographic wetness index explained the spatially autocorrelated variability at the location. In the other location with an extensive history of manure applications (but to a muck lower extent than the previous location) showed similar patterns in the $0.5 \mathrm{M} \mathrm{NaHCO} 3$ extractable $\mathrm{P}_{\mathrm{o}}$ fraction from the surface samples. Similarly, when soil and 
topographic properties were used to model variability, the spatially autocorrelated variability was full explained. This further reinforces the concept of $\mathrm{P}_{\mathrm{o}}$ movement by water and indicates the potential utility of topographic variables for modeling purposes.

\section{Modeling Sequentially Extracted P Fractions Across Complex Landforms}

Upon determining the topographic relationship to the observed spatial variability seen in $\mathrm{P}_{\mathrm{o}}$ fractions cross complex landforms, the goal was to develop predictive models for sequentially extracted $\mathrm{P}$ fractions. Knowing P mobility depends on hydrological and chemical processes (Galeone, 1996; Easton et al., 2009) there was a reasonable expectation that these P distributions could be modeled. Given that P movement follows the direction of surface and subsurface water movement (Smeck and Runge, 1971) and that the movement of water and other materials are controlled by slope configuration (Huggett, 1975), one would expect topographic variables to become significant model terms. To this end, the spatially explicit sequentially extracted $\mathrm{P}$ data was divided into a model building and model testing data set. The data was used to establish a series of statistical soil-landscape models that best explained the spatial distributions these $P$ fractions across hay and grass pastures in West Virginia, and those models compared to the actual values identified in the model test data set.

Successful models were developed. The models explained between $56 \%$ and $98 \%$ of the variability in the data. Mehlich1 STP (M1) data generally had better R2 values then the Mehlich 3 STP (M3) data. Spatially explicit STP data for the most part explained a higher percentage of variability than field averages. However, all models (M1 vs. M3 and Point vs. Field) performed well enough to potentially be useful.

\section{Implications}

Existing benchtop research can be accepted at face value. The presence of vegetation does not appear to alter the transformations of $P$ in incubation studies. Sequentially extracted $P$ fractions appear to establish themselves across landscapes in predictable patterns. Some of the spatial variability can be explained by changes in soil properties. However, this could be in part related to possible collinearity between soil properties and patterns of water movement. When fixed for changes in soil properties, few fractions exhibit patterns of spatial significance. When the variability explained by TWI was taken in account, none of the sequentially extracted $\mathrm{P}$ fractions were spatially autocorrelated. However, this does not mean sequentially extracted P fractions cannot be modeled successfully. In fact, STP levels alone and in conjunction with topographic variables can be used to create adequate models.

In time, efforts will begin to further reduce P loss into the environment. When this occurs, environmental managers will have the ability to identify the fractions that pose the greatest risk of loss, 
model interception strategies, and plot regional responses. As the P source in the environment that needs to be sequestered is identified, environmental professionals can develop techniques to sorb, restrain, or otherwise physically stop the $\mathrm{P}$ loss. The modeling techniques outlined here would enable conservation professionals to better describe risk on a field by filed basis. The modeling techniques outlined here would enable conservation professionals to allocate funds to locations with the highest potential P retained per dollar spent. 


\section{References}

Bell, J.C., C.A. Butler, J.A. Thompson. 1994. Soil-terrain modelling for site specific agricultural management. In Site specific management for agricultural systems, P.C. Robert, R.H. Rust, W.E. Larson, Eds. ASA-CSSA-SSSA, Madison WI, pp 209-228.

Bishop, T.F.A., and B. Minasny. 2006. Digital soil-terrain modeling: the predictive potential and uncertainty. In: Grunwald, S. (Ed.), Environmental Soil-Landscape Modeling - Geographic Information Technologies and Pedometrics. CRC Press, New York, pp. 185-214.

Boerner, R.E.J., Morris, S.J., Sutherland, E.K. \& Hutchinson, T.F. 2000. Spatial variability in soil nitrogen dynamics after prescribed burning in Ohio mixed-oak forests. Landscape Ecology, 15, 425- 439.

Bond, R., R.O. Maguire, and J. L. Havlin. 2006. Change in soluble phosphorus in soils following fertilization is dependent on initial mehlich-3 phosphorus. J. Environ. Qual. 35:1818-1824.

Bowman, R.A., and C.V. Cole. 1978. An exploratory method for fractionation of organic phosphorus from grassland soils. Soil Sci. 125, 95-101.

Bruland, G.L., and C.J. Richardson. 2004. A spatially explicit investigation of phosphorus sorption and related soil properties. J. Environ. Qual. 33:785-794.

Case, B.S., Meng, F.-R. \& Arp, P.A. 2005. Digital elevation modelling of soil type and drainage within small forested catchments. Canadian Journal of Soil Science, 85, 127-137.

Cross, A.F., and W.H. Schlesinger. 1995. A literature review and evaluation of the Hedley fractionation: applications to the biogeochemical cycle of soil phosphorus in natural ecosystems. Geoderma 64, 197-214.

Easton, Z.M., M.T. Walter, M. Zion, E.M. Schneiderman, T.S. Steenhuis. 2009. Including source-specific phosphorus mobility in a nonpoint source pollution model for agricultural watersheds. Journal of Environmental Engineering, ASCE 135(1): 25-35.

Eghball, B. J. Wienhold, B. L. Woodbury, and R. A. Eigenberg. 2005. Plant availability of phosphorus in swine slurry and cattle feedlot manure. Agronomy Journal, vol. 97, no. 2, pp. 542-548.

Famiglietti, J. S., J.W. Rudnicki, M. Rodell. 1998. Variability in surface moisture content along a hillslope transect: Rattlesnake Hill, Texas, Journal of Hydrology, 210, 259-281. 
Fox, R.L., and E.J. Kamprath. 1970. Phosphorus sorption isotherms for evaluating the phosphate requirement of soils. Soil Sci. Soc. Am. Proc. 34:902-907.

Gagnon, B., I. Demers, N. Ziadi, M.H. Chantigny, L.E. Parent, T.A, Forge, F.J. Larney, and K.E. Buckley. 2012. Forms of phosphorus in composts and in compost-amended soils following incubation. Can. J. Soil Sci. 92: 711_721.

Galeone, D.G. 1996. Factors affecting phosphorus transport at a conventionally-farmed site in Lancaster County, Pennsylvania. 1992-95. U.S. Geological Survey Water-Resources Investigations Report 96-4168.

Gessler, P.E., O.A., Chadwick, F. Chamran, L. Althouse, and K. Holmes. 2000. Modelling soil-landscape and ecosystem properties using terrain attributes. Soil Science Society of America Journal, 64, 2046- 2056.

Gessler, P.E., I.D. Moore, N.J. McKenzie, P.J. Ryan. 1995. Soil-landscape Modelling soil-and spatial prediction of soil attributes. Int. J Geogr. Inf. Syst. 9: 421-432.

Gracey, H.I. 1984. Availability of phosphorus in organic manures compared with monoammonium phosphate. Agricultural Wastes, vol. 11, no. 2, pp. 133-141.

Griffin, T.S., C. W. Honeycutt, Z. He. 2003. Changes in soil phosphorus from manure application. Soil Science Society of America Journal, vol. 67, no. 2, pp. 645-653.

Gruber, S. and S. Peckham. 2009. Land-surface parameters and objects in hydrology. In: Hengl, T., and Reuter H.I. (Eds.): Geomorphometry: concepts, software, applications (Vol. 33). Elsevier Science.

Harman, M.B., J.A. Thompson, L.M. McDonald, E.M. Pena-Yewtukhiw, J. Beard. 2013. Phosphorus translocation in pastures on benchmark soils in West Virginia. Soil Horizons Vol.54 - No.3.

He, Z., T.S. Griffin, and C.W. Honeycutt. 2004. Evaluation of soil phosphorus transformations by sequential fractionation and phosphatase hydrolysis. Soil Sci. 169:515-527.

Hedley, M.J., J.W.B. Stewart, and B.S. Chauhan. 1982. Changes in inorganic and organic soil phosphorus fractions induced by cultivation practices and by laboratory incubations. Soil. Sci. Soc. Am. J. 46, 970-976. 
Hornberger, G.M. \& Boyer, E.W. 1995. Recent advances in watershed modelling. Review of Geophysics, 33, 949-957.

Huggett, R.J., 1975. Soil landscape systems: a model of soil genesis. Geoderma 13, 1- 22.

Iverson, L.R., Dale, M.E., Scott, C.T. \& Prasad, A. 1997. A GIS-derived integrated moisture index to predict forest composition and productivity of Ohio forests (U.S.A). Landscape Hydrology, 12, 331-348.

McBratney, A.B., I.O.A. Odeh, T.F.A. Bishop, M.S. Dunbar, T.M. Shatar. 2000. An overview of pedometric techniques for use in soil survey. Geoderma 97: 293-327.

Miller, J.C., T. Astatkie, A. Madani. 2010. Soil test phosphorus from livestock manures compared with inorganic fertilizers in soil incubations. Applied and Environmental Soil Science. 2010:1-6.

Mohanty, B. P., and T. H. Skaggs. 2001. Spatio-temporal evolution and time-stable characteristics of soil moisture within remote sensing footprints with varying soil, slope, and vegetation. Advances in Water Resources. 24. 1051-1067.

Moore, I.D., P.E. Gessler, G.A. Nielsen, G.W. Peterson. 1993. Soil attribute prediction using terrain analysis. Soil Science Society of America Journal 57, 443- 452.

Moore, I.D., R. B. Grayson and A. R. Ladson. 1991 "Digital terrain modelling: A review of hydrological, geomorphological, and biological applications. Hydrological Processes, 5, 1: pp. 3-30.

Motavalli, P.P., K. A. Kelling, and J. C. Converse. 1989. First-year nutrient availability from injected dairy manure. Journal of Environmental Quality, vol. 18, no. 2, pp. 180-185.

Negassa W. and P. Leinweber. 2009. How does the hedley sequential phosphorus fractionation reflect impacts of land use and management on soil phosphorus: a review. J Plant Nutr. Soil Sci. 172:305-325.

Pote, D.H., J.A. Lory, and H. Zhang. 2003. Does initial soil P level affect water-extractable soil P response to applied P? Adv. Environ. Res. 7:503-509.

Qian, P., and J.J. Schoenau. 2000. Fractionation of P in soil as influenced by a single addition of liquid swine manure. Can. J. Soil Sci. 80:561-566. 
Sharpley, A.N. and I. Sisak. 1997. Differential availability of manure and inorganic sources of phosphorus in soil. Soil Science Society of America Journal, vol. 61, no. 5, pp. 1503-1508.

Sikora, L.J., and N. K. Enkiri. 2005. Comparison of phosphorus uptake from poultry litter compost with triple superphosphate in codorus soil. Agronomy Journal, vol. 97, no. 3, pp. 668-673.

Smeck, N.E. and E.C.A. Runge. 1971. Phosphorus availability and redistribution in relation to soil profile development in an Illinois landscape segment. Soil Sci. Soc. Am. Proc. 35: 952-959.

Sneller, E.G., and C. A.M. Laboski. 2009. Phosphorus source effects on corn utilization and changes in soil test. Agronomy Journal, vol. 101, no. 3, pp. 663-670.

Warren, J.G., C.J. Penn, J.M. McGrath, K. Sistani. 2008. The impact of alum addition on organic $p$ transformations in poultry litter and litter-amended soil. J. Environ. Qual. 37:469-476.

Western A., G. Bloschl and R. Grayson. 2001. Toward capturing hydrologically significant connectivity in spatial patterns. Water Resources Research, 37, 83-97, 2001.

Yang, J.E., C.A. Jones, H.J. Kim, and J.S. Jacobsen. 2002. Soil inorganic phosphorus fractions and Olsen-P in phosphorus-responsive calcareous soils: Effects of fertilizer amount and incubation time. Commun. Soil Sci. Plant Anal. 33:855-871.

Zvomuya, F., B. L. Helgason, F. J. Larney, H. H. Janzen, O. O. Akinremi, B. M. Olson. 2006. Predicting phosphorus availability from soil-applied composted and non-composted cattle feedlot manure. Journal of Environmental Quality, vol. 35, no. 3, pp. 928-937. 


\section{Appendix}

\section{Sequentially extracted phosphorus fractions (benchtop)}

History: $\mathrm{Hi}$ - long history of manure application Low - little to no manure application; Treatment: C - Control , LM -Leached Manure, M Manure, ML Manure Leachate, $\mathrm{P}_{\mathrm{i}}$ - Inorganic $\mathrm{P}, \mathrm{P}_{\mathrm{o}}$ - organic $\mathrm{P}$; Vegetation: $\mathrm{B}$ - bare/no vegetation, $\mathrm{V}$ - with actively growing plants/vegetation; Rep: replicate sample number; Sequential extracted fraction: $\mathrm{H} 2 \mathrm{Ot}$ - Deionized distilled water extractable total P fraction, $\mathrm{H} 2 \mathrm{Oi}$ - Deionized distilled water extractable inorganic $\mathrm{P}$ fraction, $\mathrm{H} 2 \mathrm{Oo}$ - Deionized distilled water extractable total P fraction, $\mathrm{NaHCO} \mathrm{t}$ - NaHCO3 extractable total $\mathrm{P}$ fraction, $\mathrm{NaHCO} 3 \mathrm{i}$ - NaHCO3 extractable inorganic $\mathrm{P}$ fraction, $\mathrm{NaHCO} 3 \mathrm{o}-\mathrm{NaHCO} 3$ extractable organic $\mathrm{P}$ fraction, $\mathrm{NaOHt}-\mathrm{NaOH}$ extractable total $\mathrm{P}$ fraction, $\mathrm{NaOHi}-\mathrm{NaOH}$ extractable inorganic $\mathrm{P}$ fraction, $\mathrm{NaOHo}-\mathrm{NaOH}$ extractable organic $\mathrm{P}$ fraction, $\mathrm{HClt}-\mathrm{HCl}$ extractable total $\mathrm{P}$ fraction, $\mathrm{HCli}$ - $\mathrm{HCl}$ extractable inorganic $\mathrm{P}$ fraction, $\mathrm{HClo}-\mathrm{HCl}$ extractable organic $\mathrm{P}$ fraction

\begin{tabular}{|c|c|c|c|c|c|c|c|c|c|c|c|c|c|c|c|c|}
\hline$\cong$ & $\begin{array}{l}\text { 产 } \\
\text { 旁 }\end{array}$ & 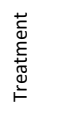 & 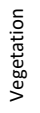 & $\stackrel{\Omega}{2}$ & $\begin{array}{l}\stackrel{+}{0} \\
\text { In }\end{array}$ & 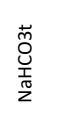 & $\begin{array}{l}\text { 蒿 } \\
\text { z }\end{array}$ & 节 & ָ̄ & 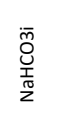 & $\begin{array}{l}\text { 景 } \\
\text { 童 }\end{array}$ & $\overline{\overline{\bar{x}}}$ & $\begin{array}{l}\stackrel{0}{x} \\
\text { In }\end{array}$ & 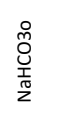 & $\begin{array}{l}\text { 오 } \\
\text { 일 }\end{array}$ & $\frac{\circ}{\underline{T}}$ \\
\hline 11 & $\mathrm{HI}$ & C & B & 3 & 29.0 & 45.5 & 209 & 54.9 & 5.0 & 9.5 & 22.5 & 39.0 & 24.0 & 36.0 & 186 & 15.9 \\
\hline 13 & $\mathrm{HI}$ & c & B & 2 & 29.2 & 47.6 & 226 & 52.6 & 4.0 & 10.1 & 19.0 & 44.0 & 25.2 & 37.4 & 207 & 8.6 \\
\hline 31 & $\mathrm{HI}$ & C & B & 1 & 23.7 & 46.7 & 203 & 51.6 & 4.5 & 10.0 & 16.0 & 38.0 & 19.2 & 36.7 & 187 & 13.6 \\
\hline 10 & $\mathrm{HI}$ & c & v & 3 & 29.6 & 45.0 & 175 & 66.2 & 5.0 & 9.9 & 20.0 & 50.0 & 24.6 & 35.1 & 155 & 16.2 \\
\hline 69 & $\mathrm{HI}$ & C & v & 2 & 34.2 & 84.4 & 247 & 46.6 & 5.5 & 11.0 & 24.5 & 39.0 & 28.7 & 73.4 & 223 & 7.6 \\
\hline 71 & $\mathrm{HI}$ & C & v & 1 & 35.7 & 80.8 & 257 & 53.6 & 5.0 & 9.0 & 23.0 & 40.0 & 30.7 & 71.8 & 234 & 13.6 \\
\hline 40 & $\mathrm{HI}$ & LM & B & 3 & 63.1 & 42.4 & 216 & 50.0 & 4.5 & 9.0 & 17.5 & 35.0 & 58.6 & 33.4 & 198 & 15.0 \\
\hline 59 & $\mathrm{HI}$ & LM & B & 2 & 34.5 & 71.2 & 312 & 49.2 & 5.0 & 11.5 & 25.5 & 39.0 & 29.5 & 59.7 & 287 & 10.2 \\
\hline 66 & $\mathrm{HI}$ & LM & B & 1 & 34.2 & 68.4 & 292 & 56.6 & 5.0 & 10.0 & 23.0 & 47.0 & 29.2 & 58.4 & 269 & 9.6 \\
\hline 41 & $\mathrm{HI}$ & LM & v & 3 & 60.7 & 46.7 & 234 & 53.2 & 5.0 & 9.0 & 18.5 & 39.0 & 55.7 & 37.8 & 215 & 14.2 \\
\hline 55 & $\mathrm{HI}$ & LM & v & 1 & 36.1 & 71.2 & 283 & 44.1 & 5.5 & 10.5 & 21.0 & 37.0 & 30.6 & 60.7 & 262 & 7.1 \\
\hline 68 & $\mathrm{HI}$ & LM & v & 2 & 35.9 & & 257 & 50.4 & 4.5 & & 23.5 & 40.0 & 31.4 & & 233 & 10.4 \\
\hline 5 & $\mathrm{HI}$ & $M$ & B & 1 & 31.0 & 49.8 & 183 & 62.8 & 4.0 & 10.3 & 23.0 & 44.0 & 27.0 & 39.5 & 160 & 18.8 \\
\hline 48 & $\mathrm{HI}$ & $M$ & B & 2 & 63.6 & 43.2 & 225 & 53.1 & 3.5 & 9.9 & 18.0 & 35.0 & 60.1 & 33.3 & 207 & 18.1 \\
\hline 62 & $\mathrm{HI}$ & $M$ & B & 3 & 32.4 & 78.9 & 285 & 51.4 & 4.5 & 10.5 & 23.5 & 43.0 & 27.9 & 68.4 & 262 & 8.4 \\
\hline 8 & $\mathrm{HI}$ & $M$ & v & 2 & 35.4 & 49.9 & 215 & 63.8 & 4.5 & 9.3 & 25.0 & 46.0 & 30.9 & 40.6 & 190 & 17.8 \\
\hline 22 & $\mathrm{HI}$ & $M$ & v & 3 & 31.2 & 41.2 & 204 & 64.5 & 4.5 & 9.7 & 17.0 & 47.0 & 26.7 & 31.5 & 187 & 17.5 \\
\hline 49 & $\mathrm{HI}$ & $M$ & v & 1 & 33.3 & 84.4 & 268 & 45.8 & 4.5 & 13.5 & 23.0 & 38.0 & 28.8 & 70.9 & 245 & 7.8 \\
\hline 58 & $\mathrm{HI}$ & $M L$ & B & 1 & 37.8 & 73.9 & 298 & 50.6 & 5.0 & 11.5 & 23.0 & 41.0 & 32.8 & 62.4 & 275 & 9.6 \\
\hline 61 & $\mathrm{HI}$ & $\mathrm{ML}$ & B & 3 & 32.8 & 75.1 & 284 & 39.9 & 4.5 & 9.5 & 21.0 & 33.0 & 28.3 & 65.6 & 263 & 6.9 \\
\hline 67 & $\mathrm{HI}$ & $\mathrm{ML}$ & B & 2 & 33.5 & 73.3 & 303 & 56.9 & 5.0 & 10.5 & 26.5 & 42.0 & 28.5 & 62.8 & 276 & 14.9 \\
\hline 56 & $\mathrm{HI}$ & $\mathrm{ML}$ & v & 1 & 34.0 & 71.8 & 283 & 51.3 & 5.0 & 11.0 & 23.0 & 42.0 & 29.0 & 60.8 & 260 & 9.3 \\
\hline 70 & $\mathrm{HI}$ & $\mathrm{ML}$ & v & 2 & 32.7 & 81.7 & 271 & 59.2 & 4.5 & 11.0 & 24.0 & 44.0 & 28.2 & 70.7 & 247 & 15.2 \\
\hline 18 & $\mathrm{HI}$ & $P_{i}$ & B & 3 & 27.4 & 51.5 & 206 & 50.2 & 4.0 & 8.7 & 23.0 & 35.0 & 23.4 & 42.8 & 183 & 15.2 \\
\hline 36 & $\mathrm{HI}$ & $P_{i}$ & B & 2 & 15.5 & 46.0 & 223 & 49.7 & 4.0 & 10.7 & 15.5 & 37.0 & 11.5 & 35.3 & 208 & 12.7 \\
\hline 57 & $\mathrm{HI}$ & $P_{i}$ & B & 1 & 37.8 & 78.1 & 355 & 47.4 & 5.0 & 11.5 & 21.5 & 33.0 & 32.8 & 66.6 & 333 & 14.4 \\
\hline 19 & $\mathrm{HI}$ & $P_{i}$ & v & 3 & 31.0 & 46.2 & 187 & 46.6 & 5.0 & 10.2 & 19.5 & 35.0 & 26.0 & 36.0 & 168 & 11.6 \\
\hline 25 & $\mathrm{HI}$ & $P_{i}$ & V & 2 & 33.4 & 50.1 & 187 & 47.6 & 4.0 & 11.4 & 19.0 & 35.0 & 29.4 & 38.6 & 168 & 12.6 \\
\hline
\end{tabular}




\begin{tabular}{|c|c|c|c|c|c|c|c|c|c|c|c|c|c|c|c|c|}
\hline$\underline{\underline{a}}$ & 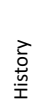 & 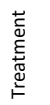 & 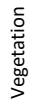 & @ & $\begin{array}{l}\underset{\text { I }}{\text { I }} \\
\text {. }\end{array}$ & 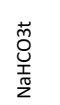 & $\begin{array}{l}\text { 㐊 } \\
0 \\
\text { ர }\end{array}$ & $\stackrel{ \pm}{\text { 노 }}$ & $\begin{array}{l}\overline{\text { }} \\
\text { I }\end{array}$ & 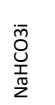 & $\begin{array}{l}\overline{\bar{\tau}} \\
\overline{0} \\
\bar{z}\end{array}$ & $\overline{\overline{\mathrm{u}}}$ & $\begin{array}{l}\stackrel{ }{\text { I }} \\
\text { I }\end{array}$ & 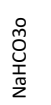 & $\begin{array}{l}\text { 옹 } \\
\text { 을 }\end{array}$ & $\frac{0}{\underline{T}}$ \\
\hline 65 & $\mathrm{HI}$ & $P_{i}$ & v & 1 & 38.0 & 70.3 & 300 & 52.4 & 5.0 & 10.0 & 24.5 & 39.0 & 33.0 & 60.3 & 276 & 13.4 \\
\hline 6 & $\mathrm{HI}$ & $P_{0}$ & B & 1 & 34.2 & 43.6 & 197 & 59.1 & 4.0 & 10.3 & 52.0 & 45.0 & 30.2 & 33.3 & 145 & 14.1 \\
\hline 46 & $\mathrm{HI}$ & $P_{0}$ & B & 2 & 69.2 & 45.7 & 237 & 49.0 & 3.5 & 9.7 & 17.5 & 33.0 & 65.7 & 36.0 & 219 & 16.0 \\
\hline 53 & $\mathrm{HI}$ & $P_{0}$ & B & 3 & 37.4 & 85.1 & 278 & 46.0 & 5.5 & 11.5 & 20.0 & 36.0 & 31.9 & 73.6 & 258 & 10.0 \\
\hline 15 & $\mathrm{HI}$ & $P_{0}$ & v & 1 & 31.3 & 41.2 & 253 & 56.6 & 4.0 & 8.5 & 18.0 & 42.0 & 27.3 & 32.8 & 235 & 14.6 \\
\hline 44 & $\mathrm{HI}$ & $P_{0}$ & v & 3 & 60.2 & 41.9 & 211 & 56.2 & 4.5 & 9.1 & 18.0 & 37.0 & 55.7 & 32.8 & 193 & 19.2 \\
\hline 51 & $\mathrm{HI}$ & $P_{0}$ & v & 2 & 41.6 & 78.5 & 276 & 43.4 & 5.5 & 11.5 & 23.5 & 36.0 & 36.1 & 67.0 & 253 & 7.4 \\
\hline 14 & Low & C & B & 3 & 1.15 & 12.2 & 47.8 & 0.00 & 1.00 & 1.39 & 2.00 & 2.00 & 0.15 & 10.8 & 45.8 & 0.00 \\
\hline 17 & Low & C & B & 1 & 1.53 & 12.9 & 59.2 & 0.00 & 0.50 & 0.41 & 1.50 & 2.00 & 1.03 & 12.5 & 57.7 & 0.00 \\
\hline 28 & Low & C & B & 2 & 1.06 & 12.3 & 53.5 & 0.00 & 1.00 & 0.68 & 1.50 & 1.00 & 0.06 & 11.6 & 52.0 & 0.00 \\
\hline 16 & Low & C & V & 1 & 1.23 & 11.2 & 47.5 & 0.00 & 0.50 & 0.64 & 2.00 & 2.00 & 0.73 & 10.6 & 45.5 & 0.00 \\
\hline 21 & Low & C & v & 2 & 1.62 & 12.0 & 53.7 & 0.00 & 0.50 & 0.62 & 2.00 & 1.00 & 1.12 & 11.4 & 51.7 & 0.00 \\
\hline 37 & Low & C & v & 3 & 0.41 & 13.2 & 70.6 & 0.00 & 0.50 & 1.13 & 1.50 & 2.00 & 0.00 & 12.1 & 69.1 & 0.00 \\
\hline 27 & Low & LM & B & 2 & 1.17 & 12.9 & 56.2 & 0.00 & 0.50 & 0.67 & 1.50 & 1.00 & 0.67 & 12.2 & 54.7 & 0.00 \\
\hline 32 & Low & LM & B & 1 & 1.04 & 13.4 & 60.3 & 0.54 & 2.00 & 0.95 & 3.00 & 2.00 & 0.00 & 12.5 & 57.3 & 0.00 \\
\hline 39 & Low & LM & B & 3 & 2.94 & 12.9 & 56.5 & 0.00 & 1.50 & 1.39 & 1.50 & 1.00 & 1.44 & 11.5 & 55.0 & 0.00 \\
\hline 12 & Low & LM & v & 3 & 1.89 & 12.5 & 57.7 & 0.00 & 1.50 & 1.76 & 1.50 & 2.00 & 0.39 & 10.7 & 56.2 & 0.00 \\
\hline 30 & Low & LM & V & 2 & 1.10 & 12.7 & 63.8 & 0.46 & 1.00 & 0.81 & 2.50 & 1.00 & 0.10 & 11.9 & 61.3 & 0.00 \\
\hline 38 & Low & LM & v & 1 & 0.10 & 13.0 & 57.8 & 0.00 & 0.50 & 1.79 & 2.00 & 2.00 & 0.00 & 11.3 & 55.8 & 0.00 \\
\hline 3 & Low & $M$ & B & 1 & 1.63 & 13.5 & 49.1 & 0.00 & 0.50 & 1.54 & 1.50 & 3.00 & 1.13 & 12.0 & 47.6 & 0.00 \\
\hline 42 & Low & $M$ & B & 2 & 2.80 & 12.6 & 61.0 & 0.00 & 1.50 & 1.07 & 2.50 & 3.00 & 1.30 & 11.6 & 58.5 & 0.00 \\
\hline 52 & Low & $M$ & B & 3 & 2.44 & & 81.5 & 0.75 & 0.50 & & 2.00 & 5.00 & 1.94 & & 79.5 & 0.00 \\
\hline 2 & Low & $M$ & v & 2 & 1.48 & 13.2 & 61.1 & 0.00 & 1.50 & 1.13 & 2.00 & 2.00 & 0.00 & 12.1 & 59.1 & 0.00 \\
\hline 24 & Low & $M$ & v & 1 & 1.17 & 12.9 & 55.7 & 0.00 & 1.00 & 0.65 & 2.00 & 1.00 & 0.17 & 12.3 & 53.7 & 0.00 \\
\hline 43 & Low & $M$ & v & 3 & 2.40 & 12.4 & 76.7 & 0.00 & 1.00 & 0.86 & 3.00 & 2.00 & 1.40 & 11.6 & 73.7 & 0.00 \\
\hline 9 & Low & $M L$ & B & 2 & 1.95 & 12.3 & 49.1 & 0.46 & 1.00 & 0.80 & 2.00 & 2.00 & 0.95 & 11.5 & 47.1 & 0.00 \\
\hline 20 & Low & $M L$ & B & 3 & 1.39 & 12.4 & 55.3 & 0.00 & 0.50 & 2.44 & 2.00 & 2.00 & 0.89 & 10.0 & 53.3 & 0.00 \\
\hline 64 & Low & $M L$ & B & 1 & 1.97 & 18.8 & 76.9 & 0.02 & 0.50 & 0.50 & 1.50 & 2.00 & 1.47 & 18.3 & 75.4 & 0.00 \\
\hline 23 & Low & $M L$ & v & 3 & 1.19 & 11.0 & 57.7 & 0.00 & 1.50 & 0.69 & 2.00 & 2.00 & 0.00 & 10.3 & 55.7 & 0.00 \\
\hline 29 & Low & $M L$ & V & 1 & 0.50 & 12.5 & 53.9 & 0.00 & 1.00 & 1.07 & 1.50 & 2.00 & 0.00 & 11.4 & 52.4 & 0.00 \\
\hline 50 & Low & $M L$ & v & 2 & 2.33 & 21.6 & 71.7 & 0.61 & 0.50 & 1.00 & 2.00 & 2.00 & 1.83 & 20.6 & 69.7 & 0.00 \\
\hline 35 & Low & $\mathrm{Pi}$ & B & 2 & 0.04 & 13.1 & 56.2 & 0.00 & 1.50 & 2.99 & 2.00 & 1.00 & 0.00 & 10.1 & 54.2 & 0.00 \\
\hline 47 & Low & $\mathrm{Pi}$ & B & 1 & 2.51 & 15.2 & 56.4 & 0.00 & 1.50 & 1.01 & 2.50 & 3.00 & 1.01 & 14.2 & 53.9 & 0.00 \\
\hline 54 & Low & $\mathrm{Pi}$ & B & 3 & 2.03 & 23.0 & 82.7 & 1.55 & 1.50 & 1.50 & 3.00 & 2.00 & 0.53 & 21.5 & 79.7 & 0.00 \\
\hline 45 & Low & $\mathrm{Pi}$ & V & 2 & 2.78 & 14.7 & 55.2 & 0.00 & 0.50 & 1.87 & 3.00 & 3.00 & 2.28 & 12.8 & 52.2 & 0.00 \\
\hline 63 & Low & $\mathrm{Pi}$ & v & 1 & 2.20 & 19.2 & 86.5 & 1.45 & 0.50 & 2.00 & 3.00 & 3.00 & 1.70 & 17.2 & 83.5 & 0.00 \\
\hline 72 & Low & $\mathrm{Pi}$ & v & 3 & 2.11 & 25.8 & 72.5 & 2.27 & 1.50 & 2.00 & 2.50 & 3.00 & 0.61 & 23.8 & 70.0 & 0.00 \\
\hline 4 & Low & Po & B & 1 & 1.87 & 11.8 & 44.7 & 0.00 & 0.50 & 0.59 & 2.00 & 2.00 & 1.37 & 11.2 & 42.7 & 0.00 \\
\hline 26 & Low & Po & B & 2 & 2.10 & 13.2 & 53.4 & 0.28 & 1.00 & 1.41 & 2.00 & 2.00 & 1.10 & 11.8 & 51.4 & 0.00 \\
\hline
\end{tabular}




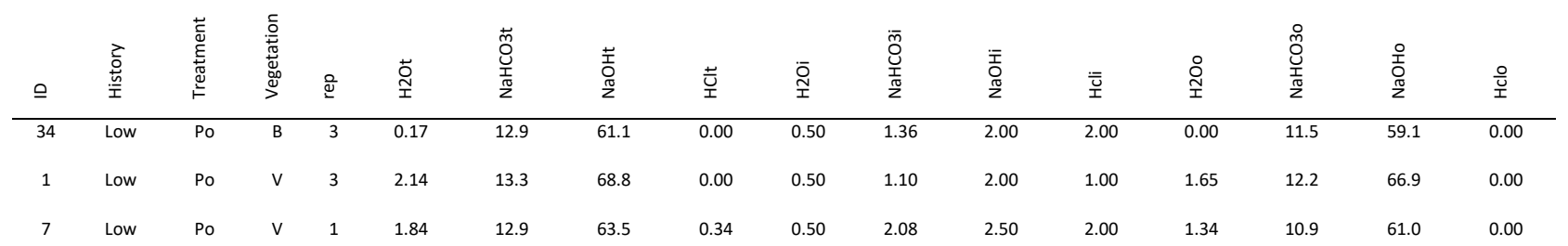

\section{Sequentially extracted phosphorus fractions (field data)}

Horizon: S - surface, SS ; Thickness: horizon thickness in cm; Site: H1 - high one (location 1 with long history of manure application), H2 - high two (location 2 with long history of manure application), L1 - low 1 (location 1 with little to no history of manure application), L2 - low 2 (location 2 with little to no history of manure application); ID: h1-10 (sample locations 1-10 in the high stratification) m1--10 (sample locations 1-10 in the medium stratification), I1-10 (sample location 1-10 in the low stratification); Sequential extracted fraction: H2Ot - Deionized distilled water extractable total $\mathrm{P}$ fraction, $\mathrm{H} 2 \mathrm{Oi}$ - Deionized distilled water extractable inorganic $\mathrm{P}$ fraction, $\mathrm{H} 2 \mathrm{Oo}$ - Deionized distilled water extractable total P fraction, NaHCO3t - NaHCO3 extractable total P fraction, NaHCO3i - NaHCO3 extractable inorganic P fraction, $\mathrm{NaHCO} 3 \mathrm{O}-\mathrm{NaHCO} 3$ extractable organic $\mathrm{P}$ fraction, $\mathrm{NaOHt}-\mathrm{NaOH}$ extractable total $\mathrm{P}$ fraction, $\mathrm{NaOHi}-\mathrm{NaOH}$ extractable inorganic $\mathrm{P}$ fraction, $\mathrm{NaOHo}-\mathrm{NaOH}$ extractable organic $\mathrm{P}$ fraction, $\mathrm{HClt}-\mathrm{HCl}$ extractable total $\mathrm{P}$ fraction, $\mathrm{HCli}-\mathrm{HCl}$ extractable inorganic $\mathrm{P}$ fraction, $\mathrm{HClo}-\mathrm{HCl}$ extractable organic $\mathrm{P}$ fraction

\begin{tabular}{|c|c|c|c|c|c|c|c|c|c|c|c|c|c|c|c|}
\hline 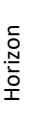 & 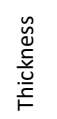 & $\stackrel{ \pm}{n}$ & 은 & $\begin{array}{l}\text { Oे } \\
\text { I }\end{array}$ & 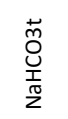 & $\begin{array}{l}\text { 蒿 } \\
\frac{\pi}{2}\end{array}$ & $\begin{array}{l}\stackrel{ \pm}{\mathrm{I}} \\
\text { }\end{array}$ & $\begin{array}{l}\overline{\mathbf{N}} \\
\text { I }\end{array}$ & 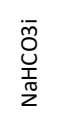 & $\begin{array}{l}\overline{\bar{\beth}} \\
\overline{0} \\
\bar{z}\end{array}$ & $\overline{\overline{\mathbf{x}}}$ & $\begin{array}{l}\stackrel{ }{\mathbf{I}} \\
\text { In }\end{array}$ & 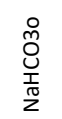 & $\begin{array}{l}\text { 옹 } \\
\text { о } \\
\text { Z }\end{array}$ & $\frac{\circ}{\frac{0}{x}}$ \\
\hline$S$ & 7 & $\mathrm{H} 1$ & h1 & 371 & 728 & 1803 & 2468 & 126 & 372 & 641 & 1326 & 245 & 356 & 1162 & 1142 \\
\hline$S$ & 5 & $\mathrm{H} 1$ & h10 & 292 & 582 & 1464 & 2050 & 93.0 & 340 & 522 & 1052 & 199 & 242 & 942 & 999 \\
\hline$S$ & 5 & $\mathrm{H} 1$ & h2 & 246 & 493 & 1857 & 1667 & 89.3 & 208 & 562 & 918 & 156 & 285 & 1295 & 749 \\
\hline$S$ & 8 & $\mathrm{H} 1$ & h3 & 254 & 646 & 2093 & 2632 & 78.3 & 358 & 745 & 1508 & 176 & 288 & 1349 & 1124 \\
\hline S & 5 & $\mathrm{H} 1$ & h4 & 243 & 613 & 1373 & 2919 & 100 & 303 & 443 & 1604 & 143 & 310 & 930 & 1315 \\
\hline S & 5 & $\mathrm{H} 1$ & h5 & 242 & 623 & 1622 & 2990 & 100 & 331 & 575 & 1628 & 141 & 292 & 1047 & 1362 \\
\hline$S$ & 6 & $\mathrm{H} 1$ & h6 & 320 & 692 & 1751 & 2387 & 138 & 376 & 610 & 1293 & 182 & 316 & 1141 & 1094 \\
\hline S & 5 & $\mathrm{H} 1$ & h7 & 429 & 668 & 1919 & 2390 & 191 & 390 & 538 & 1250 & 237 & 278 & 1381 & 1140 \\
\hline$S$ & 4 & $\mathrm{H} 1$ & h8 & 259 & 600 & 2119 & 3431 & 108 & 336 & 785 & 1644 & 152 & 265 & 1333 & 1787 \\
\hline$S$ & 5 & $\mathrm{H} 1$ & h9 & 353 & 670 & 1939 & 3709 & 136 & 355 & 643 & 1663 & 218 & 315 & 1296 & 2045 \\
\hline$S$ & 9 & $\mathrm{H} 1$ & $\mid 1$ & 320 & 748 & 3268 & 4606 & 115 & 332 & 832 & 1855 & 205 & 416 & 2436 & 2751 \\
\hline$S$ & 4 & $\mathrm{H} 1$ & $\mid 10$ & 545 & 1072 & 2857 & 5602 & 185 & 418 & 912 & 2194 & 360 & 654 & 1945 & 3408 \\
\hline$S$ & 7 & $\mathrm{H} 1$ & 12 & 454 & 639 & 3043 & 3802 & 183 & 229 & 752 & 1728 & 271 & 410 & 2291 & 2074 \\
\hline$S$ & 9 & $\mathrm{H} 1$ & 13 & 284 & 613 & 3012 & 3505 & 113 & 304 & 742 & 1651 & 171 & 310 & 2270 & 1855 \\
\hline$S$ & 5 & $\mathrm{H} 1$ & 14 & 293 & 668 & 2803 & 3874 & 121 & 305 & 731 & 1661 & 171 & 362 & 2072 & 2212 \\
\hline$S$ & 8 & $\mathrm{H} 1$ & 15 & 200 & 583 & 2572 & 3035 & 71.3 & 247 & 628 & 1442 & 129 & 336 & 1944 & 1593 \\
\hline$S$ & 8 & $\mathrm{H} 1$ & 16 & 233 & 750 & 2640 & 4998 & 89.0 & 334 & 748 & 1903 & 144 & 416 & 1892 & 3094 \\
\hline$S$ & 7.5 & $\mathrm{H} 1$ & 17 & 425 & 959 & 2583 & 5945 & 164 & 462 & 834 & 2249 & 261 & 497 & 1749 & 3697 \\
\hline$S$ & 5 & $\mathrm{H} 1$ & 18 & 409 & 808 & 2624 & 4433 & 138 & 307 & 804 & 1954 & 271 & 501 & 1820 & 2480 \\
\hline s & 5 & $\mathrm{H} 1$ & 19 & 484 & 964 & 2929 & 5122 & 167 & 377 & 896 & 2065 & 317 & 587 & 2033 & 3057 \\
\hline$S$ & 5 & $\mathrm{H} 1$ & $\mathrm{~m} 1$ & 278 & 592 & 1557 & 2225 & 77.2 & 218 & 595 & 1204 & 201 & 374 & 961 & 1021 \\
\hline S & 3 & $\mathrm{H} 1$ & m10 & 432 & 700 & 2638 & 5238 & 166 & 378 & 857 & 2111 & 267 & 322 & 1780 & 3127 \\
\hline
\end{tabular}




\begin{tabular}{|c|c|c|c|c|c|c|c|c|c|c|c|c|c|c|c|}
\hline 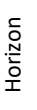 & 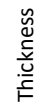 & $\stackrel{\Perp}{ \pm}$ & 으 & $\begin{array}{l}\text { ָั } \\
\text { I }\end{array}$ & 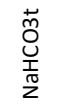 & 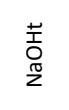 & 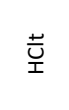 & $\begin{array}{l}\bar{O} \\
\text { I }\end{array}$ & $\begin{array}{l}\bar{m} \\
\text { Ơ⿱ } \\
\frac{\pi}{2}\end{array}$ & $\begin{array}{l}\text { 容 } \\
\text { O } \\
\text { Z }\end{array}$ & $\overline{\overline{\bar{I}}}$ & $\begin{array}{l}\stackrel{\circ}{\text { İ }} \\
\text { İ }\end{array}$ & $\begin{array}{l}\stackrel{\circ}{0} \\
\text { Ơ } \\
\frac{1}{\pi} \\
z\end{array}$ & $\begin{array}{l}\text { 움 } \\
\text { o } \\
\text { Z }\end{array}$ & $\frac{ㅇ}{\text { 는 }}$ \\
\hline$S$ & 10 & $\mathrm{H} 1$ & $\mathrm{~m} 2$ & 242 & 991 & 2008 & 4407 & 66.1 & 381 & 771 & 1884 & 176 & 609 & 1237 & 2523 \\
\hline$S$ & 4 & $\mathrm{H} 1$ & $\mathrm{~m} 3$ & 312 & 688 & 2021 & 2257 & 96.6 & 224 & 664 & 1244 & 216 & 464 & 1357 & 1013 \\
\hline$S$ & 7 & $\mathrm{H} 1$ & $\mathrm{~m} 4$ & 244 & 771 & 1817 & 2714 & 67.4 & 240 & 655 & 1051 & 176 & 532 & 1162 & 1663 \\
\hline$S$ & 7 & $\mathrm{H} 1$ & m5 & 302 & 779 & 2080 & 2189 & 83.6 & 241 & 729 & 1193 & 218 & 538 & 1351 & 997 \\
\hline$S$ & 5 & $\mathrm{H} 1$ & $\mathrm{~m} 6$ & 377 & 909 & 2121 & 3166 & 140 & 305 & 746 & 1436 & 237 & 604 & 1376 & 1730 \\
\hline$S$ & 6 & $\mathrm{H} 1$ & $\mathrm{~m} 7$ & 382 & 800 & 2423 & 3529 & 141 & 327 & 859 & 1691 & 241 & 473 & 1564 & 1838 \\
\hline$S$ & 3 & $\mathrm{H} 1$ & $\mathrm{~m} 8$ & 282 & 750 & 2430 & 3134 & 81.3 & 291 & 817 & 1509 & 201 & 459 & 1613 & 1626 \\
\hline$S$ & 3 & $\mathrm{H} 1$ & $\mathrm{~m} 9$ & 311 & 512 & 2406 & 1750 & 136 & 216 & 688 & 930 & 175 & 295 & 1719 & 820 \\
\hline$S$ & 6 & $\mathrm{H} 1$ & $\mathrm{~m} 1$ & 28.8 & 96.2 & 540 & 47.8 & 0.00 & 2.71 & 16.4 & 43.1 & 28.8 & 93.5 & 524 & 12.9 \\
\hline$S$ & 6.5 & $\mathrm{H} 2$ & h1 & 114 & 421 & 2415 & 524 & 0.00 & 160 & 725 & 219 & 114 & 261 & 1690 & 304 \\
\hline$S$ & 5 & $\mathrm{H} 2$ & h10 & 154 & 527 & 2491 & 1064 & 55.0 & 233 & 709 & 551 & 100 & 294 & 1782 & 513 \\
\hline$S$ & 9 & $\mathrm{H} 2$ & h2 & 160 & 538 & 2082 & 1009 & 35.7 & 235 & 593 & 510 & 124 & 303 & 1489 & 499 \\
\hline$S$ & 9 & $\mathrm{H} 2$ & h3 & 122 & 344 & 1519 & 725 & 37.7 & 141 & 441 & 357 & 84.5 & 203 & 1078 & 369 \\
\hline$S$ & 9 & $\mathrm{H} 2$ & h4 & 186 & 406 & 1469 & 749 & 56.8 & 171 & 390 & 359 & 129 & 235 & 1079 & 391 \\
\hline$S$ & 9 & $\mathrm{H} 2$ & h5 & 111 & 403 & 1870 & 981 & 35.8 & 98.9 & 565 & 612 & 75.3 & 304 & 1305 & 370 \\
\hline$S$ & 7 & $\mathrm{H} 2$ & h6 & 165 & 561 & 2026 & 944 & 30.7 & 246 & 529 & 446 & 134 & 315 & 1498 & 498 \\
\hline$S$ & 6 & $\mathrm{H} 2$ & h7 & 177 & 591 & 2342 & 912 & 59.0 & 226 & 640 & 434 & 118 & 365 & 1701 & 478 \\
\hline$S$ & 7 & $\mathrm{H} 2$ & h8 & 188 & 559 & 2597 & 955 & 68.0 & 235 & 744 & 444 & 120 & 324 & 1853 & 510 \\
\hline$S$ & 6 & $\mathrm{H} 2$ & h9 & 163 & 562 & 2193 & 752 & 31.2 & 234 & 573 & 438 & 132 & 328 & 1619 & 314 \\
\hline$S$ & 10 & $\mathrm{H} 2$ & 11 & 174 & 406 & 1271 & 962 & 44.1 & 212 & 414 & 511 & 130 & 194 & 857 & 451 \\
\hline$S$ & 8 & $\mathrm{H} 2$ & $\mid 10$ & 198 & 400 & 1697 & 676 & 84.7 & 162 & 486 & 311 & 113 & 238 & 1211 & 365 \\
\hline$S$ & 10 & $\mathrm{H} 2$ & 12 & 137 & 404 & 1417 & 741 & 29.6 & 192 & 447 & 358 & 108 & 212 & 970 & 383 \\
\hline$S$ & 10 & $\mathrm{H} 2$ & 13 & 153 & 444 & 873 & 1261 & 68.8 & 159 & 536 & 624 & 83.9 & 285 & 594 & 636 \\
\hline$S$ & 19 & $\mathrm{H} 2$ & 14 & 80.3 & 316 & 1301 & 621 & 38.0 & 109 & 413 & 295 & 42.3 & 207 & 888 & 326 \\
\hline$S$ & 8 & $\mathrm{H} 2$ & 15 & 208 & 498 & 2056 & 823 & 61.4 & 189 & 525 & 220 & 146 & 310 & 1531 & 603 \\
\hline$S$ & 11 & $\mathrm{H} 2$ & 16 & 128 & 455 & 2064 & 1104 & 17.0 & 167 & 597 & 583 & 111 & 289 & 1467 & 522 \\
\hline$S$ & 13 & $\mathrm{H} 2$ & 17 & 171 & 484 & 1844 & 677 & 17.4 & 173 & 480 & 321 & 154 & 311 & 1364 & 356 \\
\hline$S$ & 9 & $\mathrm{H} 2$ & 18 & 149 & 350 & 1250 & 727 & 46.7 & 159 & 321 & 336 & 102 & 192 & 929 & 391 \\
\hline$S$ & 5 & $\mathrm{H} 2$ & 19 & 187 & 434 & 2171 & 793 & 84.9 & 186 & 553 & 404 & 102 & 248 & 1618 & 388 \\
\hline$S$ & 27 & $\mathrm{H} 2$ & $\mathrm{~m} 1$ & 89.9 & 245 & 894 & 493 & 36.6 & 137 & 322 & 250 & 53.2 & 107 & 573 & 243 \\
\hline$S$ & 2 & $\mathrm{H} 2$ & $\mathrm{~m} 10$ & 243 & 498 & 1376 & 932 & 90.4 & 217 & 475 & 455 & 152 & 280 & 901 & 477 \\
\hline$S$ & 9 & $\mathrm{H} 2$ & $\mathrm{~m} 2$ & 172 & 400 & 1356 & 1334 & 55.4 & 209 & 483 & 720 & 117 & 192 & 873 & 614 \\
\hline$S$ & 10 & $\mathrm{H} 2$ & $\mathrm{~m} 3$ & 122 & 369 & 1387 & 989 & 52.4 & 180 & 449 & 608 & 69.4 & 189 & 939 & 381 \\
\hline$S$ & 12 & $\mathrm{H} 2$ & $\mathrm{~m} 4$ & 158 & 398 & 1361 & 1188 & 22.7 & 146 & 438 & 640 & 136 & 252 & 924 & 548 \\
\hline$S$ & 9 & $\mathrm{H} 2$ & m5 & 205 & 442 & 1104 & 927 & 76.4 & 177 & 391 & 521 & 129 & 265 & 713 & 406 \\
\hline$S$ & 10 & $\mathrm{H} 2$ & $\mathrm{~m} 6$ & 130 & 476 & 1503 & 1277 & 9.19 & 209 & 549 & 708 & 121 & 267 & 954 & 569 \\
\hline$S$ & 13 & $\mathrm{H} 2$ & $\mathrm{~m} 7$ & 128 & 426 & 1262 & 849 & 16.5 & 137 & 437 & 457 & 111 & 289 & 825 & 392 \\
\hline$S$ & 6 & $\mathrm{H} 2$ & $\mathrm{~m} 8$ & 156 & 409 & 1202 & 934 & 12.0 & 159 & 430 & 455 & 144 & 250 & 772 & 479 \\
\hline$S$ & 13 & $\mathrm{H} 2$ & $\mathrm{~m} 9$ & 163 & 460 & 1352 & 904 & 19.5 & 157 & 469 & 470 & 143 & 304 & 883 & 434 \\
\hline$S$ & 6 & L1 & h1 & 42.3 & 121 & 751 & 93.6 & 0.00 & 4.37 & 10.0 & 35.9 & 42.3 & 117 & 741 & 57.6 \\
\hline
\end{tabular}




\begin{tabular}{|c|c|c|c|c|c|c|c|c|c|c|c|c|c|c|c|}
\hline 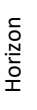 & 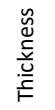 & $\stackrel{\Perp}{ \pm}$ & 으 & $\begin{array}{l}\text { ָั } \\
\text { I }\end{array}$ & 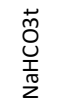 & 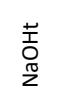 & 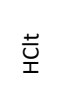 & $\begin{array}{l}\text { 모 } \\
\text { I }\end{array}$ & $\begin{array}{l}\bar{m} \\
\text { Ơ⿱ } \\
\frac{\pi}{2}\end{array}$ & $\begin{array}{l}\text { 容 } \\
\text { O } \\
\text { Z }\end{array}$ & $\overline{\overline{\bar{I}}}$ & $\begin{array}{l}\text { 옴 } \\
\text { I }\end{array}$ & $\begin{array}{l}\stackrel{\circ}{0} \\
\text { Ơ } \\
\frac{1}{\pi} \\
z\end{array}$ & 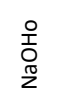 & $\frac{}{\underline{I}}$ \\
\hline$S$ & 8 & L1 & h10 & 50.3 & 119 & 666 & 49.5 & 12.1 & 36.5 & 85.4 & 48.8 & 38.2 & 82.2 & 581 & 1.46 \\
\hline$S$ & 6 & L1 & h2 & 40.4 & 130 & 750 & 88.6 & 0.00 & 15.2 & 9.78 & 7.68 & 40.4 & 115 & 741 & 80.9 \\
\hline$S$ & 5 & L1 & h3 & 46.3 & 127 & 679 & 130 & 1.40 & 0.00 & 0.00 & 16.1 & 44.9 & 127 & 679 & 114 \\
\hline$S$ & 6 & L1 & h4 & 54.4 & 98.9 & 831 & 155 & 0.03 & 24.4 & 35.0 & 47.1 & 54.4 & 74.5 & 796 & 108 \\
\hline$S$ & 7 & L1 & h5 & 57.9 & 117 & 689 & 68.4 & 0.00 & 30.3 & 72.5 & 73.2 & 57.9 & 86.4 & 616 & 21.4 \\
\hline$S$ & 7 & L1 & h6 & 83.4 & 133 & 645 & 86.5 & 0.00 & 48.3 & 72.4 & 157 & 83.4 & 84.8 & 573 & 8.17 \\
\hline$S$ & 9 & L1 & h7 & 20.1 & 95.6 & 539 & 29.9 & 0.00 & 12.0 & 59.8 & 23.9 & 20.1 & 83.6 & 479 & 6.00 \\
\hline$S$ & 7 & L1 & h8 & 37.1 & 125 & 655 & 42.0 & 37.4 & 37.4 & 62.2 & 24.9 & 0.00 & 87.3 & 593 & 17.2 \\
\hline$S$ & 8 & L1 & h9 & 42.8 & 141 & 681 & 44.5 & 0.00 & 47.9 & 72.1 & 48.1 & 42.8 & 92.8 & 609 & 0.00 \\
\hline$S$ & 8 & L1 & $\mid 1$ & 19.5 & 79.5 & 547 & 44.4 & 0.45 & 18.5 & 22.2 & 58.8 & 19.1 & 61.0 & 525 & 0.00 \\
\hline$S$ & 9 & L1 & $\mid 10$ & 19.2 & 104 & 756 & 58.1 & 0.00 & 0.54 & 0.00 & 3.26 & 19.2 & 103 & 756 & 54.8 \\
\hline$S$ & 7 & L1 & 12 & 40.8 & 126 & 433 & 24.5 & 2.73 & 24.2 & 27.7 & 77.1 & 38.1 & 102 & 405 & 0.00 \\
\hline$S$ & 9 & L1 & 13 & 25.8 & 103 & 730 & 64.9 & 0.00 & 11.2 & 0.00 & 28.3 & 25.8 & 91.7 & 730 & 36.6 \\
\hline$S$ & 9 & L1 & 14 & 53.0 & 120 & 573 & 199 & 8.66 & 13.6 & 9.11 & 40.8 & 44.4 & 107 & 564 & 158 \\
\hline$S$ & 6 & L1 & 15 & 43.8 & 87.6 & 537 & 48.5 & 23.1 & 15.9 & 7.77 & 8.27 & 20.7 & 71.8 & 529 & 40.3 \\
\hline$S$ & 8 & L1 & 16 & 29.4 & 88.0 & 522 & 58.3 & 0.00 & 11.2 & 0.76 & 15.2 & 29.4 & 76.8 & 522 & 43.2 \\
\hline$S$ & 5 & L1 & 17 & 90.2 & 152 & 731 & 98.2 & 39.3 & 29.4 & 30.2 & 30.7 & 50.9 & 122 & 700 & 67.4 \\
\hline$S$ & 7 & L1 & 18 & 39.1 & 111 & 719 & 103 & 0.00 & 12.4 & 4.96 & 19.7 & 39.1 & 98.4 & 715 & 83.1 \\
\hline$S$ & 9 & L1 & 19 & 27.3 & 92.3 & 564 & 115 & 0.00 & 5.26 & 2.55 & 12.1 & 27.3 & 87.1 & 561 & 103 \\
\hline$S$ & 5 & L1 & $\mathrm{m} 10$ & 73.3 & 192 & 746 & 68.2 & 19.4 & 50.0 & 8.83 & 95.7 & 53.8 & 142 & 737 & 0.00 \\
\hline$S$ & 8 & L1 & $\mathrm{m} 2$ & 18.9 & 116 & 590 & 28.6 & 0.00 & 7.17 & 34.3 & 58.7 & 18.9 & 109 & 555 & 0.00 \\
\hline$S$ & 5 & L1 & $\mathrm{m} 3$ & 35.9 & 85.1 & 604 & 67.4 & 0.00 & 4.58 & 4.69 & 59.9 & 35.9 & 80.5 & 600 & 9.17 \\
\hline$S$ & 6 & L1 & m4 & 40.9 & 97.3 & 538 & 83.5 & 2.93 & 21.3 & 28.3 & 75.9 & 37.9 & 76.0 & 510 & 7.54 \\
\hline$S$ & 7 & L1 & m5 & 40.2 & 125 & 602 & 52.8 & 4.07 & 21.0 & 30.5 & 71.7 & 36.1 & 104 & 571 & 7.95 \\
\hline$S$ & 9 & L1 & $\mathrm{m} 6$ & 32.2 & 106 & 507 & 44.7 & 0.00 & 15.8 & 9.39 & 75.8 & 32.2 & 90.0 & 497 & 0.00 \\
\hline$S$ & 8 & L1 & $\mathrm{m} 7$ & 39.1 & 122 & 571 & 35.4 & 2.37 & 26.4 & 33.0 & 80.7 & 36.8 & 96.0 & 538 & 0.00 \\
\hline$S$ & 9 & L1 & $\mathrm{m} 8$ & 26.0 & 86.5 & 471 & 35.6 & 0.00 & 0.00 & 7.47 & 64.1 & 26.0 & 86.5 & 463 & 0.00 \\
\hline$S$ & 6 & L1 & $\mathrm{m} 9$ & 46.0 & 126 & 663 & 73.3 & 2.48 & 16.2 & 10.1 & 69.8 & 43.5 & 110 & 653 & 15.4 \\
\hline$S$ & 4.5 & L2 & h1 & 39.8 & 93.9 & 566 & 25.0 & 0.00 & 0.00 & 30.1 & 0.00 & 39.8 & 93.9 & 536 & 25.0 \\
\hline$S$ & 5 & L2 & h10 & 21.7 & 97.5 & 453 & 6.98 & 0.00 & 5.31 & 9.49 & 14.3 & 21.7 & 92.1 & 443 & 2.94 \\
\hline$S$ & 3.5 & L2 & h2 & 61.5 & 133 & 737 & 60.2 & 0.00 & 42.5 & 69.0 & 19.2 & 61.5 & 90.5 & 668 & 41.0 \\
\hline$S$ & 5 & L2 & h3 & 19.5 & 134 & 568 & 18.9 & 0.00 & 5.29 & 32.6 & 17.9 & 19.5 & 129 & 535 & 3.98 \\
\hline$S$ & 5 & L2 & h4 & 19.8 & 74.4 & 485 & 11.2 & 0.00 & 9.18 & 4.06 & 0.00 & 19.8 & 65.2 & 481 & 11.2 \\
\hline$S$ & 4 & L2 & h5 & 11.6 & 121 & 735 & 54.9 & 0.00 & 10.6 & 61.0 & 18.9 & 11.6 & 110 & 674 & 36.1 \\
\hline$S$ & 3 & L2 & h6 & 19.2 & 41.2 & 429 & 15.1 & 0.00 & 0.00 & 6.54 & 30.3 & 19.2 & 41.2 & 423 & 0.00 \\
\hline$S$ & 5.5 & L2 & h7 & 23.7 & 49.0 & 417 & 19.5 & 0.00 & 17.4 & 21.1 & 22.4 & 23.7 & 31.7 & 396 & 5.22 \\
\hline$S$ & 5 & L2 & h8 & 15.9 & 45.3 & 392 & 6.06 & 4.24 & 3.48 & 15.5 & 0.00 & 11.7 & 41.8 & 377 & 6.06 \\
\hline$S$ & 5 & L2 & h9 & 16.4 & 75.1 & 436 & 4.70 & 0.00 & 1.91 & 14.2 & 4.03 & 16.4 & 73.2 & 421 & 3.95 \\
\hline$S$ & 4 & L2 & 12 & 28.8 & 167 & 605 & 79.0 & 0.00 & 18.3 & 52.8 & 0.00 & 28.8 & 149 & 552 & 79.0 \\
\hline$S$ & 6 & L2 & 13 & 18.5 & 97.7 & 387 & 7.48 & 0.00 & 59.6 & 49.2 & 0.00 & 18.5 & 38.2 & 338 & 7.48 \\
\hline
\end{tabular}




\begin{tabular}{|c|c|c|c|c|c|c|c|c|c|c|c|c|c|c|c|}
\hline 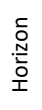 & 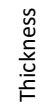 & $\stackrel{⿱ 艹 ⿻ 上 丨}{*}$ & 으 & $\underset{\text { İ }}{\stackrel{+}{X}}$ & $\begin{array}{l}\stackrel{+}{m} \\
\text { O⿱一土 } \\
\frac{\pi}{\pi} \\
\frac{\pi}{2}\end{array}$ & $\begin{array}{l}\text { 壱 } \\
\text { ठ } \\
\text { 而 }\end{array}$ & 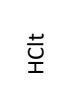 & $\begin{array}{l}\overline{\mathbf{O}} \\
\text { I }\end{array}$ & $\begin{array}{l}\bar{m} \\
\text { Ơ⿱ } \\
\frac{\pi}{2}\end{array}$ & $\begin{array}{l}\text { 品 } \\
\text { о } \\
\bar{z}\end{array}$ & $\frac{\overline{\bar{u}}}{\bar{x}}$ & $\begin{array}{l}\stackrel{\bigcirc}{\underset{N}{I}} \\
\text { }\end{array}$ & $\begin{array}{l}\stackrel{\wp}{0} \\
\text { Oِ } \\
\frac{1}{\pi} \\
z\end{array}$ & $\begin{array}{l}\text { 움 } \\
\text { 유 } \\
\text { z }\end{array}$ & 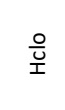 \\
\hline$S$ & 5 & L2 & 14 & 20.1 & 158 & 614 & 53.0 & 0.00 & 22.2 & 40.3 & 29.8 & 20.1 & 136 & 574 & 23.2 \\
\hline$S$ & 4.5 & L2 & 15 & 20.5 & 143 & 540 & 28.7 & 0.00 & 21.9 & 20.9 & 35.6 & 20.5 & 121 & 520 & 0.73 \\
\hline$S$ & 4 & L2 & 16 & 23.3 & 123 & 533 & 46.3 & 0.00 & 25.7 & 51.7 & 15.1 & 23.3 & 96.9 & 481 & 31.2 \\
\hline$S$ & 4 & L2 & 17 & 21.4 & 152 & 536 & 43.8 & 0.00 & 18.3 & 18.0 & 31.0 & 21.4 & 134 & 518 & 12.8 \\
\hline$S$ & 5 & L2 & 18 & 35.4 & 255 & 546 & 22.7 & 6.93 & 21.2 & 38.1 & 0.00 & 28.4 & 234 & 508 & 22.7 \\
\hline$S$ & 4 & L2 & 19 & 47.3 & 159 & 733 & 61.2 & 0.00 & 13.7 & 51.0 & 1.13 & 47.3 & 145 & 682 & 60.1 \\
\hline$S$ & 8 & L2 & $\mathrm{m} 1$ & 30.6 & 159 & 781 & 98.8 & 0.00 & 48.6 & 109 & 48.6 & 30.6 & 110 & 671 & 50.3 \\
\hline$S$ & 4 & L2 & $\mathrm{m} 10$ & 24.0 & 94.5 & 363 & 19.4 & 0.00 & 31.1 & 16.8 & 14.5 & 24.0 & 63.4 & 346 & 8.49 \\
\hline$S$ & 4 & L2 & $\mathrm{m} 2$ & 30.8 & 153 & 759 & 68.3 & 0.00 & 61.0 & 98 & 36.5 & 30.8 & 92.0 & 662 & 31.7 \\
\hline$S$ & 4 & L2 & $\mathrm{m} 3$ & 25.9 & 127 & 661 & 44.4 & 0.00 & 52.4 & 82.0 & 46.8 & 25.9 & 74.9 & 579 & 0.00 \\
\hline$S$ & 5 & L2 & $\mathrm{m} 4$ & 23.5 & 99.0 & 497 & 21.7 & 18.0 & 24.2 & 72.5 & 24.2 & 5.47 & 74.8 & 424 & 0.00 \\
\hline$S$ & 5 & L2 & $\mathrm{m} 5$ & 37.1 & 174 & 911 & 101 & 0.00 & 61.6 & 142 & 73.9 & 37.1 & 112 & 769 & 26.8 \\
\hline$S$ & 7.5 & L2 & $\mathrm{m} 6$ & 23.6 & 128 & 653 & 62.0 & 12.3 & 61.3 & 116 & 73.5 & 11.4 & 66.6 & 537 & 0.00 \\
\hline$S$ & 6 & L2 & $\mathrm{m} 7$ & 26.5 & 233 & 507 & 49.0 & 0.00 & 46.3 & 118 & 0.00 & 26.5 & 186 & 389 & 49.0 \\
\hline$S$ & 4 & L2 & $\mathrm{m} 8$ & 16.5 & 152 & 467 & 31.5 & 0.00 & 15.7 & 64.1 & 7.93 & 16.5 & 137 & 403 & 23.5 \\
\hline$S$ & 3 & L2 & $\mathrm{m} 9$ & 61.6 & 186 & 505 & 26.7 & 0.00 & 25.4 & 0.00 & 2.46 & 61.6 & 160 & 505 & 24.3 \\
\hline SS & 10 & $\mathrm{H} 1$ & h1 & 229 & 678 & 1322 & 2179 & 71.8 & 344 & 519 & 1191 & 158 & 334 & 803 & 988 \\
\hline SS & 10 & $\mathrm{H} 1$ & h10 & 230 & 487 & 1005 & 1208 & 86.9 & 285 & 341 & 648 & 143 & 202 & 664 & 560 \\
\hline SS & 10 & $\mathrm{H} 1$ & h2 & 250 & 612 & 1934 & 1450 & 89.4 & 278 & 670 & 782 & 160 & 334 & 1264 & 668 \\
\hline SS & 10 & $\mathrm{H} 1$ & h3 & 206 & 644 & 1778 & 2522 & 76.4 & 345 & 644 & 1337 & 130 & 300 & 1134 & 1186 \\
\hline SS & 10 & $\mathrm{H} 1$ & h4 & 221 & 674 & 1084 & 2126 & 86.6 & 350 & 422 & 1178 & 135 & 324 & 662 & 948 \\
\hline SS & 10 & $\mathrm{H} 1$ & h5 & 237 & 606 & 1413 & 2113 & 94.2 & 301 & 563 & 1183 & 142 & 305 & 850 & 929 \\
\hline SS & 10 & $\mathrm{H} 1$ & h6 & 231 & 646 & 1274 & 2174 & 84.0 & 357 & 570 & 1180 & 147 & 288 & 704 & 994 \\
\hline SS & 10 & $\mathrm{H} 1$ & h7 & 276 & 611 & 1533 & 2160 & 97.6 & 344 & 506 & 1146 & 179 & 267 & 1027 & 1014 \\
\hline SS & 10 & $\mathrm{H} 1$ & h8 & 253 & 590 & 1842 & 2138 & 98.7 & 319 & 660 & 1107 & 154 & 270 & 1182 & 1031 \\
\hline SS & 10 & $\mathrm{H} 1$ & h9 & 270 & 609 & 1505 & 2662 & 89.2 & 346 & 615 & 1343 & 180 & 263 & 890 & 1319 \\
\hline SS & 10 & $\mathrm{H} 1$ & 11 & 292 & 765 & 2514 & 3881 & 95.2 & 352 & 713 & 1765 & 197 & 413 & 1802 & 2116 \\
\hline SS & 10 & $\mathrm{H} 1$ & $\mid 10$ & 392 & 999 & 2417 & 4517 & 113 & 422 & 900 & 2004 & 280 & 577 & 1518 & 2513 \\
\hline SS & 10 & $\mathrm{H} 1$ & 12 & 326 & 613 & 2603 & 2776 & 127 & 277 & 724 & 1355 & 198 & 336 & 1879 & 1420 \\
\hline SS & 10 & $\mathrm{H} 1$ & 13 & 219 & 502 & 1897 & 1016 & 71.2 & 239 & 575 & 511 & 148 & 263 & 1322 & 505 \\
\hline SS & 10 & $\mathrm{H} 1$ & 14 & 229 & 652 & 2265 & 3818 & 90.0 & 286 & 720 & 1735 & 139 & 366 & 1544 & 2083 \\
\hline SS & 10 & $\mathrm{H} 1$ & 15 & 216 & 656 & 2297 & 2402 & 86.1 & 289 & 791 & 1118 & 130 & 366 & 1506 & 1283 \\
\hline SS & 10 & $\mathrm{H} 1$ & 16 & 173 & 513 & 1199 & 2308 & 53.2 & 212 & 366 & 1113 & 119 & 301 & 834 & 1195 \\
\hline SS & 10 & $\mathrm{H} 1$ & 17 & 319 & 975 & 2123 & 4523 & 103 & 438 & 862 & 2005 & 216 & 537 & 1260 & 2518 \\
\hline SS & 10 & $\mathrm{H} 1$ & 18 & 320 & 771 & 2490 & 3035 & 118 & 230 & 859 & 1668 & 202 & 541 & 1632 & 1367 \\
\hline SS & 10 & $\mathrm{H} 1$ & 19 & 361 & 968 & 2524 & 3810 & 115 & 389 & 875 & 1860 & 246 & 580 & 1649 & 1950 \\
\hline SS & 10 & $\mathrm{H} 1$ & $\mathrm{~m} 1$ & 251 & 574 & 1278 & 1578 & 75.2 & 216 & 537 & 865 & 176 & 358 & 741 & 713 \\
\hline SS & 10 & $\mathrm{H} 1$ & $\mathrm{~m} 10$ & 310 & 837 & 2250 & 5071 & 110 & 391 & 849 & 2159 & 200 & 446 & 1402 & 2912 \\
\hline SS & 10 & $\mathrm{H} 1$ & $\mathrm{~m} 2$ & 164 & 683 & 937 & 2625 & 39.2 & 287 & 438 & 1418 & 125 & 397 & 499 & 1208 \\
\hline SS & 10 & $\mathrm{H} 1$ & m3 & 234 & 612 & 1455 & 1068 & 56.4 & 208 & 592 & 616 & 178 & 404 & 863 & 452 \\
\hline
\end{tabular}




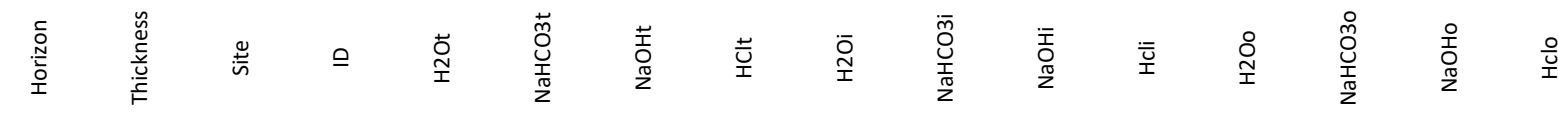

\begin{tabular}{|c|c|c|c|c|c|c|c|c|c|c|c|c|c|c|c|}
\hline SS & 10 & $\mathrm{H} 1$ & $\mathrm{~m} 4$ & 220 & 791 & 1512 & 2511 & 56.4 & 289 & 631 & 1285 & 163 & 502 & 881 & 1227 \\
\hline SS & 10 & $\mathrm{H} 1$ & m5 & 253 & 779 & 1988 & 1615 & 52.9 & 281 & 798 & 878 & 200 & 499 & 1191 & 737 \\
\hline SS & 10 & $\mathrm{H} 1$ & $\mathrm{~m} 6$ & 286 & 661 & 1585 & 1880 & 91.1 & 252 & 656 & 1011 & 195 & 409 & 928 & 869 \\
\hline SS & 10 & $\mathrm{H} 1$ & $\mathrm{~m} 7$ & 295 & 822 & 2404 & 2650 & 103 & 309 & 726 & 1318 & 192 & 513 & 1678 & 1332 \\
\hline SS & 10 & $\mathrm{H} 1$ & $\mathrm{~m} 8$ & 281 & 812 & 2131 & 1993 & 79.8 & 261 & 811 & 1074 & 202 & 551 & 1320 & 918 \\
\hline SS & 10 & $\mathrm{H} 1$ & $\mathrm{~m} 9$ & 314 & 570 & 2689 & 1870 & 113 & 194 & 817 & 1006 & 200 & 376 & 1872 & 865 \\
\hline SS & 10 & $\mathrm{H} 1$ & $\mathrm{~m} 1$ & 13.0 & 56.8 & 368 & 24.7 & 0.00 & 1.02 & 7.41 & 55.5 & 13.0 & 55.7 & 360 & 0.00 \\
\hline SS & 10 & $\mathrm{H} 2$ & h1 & 89.4 & 368 & 2170 & 445 & 12.1 & 149 & 690 & 206 & 77.3 & 219 & 1480 & 238 \\
\hline SS & 10 & $\mathrm{H} 2$ & h10 & 102 & 407 & 1995 & 502 & 20.4 & 173 & 541 & 261 & 81.4 & 234 & 1454 & 241 \\
\hline SS & 10 & $\mathrm{H} 2$ & h2 & 91.0 & 308 & 1311 & 579 & 5.61 & 134 & 351 & 257 & 85.4 & 174 & 960 & 321 \\
\hline SS & 10 & $\mathrm{H} 2$ & h3 & 108 & 347 & 1231 & 418 & 9.10 & 134 & 361 & 168 & 99.2 & 214 & 870 & 250 \\
\hline SS & 10 & $\mathrm{H} 2$ & h4 & 105 & 307 & 1007 & 452 & 20.7 & 138 & 309 & 190 & 84.3 & 169 & 698 & 262 \\
\hline SS & 10 & $\mathrm{H} 2$ & h5 & 80.0 & 310 & 1491 & 538 & 4.51 & 112 & 420 & 290 & 75.5 & 198 & 1071 & 248 \\
\hline SS & 10 & $\mathrm{H} 2$ & h6 & 79.5 & 372 & 1798 & 524 & 12.1 & 170 & 501 & 298 & 67.5 & 201 & 1297 & 226 \\
\hline SS & 10 & $\mathrm{H} 2$ & h7 & 92.3 & 302 & 1509 & 609 & 0.00 & 113 & 412 & 276 & 92.3 & 189 & 1097 & 334 \\
\hline SS & 10 & $\mathrm{H} 2$ & h8 & 98.0 & 380 & 1914 & 627 & 24.4 & 154 & 572 & 301 & 73.6 & 226 & 1343 & 326 \\
\hline SS & 10 & $\mathrm{H} 2$ & h9 & 95.2 & 411 & 1739 & 717 & 15.0 & 194 & 445 & 351 & 80.2 & 217 & 1294 & 366 \\
\hline SS & 10 & $\mathrm{H} 2$ & I1 & 94.7 & 292 & 956 & 369 & 11.7 & 165 & 359 & 197 & 83.0 & 127 & 597 & 172 \\
\hline SS & 10 & $\mathrm{H} 2$ & $\mid 10$ & 101 & 321 & 1403 & 580 & 19.4 & 148 & 393 & 263 & 81.6 & 173 & 1009 & 317 \\
\hline SS & 10 & $\mathrm{H} 2$ & 12 & 119 & 368 & 1074 & 367 & 8.28 & 188 & 384 & 160 & 111 & 180 & 690 & 207 \\
\hline SS & 10 & $\mathrm{H} 2$ & 13 & 106 & 359 & 1256 & 713 & 54.1 & 123 & 433 & 311 & 52.1 & 236 & 823 & 402 \\
\hline SS & 10 & $\mathrm{H} 2$ & 14 & 46.9 & 100 & 465 & 290 & 0.00 & 31.2 & 117 & 302 & 46.9 & 68.6 & 349 & 124 \\
\hline SS & 10 & $\mathrm{H} 2$ & 15 & 188 & 499 & 1929 & 702 & 71.8 & 188 & 580 & 329 & 116 & 311 & 1349 & 374 \\
\hline SS & 10 & $\mathrm{H} 2$ & 16 & 100 & 337 & 1164 & 547 & 0.85 & 149 & 321 & 295 & 100 & 188 & 843 & 252 \\
\hline SS & 10 & $\mathrm{H} 2$ & 17 & 212 & 536 & 1831 & 419 & 32.1 & 222 & 533 & 197 & 180 & 313 & 1298 & 222 \\
\hline SS & 10 & $\mathrm{H} 2$ & 18 & 128 & 347 & 1111 & 610 & 86.9 & 161 & 343 & 290 & 41.1 & 186 & 768 & 319 \\
\hline SS & 10 & $\mathrm{H} 2$ & 19 & 136 & 414 & 1923 & 512 & 17.0 & 173 & 534 & 280 & 119 & 241 & 1389 & 231 \\
\hline SS & 10 & $\mathrm{H} 2$ & $\mathrm{~m} 1$ & 52.1 & 90.1 & 418 & 82.7 & 0.00 & 49.3 & 134 & 39.4 & 52.1 & 40.9 & 284 & 43.4 \\
\hline SS & 10 & $\mathrm{H} 2$ & $\mathrm{~m} 10$ & 147 & 353 & 1230 & 1185 & 33.1 & 185 & 400 & 607 & 114 & 168 & 830 & 578 \\
\hline SS & 10 & $\mathrm{H} 2$ & $\mathrm{~m} 2$ & 135 & 342 & 1075 & 877 & 8.40 & 185 & 310 & 485 & 127 & 157 & 765 & 391 \\
\hline SS & 10 & $\mathrm{H} 2$ & $\mathrm{~m} 3$ & 105 & 320 & 1139 & 797 & 2.13 & 152 & 431 & 457 & 103 & 168 & 708 & 340 \\
\hline SS & 10 & $\mathrm{H} 2$ & $\mathrm{~m} 4$ & 127 & 396 & 1141 & 616 & 15.8 & 192 & 447 & 309 & 112 & 204 & 694 & 307 \\
\hline SS & 10 & $\mathrm{H} 2$ & m5 & 148 & 401 & 953 & 630 & 4.67 & 115 & 369 & 339 & 144 & 286 & 584 & 290 \\
\hline SS & 10 & $\mathrm{H} 2$ & $\mathrm{~m} 6$ & 87.0 & 282 & 763 & 419 & 0.00 & 129 & 288 & 218 & 87.0 & 152 & 475 & 201 \\
\hline SS & 10 & $\mathrm{H} 2$ & $\mathrm{~m} 7$ & 82.3 & 257 & 914 & 515 & 0.00 & 66.2 & 318 & 260 & 82.3 & 190 & 596 & 255 \\
\hline SS & 10 & $\mathrm{H} 2$ & $\mathrm{~m} 8$ & 145 & 402 & 1205 & 717 & 21.6 & 144 & 363 & 422 & 124 & 258 & 841 & 295 \\
\hline SS & 10 & $\mathrm{H} 2$ & $\mathrm{~m} 9$ & 150 & 458 & 1230 & 715 & 35.9 & 218 & 475 & 373 & 114 & 240 & 754 & 342 \\
\hline SS & 10 & L1 & h1 & 17.8 & 32.9 & 441 & 48.7 & 0.00 & 0.00 & 0.00 & 3.72 & 17.8 & 32.9 & 441 & 45.0 \\
\hline SS & 10 & L1 & h10 & 16.1 & 49.0 & 378 & 15.6 & 0.00 & 37.1 & 61.9 & 24.8 & 16.1 & 11.9 & 316 & 0.00 \\
\hline SS & 10 & L1 & h2 & 13.4 & 40.1 & 524 & 99.3 & 0.00 & 1.37 & 1.35 & 27.2 & 13.4 & 38.7 & 522 & 72.1 \\
\hline
\end{tabular}




\begin{tabular}{|c|c|c|c|c|c|c|c|c|c|c|c|c|c|c|c|}
\hline 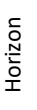 & 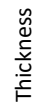 & $\stackrel{ \pm}{*}$ & 으 & $\begin{array}{l}\text { ָั } \\
\text { I }\end{array}$ & 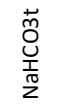 & 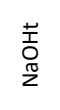 & 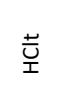 & $\begin{array}{l}\text { 모 } \\
\text { I }\end{array}$ & $\begin{array}{l}\bar{m} \\
\text { Ơ⿱ } \\
\frac{\pi}{2}\end{array}$ & $\begin{array}{l}\text { 容 } \\
\text { O } \\
\text { Z }\end{array}$ & $\overline{\overline{\bar{u}}}$ & $\begin{array}{l}\text { 옴 } \\
\text { I }\end{array}$ & $\begin{array}{l}\stackrel{\circ}{0} \\
\text { Ơ } \\
\frac{1}{\pi} \\
z\end{array}$ & 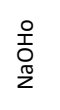 & $\frac{}{\underline{I}}$ \\
\hline SS & 10 & L1 & h3 & 20.6 & 102 & 501 & 112 & 0.00 & 3.53 & 4.67 & 1.73 & 20.6 & 98.7 & 496 & 110 \\
\hline SS & 10 & L1 & h4 & 19.8 & 74.3 & 555 & 96.7 & 0.00 & 0.00 & 0.00 & 15.7 & 19.8 & 74.3 & 555 & 81.1 \\
\hline SS & 10 & L1 & h5 & 25.1 & 59.5 & 472 & 31.0 & 0.00 & 12.0 & 60.1 & 24.0 & 25.1 & 47.5 & 412 & 6.96 \\
\hline SS & 10 & L1 & h6 & 28.6 & 67.4 & 475 & 36.7 & 0.00 & 18.4 & 61.6 & 61.5 & 28.6 & 48.9 & 414 & 0.00 \\
\hline SS & 10 & L1 & h7 & 12.2 & 38.1 & 288 & 6.68 & 5.84 & 0.00 & 35.9 & 23.9 & 6.35 & 38.1 & 252 & 0.00 \\
\hline SS & 10 & L1 & h8 & 18.0 & 60.7 & 445 & 48.8 & 46.2 & 63.5 & 46.3 & 34.8 & 0.00 & 8.25 & 399 & 14.0 \\
\hline SS & 10 & L1 & h9 & 14.7 & 48.6 & 303 & 18.0 & 0.00 & 42.1 & 72.1 & 24.0 & 14.7 & 6.61 & 231 & 0.00 \\
\hline SS & 10 & L1 & 11 & 13.5 & 36.1 & 198 & 6.17 & 1.55 & 12.8 & 3.33 & 41.2 & 12.0 & 23.3 & 195 & 0.00 \\
\hline SS & 10 & L1 & $\mid 10$ & 18.5 & 35.7 & 426 & 37.4 & 0.00 & 1.96 & 0.00 & 0.00 & 18.5 & 33.8 & 426 & 37.4 \\
\hline SS & 10 & L1 & 12 & 14.6 & 61.5 & 278 & 3.69 & 0.00 & 9.29 & 0.00 & 43.3 & 14.6 & 52.2 & 278 & 0.00 \\
\hline SS & 10 & L1 & 13 & 15.1 & 41.0 & 421 & 36.5 & 0.00 & 0.98 & 0.00 & 4.44 & 15.1 & 40.0 & 421 & 32.1 \\
\hline SS & 10 & L1 & 14 & 14.6 & 21.1 & 220 & 17.2 & 0.00 & 0.00 & 0.00 & 0.00 & 14.6 & 21.1 & 220 & 17.2 \\
\hline SS & 10 & L1 & 15 & 16.4 & 59.8 & 392 & 49.8 & 0.00 & 5.65 & 0.00 & 2.76 & 16.4 & 54.2 & 392 & 47.0 \\
\hline SS & 10 & L1 & 16 & 16.1 & 15.9 & 199 & 28.5 & 0.00 & 0.00 & 1.68 & 0.00 & 16.1 & 15.9 & 197 & 28.5 \\
\hline SS & 10 & L1 & 17 & 29.0 & 118 & 627 & 91.8 & 0.00 & 30.8 & 7.07 & 11.8 & 29.0 & 87.5 & 620 & 80.0 \\
\hline SS & 10 & L1 & 18 & 18.0 & 46.4 & 427 & 70.4 & 0.00 & 11.4 & 0.25 & 0.00 & 18.0 & 35.0 & 427 & 70.4 \\
\hline SS & 10 & L1 & 19 & 20.4 & 21.5 & 220 & 31.6 & 0.00 & 0.00 & 0.00 & 15.3 & 20.4 & 21.5 & 220 & 18.7 \\
\hline SS & 10 & L1 & $\mathrm{m} 10$ & 28.2 & 94.9 & 556 & 40.3 & 0.00 & 18.9 & 19.8 & 214 & 28.2 & 75.9 & 536 & 0.00 \\
\hline SS & 10 & L1 & $\mathrm{m} 2$ & 10.9 & 51.7 & 383 & 22.9 & 0.00 & 2.43 & 0.00 & 38.7 & 10.9 & 49.2 & 383 & 4.12 \\
\hline SS & 10 & L1 & $\mathrm{m} 3$ & 16.1 & 72.4 & 408 & 31.6 & 2.82 & 0.00 & 6.52 & 19.8 & 13.2 & 72.4 & 402 & 11.8 \\
\hline SS & 10 & L1 & $\mathrm{m} 4$ & 12.0 & 39.7 & 310 & 25.3 & 0.00 & 7.48 & 0.00 & 36.4 & 12.0 & 32.2 & 310 & 0.75 \\
\hline SS & 10 & L1 & m5 & 14.8 & 61.9 & 394 & 29.6 & 0.00 & 0.00 & 0.00 & 63.3 & 14.8 & 61.9 & 394 & 0.00 \\
\hline SS & 10 & L1 & $\mathrm{m} 6$ & 12.4 & 34.4 & 218 & 2.93 & 0.00 & 0.00 & 0.00 & 12.1 & 12.4 & 34.4 & 218 & 0.00 \\
\hline SS & 10 & L1 & $\mathrm{m} 7$ & 12.3 & 34.1 & 275 & 10.3 & 0.00 & 3.10 & 0.00 & 36.8 & 12.3 & 31.0 & 275 & 0.00 \\
\hline SS & 10 & L1 & $\mathrm{m} 8$ & 14.4 & 23.5 & 194 & 10.2 & 0.00 & 0.00 & 0.00 & 31.3 & 14.4 & 23.5 & 194 & 0.00 \\
\hline SS & 10 & L1 & $\mathrm{m} 9$ & 18.9 & 84.3 & 552 & 55.3 & 0.00 & 4.23 & 31.6 & 90.3 & 18.9 & 80.0 & 521 & 0.00 \\
\hline SS & 10 & L2 & h1 & 14.4 & 35.3 & 237 & 0.00 & 0.00 & 2.77 & 5.26 & 0.00 & 14.4 & 32.5 & 232 & 0.00 \\
\hline SS & 10 & L2 & h10 & 7.95 & 30.4 & 213 & 0.00 & 0.00 & 0.00 & 1.24 & 0.30 & 7.95 & 30.4 & 212 & 0.00 \\
\hline SS & 10 & L2 & h2 & 10.5 & 43.6 & 331 & 4.28 & 0.00 & 5.73 & 25.9 & 0.00 & 10.5 & 37.9 & 305 & 4.28 \\
\hline SS & 10 & L2 & h3 & 7.22 & 14.7 & 128 & 0.00 & 0.00 & 0.00 & 0.00 & 0.40 & 7.22 & 14.7 & 128 & 0.00 \\
\hline SS & 10 & L2 & h4 & 9.35 & 10.9 & 150 & 0.00 & 0.94 & 3.22 & 2.58 & 1.34 & 8.41 & 7.66 & 147 & 0.00 \\
\hline SS & 10 & L2 & h5 & 15.0 & 28.4 & 277 & 9.58 & 0.00 & 0.08 & 19.6 & 7.18 & 15.0 & 28.3 & 257 & 3.16 \\
\hline SS & 10 & L2 & h6 & 11.1 & 11.5 & 147 & 0.00 & 0.00 & 2.25 & 0.00 & 7.73 & 11.1 & 9.23 & 147 & 0.00 \\
\hline SS & 10 & L2 & h7 & 25.4 & 48.4 & 423 & 8.13 & 3.83 & 23.4 & 72.3 & 3.13 & 21.6 & 25.0 & 351 & 5.00 \\
\hline SS & 10 & L2 & h8 & 12.4 & 15.7 & 135 & 0.00 & 5.87 & 1.61 & 0.00 & 7.15 & 6.90 & 14.1 & 135 & 0.00 \\
\hline SS & 10 & L2 & h9 & 11.8 & 29.7 & 192 & 0.00 & 0.00 & 12.2 & 0.00 & 14.5 & 11.8 & 17.6 & 192 & 0.00 \\
\hline SS & 10 & L2 & 12 & 7.68 & 45.8 & 258 & 14.5 & 0.00 & 63.3 & 1.90 & 0.00 & 7.68 & 0.00 & 256 & 14.5 \\
\hline SS & 10 & L2 & 13 & 9.51 & 18.0 & 119 & 0.00 & 0.00 & 13.5 & 0.00 & 0.00 & 9.51 & 9.12 & 119 & 0.00 \\
\hline SS & 10 & L2 & 14 & 11.7 & 61.0 & 329 & 22.8 & 0.00 & 21.9 & 49.1 & 0.00 & 11.7 & 39.1 & 280 & 22.8 \\
\hline SS & 10 & L2 & 15 & 8.05 & 37.0 & 232 & 4.93 & 0.00 & 8.34 & 6.81 & 6.10 & 8.05 & 28.7 & 225 & 2.50 \\
\hline
\end{tabular}




\begin{tabular}{|c|c|c|c|c|c|c|c|c|c|c|c|c|c|c|c|}
\hline $\begin{array}{l}\text { 은 } \\
\text { 음 } \\
\text { 오 }\end{array}$ & 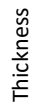 & $\stackrel{ \pm}{ \pm}$ & 으 & $\begin{array}{l}\text { ○ั } \\
\text { I }\end{array}$ & 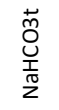 & $\begin{array}{l}\text { 㐊 } \\
0 \\
\text { त्ञ }\end{array}$ & $\stackrel{ \pm}{\stackrel{ \pm}{I}}$ & $\begin{array}{l}\bar{\Upsilon} \\
\text { I }\end{array}$ & $\begin{array}{l}\bar{n} \\
\text { O্் } \\
\text { ָ̃ } \\
z\end{array}$ & $\begin{array}{l}\text { 고 } \\
\text { 유 } \\
\bar{z}\end{array}$ & $\overline{\bar{u}}$ & $\begin{array}{l}\stackrel{\circ}{\text { İ }} \\
\text { İ }\end{array}$ & $\begin{array}{l}\text { O } \\
\text { Ô } \\
\frac{1}{\pi} \\
\frac{\pi}{z}\end{array}$ & 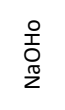 & $\frac{ㅇ ㅡ ㄴ ~}{\text { İ }}$ \\
\hline SS & 10 & L2 & 16 & 7.36 & 18.9 & 130 & 1.23 & 0.00 & 3.66 & 6.23 & 0.00 & 7.36 & 15.2 & 124 & 1.23 \\
\hline SS & 10 & L2 & 17 & 8.17 & 42.2 & 236 & 18.7 & 0.00 & 15.7 & 17.8 & 10.2 & 8.17 & 26.5 & 218 & 8.52 \\
\hline SS & 10 & L2 & 18 & 4.18 & 35.3 & 129 & 0.00 & 7.85 & 9.84 & 8.90 & 0.00 & 0.90 & 25.4 & 120 & 0.00 \\
\hline SS & 10 & L2 & 19 & 10.3 & 53.1 & 300 & 0.00 & 0.00 & 20.2 & 29.5 & 0.00 & 10.3 & 32.8 & 270 & 0.00 \\
\hline SS & 10 & L2 & $\mathrm{m} 1$ & 11.6 & 28.2 & 176 & 0.25 & 31.3 & 55.9 & 80.9 & 37.3 & 4.95 & 0.00 & 94.9 & 0.00 \\
\hline SS & 10 & L2 & $\mathrm{m} 10$ & 4.88 & 15.7 & 123 & 0.00 & 0.00 & 0.68 & 2.95 & 0.00 & 4.88 & 15.0 & 120 & 0.00 \\
\hline SS & 10 & L2 & $\mathrm{m} 2$ & 10.4 & 55.5 & 330 & 19.1 & 0.00 & 72.4 & 84.5 & 60.5 & 10.4 & 0.00 & 245 & 0.00 \\
\hline SS & 10 & L2 & $\mathrm{m} 3$ & 15.0 & 28.2 & 190 & 0.72 & 0.00 & 542 & 71.8 & 72.0 & 15.0 & 0.00 & 118 & 0.00 \\
\hline SS & 10 & L2 & $\mathrm{m} 4$ & 6.68 & 21.6 & 164 & 0.00 & 0.00 & 60.9 & 61.0 & 24.4 & 6.68 & 0.00 & 103 & 0.00 \\
\hline SS & 10 & L2 & m5 & 19.2 & 56.5 & 362 & 25.4 & 5.95 & 66.5 & 139 & 48.3 & 13.3 & 0.00 & 223 & 0.00 \\
\hline SS & 10 & L2 & $\mathrm{m} 6$ & 11.8 & 24.4 & 168 & 4.37 & 6.13 & 48.6 & 91.0 & 36.3 & 5.96 & 0.00 & 76.8 & 0.00 \\
\hline SS & 10 & L2 & $\mathrm{m} 7$ & 4.10 & 82.4 & 276 & 15.2 & 0.00 & 14.6 & 8.52 & 0.00 & 4.10 & 67.8 & 267 & 15.2 \\
\hline SS & 10 & L2 & $\mathrm{m} 8$ & 3.65 & 27.0 & 158 & 0.44 & 0.00 & 0.43 & 27.2 & 0.00 & 3.65 & 26.6 & 131 & 0.44 \\
\hline SS & 10 & L2 & $\mathrm{m} 9$ & 4.52 & 50.2 & 183 & 0.00 & 0.00 & 1.16 & 92.0 & 0.00 & 4.52 & 49.1 & 91.4 & 0.00 \\
\hline
\end{tabular}




\section{Soil test, pH, carbon, and particle size data (field data)}

Horizon: S - surface, SS ; Thickness: horizon thickness in cm; Site: H1 - high one (location 1 with long history of manure application), H2 - high two (location 2 with long history of manure application), L1 - low 1 (location 1 with little to no history of manure application), L2 - low 2

(location 2 with little to no history of manure application); ID: h1-10 (sample locations 1-10 in the high stratification) m1--10 (sample locations 1-10 in the medium stratification), I1-10 (sample location 1-10 in the low stratification); \% Carbon - \% carbon; $\mathrm{pH}-\mathrm{pH}$ in water; $\mathrm{pH}$ in CaCl - pH in $\mathrm{CaCl}_{2}$; Soil Test Results: M1 Al - Mehlich 1 extractable Al, M1 Fe - Mehlich 1 extractable Fe, M1 Ca - Mehlich 1 extractable Ca, M1 P - Mehlich 1 extractable P, M3 P - Mehlich 3 extractable P; Soil Particle size distribution: \% Sand, \% Silt, \% Clay.

\begin{tabular}{|c|c|c|c|c|c|c|c|c|c|c|c|c|c|c|}
\hline $\begin{array}{l}\text { 웜 } \\
\text { 울 }\end{array}$ & 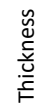 & 节 & 으 & 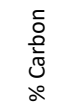 & II & $\begin{array}{l}\overline{\widetilde{J}} \\
\stackrel{.}{\subseteq} \\
\bar{I}\end{array}$ & $\begin{array}{l}\bar{\alpha} \\
\vec{\Sigma}\end{array}$ & 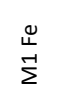 & $\begin{array}{l}\tilde{J} \\
\vec{\Sigma}\end{array}$ & $\begin{array}{l}\stackrel{a}{\Sigma} \\
\vec{\Sigma}\end{array}$ & $\stackrel{a}{m}$ & $\begin{array}{l}\text { o } \\
\text { त } \\
\text { do } \\
\text { o }\end{array}$ & 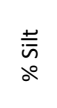 & $\begin{array}{l}\frac{\vec{\pi}}{0} \\
\stackrel{\circ}{\circ}\end{array}$ \\
\hline S & 7 & $\mathrm{H} 1$ & h1 & 3.68 & 6.32 & 6.05 & 238 & 12.6 & 3536 & 852 & 55.1 & 27.2 & 52.1 & 20.7 \\
\hline s & 5 & $\mathrm{H} 1$ & h10 & 3.30 & 6.43 & 6.05 & 210 & 16.9 & 2727 & 652 & 38.7 & 22.7 & 58.0 & 19.3 \\
\hline S & 5 & $\mathrm{H} 1$ & h2 & 5.20 & 6.25 & 5.87 & 247 & 12.3 & 2675 & 582 & 40.4 & 24.9 & 52.7 & 22.4 \\
\hline S & 8 & $\mathrm{H} 1$ & h3 & 4.46 & 6.36 & 5.87 & 284 & 18.0 & 2946 & 788 & 53.5 & 23.0 & 60.6 & 16.4 \\
\hline$S$ & 5 & $\mathrm{H} 1$ & h4 & 4.38 & 6.45 & 6.03 & 222 & 12.3 & 3594 & 857 & 48.5 & 28.6 & 50.6 & 20.8 \\
\hline S & 5 & $\mathrm{H} 1$ & h5 & 3.89 & 6.36 & 5.91 & 238 & 15.4 & 3136 & 854 & 12.7 & 29.0 & 49.5 & 21.4 \\
\hline$S$ & 6 & $\mathrm{H} 1$ & h6 & 4.63 & 6.38 & 6.00 & 237 & 13.6 & 3178 & 697 & 8.38 & 25.4 & 53.2 & 21.4 \\
\hline S & 5 & $\mathrm{H} 1$ & h7 & 4.47 & 6.41 & 6.14 & 256 & 10.8 & 3078 & 790 & 8.44 & 25.1 & 54.3 & 20.6 \\
\hline s & 4 & $\mathrm{H} 1$ & h8 & 4.56 & 6.48 & 6.05 & 285 & 16.1 & 3762 & 951 & 11.0 & 24.0 & 55.8 & 20.3 \\
\hline$S$ & 5 & $\mathrm{H} 1$ & h9 & 4.74 & 6.41 & 6.05 & 251 & 12.6 & 3732 & 973 & 8.24 & 23.1 & 57.1 & 19.8 \\
\hline S & 9 & $\mathrm{H} 1$ & 11 & 6.22 & 6.48 & 6.23 & 300 & 19.4 & 4742 & 1448 & 80.0 & 22.5 & 53.9 & 23.6 \\
\hline S & 4 & $\mathrm{H} 1$ & 110 & 8.29 & 6.41 & 6.14 & 243 & 18.6 & 5757 & 1430 & 84.6 & 26.2 & 49.4 & 24.3 \\
\hline S & 7 & $\mathrm{H} 1$ & 12 & 4.36 & 6.38 & 5.94 & 280 & 14.1 & 3225 & 1101 & 56.8 & 30.4 & 49.1 & 20.5 \\
\hline S & 9 & $\mathrm{H} 1$ & 13 & 7.41 & 6.57 & 6.02 & 288 & 18.0 & 4038 & 1007 & 51.0 & 25.7 & 56.8 & 17.5 \\
\hline S & 5 & $\mathrm{H} 1$ & 14 & 5.78 & 6.75 & 6.39 & 286 & 15.1 & 3686 & 1192 & 83.6 & 28.6 & 53.2 & 18.2 \\
\hline S & 8 & $\mathrm{H} 1$ & 15 & 4.62 & 6.45 & 6.05 & 347 & 21.9 & 3977 & 882 & 63.6 & 23.6 & 56.6 & 19.8 \\
\hline S & 8 & $\mathrm{H} 1$ & 16 & 5.08 & 6.70 & 6.29 & 213 & 21.5 & 3401 & 1263 & 72.7 & 26.9 & 52.1 & 21.0 \\
\hline$S$ & 7.5 & $\mathrm{H} 1$ & 17 & 7.73 & 6.63 & 6.23 & 250 & 16.5 & 7180 & 1805 & 106 & 26.7 & 47.7 & 25.6 \\
\hline S & 5 & $\mathrm{H} 1$ & 18 & 10.85 & 6.50 & 6.05 & 202 & 13.4 & 5229 & 1061 & 62.6 & 19.6 & 62.8 & 17.6 \\
\hline S & 5 & $\mathrm{H} 1$ & 19 & 0 & 6.57 & 6.16 & & 24.0 & 6351 & 1553 & 87.0 & 25.3 & 54.0 & 20.7 \\
\hline S & 5 & $\mathrm{H} 1$ & $\mathrm{~m} 1$ & 5.47 & 6.38 & 5.85 & 279 & 14.5 & 3525 & 751 & 48.6 & 22.6 & 45.3 & 32.1 \\
\hline S & 3 & $\mathrm{H} 1$ & $\mathrm{~m} 10$ & 7.10 & 6.36 & 5.98 & 267 & 17.8 & 5486 & 1545 & 85.2 & 26.0 & 49.8 & 24.2 \\
\hline s & 10 & $\mathrm{H} 1$ & & & 6.75 & & & 19.6 & 7146 & 1493 & & 26.0 & 52.2 & 21.8 \\
\hline S & 4 & $\mathrm{H} 1$ & $\mathrm{~m} 3$ & 7.73 & 6.27 & 5.87 & 265 & 14.0 & 2963 & 711 & 50.5 & 16.9 & 60.7 & 22.4 \\
\hline S & 7 & $\mathrm{H} 1$ & $\mathrm{~m} 4$ & 5.68 & 6.39 & 6.02 & 331 & 16.0 & 5300 & 1081 & 67.3 & 20.6 & 57.9 & 21.5 \\
\hline S & 7 & $\mathrm{H} 1$ & m5 & 5.69 & 5.98 & 5.67 & 278 & 16.6 & 2873 & 649 & 54.4 & 23.8 & 54.6 & 21.6 \\
\hline S & 5 & $\mathrm{H} 1$ & $\mathrm{~m} 6$ & 6.34 & 6.68 & 6.29 & 300 & 14.5 & 4765 & 987 & 69.0 & 23.3 & 55.0 & 21.7 \\
\hline S & 6 & $\mathrm{H} 1$ & $\mathrm{~m} 7$ & 5.22 & 6.43 & 6.03 & 369 & 17.7 & 4662 & 1061 & 66.5 & 23.0 & 53.2 & 23.8 \\
\hline S & 3 & $\mathrm{H} 1$ & $\mathrm{~m} 8$ & 7.81 & 6.41 & 5.96 & 377 & 15.3 & 4273 & 755 & 57.5 & 24.4 & 53.8 & 21.8 \\
\hline S & 3 & $\mathrm{H} 1$ & $\mathrm{~m} 9$ & 6.45 & 6.27 & 5.89 & 310 & 12.9 & 4174 & 712 & 48.6 & 27.8 & 47.6 & 24.7 \\
\hline S & 6 & $\mathrm{H} 1$ & $\mathrm{~m} 1$ & 4.33 & 5.55 & 5.21 & 98.7 & 6.79 & 757 & 12.1 & 4.44 & 46.3 & 44.6 & 9.1 \\
\hline S & 6.5 & $\mathrm{H} 2$ & h1 & 5.67 & 5.33 & 5.13 & 85.9 & 117 & 1283 & 76.0 & 9.24 & 17.6 & 51.9 & 30.5 \\
\hline S & 5 & $\mathrm{H} 2$ & h10 & 4.29 & 5.60 & 5.42 & 117 & 98.8 & 1650 & 158 & 17.7 & 20.1 & 57.9 & 22.0 \\
\hline
\end{tabular}




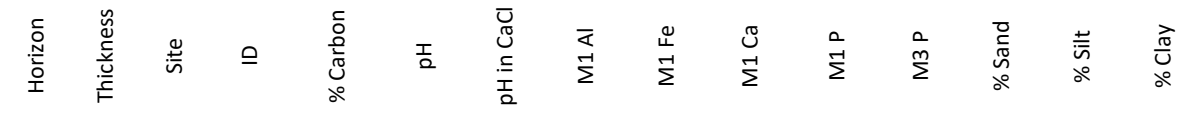

\begin{tabular}{|c|c|c|c|c|c|c|c|c|c|c|c|c|c|c|}
\hline $\mathrm{s}$ & 9 & $\mathrm{H} 2$ & h2 & 4.96 & 6.18 & 5.94 & 99.2 & 23.2 & 2747 & 219 & 15.6 & 20.6 & 47.0 & 32.4 \\
\hline$S$ & 9 & $\mathrm{H} 2$ & h3 & 2.39 & 6.03 & 5.44 & 171 & 13.4 & 1621 & 194 & 20.1 & 23.4 & 52.0 & 24.7 \\
\hline$S$ & 9 & $\mathrm{H} 2$ & h4 & 4.59 & 6.20 & 5.89 & 160 & 14.8 & 1942 & 285 & 25.2 & 20.8 & 54.8 & 24.5 \\
\hline $\mathrm{s}$ & 9 & $\mathrm{H} 2$ & h5 & 3.85 & 6.21 & 5.87 & 116 & 25.7 & 2170 & 154 & 12.9 & 20.6 & 53.3 & 26.0 \\
\hline$S$ & 7 & $\mathrm{H} 2$ & h6 & 3.83 & 6.45 & 6.27 & 129 & 39.0 & 2454 & 237 & 22.6 & 25.4 & 57.3 & 17.4 \\
\hline$S$ & 6 & $\mathrm{H} 2$ & h7 & 5.16 & 6.11 & 5.82 & 120 & 56.1 & 1793 & 188 & 20.1 & 17.1 & 53.9 & 28.9 \\
\hline$S$ & 7 & $\mathrm{H} 2$ & h8 & 4.08 & 5.64 & 5.48 & 104 & 77.6 & 1472 & 186 & 16.0 & 18.3 & 61.5 & 20.3 \\
\hline$S$ & 6 & $\mathrm{H} 2$ & h9 & 4.36 & 6.07 & 5.78 & 119 & 49.5 & 1787 & 173 & 18.5 & 20.2 & 57.9 & 22.0 \\
\hline$S$ & 10 & $\mathrm{H} 2$ & I1 & 3.18 & 5.93 & 5.51 & 181 & 15.4 & 1919 & 244 & 19.5 & 24.8 & 55.7 & 19.5 \\
\hline$S$ & 8 & $\mathrm{H} 2$ & 110 & 3.40 & 6.09 & 5.71 & 184 & 15.2 & 1929 & 267 & 23.6 & 25.0 & 52.6 & 22.4 \\
\hline$S$ & 10 & $\mathrm{H} 2$ & 12 & 0.30 & 5.75 & 5.31 & 198 & 17.1 & 1682 & 256 & 26.0 & 24.8 & 57.1 & 18.1 \\
\hline S & 10 & $\mathrm{H} 2$ & 13 & 3.22 & 5.76 & 5.46 & 167 & 16.9 & 2242 & 375 & 25.4 & 37.8 & 38.4 & 23.9 \\
\hline$S$ & 19 & $\mathrm{H} 2$ & 14 & 2.24 & 6.72 & 6.20 & 117 & 33.2 & 2255 & 99.3 & 7.27 & 35.5 & 39.6 & 24.9 \\
\hline$S$ & 8 & $\mathrm{H} 2$ & 15 & 4.67 & 6.03 & 5.76 & 206 & 9.71 & 2057 & 305 & 32.0 & 24.6 & 50.5 & 25.0 \\
\hline S & 11 & $\mathrm{H} 2$ & 16 & 3.62 & 5.55 & 5.15 & 126 & 49.7 & 1560 & 157 & 18.0 & 30.0 & 46.3 & 23.7 \\
\hline$S$ & 13 & $\mathrm{H} 2$ & 17 & 2.43 & 6.05 & 5.67 & 214 & 10.6 & 1676 & 253 & 30.4 & 30.7 & 51.0 & 18.4 \\
\hline$S$ & 9 & $\mathrm{H} 2$ & 18 & 3.42 & 6.23 & 5.89 & 156 & 9.74 & 2011 & 250 & 23.7 & 27.6 & 51.7 & 20.6 \\
\hline S & 5 & $\mathrm{H} 2$ & 19 & 4.20 & 5.71 & 5.31 & 179 & 12.0 & 1658 & 198 & 26.5 & 24.3 & 47.0 & 28.6 \\
\hline S & 27 & $\mathrm{H} 2$ & $\mathrm{~m} 1$ & 2.36 & 6.48 & 5.87 & 141 & 13.7 & 2081 & 137 & 9.71 & 24.5 & 48.0 & 27.5 \\
\hline$S$ & 2 & $\mathrm{H} 2$ & $\mathrm{~m} 10$ & 4.44 & 6.52 & 6.03 & 178 & 18.1 & 2013 & 320 & 27.6 & 28.9 & 52.2 & 18.9 \\
\hline$S$ & 9 & $\mathrm{H} 2$ & $\mathrm{~m} 2$ & 3.69 & 6.14 & 5.76 & 161 & 18.4 & 2441 & 363 & 26.4 & 26.8 & 50.5 & 22.7 \\
\hline S & 10 & $\mathrm{H} 2$ & $\mathrm{~m} 3$ & 3.62 & 5.80 & 5.53 & 143 & 23.1 & 2422 & 246 & 16.4 & 27.4 & 51.1 & 21.5 \\
\hline S & 12 & $\mathrm{H} 2$ & $\mathrm{~m} 4$ & 2.69 & 5.78 & 5.39 & 179 & 12.8 & 1745 & 262 & 25.8 & 31.3 & 53.8 & 14.9 \\
\hline$S$ & 9 & $\mathrm{H} 2$ & m5 & 3.52 & 6.29 & 5.91 & 170 & 9.67 & 2433 & 357 & 30.9 & 26.2 & 52.6 & 21.2 \\
\hline S & 10 & $\mathrm{H} 2$ & $\mathrm{~m} 6$ & 3.32 & 6.14 & 5.78 & 135 & 32.8 & 2386 & 212 & 16.7 & 28.8 & 49.4 & 21.7 \\
\hline S & 13 & $\mathrm{H} 2$ & $\mathrm{~m} 7$ & 3.33 & 6.38 & 5.98 & 146 & 18.2 & 2491 & 187 & 16.0 & 30.9 & 44.0 & 25.1 \\
\hline$S$ & 6 & $\mathrm{H} 2$ & $\mathrm{~m} 8$ & 2.81 & 6.14 & 5.58 & 162 & 15.8 & 1569 & 215 & 24.3 & 30.8 & 50.3 & 18.9 \\
\hline$S$ & 13 & $\mathrm{H} 2$ & $\mathrm{~m} 9$ & 2.98 & 6.00 & 5.57 & 198 & 15.3 & 1806 & 293 & 32.0 & 28.2 & 54.0 & 17.8 \\
\hline S & 6 & L1 & h1 & 3.76 & 5.31 & 4.92 & 116 & 14.0 & 786 & 20.1 & 6.81 & 34.2 & 53.9 & 12.0 \\
\hline$S$ & 8 & L1 & h10 & 3.81 & 5.39 & 4.97 & 89.7 & 23.0 & 574 & 12.8 & 4.96 & 48.0 & 42.2 & 9.8 \\
\hline S & 6 & L1 & h2 & 3.52 & 5.39 & 4.94 & 164 & 14.7 & 852 & 14.8 & 5.48 & 34.7 & 52.9 & 12.4 \\
\hline S & 5 & L1 & h3 & 3.57 & 5.31 & 4.95 & 121 & 20.2 & 747 & 17.8 & 7.22 & 65.9 & 28.6 & 5.5 \\
\hline S & 6 & L1 & h4 & 5.69 & 5.44 & 5.21 & 124 & 6.66 & 699 & 16.7 & 4.94 & 42.9 & 47.7 & 9.4 \\
\hline S & 7 & L1 & h5 & 4.51 & 5.53 & 5.22 & 109 & 6.54 & 876 & 15.5 & 4.78 & 48.4 & 42.8 & 8.8 \\
\hline S & 7 & L1 & h6 & 4.76 & 5.76 & 5.58 & 106 & 6.55 & 1167 & 34.4 & 6.34 & 46.4 & 44.3 & 9.4 \\
\hline S & 9 & L1 & h7 & 2.72 & 4.91 & 4.52 & 115 & 25.3 & 633 & 3.86 & 1.94 & 39.9 & 45.5 & 14.5 \\
\hline$S$ & 7 & L1 & h8 & 3.15 & 5.24 & 4.94 & 126 & 16.1 & 696 & 12.6 & 6.61 & 50.6 & 41.8 & 7.7 \\
\hline S & 8 & L1 & h9 & 4.91 & 5.26 & 4.94 & 117 & 21.0 & 1207 & 11.0 & 4.43 & 31.8 & 53.8 & 14.4 \\
\hline S & 8 & L1 & $\mid 1$ & 3.89 & 5.10 & 4.61 & 107 & 23.8 & 880 & 5.18 & 2.16 & 31.6 & 50.4 & 17.9 \\
\hline S & 9 & L1 & 110 & 3.91 & 4.97 & 4.61 & 127 & 17.4 & 528 & 3.31 & 2.20 & 22.1 & 57.6 & 20.3 \\
\hline
\end{tabular}




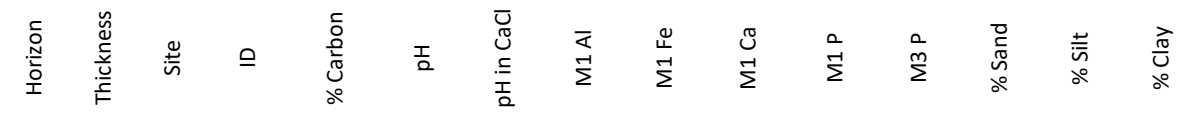

\begin{tabular}{|c|c|c|c|c|c|c|c|c|c|c|c|c|c|c|}
\hline$S$ & 7 & L1 & 12 & 3.47 & 5.73 & 4.86 & 132 & 12.1 & 503 & 15.2 & 4.96 & 54.7 & 39.1 & 6.2 \\
\hline$S$ & 9 & L1 & 13 & 4.45 & 5.24 & 4.76 & 132 & 7.38 & 584 & 4.47 & 2.24 & 21.9 & 56.2 & 21.9 \\
\hline$S$ & 9 & L1 & 14 & 5.26 & 5.35 & 4.92 & 113 & 26.7 & 1214 & 51.7 & 4.08 & 30.1 & 54.0 & 15.9 \\
\hline$S$ & 6 & L1 & 15 & 3.50 & 5.60 & 5.35 & 128 & 5.55 & 790 & 10.6 & 6.19 & 69.6 & 26.4 & 4.0 \\
\hline$S$ & 8 & L1 & 16 & 4.84 & 5.46 & 5.12 & 93.7 & 20.1 & 1102 & 7.40 & 2.24 & 26.1 & 54.7 & 19.2 \\
\hline$S$ & 5 & L1 & 17 & 6.16 & 5.57 & 5.22 & 122 & 10.7 & 1210 & 37.1 & 9.77 & 51.5 & 41.6 & 7.0 \\
\hline$S$ & 7 & L1 & 18 & 3.23 & 5.46 & 4.88 & 196 & 12.5 & 710 & 22.0 & 7.46 & 42.4 & 51.0 & 6.6 \\
\hline$S$ & 9 & L1 & 19 & 4.77 & 5.60 & 5.55 & 114 & 34.6 & 1252 & 9.47 & 1.70 & 3.5 & 75.8 & 20.7 \\
\hline$S$ & 5 & L1 & $\mathrm{m} 10$ & 7.69 & 5.35 & 5.03 & 88.9 & 22.3 & 1131 & 25.8 & 7.02 & 31.4 & 52.5 & 16.2 \\
\hline$S$ & 8 & L1 & $\mathrm{m} 2$ & 3.11 & 4.97 & 5.61 & 177 & 14.8 & 441 & 10.6 & 5.06 & 49.4 & 42.4 & 8.2 \\
\hline$S$ & 5 & L1 & $\mathrm{m} 3$ & 4.08 & 5.44 & 4.85 & 106 & 24.2 & 449 & 9.17 & 3.59 & 57.4 & 32.2 & 10.5 \\
\hline$S$ & 6 & L1 & $\mathrm{m} 4$ & 5.74 & 5.58 & 5.33 & 85.9 & 6.09 & 1119 & 15.9 & 4.50 & 43.0 & 45.1 & 11.9 \\
\hline$S$ & 7 & L1 & m5 & 4.64 & 5.31 & 4.88 & 117 & 9.88 & 615 & 12.3 & 4.76 & 46.5 & 44.0 & 9.5 \\
\hline$S$ & 9 & L1 & $\mathrm{m} 6$ & 4.10 & 5.15 & 4.72 & 126 & 36.7 & 953 & 12.8 & 4.04 & 38.6 & 48.4 & 13.1 \\
\hline$S$ & 8 & L1 & $\mathrm{m} 7$ & 4.10 & 5.46 & 5.01 & 132 & 13.0 & 684 & 16.0 & 6.59 & 53.8 & 40.2 & 5.9 \\
\hline$S$ & 9 & L1 & $\mathrm{m} 8$ & 4.59 & 5.49 & 5.12 & 89.5 & 16.6 & 1068 & 5.85 & 1.63 & 24.1 & 54.2 & 21.7 \\
\hline$S$ & 6 & L1 & $\mathrm{m} 9$ & 4.36 & 5.42 & 5.03 & 138 & 12.2 & 887 & 10.5 & 8.41 & 48.5 & 43.6 & 7.9 \\
\hline$S$ & 4.5 & L2 & h1 & 5.62 & 5.19 & 4.68 & 169 & 59.6 & 842 & 9.04 & 5.52 & 21.4 & 66.4 & 12.2 \\
\hline$S$ & 5 & L2 & h10 & 5.13 & 4.88 & 4.43 & 170 & 118 & 679 & 6.99 & 5.42 & 22.2 & 66.8 & 11.0 \\
\hline$S$ & 3.5 & L2 & h2 & 8.59 & 4.90 & 4.68 & 186 & 38.8 & 808 & 21.2 & 4.95 & 16.9 & 63.1 & 20.0 \\
\hline$S$ & 5 & L2 & h3 & 7.34 & 4.81 & 4.27 & 258 & 133 & 664 & 7.53 & 2.14 & 21.1 & 65.3 & 13.6 \\
\hline$S$ & 5 & L2 & h4 & 4.83 & 5.01 & 4.38 & 252 & 100 & 513 & 7.97 & 2.28 & 19.3 & 68.8 & 11.9 \\
\hline$S$ & 4 & L2 & h5 & 4.52 & 4.40 & 3.95 & 289 & 177 & 411 & 11.2 & 3.91 & 19.1 & 69.6 & 11.3 \\
\hline$S$ & 3 & L2 & h6 & 3.77 & 5.40 & 4.86 & 140 & 43.7 & 974 & 11.9 & 2.28 & 18.0 & 70.1 & 11.9 \\
\hline$S$ & 5.5 & L2 & h7 & 3.26 & 5.58 & 5.06 & 125 & 39.4 & 747 & 12.3 & 2.78 & 18.8 & 69.6 & 11.6 \\
\hline$S$ & 5 & L2 & h8 & 3.09 & 5.08 & 4.56 & 169 & 84.7 & 509 & 8.59 & 2.86 & 20.0 & 68.7 & 11.3 \\
\hline$S$ & 5 & L2 & h9 & 4.16 & 5.03 & 4.56 & 183 & 70.3 & 648 & 8.85 & 1.55 & 23.9 & 64.9 & 11.2 \\
\hline$S$ & 4 & L2 & 12 & 4.36 & 4.90 & 4.56 & 162 & 45.9 & 768 & 17.3 & 5.40 & 19.6 & 67.1 & 13.2 \\
\hline$S$ & 6 & L2 & 13 & 3.83 & 5.12 & 4.68 & 163 & 32.0 & 846 & 10.7 & 3.17 & 20.1 & 67.5 & 12.4 \\
\hline$S$ & 5 & L2 & 14 & 3.79 & 5.08 & 4.77 & 137 & 27.0 & 756 & 14.6 & 6.00 & 17.0 & 69.6 & 13.5 \\
\hline$S$ & 4.5 & L2 & 15 & 4.28 & 5.24 & 4.85 & 139 & 19.6 & 928 & 13.4 & 5.36 & 17.3 & 69.7 & 12.9 \\
\hline$S$ & 4 & L2 & 16 & 4.08 & 5.22 & 4.99 & 123 & 27.5 & 759 & 10.4 & 3.85 & 16.1 & 70.4 & 13.5 \\
\hline$S$ & 4 & L2 & 17 & 4.40 & 5.08 & 4.79 & 125 & 25.4 & 847 & 12.3 & 4.77 & 19.7 & 67.0 & 13.4 \\
\hline$S$ & 5 & L2 & 18 & 6.78 & 4.94 & 4.36 & 219 & 110 & 494 & 13.3 & 3.67 & 21.9 & 66.2 & 11.9 \\
\hline$S$ & 4 & L2 & 19 & 7.42 & 5.01 & 4.63 & 191 & 8.06 & 466 & 7.21 & 4.12 & 14.4 & 72.2 & 13.4 \\
\hline$S$ & 8 & L2 & $\mathrm{m} 1$ & 6.93 & 4.99 & 4.70 & 189 & 57.3 & 1278 & 17.2 & 4.64 & 16.1 & 73.1 & 10.7 \\
\hline$S$ & 4 & L2 & $\mathrm{m} 10$ & 3.89 & 5.30 & 4.94 & 129 & 33.1 & 684 & 12.6 & 3.49 & 23.9 & 64.7 & 11.4 \\
\hline$S$ & 4 & L2 & $\mathrm{m} 2$ & 5.15 & 5.01 & 4.50 & 170 & 58.1 & 1038 & 14.4 & 4.39 & 17.0 & 72.4 & 10.6 \\
\hline$S$ & 4 & L2 & $\mathrm{m} 3$ & 4.21 & 5.21 & 4.67 & 156 & 46.5 & 654 & 10.1 & 3.95 & 23.6 & 65.5 & 11.0 \\
\hline$S$ & 5 & L2 & $\mathrm{m} 4$ & 3.39 & 5.26 & 4.59 & 174 & 57.2 & 662 & 6.96 & 2.53 & 25.5 & 63.6 & 10.8 \\
\hline
\end{tabular}




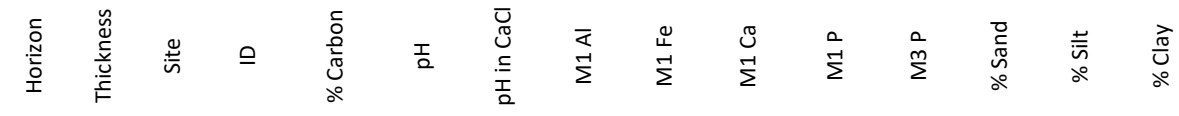

\begin{tabular}{|c|c|c|c|c|c|c|c|c|c|c|c|c|c|c|}
\hline S & 5 & L2 & m5 & 5.51 & 5.13 & 4.76 & 141 & 44.7 & 974 & 15.5 & 5.32 & 12.5 & 73.1 & 14.4 \\
\hline$S$ & 7.5 & L2 & $\mathrm{m} 6$ & 4.59 & 5.10 & 4.68 & 123 & 31.9 & 854 & 10.8 & 4.23 & 14.1 & 72.5 & 13.3 \\
\hline S & 6 & L2 & $\mathrm{m} 7$ & 4.95 & 5.06 & 4.81 & 140 & 52.1 & 585 & 15.9 & 5.88 & 23.1 & 66.8 & 10.1 \\
\hline$S$ & 4 & L2 & $\mathrm{m} 8$ & 4.48 & 4.95 & 4.72 & 145 & 49.9 & 559 & 9.13 & 3.63 & 21.5 & 68.3 & 10.3 \\
\hline$S$ & 3 & L2 & $\mathrm{m} 9$ & 5.96 & 5.15 & 4.61 & 174 & 58.9 & 673 & 24.8 & 5.45 & 20.7 & 67.3 & 12.0 \\
\hline SS & 10 & $\mathrm{H} 1$ & h1 & 2.22 & 6.68 & 6.45 & 243 & 9.31 & 3544 & 736 & & 27.9 & 53.3 & 18.8 \\
\hline SS & 10 & $\mathrm{H} 1$ & h10 & 0.79 & 6.59 & 6.14 & 233 & 12.1 & 2591 & 612 & & 27.6 & 53.0 & 19.4 \\
\hline SS & 10 & $\mathrm{H} 1$ & h2 & 2.98 & 6.36 & 5.91 & 315 & 17.4 & 2445 & 661 & & 26.1 & 51.9 & 22.0 \\
\hline SS & 10 & $\mathrm{H} 1$ & h3 & 2.28 & 6.63 & 6.12 & 300 & 21.9 & 3087 & 877 & & 27.9 & 51.9 & 20.1 \\
\hline SS & 10 & $\mathrm{H} 1$ & h4 & 1.39 & 6.65 & 6.11 & 237 & 16.5 & 2881 & 864 & & 31.6 & 47.7 & 20.7 \\
\hline SS & 10 & $\mathrm{H} 1$ & h5 & 2.11 & 6.32 & 5.85 & 266 & 17.5 & 2641 & 824 & & 28.3 & 52.3 & 19.4 \\
\hline SS & 10 & $\mathrm{H} 1$ & h6 & 1.85 & 6.50 & 6.11 & 261 & 11.1 & 2861 & 757 & & 36.9 & 43.3 & 19.7 \\
\hline SS & 10 & $\mathrm{H} 1$ & h7 & 2.74 & 6.29 & 6.00 & 268 & 10.6 & 2565 & 645 & & 27.5 & 52.8 & 19.7 \\
\hline SS & 10 & $\mathrm{H} 1$ & h8 & 3.01 & 6.02 & 5.51 & 345 & 22.3 & 2869 & 881 & & 24.5 & 54.6 & 20.9 \\
\hline SS & 10 & $\mathrm{H} 1$ & h9 & 2.11 & 6.14 & 5.89 & 299 & 14.3 & 2937 & 903 & & 27.1 & 54.4 & 18.5 \\
\hline SS & 10 & $\mathrm{H} 1$ & I1 & 2.45 & 6.81 & 6.32 & 334 & 18.0 & 4916 & 1471 & & 27.9 & 51.0 & 21.1 \\
\hline SS & 10 & $\mathrm{H} 1$ & 110 & 3.60 & 6.50 & 6.05 & 348 & 28.7 & 5785 & 1540 & & 30.1 & 48.0 & 21.9 \\
\hline SS & 10 & $\mathrm{H} 1$ & 12 & 3.99 & 6.18 & 5.89 & 340 & 17.1 & 3763 & 1162 & & 33.2 & 48.1 & 18.7 \\
\hline SS & 10 & $\mathrm{H} 1$ & 13 & 2.24 & 6.47 & 6.05 & 333 & 16.5 & 2222 & 520 & & 28.6 & 53.2 & 18.2 \\
\hline SS & 10 & $\mathrm{H} 1$ & 14 & 2.58 & 6.88 & 6.38 & 331 & 18.5 & 5233 & 1287 & & 34.3 & 48.7 & 17.1 \\
\hline SS & 10 & $\mathrm{H} 1$ & 15 & 2.62 & 6.57 & 6.12 & 440 & 19.2 & 3780 & 1102 & & 41.2 & 41.8 & 17.0 \\
\hline SS & 10 & $\mathrm{H} 1$ & 16 & 1.83 & 6.68 & 6.12 & 239 & 25.7 & 3233 & 822 & & 25.2 & 53.9 & 20.9 \\
\hline SS & 10 & $\mathrm{H} 1$ & 17 & 3.04 & 6.84 & 6.39 & 225 & 15.1 & 7686 & 1838 & & 30.0 & 50.5 & 19.5 \\
\hline SS & 10 & $\mathrm{H} 1$ & 18 & 3.81 & 6.07 & 5.73 & 394 & 28.9 & 4668 & 1167 & & 28.4 & 49.9 & 21.7 \\
\hline SS & 10 & $\mathrm{H} 1$ & 19 & 4.62 & 6.47 & 6.16 & 404 & 23.3 & 5462 & 1434 & & 28.0 & 50.3 & 21.7 \\
\hline SS & 10 & $\mathrm{H} 1$ & $\mathrm{~m} 1$ & 2.50 & 6.38 & 5.89 & 326 & 13.2 & 2962 & 730 & & 26.4 & 53.9 & 19.7 \\
\hline SS & 10 & $\mathrm{H} 1$ & $\mathrm{~m} 10$ & 3.10 & 6.47 & 6.03 & 333 & 24.4 & 6280 & 1648 & & 27.7 & 48.5 & 23.9 \\
\hline SS & 10 & $\mathrm{H} 1$ & $\mathrm{~m} 2$ & 1.85 & 7.04 & 6.45 & 276 & 16.6 & 5307 & 1148 & & 24.2 & 54.8 & 20.9 \\
\hline SS & 10 & $\mathrm{H} 1$ & $\mathrm{~m} 3$ & 2.68 & 5.98 & 5.55 & 314 & 16.1 & 2005 & 556 & & 19.7 & 59.1 & 21.2 \\
\hline SS & 10 & $\mathrm{H} 1$ & $\mathrm{~m} 4$ & 2.77 & 6.43 & 6.00 & 383 & 18.0 & 4497 & 1107 & & 20.1 & 59.7 & 20.2 \\
\hline SS & 10 & $\mathrm{H} 1$ & m5 & 2.28 & 5.73 & 5.35 & 350 & 25.2 & 2250 & 620 & & 21.4 & 58.1 & 20.5 \\
\hline SS & 10 & $\mathrm{H} 1$ & m6 & 2.84 & 6.29 & 5.75 & 386 & 18.1 & 2962 & 844 & & 21.9 & 56.9 & 21.2 \\
\hline SS & 10 & $\mathrm{H} 1$ & $\mathrm{~m} 7$ & 2.14 & 6.56 & 6.11 & 496 & 22.9 & 4052 & 1188 & & 24.9 & 52.4 & 22.7 \\
\hline SS & 10 & $\mathrm{H} 1$ & $\mathrm{~m} 8$ & 3.17 & 5.96 & 5.37 & 473 & 21.3 & 2583 & 801 & & 24.6 & 52.7 & 22.7 \\
\hline SS & 10 & $\mathrm{H} 1$ & $\mathrm{~m} 9$ & 2.76 & 5.58 & 5.15 & 379 & 22.0 & 2451 & 713 & & 29.9 & 47.1 & 23.0 \\
\hline SS & 10 & $\mathrm{H} 1$ & $\mathrm{~m} 1$ & 1.66 & 5.26 & 4.85 & 147 & 8.49 & 343 & 6.48 & & 50.2 & 41.5 & 8.3 \\
\hline SS & 10 & $\mathrm{H} 2$ & h1 & 2.76 & 5.19 & 4.86 & 96.6 & 131 & 1038 & 40.5 & & 17.9 & 59.2 & 23.0 \\
\hline SS & 10 & $\mathrm{H} 2$ & h10 & 2.22 & 5.46 & 5.21 & 108 & 84.1 & 1403 & 114 & & 23.6 & 58.1 & 18.3 \\
\hline SS & 10 & $\mathrm{H} 2$ & h2 & 2.38 & 6.72 & 6.27 & 118 & 16.3 & 2211 & 104 & & 22.3 & 47.3 & 30.4 \\
\hline SS & 10 & $\mathrm{H} 2$ & h3 & 1.16 & 6.05 & 5.53 & 165 & 8.73 & 1521 & 179 & & 24.4 & 51.9 & 23.7 \\
\hline
\end{tabular}




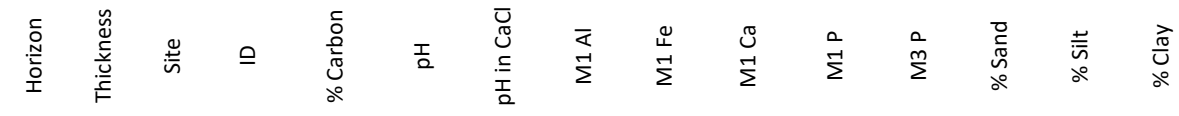

\begin{tabular}{|c|c|c|c|c|c|c|c|c|c|c|c|c|c|}
\hline SS & 10 & $\mathrm{H} 2$ & h4 & 2.04 & 6.30 & 5.85 & 141 & 11.9 & 1613 & 177 & 22.7 & 54.0 & 23.3 \\
\hline SS & 10 & $\mathrm{H} 2$ & h5 & 2.89 & 6.30 & 5.96 & 109 & 17.8 & 2182 & 118 & 22.1 & 52.7 & 25.1 \\
\hline SS & 10 & $\mathrm{H} 2$ & h6 & 2.21 & 6.41 & 6.07 & 128 & 68.6 & 1549 & 138 & 27.5 & 56.1 & 16.4 \\
\hline SS & 10 & $\mathrm{H} 2$ & h7 & 1.64 & 6.21 & 5.73 & 128 & 46.3 & 1235 & 85.0 & 16.0 & 62.1 & 22.0 \\
\hline SS & 10 & $\mathrm{H} 2$ & h8 & 2.00 & 5.75 & 5.48 & 114 & 68.2 & 1028 & 108 & 19.8 & 62.5 & 17.7 \\
\hline SS & 10 & $\mathrm{H} 2$ & h9 & 2.42 & 6.05 & 5.69 & 147 & 53.4 & 1704 & 119 & 20.7 & 58.5 & 20.8 \\
\hline SS & 10 & $\mathrm{H} 2$ & $\mid 1$ & 1.38 & 6.18 & 5.64 & 176 & 11.1 & 1380 & 139 & 26.7 & 55.2 & 18.2 \\
\hline SS & 10 & $\mathrm{H} 2$ & 110 & 2.04 & 6.14 & 5.75 & 178 & 13.4 & 1658 & 211 & 29.7 & 50.3 & 20.0 \\
\hline SS & 10 & $\mathrm{H} 2$ & 12 & 3.96 & 6.14 & 5.49 & 211 & 12.5 & 1392 & 201 & 23.9 & 59.6 & 16.4 \\
\hline SS & 10 & $\mathrm{H} 2$ & 13 & 1.62 & 6.11 & 5.57 & 173 & 13.8 & 1591 & 239 & 26.8 & 48.8 & 24.4 \\
\hline SS & 10 & $\mathrm{H} 2$ & 14 & 1.09 & 7.08 & 6.34 & 115 & 19.8 & 1639 & 29.2 & 34.9 & 39.2 & 25.9 \\
\hline SS & 10 & $\mathrm{H} 2$ & 15 & 2.74 & 6.00 & 5.51 & 243 & 16.3 & 1679 & 281 & 30.7 & 47.6 & 21.7 \\
\hline SS & 10 & $\mathrm{H} 2$ & 16 & 1.63 & 6.21 & 5.60 & 148 & 11.4 & 1290 & 156 & 31.7 & 49.3 & 19.1 \\
\hline SS & 10 & $\mathrm{H} 2$ & 17 & 1.47 & 5.70 & 5.15 & 248 & 12.9 & 928 & 214 & 31.7 & 52.4 & 15.9 \\
\hline SS & 10 & $\mathrm{H} 2$ & 18 & 2.11 & 6.30 & 5.73 & 142 & 8.51 & 1451 & 178 & 29.5 & 50.9 & 19.6 \\
\hline SS & 10 & $\mathrm{H} 2$ & 19 & 2.35 & 5.87 & 5.44 & 189 & 13.0 & 1480 & 181 & 27.7 & 47.7 & 24.6 \\
\hline SS & 10 & $\mathrm{H} 2$ & $\mathrm{~m} 1$ & 1.18 & 6.70 & 5.98 & 131 & 12.0 & 1653 & 35.0 & 9.5 & 55.3 & 35.2 \\
\hline SS & 10 & $\mathrm{H} 2$ & $\mathrm{~m} 10$ & 2.64 & 6.00 & 5.53 & 214 & 12.5 & 1901 & 344 & 29.6 & 53.6 & 16.8 \\
\hline SS & 10 & $\mathrm{H} 2$ & $\mathrm{~m} 2$ & 1.82 & 6.40 & 5.85 & 176 & 22.5 & 2114 & 309 & 34.3 & 46.4 & 19.3 \\
\hline SS & 10 & $\mathrm{H} 2$ & $\mathrm{~m} 3$ & 2.24 & 6.03 & 5.73 & 148 & 16.7 & 2119 & 229 & 31.6 & 49.2 & 19.2 \\
\hline SS & 10 & $\mathrm{H} 2$ & $\mathrm{~m} 4$ & 1.48 & 6.32 & 5.64 & 247 & 16.0 & 1544 & 284 & 31.5 & 54.8 & 13.7 \\
\hline SS & 10 & $\mathrm{H} 2$ & m5 & 1.87 & 6.52 & 6.00 & 194 & 8.85 & 2204 & 314 & 27.3 & 50.7 & 21.9 \\
\hline SS & 10 & $\mathrm{H} 2$ & $\mathrm{~m} 6$ & 1.72 & 6.54 & 6.16 & 124 & 21.2 & 1873 & 94.6 & 27.4 & 49.4 & 23.3 \\
\hline SS & 10 & $\mathrm{H} 2$ & $\mathrm{~m} 7$ & 2.43 & 6.36 & 6.00 & 143 & 14.2 & 1917 & 128 & 20.4 & 55.0 & 24.6 \\
\hline SS & 10 & $\mathrm{H} 2$ & $\mathrm{~m} 8$ & 2.42 & 6.09 & 5.53 & 185 & 16.1 & 1667 & 236 & 33.1 & 50.8 & 16.1 \\
\hline SS & 10 & $\mathrm{H} 2$ & $\mathrm{~m} 9$ & 1.94 & 6.23 & 5.71 & 225 & 12.1 & 1789 & 287 & 22.7 & 63.3 & 14.0 \\
\hline SS & 10 & L1 & h1 & 1.23 & 5.39 & 4.92 & 132 & 7.95 & 527 & 4.20 & 33.4 & 55.1 & 11.5 \\
\hline SS & 10 & L1 & h10 & 1.63 & 5.37 & 4.95 & 108 & 9.59 & 474 & 2.32 & 47.7 & 42.7 & 9.6 \\
\hline SS & 10 & L1 & h2 & 1.42 & 5.17 & 4.88 & 176 & 11.0 & 593 & 4.97 & 34.9 & 56.0 & 9.1 \\
\hline SS & 10 & L1 & h3 & 1.90 & 5.62 & 4.99 & 174 & 18.1 & 623 & 11.0 & 58.2 & 36.8 & 5.0 \\
\hline SS & 10 & L1 & h4 & 2.68 & 5.44 & 5.01 & 119 & 4.79 & 432 & 4.80 & 51.1 & 41.9 & 7.0 \\
\hline SS & 10 & L1 & h5 & 2.24 & 5.69 & 5.15 & 126 & 6.32 & 483 & 5.48 & 50.6 & 42.0 & 7.4 \\
\hline SS & 10 & L1 & h6 & 2.36 & 6.12 & 5.71 & 123 & 4.76 & 698 & 9.62 & 48.0 & 44.4 & 7.7 \\
\hline SS & 10 & L1 & h7 & 1.66 & 5.58 & 5.12 & 98.8 & 11.2 & 814 & 1.28 & 27.3 & 55.2 & 17.5 \\
\hline SS & 10 & L1 & h8 & 1.80 & 5.40 & 4.99 & 150 & 9.37 & 490 & 7.26 & 55.5 & 39.4 & 5.2 \\
\hline SS & 10 & L1 & h9 & 1.79 & 5.51 & 5.04 & 130 & 17.3 & 878 & 4.15 & 35.5 & 50.5 & 14.0 \\
\hline SS & 10 & L1 & $\mid 1$ & 1.28 & 5.75 & 4.88 & 99.3 & 10.9 & 633 & 1.63 & 38.4 & 46.9 & 14.7 \\
\hline SS & 10 & L1 & 110 & 1.62 & 5.40 & 4.85 & 100 & 7.56 & 391 & 2.10 & 26.1 & 54.6 & 19.3 \\
\hline SS & 10 & L1 & 12 & 1.23 & 5.51 & 4.61 & 147 & 9.15 & 250 & 3.56 & 59.6 & 35.4 & 4.9 \\
\hline SS & 10 & L1 & 13 & 2.30 & 5.67 & 5.03 & 109 & 4.13 & 390 & 1.08 & 22.7 & 57.3 & 20.0 \\
\hline
\end{tabular}




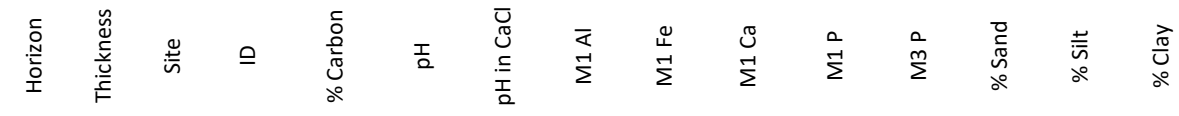

\begin{tabular}{|c|c|c|c|c|c|c|c|c|c|c|c|c|c|}
\hline SS & 10 & L1 & 14 & 1.46 & 5.53 & 5.06 & 105 & 10.8 & 480 & 1.58 & 31.3 & 55.7 & 13.0 \\
\hline SS & 10 & L1 & 15 & 1.74 & 5.42 & 4.97 & 146 & 12.3 & 381 & 3.42 & 58.0 & 36.8 & 5.2 \\
\hline SS & 10 & L1 & 16 & 1.12 & 5.82 & 5.01 & 81.8 & 8.57 & 455 & 0.56 & 28.9 & 54.2 & 16.8 \\
\hline SS & 10 & L1 & 17 & 2.02 & 5.10 & 4.68 & 188 & 19.4 & 501 & 18.5 & 45.0 & 49.1 & 5.9 \\
\hline SS & 10 & L1 & 18 & 1.63 & 5.73 & 4.98 & 218 & 18.4 & 266 & 4.74 & 51.4 & 43.0 & 5.6 \\
\hline SS & 10 & L1 & 19 & 1.62 & 5.89 & 5.46 & 171 & 31.1 & 783 & 2.69 & 26.7 & 49.8 & 23.5 \\
\hline SS & 10 & L1 & $\mathrm{m} 10$ & 4.58 & 5.19 & 4.56 & 126 & 31.5 & 1032 & 9.18 & 36.8 & 48.5 & 14.6 \\
\hline SS & 10 & L1 & $\mathrm{m} 2$ & 1.74 & 5.35 & 4.85 & 176 & 9.00 & 401 & 4.58 & 51.0 & 41.1 & 7.8 \\
\hline SS & 10 & L1 & $\mathrm{m} 3$ & 2.40 & 5.37 & 4.74 & 113 & 20.0 & 324 & 4.59 & 48.6 & 41.7 & 9.7 \\
\hline SS & 10 & L1 & $\mathrm{m} 4$ & 1.54 & 5.82 & 5.17 & 118 & 5.15 & 382 & 2.78 & 47.4 & 42.3 & 10.4 \\
\hline SS & 10 & L1 & m5 & 1.88 & 5.35 & 4.72 & 119 & 7.53 & 244 & 2.80 & 50.2 & 40.6 & 9.2 \\
\hline SS & 10 & L1 & $\mathrm{m} 6$ & 1.54 & 5.48 & 4.79 & 123 & 19.2 & 648 & 4.12 & 39.2 & 49.3 & 11.6 \\
\hline SS & 10 & L1 & $\mathrm{m} 7$ & 1.33 & 5.98 & 5.21 & 200 & 6.35 & 435 & 4.12 & 55.7 & 39.0 & 5.3 \\
\hline SS & 10 & L1 & $\mathrm{m} 8$ & 1.53 & 5.67 & 5.08 & 76.3 & 7.13 & 757 & 1.27 & 23.7 & 61.1 & 15.2 \\
\hline SS & 10 & L1 & $\mathrm{m} 9$ & 2.05 & 5.26 & 4.81 & 184 & 12.6 & 575 & 11.6 & 52.4 & 41.7 & 5.9 \\
\hline SS & 10 & L2 & h1 & 1.80 & 5.06 & 4.32 & 273 & 109 & 252 & 3.21 & 25.2 & 64.0 & 10.8 \\
\hline SS & 10 & L2 & h10 & 1.88 & 5.04 & 4.29 & 215 & 94.9 & 322 & 3.11 & 17.5 & 73.6 & 8.9 \\
\hline SS & 10 & L2 & h2 & 3.24 & 4.83 & 4.32 & 559 & 62.8 & 220 & 5.24 & 18.7 & 59.9 & 21.5 \\
\hline SS & 10 & L2 & h3 & 1.20 & 4.83 & 4.00 & 365 & 104 & 134 & 2.19 & 24.2 & 64.4 & 11.4 \\
\hline SS & 10 & L2 & h4 & 0.93 & 4.95 & 4.04 & 264 & 47.6 & 78.1 & 2.15 & 21.5 & 66.0 & 12.5 \\
\hline SS & 10 & L2 & h5 & 1.35 & 4.86 & 4.11 & 254 & 94.8 & 161 & 8.24 & 19.6 & 70.0 & 10.3 \\
\hline SS & 10 & L2 & h6 & 1.37 & 5.66 & 5.01 & 119 & 44.9 & 589 & 1.99 & 17.4 & 71.9 & 10.6 \\
\hline SS & 10 & L2 & h7 & 1.27 & 5.60 & 4.85 & 165 & 56.7 & 557 & 21.7 & 21.9 & 64.6 & 13.5 \\
\hline SS & 10 & L2 & h8 & 0.91 & 5.15 & 4.25 & 214 & 34.7 & 152 & 1.83 & 19.4 & 67.1 & 13.5 \\
\hline SS & 10 & L2 & h9 & 1.42 & 5.08 & 4.32 & 236 & 105 & 219 & 4.18 & 28.0 & 62.0 & 10.0 \\
\hline SS & 10 & L2 & 12 & 1.63 & 5.51 & 4.61 & 170 & 36.3 & 512 & 6.57 & 20.3 & 66.1 & 13.6 \\
\hline SS & 10 & L2 & 13 & 0.98 & 5.44 & 4.47 & 263 & 18.3 & 206 & 2.30 & 20.1 & 66.7 & 13.2 \\
\hline SS & 10 & L2 & 14 & 1.57 & 5.57 & 4.88 & 142 & 32.6 & 434 & 8.36 & 21.1 & 67.9 & 11.0 \\
\hline SS & 10 & L2 & 15 & 1.38 & 5.44 & 4.72 & 178 & 18.3 & 407 & 3.72 & 22.1 & 66.4 & 11.5 \\
\hline SS & 10 & L2 & 16 & 1.02 & 5.21 & 4.63 & 136 & 26.0 & 303 & 2.72 & 15.1 & 75.2 & 9.7 \\
\hline SS & 10 & L2 & 17 & 1.47 & 5.67 & 4.88 & 151 & 30.3 & 511 & 4.65 & 24.3 & 64.6 & 11.1 \\
\hline SS & 10 & L2 & 18 & 1.68 & 4.89 & 3.96 & 210 & 8.32 & 494 & 9.01 & 24.4 & 66.9 & 8.6 \\
\hline SS & 10 & L2 & 19 & 2.89 & 5.08 & 4.38 & 100 & 7.02 & 1253 & 1.37 & 14.9 & 72.0 & 13.1 \\
\hline SS & 10 & L2 & $\mathrm{m} 1$ & 0.84 & 5.21 & 4.41 & 287 & 43.9 & 299 & 6.06 & 22.2 & 64.0 & 13.8 \\
\hline SS & 10 & L2 & $\mathrm{m} 10$ & 1.09 & 5.64 & 4.63 & 157 & 35.3 & 282 & 2.61 & 25.4 & 63.2 & 11.3 \\
\hline SS & 10 & L2 & $\mathrm{m} 2$ & 1.61 & 5.10 & 4.43 & 194 & 54.1 & 446 & 7.38 & 17.3 & 72.3 & 10.4 \\
\hline SS & 10 & L2 & $\mathrm{m} 3$ & 1.11 & 5.62 & 4.58 & 235 & 38.3 & 304 & 4.14 & 23.9 & 63.7 & 12.4 \\
\hline SS & 10 & L2 & $\mathrm{m} 4$ & 1.25 & 5.44 & 4.77 & 168 & 36.3 & 326 & 1.68 & 26.7 & 64.7 & 8.6 \\
\hline SS & 10 & L2 & m5 & 1.26 & 5.67 & 4.77 & 150 & 29.0 & 607 & 11.9 & 13.3 & 72.6 & 14.0 \\
\hline SS & 10 & L2 & $\mathrm{m} 6$ & 1.08 & 5.64 & 4.92 & 126 & 23.8 & 443 & 2.57 & 13.3 & 72.5 & 14.1 \\
\hline
\end{tabular}




\begin{tabular}{|c|c|c|c|c|c|c|c|c|c|c|c|c|c|c|}
\hline 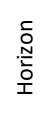 & 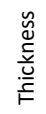 & 节 & $\underline{\underline{1}}$ & $\begin{array}{l}\text { ㅇ } \\
\text { o } \\
\text { d } \\
\text { do }\end{array}$ & I & $\begin{array}{l}\bar{J} \\
\mathbb{J} \\
. \Xi \\
\bar{I} \\
\end{array}$ & $\begin{array}{l}\bar{\alpha} \\
\vec{\Sigma}\end{array}$ & $\begin{array}{l}\stackrel{\nu}{山} \\
\stackrel{\nu}{\Sigma}\end{array}$ & $\begin{array}{l}\tilde{J} \\
\stackrel{N}{\Sigma}\end{array}$ & $\stackrel{\circ}{\vec{z}}$ & $\stackrel{0}{m}$ & $\begin{array}{l}\text { ㅁ } \\
\text { ग } \\
\text { do }\end{array}$ & $\begin{array}{l}\frac{t}{\bar{n}} \\
\text { ¿о }\end{array}$ & $\begin{array}{l}\text { 元 } \\
\text { do }\end{array}$ \\
\hline SS & 10 & L2 & $\mathrm{m} 7$ & 2.09 & 5.08 & 4.56 & 172 & 54.4 & 313 & 7.32 & & 23.9 & 66.8 & 9.3 \\
\hline SS & 10 & L2 & $\mathrm{m} 8$ & 1.14 & 5.22 & 4.41 & 176 & 34.8 & 230 & 3.20 & & 21.9 & 68.9 & 9.2 \\
\hline SS & 10 & L2 & $\mathrm{m} 9$ & 1.99 & 5.31 & 4.29 & 480 & 39.6 & 130 & 4.92 & & 19.7 & 68.1 & 12.2 \\
\hline
\end{tabular}

\section{Primary spatial data}

Site: H1 - high one (location 1 with long history of manure application), H2 - high two (location 2 with long history of manure application), L1 low 1 (location 1 with little to no history of manure application), L2 - low 2 (location 2 with little to no history of manure application); ID: h1-10 (sample locations 1-10 in the high stratification) m1--10 (sample locations 1-10 in the medium stratification), 11-10 (sample location 1-10 in the low stratification); Z Elevation - Z score of in site elevation; Z Aspect - Z score of slope aspect; Z Slope - Z score of slope gradient; PRC - Profile curvature; PLC - Plan curvature; TANC - Tangential curvature; $\mathrm{Cl}$ - Convergence index; MFD - flow accumulation (multiple directions method); D8 - flow accumulation (deterministic 8 method); INF - flow accumulation (deterministic infinity method)

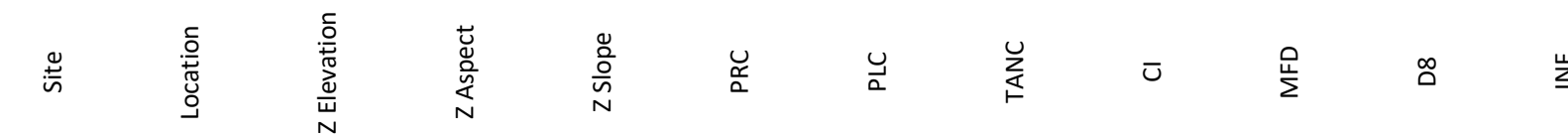

\begin{tabular}{|c|c|c|c|c|c|c|c|c|c|c|c|}
\hline L2 & h2 & 0.54 & -0.024 & -0.171 & 0.001 & -0.005 & -0.001 & -3.20 & 147 & 108 & 121 \\
\hline L2 & h3 & 0.01 & -0.002 & -0.317 & -0.006 & -0.083 & -0.009 & 2.57 & 244 & 144 & 196 \\
\hline L2 & h4 & 0.01 & 0.010 & -0.361 & 0.006 & 0.008 & 0.001 & -7.49 & 267 & 207 & 269 \\
\hline L2 & h5 & -2.36 & -0.047 & 0.133 & 0.009 & 0.025 & 0.005 & -34.66 & 452 & 9 & 548 \\
\hline L2 & h6 & -1.18 & -0.012 & 0.049 & 0.009 & 0.034 & 0.006 & 1.89 & 185 & 72 & 183 \\
\hline L2 & h7 & 0.75 & -0.023 & 0.002 & -0.009 & 0.009 & 0.001 & 1.09 & 125 & 90 & 99 \\
\hline L2 & h8 & 0.50 & -0.037 & -0.207 & 0.006 & 0.015 & 0.002 & -2.66 & 161 & 108 & 195 \\
\hline L2 & h9 & 0.66 & -0.034 & -0.038 & -0.008 & -0.049 & -0.007 & 4.81 & 128 & 171 & 103 \\
\hline L2 & 12 & 0.22 & -0.030 & 0.246 & 0.015 & 0.041 & 0.008 & 3.47 & 78 & 54 & 65 \\
\hline L2 & 13 & 1.95 & 0.019 & 0.088 & 0.010 & 0.060 & 0.010 & 14.93 & 42 & 36 & 44 \\
\hline L2 & 14 & 0.28 & 0.039 & 0.094 & -0.005 & -0.011 & -0.002 & 3.74 & 81 & 81 & 55 \\
\hline L2 & 15 & 0.20 & 0.016 & 0.466 & -0.003 & 0.006 & 0.001 & 10.54 & 53 & 36 & 46 \\
\hline L2 & 16 & -0.19 & -0.025 & 0.175 & 0.005 & 0.047 & 0.009 & 4.49 & 113 & 18 & 112 \\
\hline L2 & 17 & 0.54 & 0.016 & -0.031 & 0.002 & 0.031 & 0.005 & 4.46 & 80 & 54 & 68 \\
\hline L2 & 18 & 0.80 & 0.113 & -0.067 & -0.008 & 0.131 & 0.019 & 4.45 & 37 & 9 & 24 \\
\hline L2 & 19 & 1.38 & 0.001 & -0.034 & 0.008 & 0.093 & 0.014 & 16.94 & 35 & 45 & 42 \\
\hline
\end{tabular}




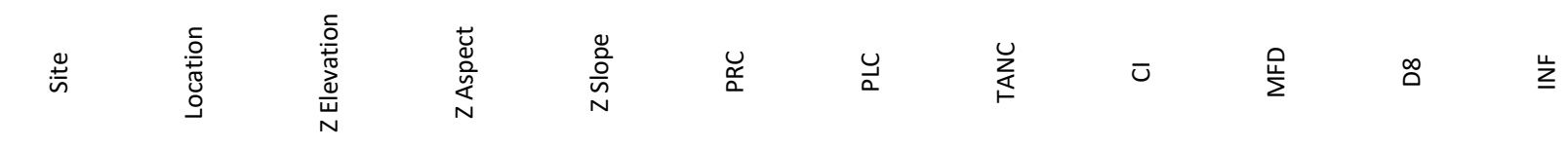

\begin{tabular}{|c|c|c|c|c|c|c|c|c|c|c|c|}
\hline L2 & $\mathrm{m} 1$ & -1.75 & -0.031 & 0.081 & -0.001 & 0.013 & 0.002 & -8.24 & 199 & 36 & 137 \\
\hline L2 & $\mathrm{m} 2$ & -1.65 & -0.008 & 0.150 & 0.002 & -0.007 & -0.001 & -3.58 & 224 & 126 & 188 \\
\hline L2 & m3 & -0.25 & 0.030 & 0.029 & -0.013 & -0.012 & -0.002 & -0.55 & 108 & 72 & 80 \\
\hline L2 & $\mathrm{m} 4$ & -0.90 & 0.030 & -0.075 & 0.000 & 0.000 & 0.000 & 5.14 & 144 & 126 & 109 \\
\hline L2 & m5 & -0.52 & -0.004 & -0.011 & 0.011 & 0.060 & 0.009 & -2.56 & 131 & 72 & 126 \\
\hline L2 & $\mathrm{m} 6$ & -0.97 & -0.018 & 0.108 & 0.003 & 0.021 & 0.004 & 0.43 & 169 & 99 & 150 \\
\hline L2 & $\mathrm{m} 8$ & -0.06 & -0.023 & 0.012 & 0.004 & 0.018 & 0.003 & -2.61 & 115 & 54 & 112 \\
\hline L2 & m9 & 1.36 & 0.066 & 0.145 & 0.000 & 0.000 & 0.000 & 5.95 & 35 & 27 & 36 \\
\hline $\mathrm{H} 1$ & h1 & 0.27 & -0.012 & 0.350 & -0.002 & -0.005 & -0.001 & -11.56 & 295 & 343 & 252 \\
\hline $\mathrm{H} 1$ & h2 & 1.22 & 0.893 & -0.248 & 0.000 & 0.014 & 0.002 & 10.66 & 161 & 135 & 163 \\
\hline $\mathrm{H} 1$ & h3 & -2.33 & -0.559 & -0.208 & 0.000 & 0.004 & 0.001 & 0.91 & 200 & 99 & 202 \\
\hline $\mathrm{H} 1$ & h4 & 0.62 & 0.099 & 0.065 & 0.002 & -0.003 & -0.001 & -8.19 & 160 & 126 & 153 \\
\hline $\mathrm{H} 1$ & h5 & 0.60 & 0.043 & 0.081 & 0.006 & 0.023 & 0.004 & 4.43 & 171 & 190 & 160 \\
\hline $\mathrm{H} 1$ & h6 & 0.33 & 0.002 & 0.345 & -0.001 & 0.002 & 0.001 & -13.74 & 226 & 262 & 164 \\
\hline $\mathrm{H} 1$ & h7 & 0.26 & 0.055 & 0.390 & -0.001 & -0.018 & -0.004 & -9.40 & 332 & 388 & 364 \\
\hline $\mathrm{H} 1$ & h8 & 1.02 & 1.197 & 0.171 & 0.006 & -0.015 & -0.003 & -8.42 & 166 & 181 & 148 \\
\hline $\mathrm{H} 1$ & h9 & 0.17 & -0.010 & 0.318 & 0.001 & 0.003 & 0.001 & -15.81 & 242 & 325 & 204 \\
\hline $\mathrm{H} 1$ & I1 & -0.28 & 0.033 & -0.118 & -0.002 & 0.097 & 0.015 & 31.17 & 47 & 27 & 30 \\
\hline $\mathrm{H} 1$ & 110 & -0.94 & -0.421 & -0.435 & 0.003 & 0.097 & 0.010 & 36.64 & 26 & 18 & 16 \\
\hline $\mathrm{H} 1$ & 12 & -1.80 & -0.602 & 0.289 & 0.002 & 0.010 & 0.002 & 9.10 & 97 & 54 & 61 \\
\hline $\mathrm{H} 1$ & 13 & 0.22 & 0.088 & -0.148 & -0.002 & -0.015 & -0.002 & 24.67 & 100 & 45 & 103 \\
\hline $\mathrm{H} 1$ & 14 & -0.01 & -0.056 & -0.055 & 0.003 & 0.057 & 0.009 & 30.95 & 75 & 18 & 59 \\
\hline $\mathrm{H} 1$ & 15 & -0.16 & -0.720 & 0.459 & -0.003 & -0.012 & -0.003 & 13.67 & 86 & 81 & 57 \\
\hline $\mathrm{H} 1$ & 16 & -0.35 & 0.220 & 0.096 & 0.003 & 0.074 & 0.014 & 16.17 & 49 & 27 & 33 \\
\hline $\mathrm{H} 1$ & 17 & -0.62 & -0.786 & 0.213 & 0.010 & 0.054 & 0.011 & 13.46 & 60 & 9 & 54 \\
\hline $\mathrm{H} 1$ & 18 & -1.07 & -0.520 & -0.376 & 0.001 & 0.019 & 0.002 & 26.39 & 49 & 36 & 36 \\
\hline $\mathrm{H} 1$ & 19 & -0.55 & -0.965 & -0.108 & 0.016 & 0.108 & 0.017 & 22.92 & 38 & 36 & 46 \\
\hline $\mathrm{H} 1$ & $\mathrm{~m} 1$ & 0.32 & -0.114 & 0.235 & -0.001 & 0.012 & 0.003 & 11.56 & 150 & 36 & 117 \\
\hline
\end{tabular}




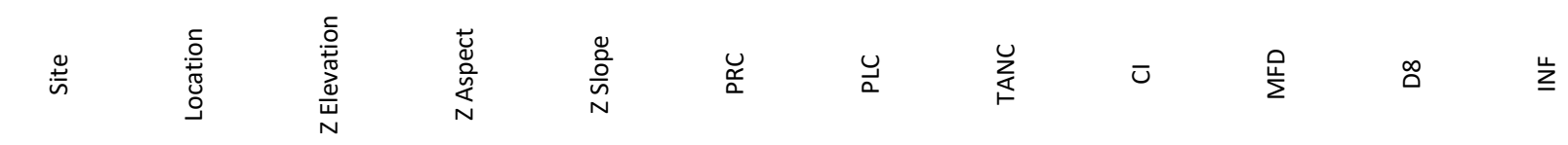

\begin{tabular}{|c|c|c|c|c|c|c|c|c|c|c|c|}
\hline $\mathrm{H} 1$ & $\mathrm{~m} 10$ & -1.04 & 0.259 & -0.292 & 0.003 & 0.003 & 0.000 & 11.85 & 74 & 90 & 77 \\
\hline $\mathrm{H} 1$ & $\mathrm{~m} 2$ & -0.31 & 0.700 & 0.300 & 0.010 & 0.012 & 0.003 & 8.99 & 70 & 27 & 42 \\
\hline $\mathrm{H} 1$ & $\mathrm{~m} 3$ & 1.15 & 0.536 & -0.114 & 0.000 & -0.037 & -0.006 & 8.27 & 112 & 126 & 108 \\
\hline $\mathrm{H} 1$ & $\mathrm{~m} 4$ & 0.09 & -0.021 & -0.192 & 0.003 & 0.046 & 0.006 & 28.56 & 92 & 72 & 83 \\
\hline $\mathrm{H} 1$ & m5 & -2.19 & -0.392 & -0.137 & 0.000 & 0.015 & 0.002 & 12.34 & 105 & 63 & 79 \\
\hline $\mathrm{H} 1$ & $\mathrm{~m} 6$ & 0.91 & -0.085 & 0.004 & -0.001 & 0.005 & 0.001 & 16.24 & 124 & 54 & 120 \\
\hline $\mathrm{H} 1$ & $\mathrm{~m} 7$ & 0.74 & -0.466 & -0.835 & -0.002 & 1.091 & 0.031 & 18.68 & 19 & 9 & 42 \\
\hline $\mathrm{H} 1$ & $\mathrm{~m} 8$ & 1.37 & 0.812 & -0.010 & -0.001 & 0.005 & 0.001 & 8.50 & 136 & 108 & 116 \\
\hline $\mathrm{H} 1$ & $\mathrm{~m} 9$ & 1.65 & 0.738 & -0.105 & 0.005 & 0.028 & 0.004 & 16.34 & 63 & 63 & 52 \\
\hline $\mathrm{H} 2$ & h1 & -1.10 & -0.701 & -0.504 & -0.001 & -0.023 & -0.001 & 3.38 & 201 & 304 & 243 \\
\hline $\mathrm{H} 2$ & h10 & -0.95 & -0.311 & -0.352 & -0.005 & -0.076 & -0.003 & 2.07 & 109 & 403 & 101 \\
\hline $\mathrm{H} 2$ & h2 & -1.11 & -0.687 & -0.433 & -0.001 & 0.048 & 0.002 & -1.48 & 90 & 18 & 64 \\
\hline $\mathrm{H} 2$ & h3 & 1.02 & -0.638 & 1.062 & -0.004 & -0.020 & -0.003 & 2.63 & 70 & 72 & 101 \\
\hline $\mathrm{H} 2$ & h4 & 0.69 & -0.003 & 0.090 & 0.003 & -0.096 & -0.007 & 2.11 & 152 & 27 & 164 \\
\hline $\mathrm{H} 2$ & h5 & -1.37 & -0.669 & -0.498 & -0.001 & 0.002 & 0.000 & -18.30 & 361 & 90 & 177 \\
\hline $\mathrm{H} 2$ & h6 & -0.94 & 2.689 & -0.725 & 0.000 & -0.424 & -0.008 & -16.47 & 1336 & 528 & 1309 \\
\hline $\mathrm{H} 2$ & h7 & -1.33 & 2.525 & -0.398 & -0.001 & -0.018 & -0.001 & -19.86 & 158 & 107 & 113 \\
\hline $\mathrm{H} 2$ & h8 & -0.93 & -0.470 & -0.430 & -0.003 & 0.000 & 0.000 & -13.12 & 241 & 18 & 117 \\
\hline $\mathrm{H} 2$ & h9 & -1.34 & 2.496 & -0.434 & 0.000 & -0.008 & 0.000 & -19.18 & 180 & 179 & 136 \\
\hline $\mathrm{H} 2$ & 11 & -0.68 & -0.342 & 0.007 & 0.001 & 0.037 & 0.002 & 11.20 & 66 & 233 & 69 \\
\hline $\mathrm{H} 2$ & 110 & 1.26 & -0.452 & 0.619 & 0.001 & 0.024 & 0.003 & 0.49 & 79 & 63 & 72 \\
\hline $\mathrm{H} 2$ & 12 & 0.57 & -0.612 & -0.035 & 0.000 & 0.020 & 0.001 & 29.20 & 66 & 54 & 48 \\
\hline H2 & 13 & 1.52 & -0.561 & 0.679 & 0.003 & -0.007 & -0.001 & 17.65 & 25 & 18 & 28 \\
\hline $\mathrm{H} 2$ & 14 & -0.48 & 0.172 & 0.341 & -0.009 & -0.060 & -0.005 & -33.68 & 276 & 107 & 90 \\
\hline $\mathrm{H} 2$ & 15 & 1.04 & -0.639 & 0.546 & 0.003 & 0.008 & 0.001 & 24.46 & 75 & 18 & 69 \\
\hline $\mathrm{H} 2$ & 16 & 1.56 & -0.462 & 0.224 & 0.002 & 0.009 & 0.001 & 13.60 & 58 & 45 & 49 \\
\hline $\mathrm{H} 2$ & 17 & -0.09 & -0.903 & 0.115 & 0.000 & 0.051 & 0.004 & 20.62 & 65 & 107 & 66 \\
\hline $\mathrm{H} 2$ & 18 & 1.34 & -0.440 & 0.629 & 0.001 & -0.002 & 0.000 & 9.77 & 82 & 54 & 67 \\
\hline
\end{tabular}




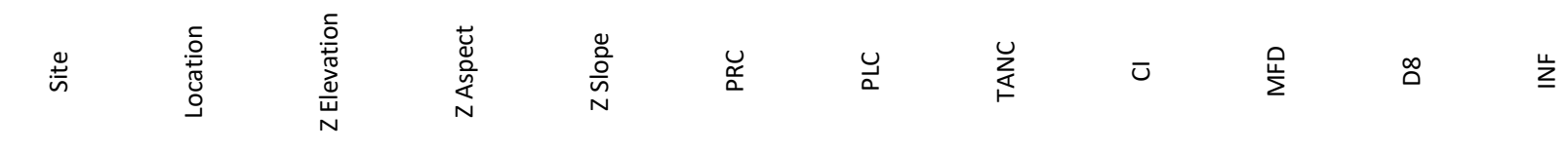

\begin{tabular}{|c|c|c|c|c|c|c|c|c|c|c|c|}
\hline $\mathrm{H} 2$ & 19 & 1.38 & 2.351 & 0.215 & 0.019 & 0.216 & 0.017 & 22.88 & 27 & 9 & 13 \\
\hline $\mathrm{H} 2$ & $\mathrm{~m} 1$ & -1.24 & -0.863 & -0.462 & 0.001 & 0.044 & 0.002 & 7.81 & 143 & 90 & 51 \\
\hline $\mathrm{H} 2$ & $\mathrm{~m} 10$ & -0.07 & -0.635 & -0.524 & -0.003 & 0.042 & 0.001 & 20.67 & 101 & 134 & 87 \\
\hline $\mathrm{H} 2$ & $\mathrm{~m} 2$ & 0.91 & -0.446 & 0.759 & -0.003 & -0.010 & -0.001 & -3.62 & 129 & 90 & 103 \\
\hline $\mathrm{H} 2$ & $\mathrm{~m} 3$ & -0.14 & -0.221 & -0.305 & 0.001 & 0.042 & 0.002 & 17.75 & 112 & 18 & 130 \\
\hline $\mathrm{H} 2$ & $\mathrm{~m} 4$ & 0.14 & -0.689 & -0.304 & 0.000 & 0.007 & 0.000 & 18.73 & 122 & 107 & 102 \\
\hline $\mathrm{H} 2$ & m5 & 0.82 & -0.473 & 0.564 & -0.001 & -0.005 & -0.001 & -3.17 & 132 & 90 & 100 \\
\hline $\mathrm{H} 2$ & $\mathrm{~m} 6$ & -0.05 & -0.717 & 0.363 & -0.007 & -0.034 & -0.003 & -2.03 & 90 & 54 & 54 \\
\hline $\mathrm{H} 2$ & $\mathrm{~m} 7$ & -1.19 & 2.705 & -0.514 & 0.000 & 0.059 & 0.002 & 13.46 & 73 & 18 & 47 \\
\hline $\mathrm{H} 2$ & $\mathrm{~m} 8$ & 0.41 & -0.347 & -0.192 & -0.001 & 0.016 & 0.001 & 9.27 & 111 & 295 & 109 \\
\hline $\mathrm{H} 2$ & $\mathrm{~m} 9$ & 0.37 & -0.659 & -0.102 & 0.000 & 0.011 & 0.001 & 25.08 & 85 & 63 & 67 \\
\hline L1 & h1 & 1.28 & -0.155 & -0.127 & 0.003 & -0.006 & -0.001 & -4.22 & 239 & 621 & 249 \\
\hline L1 & h10 & -0.36 & 0.157 & -0.180 & 0.001 & -0.011 & -0.001 & -17.29 & 698 & 1133 & 539 \\
\hline L1 & h2 & -0.20 & -0.065 & -0.106 & 0.002 & -0.006 & -0.001 & -16.03 & 362 & 441 & 384 \\
\hline L1 & h3 & 1.28 & -0.138 & -0.077 & 0.001 & -0.011 & -0.002 & -1.38 & 132 & 99 & 146 \\
\hline L1 & h4 & 0.42 & 0.096 & -0.141 & -0.001 & -0.015 & -0.002 & -6.42 & 302 & 162 & 212 \\
\hline L1 & h5 & 0.01 & 0.118 & -0.110 & -0.003 & -0.006 & -0.001 & -10.29 & 712 & 243 & 607 \\
\hline L1 & h6 & 0.13 & -0.025 & -0.255 & 0.002 & -0.008 & -0.001 & -19.86 & 587 & 117 & 409 \\
\hline L1 & h7 & -0.53 & 0.207 & -0.024 & 0.009 & -0.011 & -0.002 & -15.63 & 668 & 216 & 1074 \\
\hline L1 & h8 & 0.13 & 0.109 & -0.152 & 0.002 & 0.006 & 0.001 & -8.99 & 601 & 234 & 456 \\
\hline L1 & h9 & -0.53 & -0.108 & -0.060 & 0.001 & -0.019 & -0.003 & -10.74 & 432 & 288 & 418 \\
\hline L1 & 11 & -1.55 & 0.047 & 0.422 & -0.002 & 0.005 & 0.001 & 7.28 & 120 & 63 & 94 \\
\hline L1 & 110 & -0.57 & -0.048 & 0.171 & -0.002 & -0.007 & -0.001 & 6.43 & 103 & 108 & 91 \\
\hline L1 & 12 & 1.07 & -0.076 & 0.095 & -0.003 & 0.004 & 0.001 & 13.90 & 105 & 171 & 92 \\
\hline L1 & 13 & -0.73 & -0.018 & 0.273 & 0.001 & 0.011 & 0.002 & 7.37 & 96 & 99 & 84 \\
\hline L1 & 14 & -1.31 & 0.053 & 0.468 & 0.000 & 0.011 & 0.002 & 9.05 & 110 & 72 & 84 \\
\hline L1 & 15 & 1.15 & -0.068 & 0.104 & 0.001 & 0.026 & 0.004 & 16.90 & 80 & 63 & 65 \\
\hline L1 & 16 & -1.18 & -0.020 & 0.245 & 0.000 & 0.007 & 0.001 & 3.92 & 148 & 153 & 128 \\
\hline
\end{tabular}




\begin{tabular}{|c|c|c|c|c|c|c|c|c|c|c|c|}
\hline 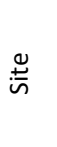 & $\begin{array}{l}\stackrel{0}{+0} \\
\stackrel{0}{0} \\
0 \\
0\end{array}$ & 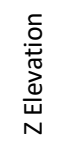 & 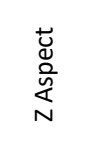 & $\frac{\stackrel{0}{O}}{\frac{0}{N}}$ & $\underset{\dddot{x}}{Q}$ & 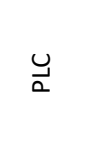 & 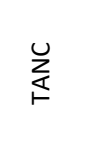 & $\bar{v}$ & $\stackrel{0}{\stackrel{0}{L}}$ & $\stackrel{\infty}{\circ}$ & 屴 \\
\hline L1 & 17 & 1.77 & -0.146 & -0.155 & -0.003 & 0.006 & 0.001 & 14.83 & 109 & 36 & 84 \\
\hline L1 & 18 & 1.48 & -0.033 & -0.204 & 0.003 & 0.038 & 0.004 & 22.21 & 64 & 99 & 63 \\
\hline L1 & 19 & -1.31 & 0.190 & 0.257 & -0.001 & 0.193 & 0.035 & 3.58 & 27 & 9 & 17 \\
\hline L1 & $\mathrm{m} 1$ & 0.46 & 0.009 & -0.359 & -0.004 & 0.039 & 0.004 & 18.02 & 96 & 9 & 71 \\
\hline L1 & $\mathrm{m} 10$ & -1.68 & 0.045 & 0.338 & -0.004 & 0.003 & 0.001 & 3.05 & 133 & 72 & 103 \\
\hline L1 & $\mathrm{m} 2$ & 0.17 & -0.089 & -0.038 & 0.000 & 0.002 & 0.000 & -0.62 & 197 & 225 & 174 \\
\hline L1 & $\mathrm{m} 3$ & 0.13 & 0.109 & -0.213 & 0.001 & 0.004 & 0.000 & -7.98 & 413 & 207 & 285 \\
\hline L1 & $\mathrm{m} 4$ & 0.25 & 0.101 & -0.208 & 0.000 & -0.007 & -0.001 & -8.77 & 545 & 216 & 380 \\
\hline L1 & $\mathrm{m} 5$ & 0.58 & -0.089 & -0.062 & 0.000 & 0.002 & 0.000 & 5.72 & 165 & 369 & 152 \\
\hline L1 & $\mathrm{m} 6$ & -1.06 & -0.063 & 0.123 & 0.000 & 0.009 & 0.001 & -11.90 & 244 & 189 & 157 \\
\hline L1 & $\mathrm{m} 7$ & 0.05 & -0.108 & -0.149 & -0.002 & -0.010 & -0.001 & 1.80 & 190 & 99 & 171 \\
\hline L1 & $\mathrm{m} 8$ & -1.10 & -0.051 & 0.161 & 0.001 & 0.010 & 0.002 & 8.55 & 136 & 126 & 161 \\
\hline L1 & $\mathrm{m} 9$ & 1.77 & 0.058 & -0.038 & -0.002 & 0.000 & 0.000 & 8.99 & 111 & 117 & 86 \\
\hline
\end{tabular}

\section{Compound topographic data}

Site: H1 - high one (location 1 with long history of manure application), H2 - high two (location 2 with long history of manure application), L1 low 1 (location 1 with little to no history of manure application), L2 - low 2 (location 2 with little to no history of manure application); ID: h1-10 (sample locations 1-10 in the high stratification) m1--10 (sample locations 1-10 in the medium stratification), 11-10 (sample location 1-10 in the low stratification); $\mathrm{TWI}_{\mathrm{s}}$ - topographic wetness index (saga method); D8 TWI - topographic wetness index (deterministic 8 method); MFD TWItopographic wetness index (multiple flow direction method); D $\infty$ TWI - topographic wetness index (deterministic infinity method); MC SPI stream power index (calculated with saga modified catchment method); D8 SPI - stream power index (deterministic 8 method); MFD SPIstream power index (multiple flow direction method); D $\infty$ SPI - stream power index (deterministic infinity method)

\begin{tabular}{|c|c|c|c|c|c|c|c|c|c|}
\hline$\stackrel{ \pm}{*}$ & 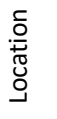 & $\sum_{i}^{\infty}$ & $\underset{\substack{\infty \\
\Delta}}{\sum}$ & $\begin{array}{l}\sum \\
\sum \\
\text { 崖 }\end{array}$ & $\begin{array}{l}\sum \\
8 \\
8\end{array}$ & $\begin{array}{l}\overline{\hat{n}} \\
0 \\
\dot{u} \Sigma\end{array}$ & $\begin{array}{l}\bar{\vdots} \\
\tilde{u} \\
\Sigma\end{array}$ & $\begin{array}{l}\bar{a} \\
\bar{n} \\
8 \\
\Delta\end{array}$ & $\begin{array}{l}\overline{\hat{n}} \\
\infty \\
\Delta\end{array}$ \\
\hline L2 & h2 & 2.47 & 5.12 & 5.43 & 5.23 & 95.0 & 109.4 & 78.0 & 69.8 \\
\hline L2 & h3 & 2.81 & 3.21 & 3.74 & 3.52 & 1413.3 & 1499.7 & 1135.4 & 834.8 \\
\hline L2 & h4 & 2.87 & 5.52 & 5.78 & 5.78 & 221.7 & 265.8 & 222.9 & 171.7 \\
\hline L2 & h5 & 3.12 & 9.11 & 13.02 & 13.21 & -568.0 & -639.6 & -689.1 & -11.3 \\
\hline L2 & h6 & 2.64 & 4.02 & 4.97 & 4.96 & 238.9 & 251.7 & 236.5 & 92.8 \\
\hline L2 & h7 & 2.37 & 6.33 & 6.66 & 6.42 & 20.1 & 22.0 & 15.9 & 14.5 \\
\hline L2 & h8 & 2.51 & 9.98 & 10.38 & 10.57 & 0.8 & 0.9 & 1.0 & 0.5 \\
\hline
\end{tabular}




\begin{tabular}{|c|c|c|c|c|c|c|c|c|c|}
\hline$\stackrel{\stackrel{\Xi}{*}}{*}$ & 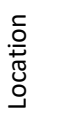 & $\sum_{k}^{\infty}$ & 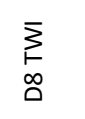 & $\begin{array}{l}\sum \\
\sum \\
\dot{1} \\
\Sigma\end{array}$ & $\begin{array}{l}\sum \\
8 \\
8\end{array}$ & $\begin{array}{l}\bar{\Delta} \\
\hat{n} \\
\dot{u} \\
\Sigma\end{array}$ & $\begin{array}{l}\overline{\hat{n}} \\
\bar{u}\end{array}$ & $\begin{array}{l}\overline{0} \\
\hat{n} \\
8 \\
0\end{array}$ & $\begin{array}{l}\bar{a} \\
\hat{\infty} \\
\Delta\end{array}$ \\
\hline L2 & h9 & 2.51 & 12.05 & 11.76 & 11.54 & -63.7 & -69.9 & -51.4 & -85.3 \\
\hline L2 & 12 & 2.29 & 3.78 & 4.14 & 3.96 & 95.7 & 106.1 & 80.1 & 66.6 \\
\hline L2 & 13 & 1.98 & 0.43 & 0.59 & 0.63 & 981.6 & 1240.4 & 1016.0 & 839.5 \\
\hline L2 & 14 & 2.36 & 11.30 & 11.30 & 10.92 & -1554.5 & -1816.8 & -1063.2 & -1554.0 \\
\hline L2 & 15 & 1.91 & 2.51 & 2.89 & 2.75 & 154.6 & 191.3 & 134.5 & 105.5 \\
\hline L2 & 16 & 2.45 & 9.80 & 11.64 & 11.62 & -27.2 & -29.8 & -26.8 & -4.3 \\
\hline L2 & 17 & 2.37 & 10.90 & 11.29 & 11.13 & -30.1 & -34.4 & -25.6 & -20.3 \\
\hline L2 & 18 & 1.92 & 9.11 & 10.51 & 10.07 & -48.9 & -50.7 & -31.5 & -11.9 \\
\hline L2 & 19 & 1.93 & 10.71 & 10.46 & 10.65 & -15.2 & -16.9 & -18.2 & -19.5 \\
\hline L2 & $\mathrm{m} 1$ & 2.67 & 1.69 & 3.40 & 3.03 & 1319.2 & 1386.7 & 911.1 & 238.7 \\
\hline L2 & $\mathrm{m} 2$ & 2.72 & 11.74 & 12.32 & 12.15 & -165.1 & -172.3 & -138.8 & -92.9 \\
\hline L2 & m3 & 2.32 & 4.66 & 5.07 & 4.77 & 73.4 & 82.2 & 54.7 & 49.0 \\
\hline L2 & $\mathrm{m} 4$ & 2.53 & 11.74 & 11.87 & 11.60 & -248.5 & -264.8 & -189.4 & -218.1 \\
\hline L2 & m5 & 2.49 & 11.18 & 11.79 & 11.74 & -4.9 & -5.2 & -4.7 & -2.7 \\
\hline L2 & $\mathrm{m} 6$ & 2.59 & 11.50 & 12.04 & 11.92 & -597.4 & -629.8 & -530.3 & -350.0 \\
\hline L2 & $\mathrm{m} 8$ & 2.43 & 5.08 & 5.83 & 5.80 & 38.6 & 41.8 & 37.6 & 18.2 \\
\hline L2 & $\mathrm{m} 9$ & 1.99 & 10.20 & 10.46 & 10.48 & -30.0 & -41.4 & -30.6 & -23.3 \\
\hline $\mathrm{H} 1$ & h1 & 2.73 & 1.76 & 1.61 & 1.45 & 17441.5 & 17641.0 & 14933.9 & 20286.8 \\
\hline $\mathrm{H} 1$ & h2 & 2.69 & 5.38 & 5.56 & 5.57 & 100.2 & 103.5 & 101.3 & 84.1 \\
\hline $\mathrm{H} 1$ & h3 & 2.63 & 3.50 & 4.20 & 4.21 & 600.4 & 630.8 & 608.1 & 298.6 \\
\hline $\mathrm{H} 1$ & h4 & 2.52 & 11.75 & 11.98 & 11.94 & -45.3 & -45.4 & -43.2 & -35.8 \\
\hline $\mathrm{H} 1$ & h5 & 2.57 & 9.55 & 9.44 & 9.38 & 2.3 & 2.3 & 2.2 & 2.6 \\
\hline $\mathrm{H} 1$ & h6 & 2.68 & 3.35 & 3.21 & 2.89 & 2072.1 & 2352.7 & 1505.2 & 2397.3 \\
\hline $\mathrm{H} 1$ & h7 & 2.79 & 12.87 & 12.71 & 12.81 & -400.8 & -402.2 & -439.1 & -468.0 \\
\hline $\mathrm{H} 1$ & h8 & 2.57 & 12.10 & 12.02 & 11.91 & -15934.4 & -16281.7 & -14197.2 & -17296.9 \\
\hline $\mathrm{H} 1$ & h9 & 3.09 & 5.33 & 5.03 & 4.86 & 382.9 & 832.6 & 322.8 & 513.7 \\
\hline $\mathrm{H} 1$ & I1 & 1.92 & 10.21 & 10.76 & 10.30 & -15.8 & -15.8 & -10.0 & -9.1 \\
\hline $\mathrm{H} 1$ & $\mid 10$ & 2.20 & 3.66 & 4.01 & 3.53 & 11.9 & 11.9 & 7.4 & 8.4 \\
\hline $\mathrm{H} 1$ & 12 & 2.09 & 4.62 & 5.20 & 4.73 & 51.8 & 51.9 & 32.4 & 29.0 \\
\hline $\mathrm{H} 1$ & 13 & 2.30 & 10.72 & 11.52 & 11.54 & -112.4 & -112.5 & -115.5 & -50.5 \\
\hline $\mathrm{H} 1$ & 14 & 2.20 & 2.91 & 4.33 & 4.10 & 74.1 & 74.2 & 58.4 & 17.8 \\
\hline $\mathrm{H} 1$ & 15 & 1.99 & 5.53 & 5.58 & 5.17 & 27.8 & 27.8 & 18.4 & 26.3 \\
\hline $\mathrm{H} 1$ & 16 & 1.90 & 4.57 & 5.16 & 4.77 & 13.6 & 13.7 & 9.2 & 7.6 \\
\hline $\mathrm{H} 1$ & 17 & 2.10 & 9.11 & 11.00 & 10.90 & -65.5 & -65.6 & -58.7 & -9.8 \\
\hline $\mathrm{H} 1$ & 18 & 2.44 & 1.38 & 1.69 & 1.39 & 444.4 & 444.5 & 330.5 & 327.2 \\
\hline $\mathrm{H} 1$ & 19 & 2.06 & 10.49 & 10.54 & 10.73 & -5.5 & -5.5 & -6.7 & -5.2 \\
\hline $\mathrm{H} 1$ & $\mathrm{~m} 1$ & 2.43 & 10.49 & 11.92 & 11.67 & -72.2 & -72.4 & -56.2 & -17.3 \\
\hline
\end{tabular}




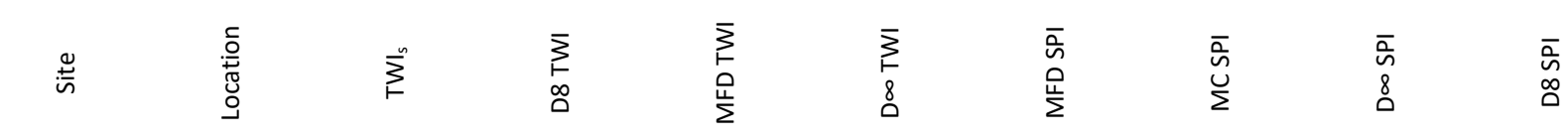

\begin{tabular}{|c|c|c|c|c|c|c|c|c|c|}
\hline $\mathrm{H} 1$ & $\mathrm{~m} 10$ & 2.68 & 11.41 & 11.21 & 11.26 & -16.7 & -16.6 & -17.5 & -20.5 \\
\hline $\mathrm{H} 1$ & $\mathrm{~m} 2$ & 2.05 & 3.49 & 4.45 & 3.93 & 58.2 & 58.4 & 34.7 & 22.4 \\
\hline $\mathrm{H} 1$ & $\mathrm{~m} 3$ & 2.48 & 11.75 & 11.62 & 11.59 & -27.7 & -28.1 & -26.8 & -31.3 \\
\hline $\mathrm{H} 1$ & $\mathrm{~m} 4$ & 2.31 & 1.27 & 1.52 & 1.42 & 1860.7 & 1862.7 & 1682.2 & 1457.1 \\
\hline $\mathrm{H} 1$ & m5 & 2.33 & 11.05 & 11.57 & 11.28 & -81.0 & -93.6 & -60.9 & -48.5 \\
\hline $\mathrm{H} 1$ & $\mathrm{~m} 6$ & 2.41 & 10.90 & 11.73 & 11.70 & -505.5 & -509.1 & -487.3 & -219.9 \\
\hline $\mathrm{H} 1$ & $\mathrm{~m} 7$ & 2.93 & 9.11 & 9.83 & 10.65 & -5.0 & -25.0 & -11.3 & -2.4 \\
\hline $\mathrm{H} 1$ & $\mathrm{~m} 8$ & 2.57 & -0.49 & -0.25 & -0.42 & 23989.6 & 24976.6 & 20434.9 & 19053.1 \\
\hline $\mathrm{H} 1$ & $\mathrm{~m} 9$ & 2.33 & 11.05 & 11.05 & 10.86 & -6.4 & -7.1 & -5.3 & -6.5 \\
\hline $\mathrm{H} 2$ & h1 & 4.08 & 8.30 & 7.88 & 8.07 & 15.3 & 34.5 & 18.5 & 23.1 \\
\hline $\mathrm{H} 2$ & h10 & 4.40 & 5.41 & 4.10 & 4.02 & 197.2 & 1519.9 & 183.2 & 728.9 \\
\hline $\mathrm{H} 2$ & h2 & 3.97 & 3.39 & 5.00 & 4.67 & 54.1 & 210.1 & 38.9 & 10.8 \\
\hline $\mathrm{H} 2$ & h3 & 2.78 & 4.20 & 4.17 & 4.54 & 74.8 & 102.8 & 108.3 & 76.8 \\
\hline $\mathrm{H} 2$ & h4 & 3.20 & 3.27 & 5.01 & 5.08 & 155.3 & 192.7 & 167.6 & 27.4 \\
\hline $\mathrm{H} 2$ & h5 & 4.82 & 6.66 & 8.05 & 7.34 & 41.5 & 214.9 & 20.3 & 10.3 \\
\hline $\mathrm{H} 2$ & h6 & 4.32 & 13.18 & 14.11 & 14.08 & -6105.0 & -5479.4 & -5980.3 & -2413.1 \\
\hline $\mathrm{H} 2$ & h7 & 4.11 & 4.71 & 5.09 & 4.76 & 152.7 & 498.3 & 109.7 & 104.0 \\
\hline $\mathrm{H} 2$ & h8 & 4.30 & 3.35 & 5.95 & 5.22 & 151.9 & 593.1 & 73.5 & 11.3 \\
\hline $\mathrm{H} 2$ & h9 & 4.23 & 5.72 & 5.72 & 5.44 & 106.4 & 313.1 & 80.2 & 105.7 \\
\hline $\mathrm{H} 2$ & 11 & 3.49 & 6.79 & 5.53 & 5.57 & 17.3 & 38.1 & 18.1 & 61.0 \\
\hline $\mathrm{H} 2$ & 110 & 2.83 & 3.50 & 3.74 & 3.64 & 149.7 & 167.3 & 135.6 & 118.1 \\
\hline $\mathrm{H} 2$ & 12 & 3.03 & 10.89 & 11.09 & 10.79 & -1.2 & -1.2 & -0.9 & -1.0 \\
\hline $\mathrm{H} 2$ & 13 & 2.31 & 0.58 & 0.89 & 1.04 & 245.7 & 376.7 & 284.8 & 179.6 \\
\hline $\mathrm{H} 2$ & 14 & 4.80 & 11.58 & 12.53 & 11.40 & -241.5 & -1291.2 & -78.3 & -93.9 \\
\hline $\mathrm{H} 2$ & 15 & 3.07 & 3.24 & 4.67 & 4.58 & 52.7 & 53.6 & 48.6 & 12.6 \\
\hline $\mathrm{H} 2$ & 16 & 2.87 & 10.71 & 10.96 & 10.79 & -623.3 & -728.8 & -525.2 & -484.3 \\
\hline $\mathrm{H} 2$ & 17 & 2.95 & 4.34 & 3.84 & 3.85 & 92.0 & 92.0 & 92.6 & 151.0 \\
\hline $\mathrm{H} 2$ & 18 & 3.12 & 3.18 & 3.60 & 3.39 & 183.1 & 194.1 & 149.2 & 120.4 \\
\hline $\mathrm{H} 2$ & 19 & 2.92 & 9.10 & 10.21 & 9.48 & -847.7 & -1493.9 & -406.9 & -278.3 \\
\hline $\mathrm{H} 2$ & $\mathrm{~m} 1$ & 4.12 & 5.49 & 5.96 & 4.93 & 52.5 & 156.0 & 18.8 & 33.0 \\
\hline $\mathrm{H} 2$ & $\mathrm{~m} 10$ & 3.46 & 11.81 & 11.52 & 11.37 & -5.4 & -5.5 & -4.6 & -7.2 \\
\hline $\mathrm{H} 2$ & $\mathrm{~m} 2$ & 3.07 & 11.40 & 11.77 & 11.55 & -288.1 & -309.8 & -230.7 & -199.7 \\
\hline $\mathrm{H} 2$ & m3 & 3.64 & 1.30 & 3.13 & 3.28 & 547.7 & 718.1 & 637.9 & 87.7 \\
\hline $\mathrm{H} 2$ & $\mathrm{~m} 4$ & 3.43 & 3.06 & 3.18 & 3.00 & 615.8 & 616.1 & 513.9 & 543.2 \\
\hline $\mathrm{H} 2$ & $\mathrm{~m} 5$ & 3.16 & 4.61 & 5.00 & 4.72 & 117.4 & 122.3 & 88.6 & 79.5 \\
\hline $\mathrm{H} 2$ & $\mathrm{~m} 6$ & 2.93 & 10.89 & 11.40 & 10.90 & -58.8 & -79.5 & -35.5 & -35.2 \\
\hline $\mathrm{H} 2$ & $\mathrm{~m} 7$ & 4.20 & 7.44 & 8.85 & 8.40 & 0.8 & 4.0 & 0.5 & 0.2 \\
\hline
\end{tabular}




\begin{tabular}{|c|c|c|c|c|c|c|c|c|c|}
\hline$\stackrel{ \pm}{*}$ & 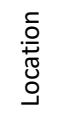 & $\sum_{l}^{\infty}$ & $\underset{\substack{\infty \\
\Delta}}{\sum}$ & $\begin{array}{l}\sum \\
\sum \\
\sum \\
\sum\end{array}$ & $\begin{array}{l}\underset{3}{8} \\
8 \\
0\end{array}$ & $\begin{array}{l}\bar{\Delta} \\
\hat{n} \\
\stackrel{0}{\Sigma}\end{array}$ & $\begin{array}{l}\overline{\bar{n}} \\
\hat{U} \\
\Sigma\end{array}$ & $\begin{array}{l}\bar{a} \\
\tilde{8} \\
8\end{array}$ & $\begin{array}{l}\overline{0} \\
\infty \\
\infty\end{array}$ \\
\hline $\mathrm{H} 2$ & $\mathrm{~m} 8$ & 3.37 & 12.60 & 11.61 & 11.60 & -187.9 & -220.4 & -185.4 & -501.7 \\
\hline $\mathrm{H} 2$ & $\mathrm{~m} 9$ & 3.19 & 11.05 & 11.35 & 11.11 & -41.7 & -41.7 & -32.7 & -30.7 \\
\hline L1 & h1 & 3.17 & 8.55 & 7.60 & 7.64 & 28.7 & 31.6 & 29.8 & 74.3 \\
\hline L1 & h10 & 3.51 & 13.94 & 13.46 & 13.20 & -534.0 & -536.2 & -412.3 & -867.7 \\
\hline L1 & h2 & 3.19 & 6.92 & 6.72 & 6.78 & 158.2 & 163.1 & 167.7 & 192.6 \\
\hline L1 & h3 & 2.86 & 4.48 & 4.76 & 4.86 & 148.1 & 166.4 & 163.8 & 111.3 \\
\hline L1 & h4 & 3.01 & 11.99 & 12.62 & 12.26 & -28.6 & -28.7 & -20.1 & -15.4 \\
\hline L1 & h5 & 3.43 & 6.45 & 7.53 & 7.37 & 272.7 & 276.2 & 232.3 & 93.0 \\
\hline L1 & h6 & 3.61 & 3.03 & 4.65 & 4.29 & 3311.1 & 4116.3 & 2307.6 & 659.1 \\
\hline L1 & h7 & 3.60 & 12.28 & 13.41 & 13.89 & -17152.1 & -17161.2 & -27553.4 & -5540.0 \\
\hline L1 & h8 & 3.35 & 12.36 & 13.31 & 13.03 & -155.1 & -156.3 & -117.6 & -60.4 \\
\hline L1 & h9 & 3.28 & 5.02 & 5.43 & 5.39 & 823.1 & 823.3 & 796.7 & 548.1 \\
\hline L1 & I1 & 2.28 & 11.05 & 11.70 & 11.45 & -502.6 & -503.1 & -393.5 & -262.8 \\
\hline L1 & $\mid 10$ & 2.29 & 3.41 & 3.36 & 3.24 & 368.3 & 368.3 & 326.3 & 385.9 \\
\hline L1 & 12 & 2.54 & 6.76 & 6.27 & 6.13 & 20.8 & 20.8 & 18.2 & 34.0 \\
\hline L1 & 13 & 2.28 & 11.50 & 11.47 & 11.34 & -35.9 & -36.0 & -31.5 & -37.1 \\
\hline L1 & 14 & 2.25 & 11.18 & 11.61 & 11.34 & -88.5 & -88.6 & -67.7 & -58.0 \\
\hline L1 & 15 & 2.44 & 5.21 & 5.45 & 5.25 & 27.4 & 27.5 & 22.5 & 21.7 \\
\hline L1 & 16 & 2.45 & 11.94 & 11.91 & 11.76 & -144.6 & -144.7 & -124.4 & -149.2 \\
\hline L1 & 17 & 2.61 & 10.49 & 11.60 & 11.34 & -33.3 & -34.1 & -25.7 & -11.0 \\
\hline L1 & 18 & 2.49 & 11.50 & 11.07 & 11.04 & -99.5 & -99.8 & -97.0 & -153.6 \\
\hline L1 & 19 & 2.40 & 9.10 & 10.21 & 9.76 & -18.6 & -105.6 & -11.9 & -6.2 \\
\hline L1 & $\mathrm{m} 1$ & 2.57 & 9.10 & 11.47 & 11.17 & -10.9 & -10.9 & -8.0 & -1.0 \\
\hline L1 & $\mathrm{m} 10$ & 2.32 & 4.69 & 5.30 & 5.05 & 87.4 & 87.5 & 68.1 & 47.5 \\
\hline L1 & $\mathrm{m} 2$ & 2.85 & 3.62 & 3.49 & 3.37 & 1186.8 & 1188.1 & 1050.3 & 1354.3 \\
\hline L1 & $\mathrm{m} 3$ & 3.19 & 12.24 & 12.93 & 12.56 & -888.9 & -891.9 & -614.0 & -445.4 \\
\hline L1 & $\mathrm{m} 4$ & 3.30 & 12.28 & 13.21 & 12.85 & -984.3 & -990.2 & -686.7 & -390.1 \\
\hline L1 & m5 & 2.77 & 5.33 & 4.53 & 4.44 & 292.9 & 293.4 & 269.9 & 656.8 \\
\hline L1 & $\mathrm{m} 6$ & 3.20 & 5.63 & 5.89 & 5.45 & 165.3 & 276.5 & 106.5 & 127.8 \\
\hline L1 & $\mathrm{m} 7$ & 2.91 & 11.50 & 12.16 & 12.05 & -40.5 & -40.5 & -36.3 & -21.0 \\
\hline L1 & $\mathrm{m} 8$ & 2.45 & 4.04 & 4.11 & 4.28 & 300.9 & 301.0 & 357.4 & 279.7 \\
\hline L1 & $\mathrm{m} 9$ & 2.46 & 2.93 & 2.87 & 2.62 & 693.1 & 708.5 & 536.6 & 732.1 \\
\hline
\end{tabular}

